\title{
Making lifestyle work : long-term effects in the prevention of type 2 diabetes
}

Citation for published version (APA):

Roumen, C. (2009). Making lifestyle work : long-term effects in the prevention of type 2 diabetes. [Doctoral Thesis, Maastricht University]. Universitaire Pers Maastricht. https://doi.org/10.26481/dis.20091106cr

Document status and date:

Published: 01/01/2009

DOI:

$10.26481 /$ dis.20091106cr

Document Version:

Publisher's PDF, also known as Version of record

\section{Please check the document version of this publication:}

- A submitted manuscript is the version of the article upon submission and before peer-review. There can be important differences between the submitted version and the official published version of record.

People interested in the research are advised to contact the author for the final version of the publication, or visit the DOI to the publisher's website.

- The final author version and the galley proof are versions of the publication after peer review.

- The final published version features the final layout of the paper including the volume, issue and page numbers.

Link to publication

\footnotetext{
General rights rights.

- You may freely distribute the URL identifying the publication in the public portal. please follow below link for the End User Agreement:

www.umlib.nl/taverne-license

Take down policy

If you believe that this document breaches copyright please contact us at:

repository@maastrichtuniversity.nl

providing details and we will investigate your claim.
}

Copyright and moral rights for the publications made accessible in the public portal are retained by the authors and/or other copyright owners and it is a condition of accessing publications that users recognise and abide by the legal requirements associated with these

- Users may download and print one copy of any publication from the public portal for the purpose of private study or research.

- You may not further distribute the material or use it for any profit-making activity or commercial gain

If the publication is distributed under the terms of Article $25 \mathrm{fa}$ of the Dutch Copyright Act, indicated by the "Taverne" license above, 


\section{Making Lifestyle work}

Long-term effects in the prevention of type 2 diabetes 


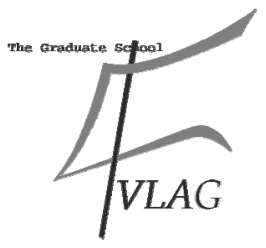

The study presented in this thesis was performed within the Nutrition and Toxicology Research Institute Maastricht (NUTRIM) which participates in the Graduate School VLAG (Food Technology, Agrobiotechnology, Nutrition and Health Sciences), accredited by the Royal Netherlands Academy of Arts and Sciences.

Layout: Cheryl Roumen

Printed by: Datawyse, Universitaire Pers Maastricht

Cover design: Cheryl Roumen and Datawyse, Universitaire Pers Maastricht

(C) Copyright Cheryl Roumen, Maastricht 2009

Universitaire Pers Maastricht

ISBN 978-90-5278-870-8 


\title{
Making Lifestyle work
}

\section{Long-term effects in the prevention of type 2 diabetes}

\author{
DISSERTATION \\ to obtain the degree of doctor at \\ the Maastricht University, \\ on the authority of Rector Magnificus, \\ Prof. dr. G.P.M.F. Mols \\ In accordance with the decision of the Board of Deans \\ To be defended in public on \\ Friday November $6^{\text {th }} 2009$ at 14:00 hour
}

by

Cheryl Roumen

Born $7^{\text {th }}$ December 1979, Geleen, The Netherlands

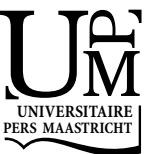




\section{Supervisors}

Prof. dr. ir. E.E. Blaak

Prof. dr. ir. W.H.M. Saris

Prof. dr. ir. E.J.M. Feskens, Wageningen University

\section{Assessment Committee}

Prof. dr. N.C. Schaper (chairman)

Prof. dr. M.A. van Baak

Dr. L.J.C. van Loon

Prof. dr. G. Nijpels, VU Medical Center

Prof. dr. N.J. Wareham, Cambridge

The research described in this thesis was supported by grants of the Dutch Diabetes Research Foundation (DFN 98.901 and DFN 2000.00.020) and the Netherlands Organization for Scientific Research (ZonMW 940-35-034 and 2200.0139).

Financial support by the Dutch Diabetes Research Foundation for the publication of this thesis is gratefully acknowledged.

Printing of this thesis was financially supported by Novo Nordisk B.V., AstraZeneca B.V. and Nutricia Advanced Medical Nutrition. 
De tijd

Soms droom ik dat zij stilstaat

Om van haar te genieten

Het moment dat nooit voorbij gaat

En andere keren hoop ik

Dat zij sneller vooruit loopt

Naar daar waar ik niet weet

Maar vooruit zodat ik vergeet

Heel langzaam of heel snel

Een ding weet ik wel

Hoe ik haar bekijk

Verandert niet haar voortbestaan

Zij zal niet bij mij blijven

Zij zal ook vergaan

Maar haar effect is niet onbemerkt

Zij raakt mij altijd even aan

In dat wat ik voel, wat ik denk

En hoe ik me beweeg

Met gevoel blijf ik achter

Soms vol, soms leeg

(C) Copyright Cheryl Roumen, Eyserheide 2005 



\section{Content}

\section{Chapter 1}

General introduction

9

\section{Chapter 2}

Lifestyle intervention in the prevention of diabetes: determinants of success for future implementation

\section{Chapter 3}

Impact of 3-year lifestyle intervention on postprandial glucose metabolism:

the SLIM study

\section{Chapter 4}

Predictors of intervention outcome and dropout: the SLIM study

\section{Chapter 5}

Personal and environmental factors associated with adherence to a lifestyle intervention among persons with impaired glucose intolerance: the SLIM study

\section{Chapter 6}

Lifestyle intervention, 1-year changes in glucose tolerance and inflammatory and immune markers: the SLIM study

\section{Chapter 7}

Inflammation factors and lifestyle intervention outcome after 3 years in

high-risk subjects for type 2 diabetes: the SLIM study

\section{Chapter 8}

Changes in transferrin are related to changes in insulin resistance:

the SLIM study

\section{Chapter 9}

General Discussion

Summary - Samenvatting

Acknowledgements - Dankwoord

Resume

List of Publications 



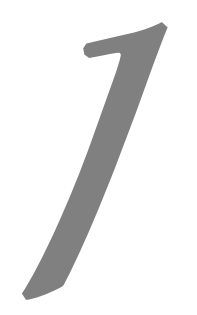

GENERAL INTRODUCTION 

Diabetes mellitus is a public health problem, which has reached pandemic proportions. The global prevalence of diabetes is expected to increase with $39 \%$ between 2000 and 2030, increasing absolute numbers to 366 million people (1).

Diabetes mellitus is a multi-factorial disease, characterized by hyperglycemia, resulting from a disturbed insulin secretion, insulin action or both. The long-term effects of diabetes mellitus include increased risk on complications such as foot ulcers, retinopathy, nephropathy and neuropathy. Even more problematic is the fact that 70$80 \%$ of people with diabetes die of cardiovascular disease (2). From a public health perspective, diabetes and its complications are relevant for treatment and prevention due to the related human suffering and disability and the huge socio-economic costs (3, 4 ) through premature morbidity (5) and mortality $(6,7)$. Clearly, there would be great benefits if research could provide evidence for effective prevention measures. The introduction of this thesis is composed of three main sections. First, the diagnosis and pathogenesis of type 2 diabetes are discussed, including the impaired glucose tolerance state (paragraph 1). The second section focuses on the prevention of type 2 diabetes by the use of different lifestyle intervention strategies and includes some aspects of implementation (paragraph 2). In the third section several mechanisms are discussed that may underlie the development of type 2 diabetes and that may be responsible for the lifestyle intervention-induced improvement in metabolic profile (paragraph 3). Finally, an outline is given of the chapters covering the present thesis (paragraph 4).

\section{Type 2 Diabetes Mellitus}

Several forms of diabetes exist of which type 1 and type 2 diabetes mellitus are the most common. Type 1 diabetes mellitus accounts for approximately $15 \%$ of all diabetes cases and results from pancreatic beta-cell dysfunction, causing insulin deficiency, and leading to the requirement of exogenously administrated insulin for survival. Type 2 diabetes mellitus is the most common form of diabetes accounting for approximately $85 \%$ of all cases. Type 2 diabetes mellitus results when pancreatic beta-cells fail to compensate for insulin resistance through an increased secretion of insulin by the beta-cells of the pancreas. Already several years ago, large scale analysis in 22 cohorts in Europe by the Diabetes Epidemiology Collaborative analysis Of Diagnosis criteria in Europe (DECODE) study group, showed a J shaped relationship, rather than showing a threshold effect, between high fasting glucose levels and all-cause mortality (8). Interestingly, all-cause mortality risks were similar in subjects with fasting glucose levels $\geq 7.0 \mathrm{mmol} / \mathrm{l}$ and in subjects with high 2-hr glucose levels of $10.01-11.09 \mathrm{mmol} / \mathrm{l}$, when testing almost 30,000 people for their hazard ratio for death. Compared to the $J$ shape of fasting glucose, the relationship between 2-hr glucose levels and cardiovascular mortality seemed to be graded and increasing (8). Overall, there seems to be a continuously graded risk for mortality with increasing glucose levels. 


\section{Chapter 1}

\section{$1.1 \quad$ Diagnosis}

In general, diagnosis is based upon the presence of clinical symptoms and gross hyperglycemia during a visit at the general medical practice. Indications for a visit at the general medical practice include diabetes symptoms like itching, tiredness, blurred vision and unintended weight loss. However, at present, health checks may be a reason for a visit. In the prediabetic state, in which symptoms are mostly absent, an oral glucose tolerance test (OGTT) can be performed (9). This is a blood glucose measurement during fasting and 2 hours after a 75-gram glucose bolus, dissolved in $250 \mathrm{ml}$ water. According to the WHO, results can be interpreted as normal glucose tolerance (NGT), impaired glucose tolerance (IGT), impaired fasting glucose (IFG) and type 2 diabetes (table 1.1).

Table 1.1 WHO criteria for the diagnosis of impaired glucose metabolism (1999).

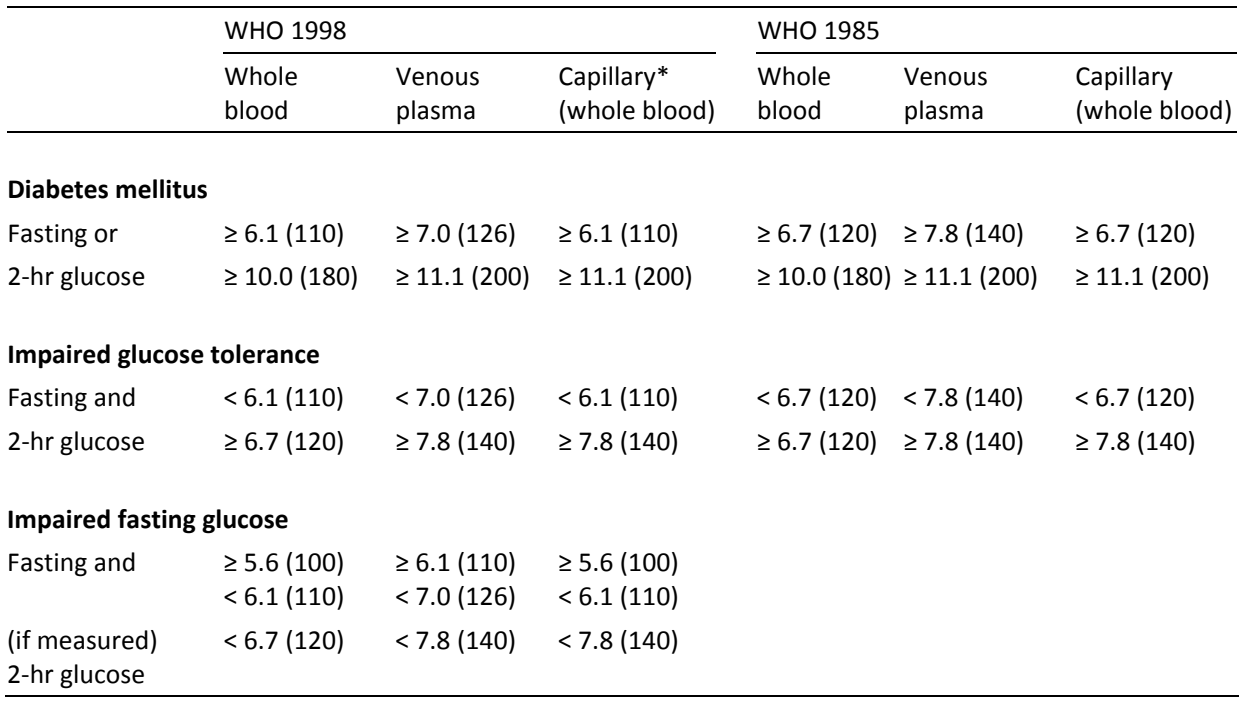

\subsection{Pathogenesis}

In the pathogenesis of type 2 diabetes, two key features play a role, namely insulin resistance and beta-cell failure. Insulin resistance is characterized by the diminished ability of insulin to stimulate glucose uptake. Beta-cell failure is characterized by the inability to adequately produce sufficient amounts of the insulin. In the development of type 2 diabetes, which takes several decades, impairments in both features are believed to result in a transition from normal glycemia to hyperglycemia and hyperinsulinemia (10). Mild hyperglycemia can be classified as IFG when present in the fasted state and as IGT when present in the postprandial state (11). Subsequent deterioration of insulin resistance and beta-cell failure will lead to overt type 2 diabetes mellitus (figure 1.1) $(11,12)$. Insulin resistance and beta-cell failure are both under the influence of genetic variation and other factors, such as dietary intake, physical activity, 
obesity. The relative contribution of these factors is strongly influenced by the patient population, e.g. ethnicity and age. With increasing age the risk for developing type 2 diabetes also increases.

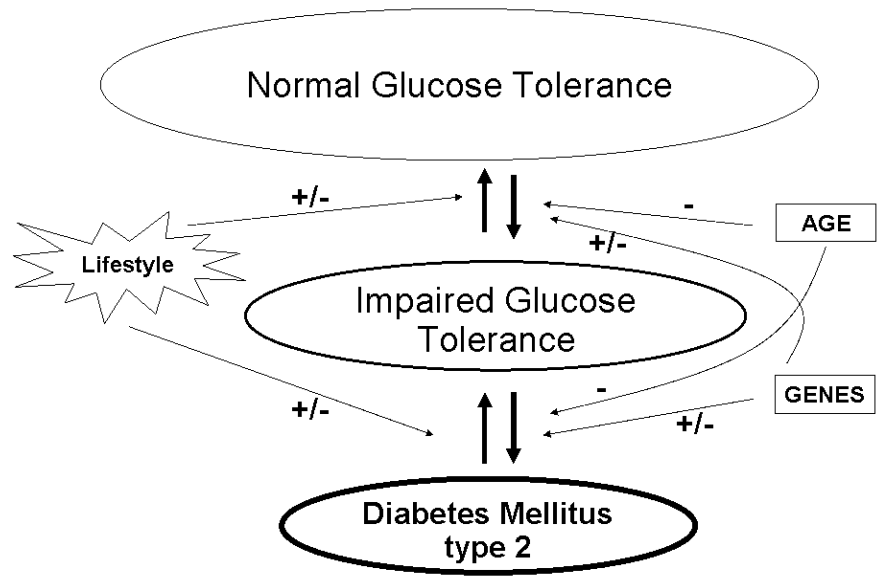

Figure 1.1 Progression from normal glucose tolerance to impaired glucose tolerance and type 2 diabetes mellitus (adapted from Saad et al. A two-step model for development of non-insulin-dependent diabetes. American Journal of Medicine. 1991;90(2):229-35). The progression can be effected by older age, genes and lifestyle, while changes towards a healthy lifestyle can delay or (partly) reverse the process.

\subsection{Impaired glucose tolerance}

The global prevalence of IGT is expected to increase from 314 million people in 2003 to 472 million in 2025, accounting for approximately $9 \%$ of the adult worldwide population (2). Depending on the characteristics of the population, e.g. age, BMI and ethnicity, the prevalence may range between $2 \%$ in rural areas and $20 \%$ in high-risk populations (13).

IGT is a strong predictor for the development of type 2 diabetes mellitus. In the Dutch Hoorn study, IGT, IFG and IGT/IFG combined predict the development of type 2 diabetes over 6 years with 9.1\% progression for IFG, 32.5\% progression for IGT and $64.5 \%$ for combined IGT/IFG (14). Besides the risk for development of type 2 diabetes, a graded positive relationship is also observed between postprandial glucose levels and cardiovascular mortality (8).

\subsection{Risk factors for diabetes progression}

Risk factors for the progression towards type 2 diabetes include lifestyle components such as body weight, dietary composition, and physical activity. Obesity is the most modifiable risk factor and BMI and body weight gain are strongly associated with diabetes risk (15). In addition to over-all obesity, body fat distribution and especially increased intra-abdominal fat mass is a predictor of type 2 diabetes $(16,17)$. Specifi- 
cally an increased visceral fat depot, as shown by using magnetic resonance imaging and computed tomography, has been shown to be related to the presence of insulin resistance (18-21). Besides obesity, total fat intake and saturated fat intake are important risk factors for the development of type 2 diabetes. The energy-density of fat favors increased food intake and obesity. In the San Louis Valley Diabetes Study, a 40g higher fat intake corresponded with a 6-fold increase in diabetes risk in IGT subjects after adjustment for obesity and markers of glucose metabolism (i.e. fasting glucose and insulin) (22). Also, the kind of dietary fats seem to influence postprandial glucose metabolism and insulin resistance. The KANWU study reported an improved insulin sensitivity when replacing saturated fatty acids in the diet with mono-unsaturated fat in healthy volunteers during a period of 3 months, when a habitual diet low in fat was consumed. (23). In a recent study in subjects with normal glucose and triglyceride levels, beta cell function and insulin sensitivity progressively improved in the postprandial state as the proportion of mono unsaturated fatty acids as compared to saturated fatty acids in dietary fats increased (24). Also, a low glycemic-index diet and low glycemic load in type 2 diabetes patients during 6 months seems to moderately reduce body weight and $\mathrm{HbA1c}$ levels and increase high-density lipoprotein-cholesterol (HDL-cholesterol) (25). Besides the diet also other lifestyle factors influence diabetes risk. A recent systematic review and meta-analysis has shown that active smoking is associated with an increased risk for type 2 diabetes, with a greater risk for heavy smokers compared to light smokers (26). The causality and mechanism still need to be unraveled. Also lack of physical activity influences diabetes progression. Increasing physical activity has shown to decrease diabetes risk. For example, in IGT men from the Diabetes Prevention Study (DPS), individuals with the highest increase in their level of moderate-to-vigorous physical activity were 63-65\% less likely to develop type 2 diabetes during the 4.1 year follow-up compared to individuals with the lowest increase in physical activity (27).

\section{Prevention of Type 2 Diabetes}

Over the past decades, several lifestyle intervention studies have been performed trying to reveal if, how and to what extent these programs could postpone or prevent deterioration of glucose tolerance and progression towards type 2 diabetes mellitus. These lifestyle intervention studies are composed of dietary intervention, exercise intervention, or the combination of diet and exercise.

\subsection{The SLIM study: design, purpose and previous results}

The SLIM study was designed to study the effect of a lifestyle intervention according to general public health recommendations regarding dietary intake and composition and physical activity on Dutch subjects at high risk for developing type 2 diabetes mellitus. Therefore, 147 subjects were randomized into an intervention and control group with stratification for sex and 2-hr glucose levels. Details of the design and screening has been described previously (28). A previous publication of this study show that the largest decrease in body weight and 2-hr glucose levels was observed after 1 year of 
lifestyle intervention (29). Is was also shown that after 2 years, adherence to the diet and exercise recommendations gave the largest improvement in body weight, waist circumference, fasting insulin and 2-hr glucose levels, compared to adherence to the diet or exercise recommendations alone (29). This thesis describes the effects of the SLIM lifestyle intervention after 3-6 years as well as additional analyses on metabolic factors possibly associated with glucose tolerance, insulin resistance or the development of type 2 diabetes.

\subsection{Dietary intervention}

Several dietary components are related to body weight, insulin resistance and the development of type 2 diabetes (for more detail, see chapter 2). In normalweight and overweight subjects, ad libitum reduced-fat diet without energy restriction resulted in a moderate body weight reduction between 3-5 kilograms $(30,31)$. Besides reducing body weight and sustaining a body weight reduction, a high-fiber, low-fat diet also reduces the development of type 2 diabetes (32). In addition, the type of fatty acid may modify insulin sensitivity (23) and diabetes risk, e.g. by positive effects on skeletal muscle insulin sensitivity (33-35). In this thesis, we examined if dietary advice as part of a lifestyle intervention according to general public health recommendations has an effect on the dietary composition, glucose tolerance, insulin resistance and diabetes risk, and whether these changes are prolonged during a period of 3-6 years.

\subsection{Exercise intervention within a lifestyle intervention}

A recent meta-analysis has shown that lifestyle interventions aimed at increasing exercise combined with diet are able to decrease the incidence of type 2 diabetes mellitus in high risk groups (36) (for more detail, see chapter 2). Vigorous physical activities seem to give the largest reduction in diabetes risk, whereas also small but sustained increases in physical activity seem beneficial in the long-term $(27,37)$. There seems to be a dose-response relationship between physical activity and fitness (38), exemplifying that even a little exercise is good for health but that increasing exercise may even be better. Besides reducing diabetes risk and increasing fitness, physical activity may also prevent weight regain after weight loss. Currently, approximately 420 minutes of moderate intensity exercise ( 30 minutes a day) is recommended to prevent weight gain in overweight subjects (39). In this thesis, we examined if exercise recommendations and a physical activity program consisting of combined aerobic and resistance training, as part of a lifestyle intervention according to general public health recommendations, had an effect on maximal aerobic capacity, glucose tolerance, insulin resistance and diabetes risk and whether these changes are prolonged during a period of 3-6 years.

\subsection{Diet and exercise intervention}

Several combined diet and exercise lifestyle interventions have shown to reduce diabetes risk by $\sim 40-60 \%$ during 3-6 years in European (40-42) and non-European IGT 
people $(43,44)$ (for more detail, see chapter 2$)$. Recently, the first studies have been published showing a significant diabetes reduction of $43 \%$ following 3-14 years cessation of the lifestyle intervention $(45,46)$. The effect of combined diet and exercise lifestyle interventions on 2 -hr glucose levels has been less consistent $(47,48)$ (for more detail, see chapter 2).

Although combined diet and exercise lifestyle interventions have proven to be effective in reducing diabetes risk, it is not know if these lifestyle interventions can be effectively implemented in the general population. Currently, different approaches for lifestyle implementation are evaluated (49), which is a complex process that involves multiple factors that have to be aligned to achieve success. In chapter 2 , more details regarding implementation are stated.

In this thesis, we assessed which factors are related to adherence to the diet and exercise recommendations and which factors are indicative for dropout to the lifestyle intervention program. Identification of these factors is the first step that can lead to increased effectiveness and efficacy of lifestyle interventions and can help to clarify difficulties that may interfere with successful implementation in the general population. In the next paragraph, metabolic mechanisms of importance in the etiology of diabetes, and thus possibly responsible for the lifestyle intervention effect, will be covered.

3. Metabolic disturbances associated with the development of type 2 diabetes

\subsection{Ectopic fat accumulation}

In the etiology of type 2 diabetes mellitus, several major organs and their interactions play a role like adipose tissue, liver, skeletal muscle and pancreas. Adipose tissue is the major organ for triglyceride storage. Normally, adipose tissue functions as a lipid buffering depot, taking up dietary fatty acids in the postprandial state, to release them later on when there is an increased need for fat as a fuel. In insulin resistance, this buffering capacity is disturbed leading to an excess of lipids (free fatty acids (FFA) and triglycerides) in the circulation. This increased lipid overflow to non-adipose tissue organs may result in ectopic fat deposition in tissues like liver, pancreas and skeletal muscle $(33-35,50-52)$ (figure 1.2). Elevated levels of FFA can cause peripheral insulin resistance $(53,54)$ and acute lowering of FFA by the antilipolytic drug acipimox enhances insulin action on glucose uptake in the periphery (55). Fat storage in the liver in the form of triacylglycerol (TAG), e.g. in non-alcoholic fatty liver disease (NAFLD), has been associated with all features of the metabolic syndrome including hepatic insulin resistance, type 2 diabetes and elevated triglyceride levels $(56,57)$. Hepatic insulin resistance results in a reduced inhibition of hepatic glucose production during fasting contributing to hyperglycemia. The increased TAG storage in liver seems to be largely due to increased delivery of free fatty acids from adipose tissue to the liver (58). 


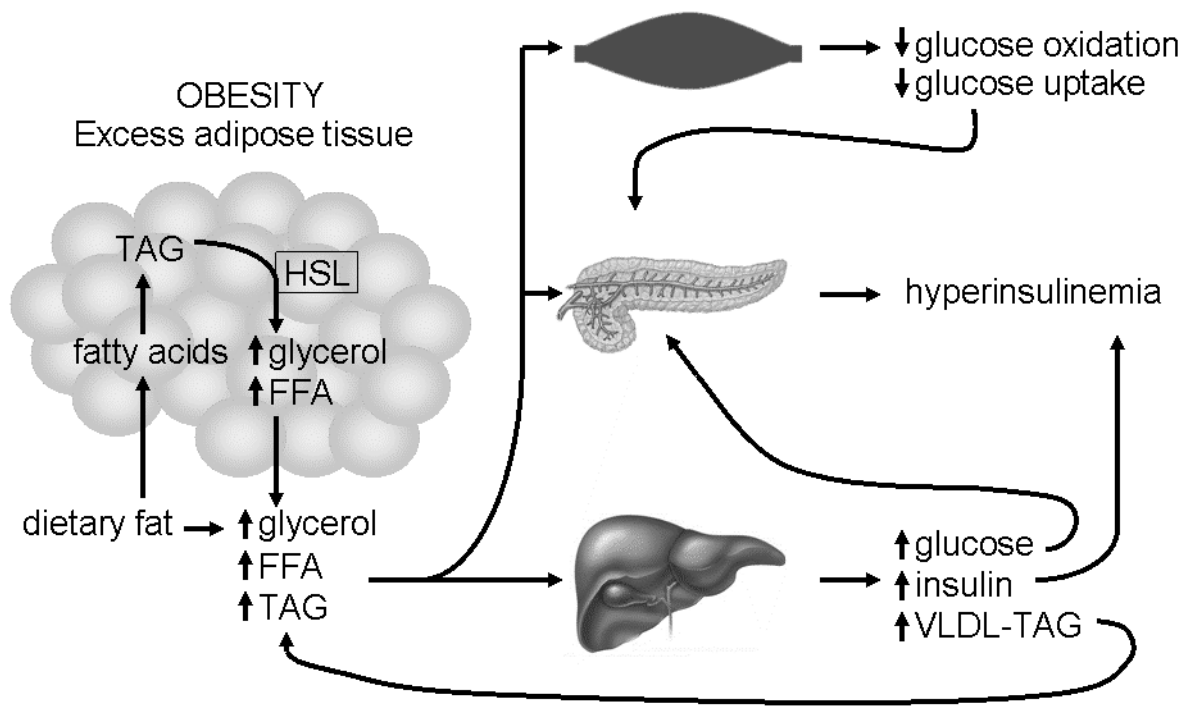

Figure 1.2 The normal function of adipose tissue is to buffer the daily influx of dietary fat. When the buffering capacity for lipid storage in adipose tissue is decreased, as in obesity (when the fat cells are overloaded), other tissues like skeletal muscle, pancreas and liver are exposed to an excessive influx of fatty acids and TAG. TAG storage in these tissues may result in conditions related to insulin resistance, such as glucose intolerance, hyperinsulinemia and hyperlipidemia (adapted from Frayn, KN. Adipose tissue and the insulin resistance syndrome. The Proceedings of the Nutrition Society. 2001; 60(3): 375-80 and Goossens, G. PhD thesis: The renin-angiotensin system in obesity, metabolic and hemodynamic effects. ISBN-13: 978-905278542-4)

In skeletal muscle, accumulation of lipids as intramyocellular lipid (IMCL) has been strongly linked with skeletal muscle insulin resistance in both lean and obese subjects (59-62). In particular lipid intermediates like diacylglycerol (DAG) and ceramides, may interfere with insulin signaling or induce inflammatory pathways thereby reducing insulin action (63-66).

Also, the insulin resistant muscle may be characterized by a reduced fat oxidation (67-69) or an inability to adjust fat oxidation to different metabolic conditions (metabolic inflexibility, (70)). Mitochondrial dysfunction has been proposed to contribute to a reduced or insufficient capacity to oxidize fatty acids and to skeletal muscle insulin resistance, $(71,72)$, while evidence is increasing that this relationship is not as straightforward as originally thought (73). Previous studies have suggested that one of the underlying mechanisms by which physical activity may contribute to type 2 diabetes prevention is via improved capacity to oxidize fatty acids (74-76).

\subsection{Adipose tissue as endocrine organ}

During recent years it has become increasingly clear that adipose tissue is not only a lipid buffering depot, but also produces many peptides and hormones, which may act locally (autocrine and/or paracrine) or may be secreted in the circulation to act as 
endocrine factors. These adipo(cyto)kines may provide a link between obesity and insulin resistance and related metabolic complications (figure 1.3). As adiposity increases adipocytes become hypertrophied and the ability of adipose tissue to function as an endocrine organ and secrete multiple biologically active proteins is affected (77).

Among others, adipose tissue secretes adiponectin, leptin and resistin. Several prospective studies have shown that low adiponectin levels are predictive of the development of insulin resistance and type 2 diabetes mellitus (78-82). Adiponectin has been shown to inhibit TNF- $\alpha$ (83) and activate AMP-activated protein kinase (AMPK) and, in turn, modulate inflammatory signals (84). High-molecular weight (HMW) adiponectin has been proposed to be the biologically active form of the hormone (85), although although HMW adiponectin and total adiponectin had similar ability to predict the presence of insulin resistance (86).

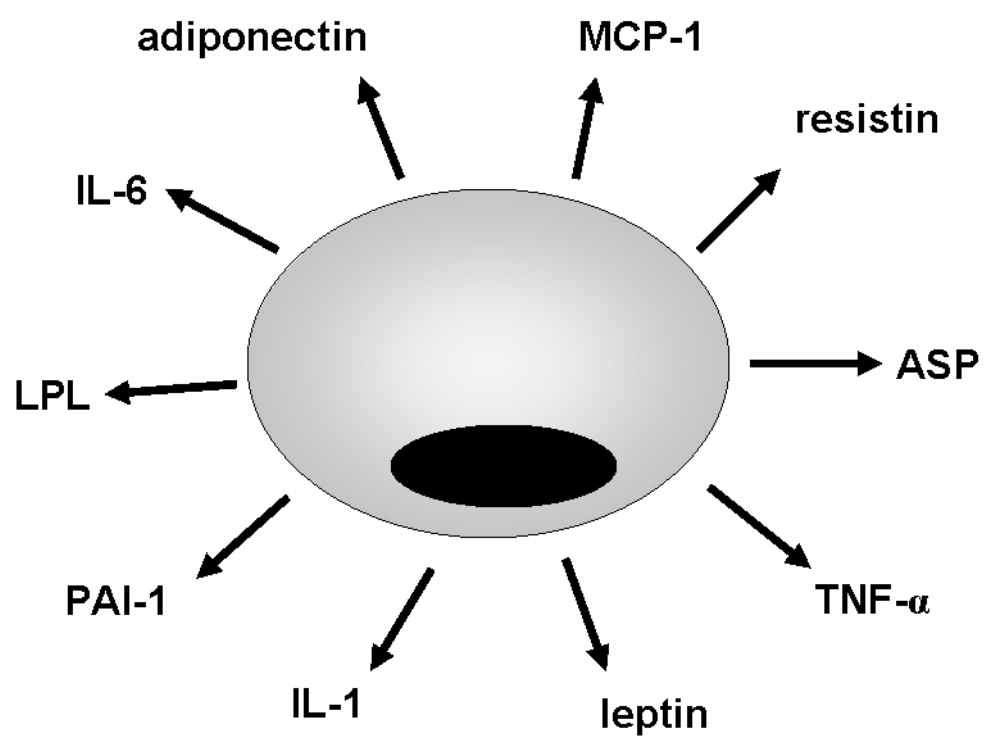

Figure 1.3 Adipocytes secrete a variety of substances which can have autocrine/paracrine and endocrine functions. Some of these factors may be associated with disturbances in obesity, glucose intolerance and insulin resistance (adapted from Goossens, Physiology and Behavior, 2008).

Leptin was originally thought to be a hormone whose primary role was to inhibit obesity by reducing food intake $(87,88)$. This idea was driven by the observation that rodents and humans lacking leptin or functional leptin receptors develop hyperphagia and obesity (87). The hypothesis was questioned when it was observed that obesity is typically associated with high leptin levels $(89,90)$ and fasting (or weight loss) induces a rapid fall in leptin levels, e.g. in obese subjects (91). A fall in leptin levels induces changes in energy balance and hormone levels $(88,89)$. Recently is was shown that in 6 obese subjects, restoration of leptin levels to the original levels before body weight loss, causes maintenance of weight loss and reversal of changes in brain control of 
food intake (91), indicating a potential of leptin to induce and sustain body weight loss (92).

With regard to resistin, conflicting data have been provided that do (93) and do not $(94,95)$ find an association with insulin resistance. For the complement system, data are more conclusive about a linear correlation with insulin resistance, in particular complement factor 3 (C3) and complement factor 4 (C4) $(96,97)$. Besides the liver, adipose tissue may be a source of $\mathrm{C} 3$ production, through activated macrophages (98) and adipocytes (99), thereby contributing to the development of type 2 diabetes. Creactive protein (CRP), which is also produced by the liver, has also shown to be a predictor of future risk of type 2 diabetes (100-102). Lifestyle interventions have shown to be able to reduce CRP levels $(103,104)$.

In recent years, the metabolic role of IL- 6 regained interest with the new concept of skeletal muscle producing cytokines (myokines), e.g. IL-6, during physical activity (105). IL-6 seems to be paradoxically related to both an enhanced and reduced insulin action. On one hand, IL- 6 is markedly produced and released in the post-exercise period (106) when insulin action is enhanced but (107-109), on the other hand, IL-6 has been associated with obesity (110), diabetes and atherosclerotic vascular disease (111). It seems that chronic elevation of IL-6 is not desirable (110), while short elevations of IL-6 do not seem to be harmful.

A discussion on the mechanisms for the increased inflammatory state in obesity, insulin resistance $(112,113)$, and type 2 diabetes $(101,114-116)$, would go beyond the scope of this introduction. In this respect, it has been demonstrated that hypertrophied adipocytes secrete macrophage chemoattractants, including monocyte chemoattractant protein-1 (MCP-1). MCP-1 recruits macrophage infiltration which, in turn, leads to a pro-inflammatory state in which macrophages secrete, among others, large amounts of tumour necrosis factor- $\alpha$ (TNF- $\alpha)(77,117,118)$. The proinflammatory state may in turn increase lipolysis, e.g. by interfering with the insulin signaling, and decrease triglyceride synthesis within the adipocyte by downregulation of peroxisome proliferator-activated receptor- $\gamma$ (PPAR- $-\gamma)$, and thereby increase lipid overflow to other organs (77).

Furthermore, although recent progress has been made in the understanding by which mechanisms biologically active proteins act on adipose tissue and skeletal muscle, a lot of questions remain to be answered to reveal the complex process of the pathogenesis of type 2 diabetes, thereby creating exciting opportunities in science.

\subsection{Iron metabolism}

The iron metabolism has been associated with insulin resistance and the development of type 2 diabetes (119). Until recently, however, it was not clear whether elevated iron stores predicted the risk of development of insulin resistance and type 2 diabetes. Proof of concept was provided by a large prospective study in healthy women that showed that higher iron stores (reflected by ferritin concentrations and the ratio of transferrin receptors to ferritin) were associated with an increased risk of type 2 diabetes, independently of known diabetes risk factors (120). Epidemiological studies have further demonstrated that both ferritin and transferrin predict the development of type 2 diabetes (121-123). The mechanism by which ferritin and transferrin may 


\section{Chapter 1}

contribute to insulin resistance is still unclear. Transferrin has been shown to be a determinant of lipolytic activity in human adipocytes (124), and adipose tissue lipolysis has been recognized as a major determinant of insulin resistance (125). Also, ferritin has been suggested to affect insulin action (126) or catalyze hydroxyl radicals (124, 127). Ferritin may stimulate lipolysis and subsequent lipid overflow towards liver and skeletal muscle, and the development of insulin resistance, thereby affecting the pathogenesis of type 2 diabetes.

\section{Outline of the thesis}

The leading thread through this thesis is the Study on Lifestyle intervention and Impaired glucose tolerance Maastricht (the SLIM-study) and each chapter will address a different question with respect to this study. In chapter 2 an overview is given about lifestyle intervention studies in the prevention of type 2 diabetes with respect to the main outcome and determinants of outcome and adherence, recent cost-effectiveness analyses and future implementation strategies. After 1 and 2 years, results of the SLIM study have shown that most improvement in glucose tolerance is achieved after 1 year of intervention and that adherence to the diet and exercise recommendations gives the largest improvement in body weight, waist circumference, fasting insulin and 2-hr glucose levels, compared to adherence to the diet or exercise recommendations alone (29). Chapter 3 addresses the 3-yr effects of on glucose tolerance, insulin resistance and the effect on metabolic cardiovascular risk factors, i.e. factors associated with the Metabolic Syndrome. Long-term effects of a lifestyle intervention (mean 4.2 years) as well as determinants of the main outcome and characteristics of dropout are evaluated in chapter 4 . Non-adherence to lifestyle interventions is a widespread problem (128) in need of clarification so that the success of lifestyle interventions involves the majority of the target group. Therefore, the study in chapter 5 aims to assess adherence to the physical activity and nutrition advices and to determine personal and environmental factors that may have affected adherence. In the chapters thereafter, factors are examined, which may be associated with the success of the lifestyle intervention. This may reveal predictors of intervention outcome and/or clues underlying the mechanism of the pathogenesis of type 2 diabetes mellitus. The 1-year and 3-year lifestyle-associated changes in inflammatory and immune markers with insulin resistance and glucose tolerance are discussed in chapter 6 and 7. Increasing adipose tissue (adiposity), as observed in obesity, is the main risk factor for type 2 diabetes. As adiposity increases, the ability of adipose tissue to function as endocrine organ and secrete multiple biologically active proteins, also called adipokines, is affected. In chapter 8 , the relationship between the iron metabolism and insulin resistance after 1 year of lifestyle intervention is discussed. In chapter 9 , the results and conclusions of the previous chapters are integrated and discussed in a broader perspective and implications for future research are given. 


\section{References}

1. Wild S, Roglic G, Green A, Sicree R, King H. Global prevalence of diabetes: estimates for the year 2000 and projections for 2030. Diabetes Care. 2004 May;27(5):1047-53.

2. IDF. Diabetes Atlas, second edition: www.eatlas.idf.org Accessed October 14, 2008.

3. Currie CJ, Poople CD, Woehl A, Morgan CL, Cawley S, Rousculp MD, et al. The financial costs of healthcare treatment for people with Type 1 or Type 2 diabetes in the UK with particular reference to differing severity of peripheral neuropathy. Diabetes Medicine. 2007;24:187-94.

4. Johnson JA, Pohar SL, Majumdar SR. Health care use and costs in the decade after identification of type 1 and type 2 diabetes: a population-based study. Diabetes Care. 2006;29:2403-8.

5. Chaturvedi $\mathrm{N}$. The burden of diabetes and its complications: trends and implications for intervention. Diabetes Res Clin Pract. 2007 May;76 Suppl 1:S3-12.

6. Cusick M, Meleth AD, Agron E, Fisher MR, Reed GF, Knatterud GL, et al. Associations of mortality and diabetes complications in patients with type 1 and type 2 diabetes: early treatment diabetic retinopathy study report no.27. Diabetes Care. 2005;28:617-25.

7. Mulnier HE, Seaman HE, Raleigh VS, Soedamah-Muthu SS, Colhoun HM, Lawrenson RA. Mortality in people with type 2 diabetes in the UK. Diabetes Medicine. 2006;23:516-21.

8. Is the current definition for diabetes relevant to mortality risk from all causes and cardiovascular and noncardiovascular diseases? Diabetes Care. 2003 Mar;26(3):688-96.

9. WHO. Definition, diagnosis and classification of diabetes mellitus. Report of WHO Consultation. Part 1: Diagnosis and Classification of Diabetes Mellitus Geneva, Switzerland; 1999.

10. Leahy JL. Pathogenesis of type 2 diabetes mellitus. Arch Med Res. 2005 May-Jun;36(3):197-209.

11. Saad MF, Knowler WC, Pettitt DJ, Nelson RG, Charles MA, Bennett PH. A two-step model for development of non-insulin-dependent diabetes. Am J Med. 1991 Feb;90(2):229-35.

12. Nijpels G. Determinants for the progression from impaired glucose tolerance to non-insulin-dependent diabetes mellitus. Eur J Clin Invest. 1998 Sep;28 Suppl 2:8-13.

13. Unwin N, Shaw J, Zimmet P, Alberti KG. Impaired glucose tolerance and impaired fasting glycaemia: the current status on definition and intervention. Diabet Med. 2002 Sep;19(9):708-23.

14. de Vegt F, Dekker JM, Jager A, Hienkens E, Kostense PJ, Stehouwer CD, et al. Relation of impaired fasting and postload glucose with incident type 2 diabetes in a Dutch population: The Hoorn Study. Jama. 2001 Apr 25;285(16):2109-13.

15. Colditz GA, Willett WC, Rotnitzky A, Manson JE. Weight gain as a risk factor for clinical diabetes mellitus in women. Ann Intern Med. 1995 Apr 1;122(7):481-6.

16. Chan JM, Rimm EB, Colditz GA, Stampfer MJ, Willett WC. Obesity, fat distribution, and weight gain as risk factors for clinical diabetes in men. Diabetes Care. 1994 Sep;17(9):961-9.

17. Han TS, Feskens EJ, Lean ME, Seidell JC. Associations of body composition with type 2 diabetes mellitus. Diabet Med. 1998 Feb;15(2):129-35.

18. Albu JB, Kovera AJ, Johnson JA. Fat distribution and health in obesity. Ann N Y Acad Sci. 2000 May;904:491-501.

19. Kissebah AH, Peiris AN. Biology of regional body fat distribution: relationship to non-insulin-dependent diabetes mellitus. Diabetes Metab Rev. 1989 Mar;5(2):83-109.

20. Despres JP, Lemieux S, Lamarche B, Prud'homme D, Moorjani S, Brun LD, et al. The insulin resistancedyslipidemic syndrome: contribution of visceral obesity and therapeutic implications. Int J Obes Relat Metab Disord. 1995 May;19 Suppl 1:S76-86.

21. Banerji MA, Chaiken RL, Gordon D, Kral JG, Lebovitz HE. Does intra-abdominal adipose tissue in black men determine whether NIDDM is insulin-resistant or insulin-sensitive? Diabetes. 1995 Feb;44(2):141-6.

22. Marshall JA, Hoag S, Shetterly S, Hamman RF. Dietary fat predicts conversion from impaired glucose tolerance to NIDDM. The San Luis Valley Diabetes Study. Diabetes Care. 1994 Jan;17(1):50-6.

23. Vessby B, Unsitupa M, Hermansen K, Riccardi G, Rivellese AA, Tapsell LC, et al. Substituting dietary saturated for monounsaturated fat impairs insulin sensitivity in healthy men and women: The KANWU Study. Diabetologia. 2001 Mar;44(3):312-9.

24. Lopez S, Bermudez B, Pacheco YM, Villar J, Abia R, Muriana FJ. Distinctive postprandial modulation of beta cell function and insulin sensitivity by dietary fats: monounsaturated compared with saturated fatty acids. Am J Clin Nutr. 2008 Sep;88(3):638-44.

25. Jenkins DJ, Kendall CW, McKeown-Eyssen G, Josse RG, Silverberg J, Booth GL, et al. Effect of a lowglycemic index or a high-cereal fiber diet on type 2 diabetes: a randomized trial. Jama. 2008 Dec $17 ; 300(23): 2742-53$. 


\section{Chapter 1}

26. Willi C, Bodenmann P, Ghali WA, Faris PD, Cornuz J. Active smoking and the risk of type 2 diabetes: a systematic review and meta-analysis. Jama. 2007 Dec 12;298(22):2654-64.

27. Laaksonen DE, Lindstrom J, Lakka TA, Eriksson JG, Niskanen L, Wikstrom K, et al. Physical activity in the prevention of type 2 diabetes: the Finnish diabetes prevention study. Diabetes. 2005 Jan;54(1):158-65.

28. Mensink M, Corpeleijn E, Feskens EJ, Kruijshoop M, Saris WH, de Bruin TW, et al. Study on lifestyleintervention and impaired glucose tolerance Maastricht (SLIM): design and screening results. Diabetes Res Clin Pract. 2003 Jul;61(1):49-58.

29. Mensink M, Blaak EE, Corpeleijn E, Saris WH, de Bruin TW, Feskens EJ. Lifestyle intervention according to general recommendations improves glucose tolerance. Obes Res. 2003 Dec;11(12):1588-96.

30. Astrup A, Astrup A, Buemann B, Flint A, Raben A. Low-fat diets and energy balance: how does the evidence stand in 2002? Proc Nutr Soc. 2002 May;61(2):299-309.

31. Hays NP, Starling RD, Liu X, Sullivan DH, Trappe TA, Fluckey JD, et al. Effects of an ad libitum low-fat, high-carbohydrate diet on body weight, body composition, and fat distribution in older men and women: a randomized controlled trial. Arch Intern Med. 2004 Jan 26;164(2):210-7.

32. Lindstrom J, Peltonen M, Eriksson JG, Louheranta A, Fogelholm M, Uusitupa M, et al. High-fibre, low-fat diet predicts long-term weight loss and decreased type 2 diabetes risk: the Finnish Diabetes Prevention Study. Diabetologia. 2006 May;49(5):912-20.

33. Borkman M, Storlien LH, Pan DA, Jenkins AB, Chisholm DJ, Campbell LV. The relation between insulin sensitivity and the fatty-acid composition of skeletal-muscle phospholipids. N Engl J Med. 1993 Jan 28;328(4):238-44.

34. Feskens EJ, van Dam RM. Dietary fat and the etiology of type 2 diabetes: an epidemiological perspective. Nutr Metab Cardiovasc Dis. 1999 Apr;9(2):87-95.

35. Vessby B, Aro A, Skarfors E, Berglund L, Salminen I, Lithell H. The risk to develop NIDDM is related to the fatty acid composition of the serum cholesterol esters. Diabetes. $1994 \mathrm{Nov}$;43(11):1353-7.

36. Orozco LJ, Buchleitner AM, Gimenez-Perez G, Roque IFM, Richter B, Mauricio D. Exercise or exercise and diet for preventing type 2 diabetes mellitus. Cochrane Database Syst Rev. 2008(3):CD003054.

37. Hu FB, Sigal RJ, Rich-Edwards JW, Colditz GA, Solomon CG, Willett WC, et al. Walking compared with vigorous physical activity and risk of type 2 diabetes in women: a prospective study. Jama. 1999 Oct 20;282(15):1433-9.

38. Church TS, Earnest CP, Skinner JS, Blair SN. Effects of different doses of physical activity on cardiorespiratory fitness among sedentary, overweight or obese postmenopausal women with elevated blood pressure: a randomized controlled trial. Jama. 2007 May 16;297(19):2081-91.

39. Donnelly JE, Smith B, Jacobsen DJ, Kirk E, Dubose K, Hyder M, et al. The role of exercise for weight loss and maintenance. Best Pract Res Clin Gastroenterol. 2004 Dec;18(6):1009-29.

40. Pan XR, Li GW, Hu YH, Wang JX, Yang WY, An ZX, et al. Effects of diet and exercise in preventing NIDDM in people with impaired glucose tolerance. The Da Qing IGT and Diabetes Study. Diabetes Care. 1997 Apr;20(4):537-44.

41. Tuomilehto J, Lindstrom J, Eriksson JG, Valle TT, Hamalainen H, llanne-Parikka P, et al. Prevention of type 2 diabetes mellitus by changes in lifestyle among subjects with impaired glucose tolerance. N Engl J Med. 2001 May 3;344(18):1343-50.

42. Knowler WC, Barrett-Connor E, Fowler SE, Hamman RF, Lachin JM, Walker EA, et al. Reduction in the incidence of type 2 diabetes with lifestyle intervention or metformin. N Engl J Med. 2002 Feb 7;346(6):393-403.

43. Kosaka K, Noda M, Kuzuya T. Prevention of type 2 diabetes by lifestyle intervention: a Japanese trial in IGT males. Diabetes Res Clin Pract. 2005 Feb;67(2):152-62.

44. Ramachandran A, Snehalatha C, Mary S, Mukesh B, Bhaskar AD, Vijay V. The Indian Diabetes Prevention Programme shows that lifestyle modification and metformin prevent type 2 diabetes in Asian Indian subjects with impaired glucose tolerance (IDPP-1). Diabetologia. 2006 Feb;49(2):289-97.

45. Lindstrom J, llanne-Parikka P, Peltonen M, Aunola S, Eriksson JG, Hemio K, et al. Sustained reduction in the incidence of type 2 diabetes by lifestyle intervention: follow-up of the Finnish Diabetes Prevention Study. Lancet. 2006 Nov 11;368(9548):1673-9.

46. Li G, Zhang P, Wang J, Gregg EW, Yang W, Gong Q, et al. The long-term effect of lifestyle interventions to prevent diabetes in the China Da Qing Diabetes Prevention Study: a 20-year follow-up study. Lancet. 2008 May 24;371(9626):1783-9.

47. Carr DB, Utzschneider KM, Boyko EJ, Asberry PJ, Hull RL, Kodama K, et al. A reduced-fat diet and aerobic exercise in Japanese Americans with impaired glucose tolerance decreases intra-abdominal fat and improves insulin sensitivity but not beta-cell function. Diabetes. 2005 Feb;54(2):340-7. 
48. Oldroyd JC, Unwin NC, White M, Mathers JC, Alberti KG. Randomised controlled trial evaluating lifestyle interventions in people with impaired glucose tolerance. Diabetes Res Clin Pract. 2006 May;72(2):117-27.

49. Saaristo T, Peltonen M, Keinanen-Kiukaanniemi S, Vanhala M, Saltevo J, Niskanen L, et al. National type 2 diabetes prevention programme in Finland: FIN-D2D. Int J Circumpolar Health. 2007 Apr;66(2):101-12.

50. Frayn KN BE. Metabolic fuels and obesity; carbohydrate and lipid metabolism in skeletal muscle and adipose tissue: Blackwell Publishing Ltd 2005.

51. Heilbronn L, Smith SR, Ravussin E. Failure of fat cell proliferation, mitochondrial function and fat oxidation results in ectopic fat storage, insulin resistance and type II diabetes mellitus. Int J Obes Relat Metab Disord. 2004 Dec;28 Suppl 4:S12-21.

52. Muoio DM, Newgard CB. Obesity-related derangements in metabolic regulation. Annu Rev Biochem. 2006;75:367-401.

53. Boden G. Role of fatty acids in the pathogenesis of insulin resistance and NIDDM. Diabetes. 1997 Jan;46(1):3-10.

54. Kelley DE, Mokan M, Simoneau JA, Mandarino LJ. Interaction between glucose and free fatty acid metabolism in human skeletal muscle. J Clin Invest. 1993 Jul;92(1):91-8.

55. Santomauro AT, Boden G, Silva ME, Rocha DM, Santos RF, Ursich MJ, et al. Overnight lowering of free fatty acids with Acipimox improves insulin resistance and glucose tolerance in obese diabetic and nondiabetic subjects. Diabetes. 1999 Sep;48(9):1836-41.

56. Abdelmalek MF, Diehl AM. Nonalcoholic fatty liver disease as a complication of insulin resistance. Med Clin North Am. 2007 Nov;91(6):1125-49, ix.

57. Charlton M. Nonalcoholic fatty liver disease: a review of current understanding and future impact. Clin Gastroenterol Hepatol. 2004 Dec;2(12):1048-58.

58. Lewis GF, Carpentier A, Adeli K, Giacca A. Disordered fat storage and mobilization in the pathogenesis of insulin resistance and type 2 diabetes. Endocr Rev. 2002 Apr;23(2):201-29.

59. Jacob S, Machann J, Rett K, Brechtel K, Volk A, Renn W, et al. Association of increased intramyocellular lipid content with insulin resistance in lean nondiabetic offspring of type 2 diabetic subjects. Diabetes. 1999 May;48(5):1113-9.

60. Krssak M, Falk Petersen K, Dresner A, DiPietro L, Vogel SM, Rothman DL, et al. Intramyocellular lipid concentrations are correlated with insulin sensitivity in humans: a $1 \mathrm{H}$ NMR spectroscopy study. Diabetologia. 1999 Jan;42(1):113-6.

61. Perseghin G, Scifo P, De Cobelli F, Pagliato E, Battezzati A, Arcelloni C, et al. Intramyocellular triglyceride content is a determinant of in vivo insulin resistance in humans: a $1 \mathrm{H}-13 \mathrm{C}$ nuclear magnetic resonance spectroscopy assessment in offspring of type 2 diabetic parents. Diabetes. 1999 Aug;48(8):1600-6.

62. Pan DA, Lillioja S, Kriketos AD, Milner MR, Baur LA, Bogardus C, et al. Skeletal muscle triglyceride levels are inversely related to insulin action. Diabetes. 1997 Jun;46(6):983-8.

63. Schmitz-Peiffer C. Signalling aspects of insulin resistance in skeletal muscle: mechanisms induced by lipid oversupply. Cell Signal. 2000 Oct;12(9-10):583-94.

64. Itani SI, Ruderman NB, Schmieder F, Boden G. Lipid-induced insulin resistance in human muscle is associated with changes in diacylglycerol, protein kinase C, and IkappaB-alpha. Diabetes. 2002 Jul;51(7):2005-11.

65. Cooney GJ, Thompson AL, Furler SM, Ye J, Kraegen EW. Muscle long-chain acyl CoA esters and insulin resistance. Ann N Y Acad Sci. 2002 Jun;967:196-207.

66. Summers SA. Ceramides in insulin resistance and lipotoxicity. Prog Lipid Res. 2006 Jan;45(1):42-72.

67. Mensink M, Blaak EE, van Baak MA, Wagenmakers AJ, Saris WH. Plasma free Fatty Acid uptake and oxidation are already diminished in subjects at high risk for developing type 2 diabetes. Diabetes. 2001 Nov;50(11):2548-54.

68. Blaak EE, Wagenmakers AJ, Glatz JF, Wolffenbuttel BH, Kemerink GJ, Langenberg CJ, et al. Plasma FFA utilization and fatty acid-binding protein content are diminished in type 2 diabetic muscle. Am J Physiol Endocrinol Metab. 2000 Jul;279(1):E146-54.

69. Blaak EE, Wagenmakers AJ. The fate of $[\mathrm{U}-(13) \mathrm{C}]$ palmitate extracted by skeletal muscle in subjects with type 2 diabetes and control subjects. Diabetes. 2002 Mar;51(3):784-9.

70. Corpeleijn E, Saris WH, Blaak EE. Metabolic flexibility in the development of insulin resistance and type 2 diabetes: effects of lifestyle. Obes Rev. 2009 Mar;10(2):178-93.

71. Morino K, Petersen KF, Shulman Gl. Molecular mechanisms of insulin resistance in humans and their potential links with mitochondrial dysfunction. Diabetes. 2006 Dec;55 Suppl 2:S9-S15.

72. Maassen JA, Romijn JA, Heine RJ. Fatty acid-induced mitochondrial uncoupling in adipocytes as a key protective factor against insulin resistance and beta cell dysfunction: a new concept in the pathogenesis of obesity-associated type 2 diabetes mellitus. Diabetologia. 2007 Oct;50(10):2036-41. 


\section{Chapter 1}

73. Choi CS, Befroy DE, Codella R, Kim S, Reznick RM, Hwang YJ, et al. Paradoxical effects of increased expression of PGC-1alpha on muscle mitochondrial function and insulin-stimulated muscle glucose metabolism. Proc Natl Acad Sci U S A. 2008 Dec 16;105(50):19926-31.

74. Sial S, Coggan AR, Hickner RC, Klein S. Training-induced alterations in fat and carbohydrate metabolism during exercise in elderly subjects. Am J Physiol. 1998 May;274(5 Pt 1):E785-90.

75. Schrauwen P, van Aggel-Leijssen DP, Hul G, Wagenmakers AJ, Vidal H, Saris WH, et al. The effect of a 3month low-intensity endurance training program on fat oxidation and acetyl-CoA carboxylase-2 expression. Diabetes. 2002 Jul;51(7):2220-6.

76. van Aggel-Leijssen DP, Saris WH, Wagenmakers AJ, Senden JM, van Baak MA. Effect of exercise training at different intensities on fat metabolism of obese men. J Appl Physiol. 2002 Mar;92(3):1300-9.

77. Guilherme A, Virbasius JV, Puri V, Czech MP. Adipocyte dysfunctions linking obesity to insulin resistance and type 2 diabetes. Nat Rev Mol Cell Biol. 2008 May;9(5):367-77.

78. Snijder MB, Heine RJ, Seidell JC, Bouter LM, Stehouwer CD, Nijpels G, et al. Associations of adiponectin levels with incident impaired glucose metabolism and type 2 diabetes in older men and women: the hoorn study. Diabetes Care. 2006 Nov;29(11):2498-503.

79. Nakashima R, Kamei N, Yamane K, Nakanishi S, Nakashima A, Kohno N. Decreased total and high molecular weight adiponectin are independent risk factors for the development of type 2 diabetes in Japanese-Americans. J Clin Endocrinol Metab. 2006 Oct;91(10):3873-7.

80. Snehalatha C, Mukesh B, Simon M, Viswanathan V, Haffner SM, Ramachandran A. Plasma adiponectin is an independent predictor of type 2 diabetes in Asian indians. Diabetes Care. 2003 Dec;26(12):3226-9.

81. Lindsay RS, Funahashi T, Hanson RL, Matsuzawa Y, Tanaka S, Tataranni PA, et al. Adiponectin and development of type 2 diabetes in the Pima Indian population. Lancet. 2002 Jul 6;360(9326):57-8.

82. Otsuka F, Sugiyama S, Kojima S, Maruyoshi H, Funahashi T, Sakamoto T, et al. Hypoadiponectinemia is associated with impaired glucose tolerance and coronary artery disease in non-diabetic men. Circ J. 2007 Nov;71(11):1703-9.

83. Tilg $\mathrm{H}$, Moschen AR. Adipocytokines: mediators linking adipose tissue, inflammation and immunity. Nat Rev Immunol. 2006 Oct;6(10):772-83.

84. Kadowaki T, Yamauchi T. Adiponectin and adiponectin receptors. Endocr Rev. 2005 May;26(3):439-51.

85. Hara K, Horikoshi M, Yamauchi T, Yago H, Miyazaki O, Ebinuma $H$, et al. Measurement of the highmolecular weight form of adiponectin in plasma is useful for the prediction of insulin resistance and metabolic syndrome. Diabetes Care. 2006 Jun;29(6):1357-62.

86. Bluher M, Brennan AM, Kelesidis T, Kratzsch J, Fasshauer M, Kralisch S, et al. Total and high-molecular weight adiponectin in relation to metabolic variables at baseline and in response to an exercise treatment program: comparative evaluation of three assays. Diabetes Care. 2007 Feb;30(2):280-5.

87. Zhang Y, Proenca R, Maffei M, Barone M, Leopold L, Friedman JM. Positional cloning of the mouse obese gene and its human homologue. Nature. 1994 Dec 1;372(6505):425-32.

88. Ahima RS, Prabakaran D, Mantzoros C, Qu D, Lowell B, Maratos-Flier E, et al. Role of leptin in the neuroendocrine response to fasting. Nature. $1996 \mathrm{Jul}$ 18;382(6588):250-2.

89. Flier JS. Clinical review 94: What's in a name? In search of leptin's physiologic role. J Clin Endocrinol Metab. 1998 May;83(5):1407-13.

90. Heymsfield SB, Greenberg AS, Fujioka K, Dixon RM, Kushner R, Hunt T, et al. Recombinant leptin for weight loss in obese and lean adults: a randomized, controlled, dose-escalation trial. Jama. 1999 Oct 27;282(16):1568-75.

91. Rosenbaum M, Sy M, Pavlovich K, Leibel RL, Hirsch J. Leptin reverses weight loss-induced changes in regional neural activity responses to visual food stimuli. J Clin Invest. 2008 Jul;118(7):2583-91.

92. Ahima RS. Revisiting leptin's role in obesity and weight loss. J Clin Invest. 2008 Jul;118(7):2380-3.

93. Steppan CM, Bailey ST, Bhat S, Brown EJ, Banerjee RR, Wright CM, et al. The hormone resistin links obesity to diabetes. Nature. 2001 Jan 18;409(6818):307-12.

94. Lee JH, Chan JL, Yiannakouris N, Kontogianni M, Estrada E, Seip R, et al. Circulating resistin levels are not associated with obesity or insulin resistance in humans and are not regulated by fasting or leptin administration: cross-sectional and interventional studies in normal, insulin-resistant, and diabetic subjects. J Clin Endocrinol Metab. 2003 Oct;88(10):4848-56.

95. Hasegawa G, Ohta M, Ichida Y, Obayashi H, Shigeta M, Yamasaki M, et al. Increased serum resistin levels in patients with type 2 diabetes are not linked with markers of insulin resistance and adiposity. Acta Diabetol. 2005 Jun;42(2):104-9.

96. Engstrom G, Hedblad B, Eriksson KF, Janzon L, Lindgarde F. Complement C3 is a risk factor for the development of diabetes: a population-based cohort study. Diabetes. 2005 Feb;54(2):570-5. 
97. Gabrielsson BG, Johansson JM, Lonn $M$, Jernas $M$, Olbers $T$, Peltonen $M$, et al. High expression of complement components in omental adipose tissue in obese men. Obes Res. 2003 Jun;11(6):699-708.

98. Zimmer B, Hartung HP, Scharfenberger G, Bitter-Suermann D, Hadding U. Quantitative studies of the secretion of complement component $\mathrm{C} 3$ by resident, elicited and activated macrophages. Comparison with C2, C4 and lysosomal enzyme release. Eur J Immunol. 1982 May;12(5):426-30.

99. Choy LN, Rosen BS, Spiegelman BM. Adipsin and an endogenous pathway of complement from adipose cells. J Biol Chem. 1992 Jun 25;267(18):12736-41.

100. Hu FB, Meigs JB, Li TY, Rifai N, Manson JE. Inflammatory markers and risk of developing type 2 diabetes in women. Diabetes. 2004 Mar;53(3):693-700.

101.Pradhan AD, Manson JE, Rifai N, Buring JE, Ridker PM. C-reactive protein, interleukin 6, and risk of developing type 2 diabetes mellitus. Jama. 2001 Jul 18;286(3):327-34.

102.Spranger J, Kroke A, Mohlig M, Hoffmann K, Bergmann MM, Ristow M, et al. Inflammatory cytokines and the risk to develop type 2 diabetes: results of the prospective population-based European Prospective Investigation into Cancer and Nutrition (EPIC)-Potsdam Study. Diabetes. 2003 Mar;52(3):812-7.

103. Esposito K, Pontillo A, Di Palo C, Giugliano G, Masella M, Marfella R, et al. Effect of weight loss and lifestyle changes on vascular inflammatory markers in obese women: a randomized trial. Jama. $2003 \mathrm{Apr}$ 9;289(14):1799-804.

104. Haffner S, Temprosa M, Crandall J, Fowler S, Goldberg R, Horton E, et al. Intensive lifestyle intervention or metformin on inflammation and coagulation in participants with impaired glucose tolerance. Diabetes. 2005 May;54(5):1566-72.

105. Keller P, Keller C, Carey AL, Jauffred S, Fischer CP, Steensberg A, et al. Interleukin-6 production by contracting human skeletal muscle: autocrine regulation by IL-6. Biochem Biophys Res Commun. 2003 Oct 17;310(2):550-4.

106.Petersen AM, Pedersen BK. The anti-inflammatory effect of exercise. J Appl Physiol. 2005 Apr;98(4):1154-62.

107.Pedersen BK, Steensberg A, Schjerling P. Muscle-derived interleukin-6: possible biological effects. J Physiol. 2001 Oct 15;536(Pt 2):329-37.

108. Febbraio MA, Pedersen BK. Muscle-derived interleukin-6: mechanisms for activation and possible biological roles. Faseb J. 2002 Sep;16(11):1335-47.

109.Steensberg A, van Hall G, Osada T, Sacchetti M, Saltin B, Klarlund Pedersen B. Production of interleukin6 in contracting human skeletal muscles can account for the exercise-induced increase in plasma interleukin-6. J Physiol. 2000 Nov 15;529 Pt 1:237-42.

110.Carey AL, Febbraio MA. Interleukin-6 and insulin sensitivity: friend or foe? Diabetologia. 2004 Jul;47(7):1135-42.

111.Ridker PM, Rifai N, Stampfer MJ, Hennekens CH. Plasma concentration of interleukin-6 and the risk of future myocardial infarction among apparently healthy men. Circulation. 2000 Apr 18;101(15):1767-72.

112.Pedersen BK. IL-6 signalling in exercise and disease. Biochem Soc Trans. 2007 Nov;35(Pt 5):1295-7.

113. Festa A, Hanley AJ, Tracy RP, D'Agostino R, Jr., Haffner SM. Inflammation in the prediabetic state is related to increased insulin resistance rather than decreased insulin secretion. Circulation. 2003 Oct 14;108(15):1822-30.

114. Herder C, Peltonen M, Koenig W, Kraft I, Muller-Scholze S, Martin S, et al. Systemic immune mediators and lifestyle changes in the prevention of type 2 diabetes: results from the Finnish Diabetes Prevention Study. Diabetes. 2006 Aug;55(8):2340-6.

115.Schmidt MI, Duncan BB, Sharrett AR, Lindberg G, Savage PJ, Offenbacher S, et al. Markers of inflammation and prediction of diabetes mellitus in adults (Atherosclerosis Risk in Communities study): a cohort study. Lancet. 1999 May 15;353(9165):1649-52.

116. Festa A, D'Agostino R, Jr., Tracy RP, Haffner SM. Elevated levels of acute-phase proteins and plasminogen activator inhibitor-1 predict the development of type 2 diabetes: the insulin resistance atherosclerosis study. Diabetes. 2002 Apr;51(4):1131-7.

117.Sartipy P, Loskutoff DJ. Monocyte chemoattractant protein 1 in obesity and insulin resistance. Proc Natl Acad Sci U S A. 2003 Jun 10;100(12):7265-70.

118.Curat CA, Miranville A, Sengenes C, Diehl M, Tonus C, Busse R, et al. From blood monocytes to adipose tissue-resident macrophages: induction of diapedesis by human mature adipocytes. Diabetes. 2004 May;53(5):1285-92.

119.Fernandez-Real JM, Lopez-Bermejo A, Ricart W. Cross-talk between iron metabolism and diabetes. Diabetes. 2002 Aug;51(8):2348-54.

120.Jiang R, Manson JE, Meigs JB, Ma J, Rifai N, Hu FB. Body iron stores in relation to risk of type 2 diabetes in apparently healthy women. Jama. 2004 Feb 11;291(6):711-7. 


\section{Chapter 1}

121. Fumeron F, Pean F, Driss F, Balkau B, Tichet J, Marre M, et al. Ferritin and transferrin are both predictive of the onset of hyperglycemia in men and women over 3 years: the data from an epidemiological study on the Insulin Resistance Syndrome (DESIR) study. Diabetes Care. 2006 Sep;29(9):2090-4.

122. Forouhi NG, Harding AH, Allison M, Sandhu MS, Welch A, Luben R, et al. Elevated serum ferritin levels predict new-onset type 2 diabetes: results from the EPIC-Norfolk prospective study. Diabetologia. 2007 May;50(5):949-56.

123.Fernandez-Real JM, Moreno JM, Lopez-Bermejo A, Chico B, Vendrell J, Ricart W. Circulating soluble transferrin receptor according to glucose tolerance status and insulin sensitivity. Diabetes Care. 2007 Mar;30(3):604-8.

124.Rumberger JM, Peters T, Jr., Burrington C, Green A. Transferrin and iron contribute to the lipolytic effect of serum in isolated adipocytes. Diabetes. 2004 Oct;53(10):2535-41.

125.Arner P. Insulin resistance in type 2 diabetes: role of fatty acids. Diabetes Metab Res Rev. 2002 MarApr;18 Suppl 2:S5-9.

126.Vargas L, Kawada ME, Bazaes S, Karplus PA, Faerman CH. Insulin antagonism: a novel role for human serum transferrin. Horm Metab Res. 1998 Mar;30(3):113-7.

127. Meneghini R. Iron homeostasis, oxidative stress, and DNA damage. Free Radic Biol Med. 1997;23(5):78392.

128.WHO. Adherence to long-term therapies: Evidence for action. Geneva: WHO; 2003. 


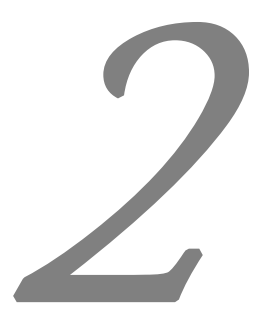

\title{
LIFESTYLE INTERVENTION IN THE PREVENTION OF TYPE DIABETES
}

\author{
Determinants of success for future \\ implementation
}

Cheryl Roumen, Ellen E. Blaak, Eva Corpeleijn.

Nutrition Reviews 2009 Mar;67(3):132-46. 


\begin{abstract}
Lifestyle interventions are reported to reduce the risk of type 2 diabetes in high-risk individuals after mid- and long-term follow-up. Information on determinants of intervention outcome and adherence and the mechanisms underlying diabetes progression are valuable for a more targeted implementation. Weight loss seems a major determinant of diabetes risk reduction, whereas physical activity, dietary composition may also independently contribute. Also, body composition and genetic variation may affect the response to intervention. Lifestyle interventions are cost-effective and should be optimized to increase adherence and compliance, especially for the high-risk group with a low socio-economic status, so that public health policy can introduce targeted implementation programs nationwide. The aim of this review is to summarize the midand long-term effects of lifestyle interventions on impaired glucose tolerance and type 2 diabetes mellitus and to provide determinants of intervention outcome and adherence which can be used for future implementation of lifestyle interventions.
\end{abstract}




\section{Introduction}

The World Health Organization predicts a global increase in diabetes prevalence of $39 \%$ between 2000 and 2030, increasing absolute numbers to 366 million people (1). Impaired glucose tolerance (IGT), impaired fasting glucose (IFG) and IGT/IFG combined predict the development of type 2 diabetes over 6 years with $9.1 \%$ progression for IFG, $32.5 \%$ progression for IGT and $64.5 \%$ for combined IGT/IFG (2). IGT is characterized by insulin resistance and reduced $\beta$-cell glucose sensitivity (3-5), which may develop over many years. Lifestyle intervention may improve the metabolic profile and reverse the progression towards diabetes (figure 2.1) (5).

In this manuscript, we summarize the mid- and long-term effects of lifestyle interventions in subjects with IGT to lifestyle intervention outcome, i.e. changes in glucose tolerance or diabetes incidence. To develop implementation strategies it is important to know which factors determine the effectiveness and adherence to the intervention. Therefore, we provide information on lifestyle factors, i.e. (central) obesity, physical activity, dietary patterns (2, 6-9), on metabolic factors and genetic variation. Implementation of lifestyle interventions in general health care services will only start after lifestyle interventions have shown to be cost-effective. Therefore, this subject is discussed in a separate section. To conclude, this manuscript provides conclusive paragraphs regarding the long-term effects of lifestyle interventions and the major determinants of intervention outcome and adherence. In addition this manuscript discusses the cost-effectiveness of lifestyle interventions and concludes with a summary on these paragraphs and additional implementation strategies for the future, which also include social-economic, social and psychological factors.

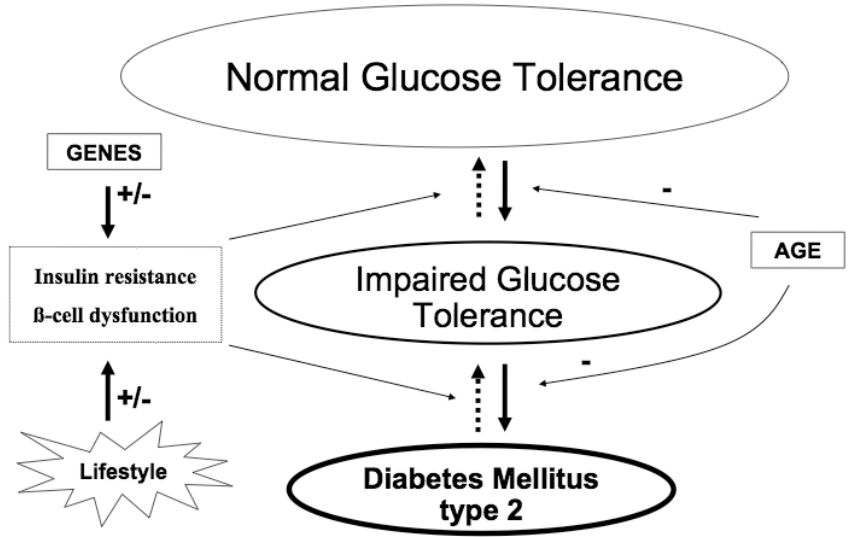

Figure 2.1 Transition from normal glucose tolerance to diabetes mellitus type 2: three step model (adapted from Saad et al. (1999) (5)). The development of normal glucose tolerance to impaired glucose tolerance and type 2 diabetes mellitus can be affected by age, genes and lifestyle. It is (partly) reversible by healthy changes in lifestyle. 
Lifestyle interventions: effect on diabetes incidence and 2-hour glucose concentrations

In table 2.1 and 2.2 a summary is given of lifestyle intervention studies to prevent type 2 diabetes in IGT subjects. Only studies were included, that investigated the effect of exercise and/or dietary intake on 2-hour glucose concentration as an intermediate endpoint (table 2.1) or diabetes incidence as primary endpoint and that lasted more than 1 year (table 2.2 ).

\section{Glucose tolerance}

There is evidence that lifestyle intervention leads to an improvement in glucose tolerance, measured as the 2-hr plasma glucose concentration after a 75-g glucose load. Lifestyle interventions generally aim to achieve a body weight loss of at least 5 percent, through a healthy diet and energy restriction and to increase physical activity of moderate intensity to at least 30 minutes a day (table 2.3). The healthy diet most often refers to a total fat intake of less than 30 percent of energy consumed (E\%), a saturated fat intake of less than $10 \mathrm{E} \%$ and an increase in fiber intake to at least $15 \mathrm{~g}$ per $1000 \mathrm{kcal}$. In the Diabetes Prevention Study (DPS), 2-hour glucose levels tended to decrease more in the intervention as compared to the control group after 3 years of lifestyle intervention (10). In New Zealand, a 1-year lifestyle intervention directed at reducing fat intake, by education of IGT participants on dietary fat intake, showed a lower increase in 2-hour glucose levels in the intervention group after a follow-up of 5 years (11) ( $p<0.01$, table 2.1). Three smaller diet and exercise intervention studies, one in Swedish participants, one in Japanese Americans and one in British subjects with IGT, demonstrated a reduced body weight (12-14) and an improved insulin sensitivity, but no significant differences in 2 -hour glucose changes after 2 years $(13,14)$. In Japanese Americans, central adiposity measured with computed tomography was reduced and the incremental area under the curve for glucose during an oral glucose tolerance test (OGTT) was improved after 6 months in the diet plus endurance training group versus the diet plus stretching (control) group (13). The Dutch Study on Lifestyle intervention and Impaired glucose tolerance Maastricht (SLIM) evaluated a combined diet-and-exercise lifestyle intervention in IGT subjects. After 3 years, the postprandial glucose concentration was $0.8 \mathrm{mmol} / \mathrm{l}$ lower in the lifestyle group compared to the control group, representing a substantial diabetes risk reduction (15).

Most, but not all studies show a beneficial effect of lifestyle intervention on glucose tolerance. Sample size and a short follow-up of 1-2 years may explain part of the variation in effect size. Differences in baseline characteristics between intervention and control group, like waist circumference (13), fasting glucose and insulin levels (12) and percentage of subjects engaging physical activity at least once a week (14) may have influenced the effect of lifestyle interventions on 2-hr glucose levels. Interesting is that a lack of significant effect on 2-hr glucose is not necessarily related to a lack of effect on diabetes risk reduction. In the DPS, the reduction in 2-hr glucose levels was not significant (10) (0.4 mM difference between intervention and control), but risk reduction was $58 \%$ (table 2.2 ). Part of the risk reduction may be mediated via other pathways than 2-hr-glucose, e.g. via sub-clinical inflammatory factors (16) or preservation of $\beta$-cell function (4). 
Lifestyle interventions and type 2 diabetes

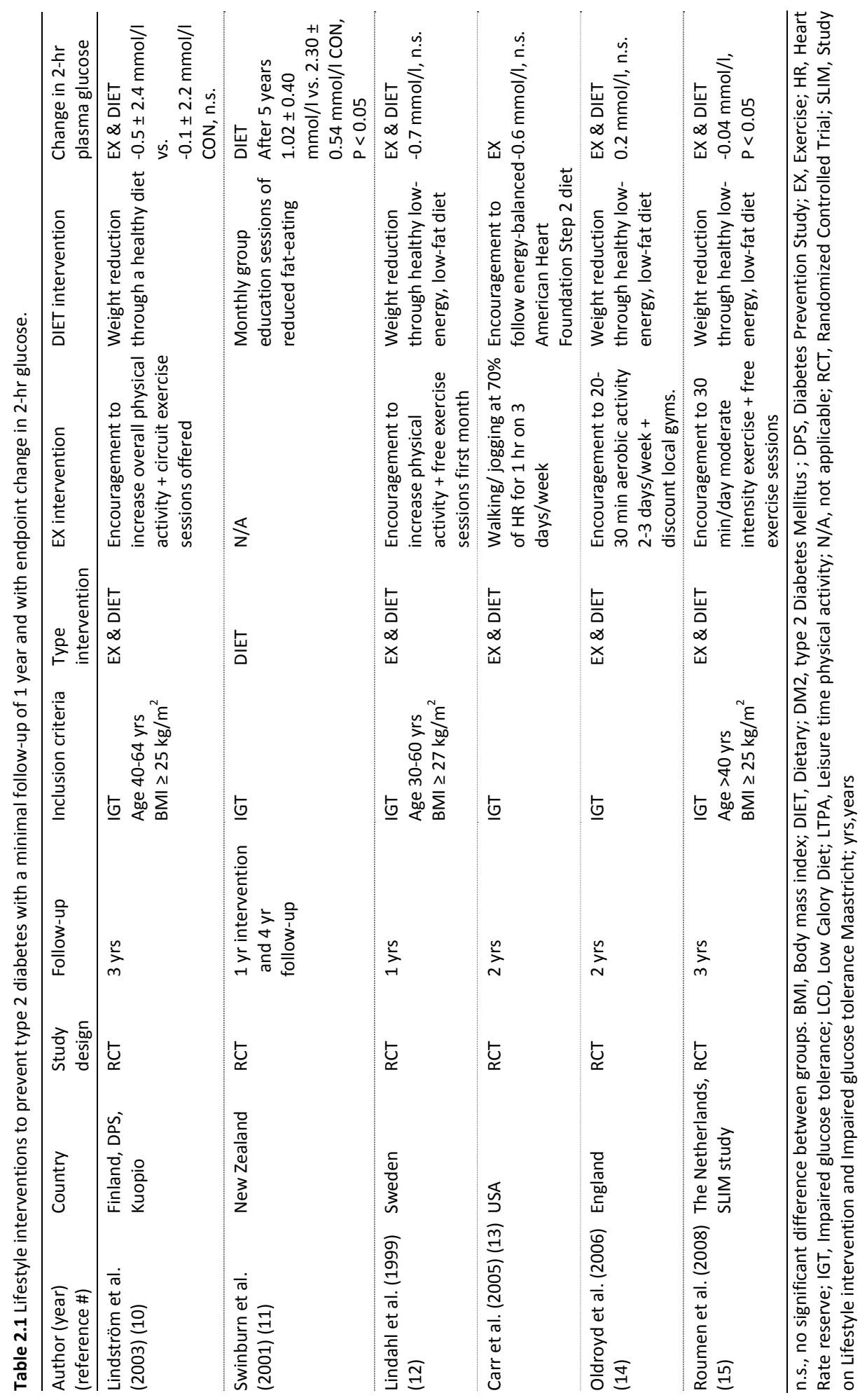


Chapter 2

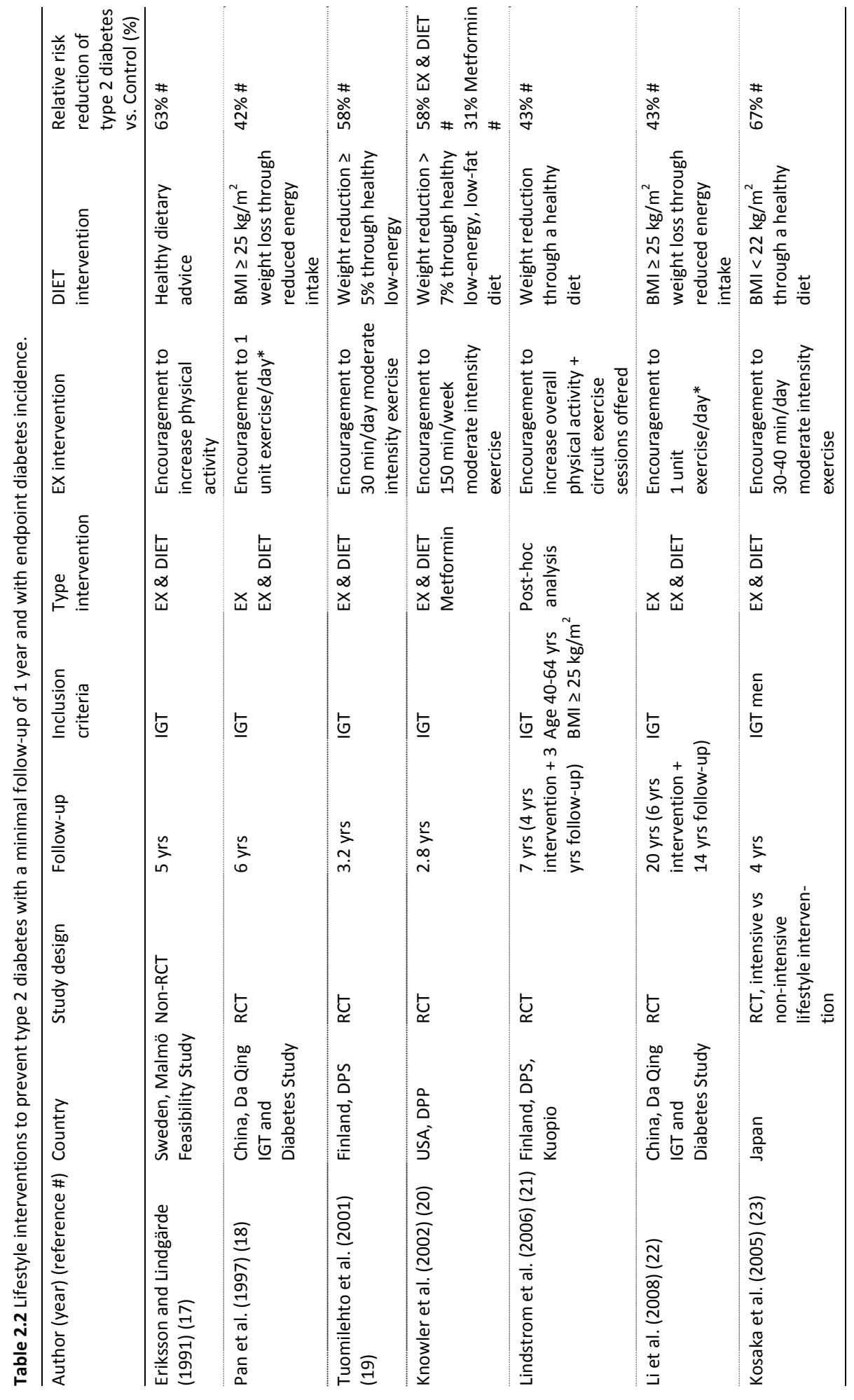


Lifestyle interventions and type 2 diabetes

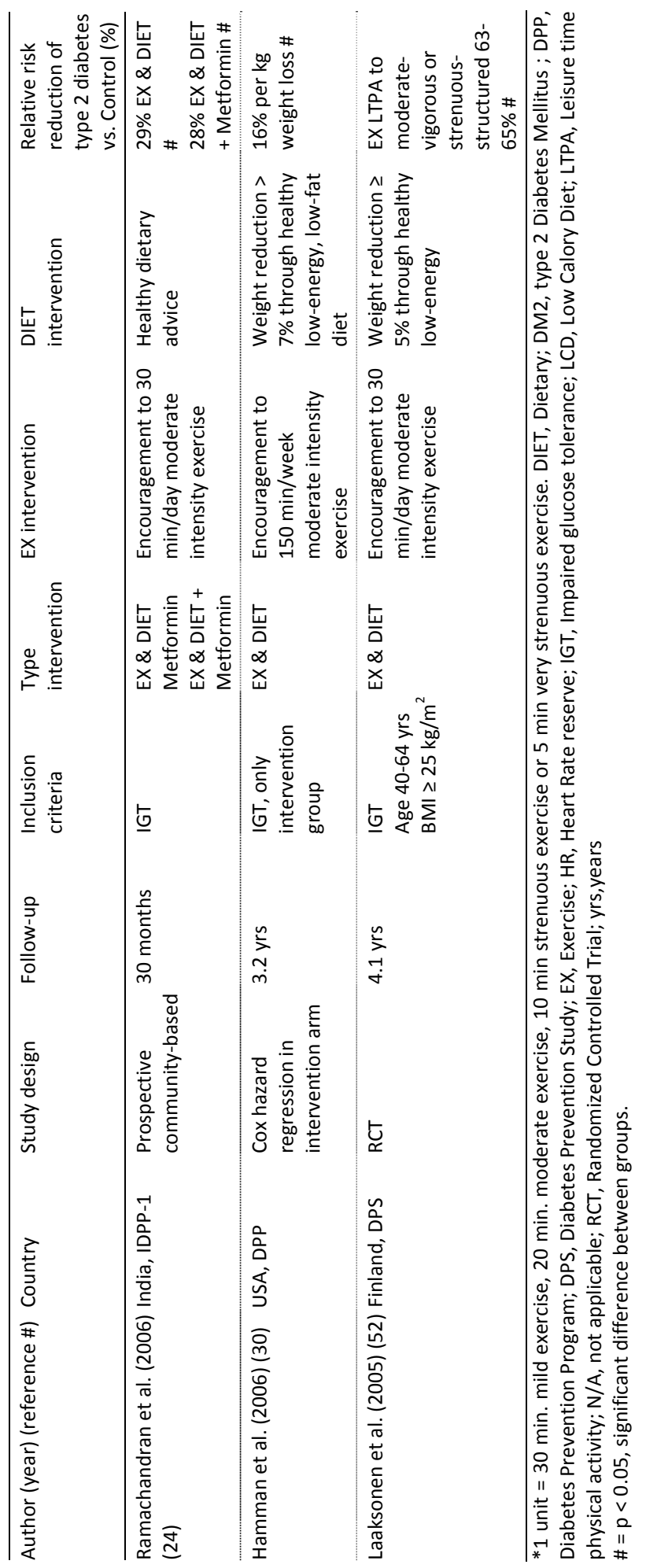




\section{Diabetes incidence}

The Malmö-study (17) and the Chinese Da Qing IGT and Diabetes study (18) were two of the first studies to show a reduced type 2 diabetes risk of more than $50 \%$ and $42 \%$, respectively, by a diet and exercise program during a follow-up of 6 years. More recently, both the Finnish Diabetes Prevention Study (DPS) (19) and the Diabetes Prevention Program (DPP) in the USA (20) confirmed the beneficial effect of lifestyle and showed a diabetes risk reduction of $58 \%$ in IGT subjects that received a lifestyle intervention consisting of dietary and exercise advice during a follow-up of 3.2 and 2.8 years, respectively. Interestingly, in an additional follow-up, the DPS showed that even after 3 years cessation of a 4-year lifestyle program (total follow-up 7 years), diabetes risk was still reduced with $43 \%$ (21). The Chinese Da Qing IGT and Diabetes study found the same diabetes risk reduction after a 14-year follow-up of a 6-year lifestyle intervention (22). A 4-year randomized controlled trial in Japan reduced diabetes risk with $67.4 \%$ by a combined dietary and exercise advice to IGT men (23) and the Indian Diabetes Prevention Program (IDPP-1) reduced diabetes risk by $28.5 \%$ in the diet and exercise intervention after 3 years (24). Thus, lifestyle changes in IGT subjects reduce or delay the development of type 2 diabetes. The risk reduction of studies that follow the lifestyle criteria listed in table 2.3 (the DPP (20), DPS (19) and SLIM (15)) is approximately $58 \%$ after 3 years follow-up. Although all studies show a beneficial lifestyle effect, the risk reduction ranges from $28 \%$ to $67 \%$. Differences in risk reductions may be due to different population characteristics, ethnicity, duration of the lifestyle intervention and follow-up, and the lifestyle goals accomplished.

A recent systematic review and meta-analysis shows that lifestyle interventions seem at least as effective as pharmacological interventions, e.g. with orlistat, a drug which reduces intestinal fat absorption (25). In the DPP, metformin, a drug which suppresses hepatic glucose production, was less effective to reduce type 2 diabetes risk $(-31 \%)$ than lifestyle intervention (20).

In general, lifestyle changes in subjects with IGT considerably reduce or delay the development of type 2 diabetes and is at least equally effective as pharmacological interventions.

Table 2.3 Common features of lifestyle interventions.

\begin{tabular}{ll}
\hline Body weight loss & $\geq 5 \%$ \\
Dietary guidelines & \\
Carbohydrates & $\pm 55 \mathrm{E} \%$ \\
Total Fat & $<30 \mathrm{E} \%$ \\
- Saturated Fat & $\leq 10 \mathrm{E} \%$ \\
- Cholesterol & $<33 \mathrm{mg} / \mathrm{MJ}$ \\
Proteins & $10-15 \mathrm{E} \%$ \\
Fiber & $3 \mathrm{~g} / \mathrm{MJ}$ a day \\
& \\
Exercise guidelines & 30 minutes of moderate physical activity \\
& a day for at least 5 days a week \\
\hline
\end{tabular}




\section{Determinants of intervention outcome and adherence}

The progression towards type 2 diabetes can be influenced by lifestyle components such as body weight loss, dietary composition, and physical activity. These factors may all contribute to the improved glucose metabolism and the response and adherence to the lifestyle intervention.

\section{Body weight and diabetes risk}

Body mass index (BMI) and body weight gain are strongly associated with diabetes risk (26). Weight gain of $11-20 \mathrm{~kg}$ in 14 years of follow-up increased age-adjusted relative diabetes risk 5.4-fold in female nurses who had normal weight at age 18 (BMI 22-25 $\mathrm{kg} / \mathrm{m}^{2}$ ) relative to nurses with normal weight at age 18 y who had no weight gain or loss of more than $5 \mathrm{~kg}$. In addition to over-all obesity, body fat distribution and especially increased intra-abdominal fat is a predictor of type 2 diabetes $(27,28)$. The BMI of middle-aged women at midlife strongly predicts 3-year incidence rates of type 2 diabetes (29), whereas short-term weight changes during this period did not significantly affect the onset of type 2 diabetes (29).

\section{The effect of changes in body weight on diabetes risk}

In the lifestyle intervention group of the DPP, weight loss was the dominant predictor of reduced diabetes risk with a $16 \%$ reduction for every kilogram weight loss during the 3.2 year follow-up (30). Thereafter, in the 4-year follow-up, insulin sensitivity in the entire group (intervention plus control) improved by $64 \%$ in the highest tertile of weight loss, but deteriorated with $24 \%$ in those who gained weight, while insulin secretion remained unchanged in IGT subjects who managed to loose weight (31). Overall, weight loss is a major contributor in the prevention of type 2 diabetes mellitus.

Besides weight loss, changes in body fat distribution may influence diabetes risk. It has been shown that a relatively minor loss of body weight $(-3 \%)$ which was accompanied by a major reduction in visceral fat mass $(-12 \%)$ and liver fat content $(-33 \%)$ was associated with improved insulin sensitivity $(32,33)$. However, to bring the visceral depot to normal levels, subjects with upper body obesity, those with a larger visceral depot compared to subjects with lower body obesity, may need to loose larger amounts of body weight compared to subjects with lower body obesity (34). The loss of visceral fat seems to be predominantly determined by the initial amount of fat in the visceral fat depot $(35,36)$. Subjects with high visceral adipose tissue and liver fat or high BMI may more easily loose body weight and visceral fat, while this does not imply metabolic benefits (32). Even after weight loss, fat deposition in these subjects is above average, which may not make a metabolic difference, because an improvement in insulin sensitivity may require a reduction in ectopic fat deposition below a specific threshold (32). Overall, with regard to body fat distribution, lifestyle interventions have lead to a reduced diabetes risk, in parallel with reductions in preferentially visceral fat but also subcutaneous fat and total body fat $(13,37)$. It is still unclear to what extent body fat distribution adds to the metabolic benefits of lifestyle interventions. There- 
fore, no clear suggestions can be made at this point regarding body fat distribution as determinant of intervention outcome.

The relationship between increased adiposity and insulin resistance and diabetes may, on one hand be explained by an increased lipid overflow in the circulation. Normally, adipose tissue functions as a 'metabolic buffer' trapping dietary fatty acids, whilst in insulin resistant conditions this buffering action is impaired resulting in exposure of non-adipose tissues like muscle and liver to excessive fluxes of lipids. Accumulation of lipids in these tissues plays a critical role in the etiology of insulin resistance and type 2 diabetes mellitus (38-43). On the other hand, the relationship between adiposity and insulin resistance may be explained by an alteration in the production of inflammatory factors. Inflammatory factors, which can be produced by adipose tissue but also numerous other cell types, may have autocrine effects (i.e. effects on gene expression, lipid and glucose metabolism) (44) or may be secreted as endocrine factors influencing energy and substrate metabolism and insulin sensitivity in other tissues like skeletal muscle and liver (45). For example, baseline adiponectin levels, an adipose-derived adipokine, seems a strong predictor of incident diabetes in the DPP (46). Considerable weight loss seems to restore high adiponectin levels (47, 48), but lifestyle interventions according to general guidelines do not seem to have a relevant effect on adiponectin in either diabetic patients (49), IGT subjects (50) or obese subjects (51). Leptin, another adipokine, seems also related to improvements in insulin sensitivity, independent of changes in body composition (50).

\section{The effect of changes in physical activity on diabetes risk}

To design optimal guidelines for physical activity as part of lifestyle programs, it is important to define the independent effect of physical activity on the risk of type 2 diabetes. Post-hoc analysis of 487 IGT men and women in the DPS on whom data of leisure-time physical activity were available revealed that individuals with the highest increase in their level of moderate-to-vigorous physical activity were $63-65 \%$ less likely to develop type 2 diabetes during the 4.1 year follow-up compared to individuals with the lowest increase in physical activity (52). Similarly, in the DPP, indexes that reflect autonomic function and fitness improved (i.e., heart rate decreased and heart rate variability increased) during a 3.2 year intervention and were inversely related to diabetes risk, independent of weight change (53). In the Chinese Da Qing IGT and Diabetes Study (18), diet and exercise were equally effective as exercise alone to prevent the progression of IGT to type 2 diabetes. Results from the Dutch SLIM study (54) and the Oslo Diet and Exercise study (55) showed most effect in improving glucose tolerance and preventing type 2 diabetes by the combination of diet and exercise. These post-hoc analyses show that exercise contributes to improve glucose metabolism, independent of weight loss (52) and therefore seems to have an additive effect on diabetes prevention. Besides reducing diabetes risk, increasing exercise training results in an improved fitness in a dose dependent manner (56), which may positively influence daily-life activities. Physical activity is also an important predictor of weight maintenance after weight loss (57). To conclude, physical activity is besides body weight loss an independent contributor to improve glucose metabolism. There are 
indications that especially moderate-to-vigorous physical activity help prevent type 2 diabetes.

One of the underlying mechanisms by which physical activity may contribute to type 2 diabetes prevention is via improved capacity to oxidize fatty acids (58-60). Free fatty acid (FFA) oxidation is reduced in subjects with type 2 diabetes mellitus and impaired glucose tolerance (IGT) and it has been shown that a combined diet and physical activity intervention program can prevent further deterioration of impaired fatty acid oxidation during exercise in subjects with IGT (61). An improved utilization of fatty acids for energy may reduce the accumulation of lipids and lipotoxic intermediates in skeletal muscle and thereby improve insulin sensitivity (62-64). Additionally, it has also been suggested that training can bring about improvements in the regulation of hepatic glucose output $(65,66)$.

With respect to duration and intensity, the guidelines of the International Diabetes Federation (IDF) and the American College of Sports Medicine prescribe at least 30 minutes of moderate-intensity physical activity on most, preferably all days of the week $(6,67)$. However, in formerly obese or overweight subjects $60-90$ minutes/day or 45-60 minutes/day of moderate intensity physical activity are recommended, respectively, to prevent further weight gain (68). To date, a recent review indicated that 30 $\mathrm{min} /$ day of moderate- or high-level physical activity is an effective and safe way to prevent type 2 diabetes in all populations (69). There is enough evidence to justify that physical activity has an additive effect when combined with a dietary intervention and should be included in lifestyle programs, despite the uncertainty about the exact duration and intensity to effectively prevent diabetes (70).

With respect to the kind of physical activity, a recent trial showed most improvement in hemoglobin A1c levels of patients with type 2 diabetes when the physical activity consisted of combined aerobic and resistance training (71). Recent guidelines on physical activity and public health in older adults from the American College of Sports Medicine and American Heart Association also recommend muscle strengthening and balance exercise as an integrated part of physical activity intervention in older adults $(72,73)$.

Lifestyle interventions face the challenge of increasing adherence and compliance to the program and it seems that men and women with a low initial BMI may be more likely to meet activity goals (74). However, reaching the recommended physical activity level for the majority of people at risk for diabetes may be quite a challenge, since the majority (61\%) of US patients with diabetes or at highest risk for diabetes do not engage in regular physical activity (75). On the other hand, in the Nurses' Health Study it was shown that even among women who did not perform vigorous physical activity, diabetes risk was reduced with $26 \%$ after 8 years of follow-up for those who had walked most relative to those who walked least (76). This seems to indicate that even small but sustained increases in physical activity are beneficial in the long-term; exemplifying that physical activity should be included in lifestyle programs. Since there is a high heterogeneity in high-risk subjects, i.e. with regard to co-morbidity and muscle strength, as is the case for diabetic patients, the exercise intervention should become more individualized to optimize its therapeutic value (73). A personalized activity plan may be one of the ways to achieve the physical activity recommendations (72). 
Dietary factors related to the development of type 2 diabetes include, besides energy intake restriction, total fat intake, fat quality, fiber, glycemic index/glycemic load, alcohol consumption and coffee consumption (7). A western diet, emphasizing red meat, French fries and high fat dairy products has been associated with increased diabetes risk $(77,78)$, while a 'prudent' diet, emphasizing fruits, vegetables, fish and whole grains has been associated with a reduced diabetes risk (79-82). The Women's Health study, a large prospective study, showed a relative risk of 1.28 for women in the highest quintile of red meat use, versus the lowest quintile (83). Short-term dietary changes towards high-carbohydrate and low glycemic index seem to improve $\beta$-cell function in IGT subjects (84). Dietary fibers can reduce the rate of glucose absorption in the intestine, thereby lowering postprandial glycemic and insulinemic responses (85). Also the total fat intake is an important risk factor for the development of type 2 diabetes as its energy-density favors increased food intake and obesity. In the San Louis Valley Diabetes Study, a $40 \mathrm{~g}$ higher fat intake corresponded with a 6-fold increase in diabetes risk in IGT subjects after adjustment for obesity and markers of glucose metabolism (i.e. fasting glucose and insulin) (9). An ad libitum reduced-fat diet without energy restriction has been shown to produce a moderate weight reduction between 3-5 kilograms $(86,87)$. In agreement with these findings, results from the DPS in 500 IGT subjects (intervention plus control group) during a 4.1 year follow-up suggest that a high-fiber, low-fat diet predict sustained weight loss and reduces the development of type 2 diabetes, even after adjustment for other risk factors such as physical activity (88). In addition, the quality of dietary fat modifies diabetes risk. In particular, an excess of saturated fat may have detrimental effects on skeletal muscle insulin sensitivity (38-40). Insulin sensitivity improved when saturated fatty acids in the diet were replaced either by mono-unsaturated fat (89) or poly-unsaturated fat (90). Unsaturated fatty acids may influence diabetes risk by increasing the fluidity of membranes, thereby facilitating membrane signaling, including insulin signaling (91) and/or by influencing the regulation of genes involved in the breakdown and oxidation of fatty acids (92). The relation between insulin sensitivity and n-3 poly-unsaturated fatty acids (PUFAs) is less clear, but most studies using a euglycemic hyperinsulinemic clamp have found no effect of n-3 PUFAs on insulin sensitivity in healthy or diabetic subjects (89, $91,93)$. Recent interest has developed for specific fatty acids, and for enzymes that alter the saturation of ingested fatty acids, the so-called desaturase enzymes (94). In the SLIM study, lifestyle-induced changes in insulin sensitivity were partly related to changes in fatty acid profile of serum cholesteryl esters, and in particular to changes in desaturase activities (95).

To conclude, multiple components of a healthy diet, e.g. high fiber and a low saturated fat intake, reduce diabetes risk, and contribute to sustained weight loss and should therefore be included in long-term lifestyle interventions. Composition of the diet plays a key role in diabetes prevention in the first place to sustain weight loss in the long-term and in the second place to initiate weight loss and diabetes risk reduction. 
Genetic variability may partly explain why there are non-responders to lifestyle treatment despite compliance and adherence to the lifestyle intervention program. In the DPS a large number of genes have been examined for their effect on diabetes incidence and intervention success (for review of genes investigated in the DPS, see (96)). An interaction with intervention outcome has been found for the TT genotype of SNP rs12255372 in the TCF7L2 gene which was associated with 2.85 -fold increased risk of incident type 2 diabetes in the control subjects of the DPS, but not in the intervention subjects (97). The TCF7L2 gene is presumed to play a role in the first-phase insulin release (97). A similar pattern was found for a single nucleotide polymorphism (SNP), the X/Ala genotype of the PPARY-2 Pro12Ala SNP, which was associated with increased diabetes risk in the control group, whereas there was no newly diagnosed diabetes in the Ala/Ala genotype subjects of the intervention group (98). One explanation is that subjects with the Ala12 allele are more responsive to weight reduction and physical activity than subjects with the Pro/Pro genotype, and thus suffer more from bad lifestyle habits but profit more from the lifestyle intervention as well.

A large study that investigates the interaction between exercise training and genes, is the Health, Risk Factors, Exercise Training, and Genetics (HERITAGE) Family Study (99). Multiple genes related to the response of an exercise program were identified, including several Quantitative Trait Loci (QTL) on chromosome 1p, 3q, 6p, 7q, 10p, $12 q$ and $19 q$ in white participants $(100,101)$, the -514 C>T SNP in the Hepatic Lipase gene (LIPC) in both white and black individuals (101) and the rs2180062 and rs9018 of the Four and a Half LIM domains 1 (FHL1) gene (102).

The Tübinger Lifestyle Intervention Program (TULIP) (103) followed the lifestyle protocol from the Finnish DPS study (weight loss, increase physical activity and healthy diet) (19). They showed that the minor G allele of SNP rs2267668 in PPARD and the minor serine-encoding allele of the common Gly482Ser SNP in PPARGC1A were independently associated with less increase in individual anaerobic threshold (104), indicating that these alleles impair the effectiveness of aerobic training. In addition, low skeletal muscle mitochondrial function in vitro was detected in young carriers of the $G$ allele of the rs2267668 SNP of PPARD. They also showed that variation in the adiponectin receptor 1 (ADIPOR1) gene predicted the improvement of insulin sensitivity and the reduction of liver fat after lifestyle intervention (105). The adiponectin receptor 1 may have a putative role in the development of body size, as has been suggested by the Finnish DPS (106).

To conclude, genetic variation can play a role in the response to a lifestyle intervention. Some SNP's may increase the vulnerability for lifestyle factors. This means that these individuals run an increased risk for developing type 2 diabetes with adverse lifestyle behavior, and at the same time may benefit more from lifestyle intervention. Other SNP's increase diabetes risk independent of lifestyle factors. Studies involving interactions between genes and lifestyle intervention response are still limited and need confirmation in large cohorts. When more conclusive evidence is provided, the effectiveness of tailored lifestyle programs should be tested in subgroups with genotypes that are associated with adequate and impaired metabolic response to a lifestyle intervention (96). 


\section{Costs and cost-effectiveness}

The potential benefits of lifestyle intervention are substantial, but so are the costs for implementing such programs. In return, the potential for cost savings from the prevention or delay of type 2 diabetes and its complications is also considerable. Although several studies have shown effectiveness over longer periods, up to 6 years, it is important for policy makers and health care providers to predict its effectiveness in 10, 20 or 30 years time. To assist policy makers, researchers have developed computer models that simulate the progression of diabetes, expenditures on diabetes care, and effects of interventions. Two principal types of diabetes models exist. The Markov model simulates transitions from one disease state to another (e.g. from IGT to type 2 diabetes) as chance events. A second novel type of model, named Archimedes, integrates detailed biological and administrative information in complex differential equations to simulate pathophysiological processes (e.g. postprandial glucose disposal) that change over time and can lead to disease (107).

The results of the DPP and DPS have been extensively used for cost-effectiveness analyses using both models, resulting in different outcomes. The outcome depends on many factors, such as the assumptions for the natural progression of glycemia and the effectiveness of the lifestyle intervention, the time horizon that is used (30 years or until death after diagnosis), characteristics of included patients (age, degree of obesity, ethnicity, gender), and the costs of the lifestyle program, which depends on the approach (group or individual counseling) and country where the implementation will take place (108).

The DPP developed an analysis based on the Markov model, lifetime horizon and a societal perspective. The cost was $\$ 8800$ per quality-adjusted life-years (QALY) for the lifestyle intervention and $\$ 29.900$ for metformin that would be saved (109), which fall both within a range generally accepted as being cost-effective (110). When using the Archimedes model with time horizons of 10, 20 and 30 years and a societal perspective, the cost per QALY of beginning the intensive lifestyle intervention in subjects with IGT was $\$ 62.600$, and $\$ 35.400$ for metformin over 30 years, when compared with no intervention (111). The cost per QALY for an intensive lifestyle intervention started after the onset of diabetes was $\$ 24.500$ (111). The Archimedes model adopted more conservative assumptions for the development of diabetes and its complications, which may have reduced cost-effectiveness. Both studies underline that lifestyle intervention will substantially reduce the proportion of patients at risk to develop diabetes, it will postpone the onset of diabetes from 7 or 8 to 14 or 18 years, and it will lead to fewer complications, longer life, and improved quality of life.

When the DPS results were applied to a Swedish setting, the cost-effectiveness analysis based on the Markov model predicted that the program would be cost-saving from the healthcare payers' perspective (112). In the Netherlands, two different approaches for health care interventions were evaluated: a community based approach targeted at the general population with a high number needed to treat $(300-$ 1500 individuals) but low costs per individual (113), and a health care intervention approach aimed at high risk individuals with a low number needed-to-treat (7-30 individuals) but relative high costs per individual (54). Both approaches were evaluated using a Markov-type, multistage transition model, which describes the development 
over time of demography, risk factor prevalence, disease incidence, and mortality in the Dutch population (114). Both approaches were cost-effective in the range of $€ 5600-€ 9900$ (114).

To design cost-effective lifestyle interventions, the effectiveness of lifestyle intervention for different subgroups may need to be taken into account. The results from the DPP show no differences in progression towards type 2 diabetes between ethnic groups, once they are identified as impaired glucose tolerant (115). Age may be important: metformin was only cost-effective in IGT subjects under the age of 65 , but lifestyle intervention was effective in all age groups (109). Metformin had a better impact on costs in younger and more obese subjects, whereas lifestyle intervention was more effective in subjects with a BMI below $30 \mathrm{~kg} / \mathrm{m}^{2}$ (108). Further identification of factors that modify intervention outcome may increase the efficacy of tailored advice, improving cost-effectiveness.

In general, the implementation of lifestyle intervention as a therapy to prevent and postpone type 2 diabetes and its complications looks promising and costeffectiveness seems acceptable. In particular differences in the effectiveness of lifestyle intervention between groups and countries, and approach for implementation (group or individual counseling), will be of influence on the cost-effectiveness. In Finland, a large implementation trial to evaluate different approaches for lifestyle intervention in the health care system started recently (116). It will provide valuable information about the barriers, strategies and costs of lifestyle implementation in a real-life setting.

\section{Implementation strategies}

Lifestyle interventions are cost-effective in reducing the risk for type 2 diabetes on the long-term. The next question is how to implement a lifestyle intervention in the general public health setting in a way that is most successful. The high-risk approach has the advantage over a community-based strategy that tailored advice can increase personal risk awareness of diabetes as well as the magnitude and durability of behavioral changes, whereas a community-based strategy will prompt the individual to a lesser extent to undertake action.

Recently, the IDF has proposed a simple three-step plan for the prevention of type 2 diabetes in high-risk individuals: first, identification of those who may be at increased risk, second, measurement of risk and third, intervention to prevent the development of type 2 diabetes (6). For identification the IDF recommends brief questionnaires with criteria of obesity, family history, age, cardiovascular history, gestational history and drug history to assess the level of risk. These questionnaires are simple, practical, non-invasive and inexpensive. In Finland, a type 2 diabetes risk assessment form has already been developed which assesses diabetes risk based on age, BMI, waist, physical activity, fruit and vegetable intake, blood pressure medication, previous high blood glucose (i.e. during pregnancy or illness) and family history of type 2 diabetes, the so-called FINDRISC score (117). A recent post-hoc analysis of the DPS results shows that the FINDRISC may be useful in identifying high-risk groups most likely to benefit from intensive lifestyle intervention to prevent type 2 diabetes (118). 
For measurement of risk the IDF recommends the measurement of venous fasting plasma glucose levels. If plasma glucose levels are above $6.1 \mathrm{mmol} / \mathrm{l}$, a 2-hour OGTT is recommended to detect cases of IGT and undiagnosed diabetes. For intervention the IDF recommends gradual weight loss, change in dietary composition and increasing physical activity to 30 minutes moderate intensity physical activity per day, on most days of the week (6). Similar recommendations are made in recent reviews evaluating diet, glucose tolerance and type 2 diabetes $(119,120)$. Furthermore, although smoking is not usually included as part of a lifestyle intervention program, it is an important lifestyle-related risk factor for diabetes. Since quitting smoking may lead to weight gain (121), special attention is necessary with regard to weight control (122). Lifestyle intervention programs can be suitable for this.

However, merely providing the method of implementation will not be sufficient for successful implementation of lifestyle interventions. For achieving and sustaining lifestyle changes throughout the lifespan, intervention mapping can be used as a tool for the development of health promotion interventions (123). However, efforts from the individual, the practitioner, the community and policy makers fulfill a key role in giving high-risk individuals tailored advice and encouragement to decrease their diabetes risk.

To increase sustainable lifestyle changes, first, the individual should be aware of his/her increased risk for type 2 diabetes and his/her lifestyle. This can be achieved by e.g. the general practitioner who asks individuals at risk if they have family or friends who suffer from the disease. In a recent cross-sectional study, African Americans with a family history of diabetes were more aware of diabetes risk factors and were more likely to engage in certain health behaviors than were subjects without a family history of the disease (124).

Second, motivational interviewing by nurse practitioners can be applied to assist individuals to achieve a positive attitude towards changes in diet, physical activity or the social aspects associated with it. The intentional behavior stage of an individual, as identified by the transtheoretical model of behavior change, is of influence on the preparedness for lifestyle changes (for review with regard to exercise see (125)). In subjects who have developed type 2 diabetes, being in the action stage was associated with healthier eating, compared to those in a pre-action stage (126). In the action stage people are active as in undertaking action for less than 6 months and in the preaction stages (precontemplation, contemplation and preparation), individuals are not active and have no intention to become active or, in the latter two cases, have the intention to become active within 6 months or 1 month, respectively (127). Knowing the behavioral stage of the individual gives the advantage of formulating specific advice. Altogether, tailored information and advice may increase the intention to adopt a certain lifestyle aspect $(125,128)$.

Third, general practitioners should be aware and convinced of the clinical significance of IGT and reducing type 2 diabetes incidence by targeting lifestyle interventions at patients at risk (129). Practitioners or dieticians should inform subjects about reading food labels and understanding portion size (130). Therefore, it is desired that practitioners have skills that include assessment of dietary history and physical activity counseling, or refer patients to professionals who have those skills, such as dieticians and physiotherapists. A Finnish study evaluating lifestyle counseling in primary care 
has recently shown a lack of communication skills of nurses and physicians counseling subjects with diabetes and IGT with regard to diet and physical activity (131). Improving communication skills, e.g. by teaching the motivational interviewing approach to health care professionals, may therefore improve intervention outcome.

To conclude, high-risk screening and tailored advice seem to have potential for success. In addition, it is acknowledged that community-based strategies involving the food industry and government policies may be necessary as an integral component of diabetes prevention to create an environment supportive of an active and healthy lifestyle (6).

\section{Conclusion}

The studies mentioned in this review clearly illustrate that improvements in lifestyle can have a large beneficial impact on diabetes risk. Very promising are the new data on long-term effects of lifestyle programs, showing a sustained diabetes risk reduction, even after counseling was stopped $(21,23)$. Lifestyle intervention can additionally have a positive impact on cardiovascular risk profile (132) and features of the metabolic syndrome (133). Therefore, we conclude that lifestyle interventions can reduce the diabetes risk substantially in subjects with impaired glucose tolerance, especially when existing of a combined diet and exercise program. We underscore the importance of cost-effective changes in lifestyle that are sustainable over a long period.

With regard to determinants of intervention outcome, weight loss seems the most important factor for reducing diabetes risk. At the same time, physical activity has shown to be an important contributor, independent of obesity, as well. Relatively small changes in physical activity that are prolonged over several years already seem to contribute to a diabetes risk reduction, although moderate-to-vigorous physical activity seems to have a larger effect. Changes in dietary composition are in the first place important to sustain achieved weight loss in the long-term and in the second place to initiate weight loss and reduce diabetes risk. Body composition and genetic variation seem to modulate the effect of lifestyle intervention on metabolic benefits. However, on both subjects no conclusive data are yet available for evidence-based recommendations. More large studies are necessary to elucidate the major modulators and the way they interact with lifestyle effect.

With respect to determinants of adherence, this paper shows that lifestyle intervention outcome is not just the result of the individuals' motivation, but the result of a variety of metabolic, genetic and socio-economic factors, i.e. low social economic class (134-136). Increasing self-efficacy, motivational readiness, social activities (137) and decreasing perceived stress (126), exemplifying the importance of prevention and giving tailored personal advice may be a first step in increasing adherence. As an alternative for non-effective lifestyle intervention, subscription of medication or change of policy to adjust the environment to a more favorable one may be necessary. Furthermore, concise and conclusive reporting on risk genotypes and reasons for nonadherence in future publications is essential, so that 1 ) lifestyle interventions can be adjusted for those less likely to adhere and benefit from it or so that 2 ) the environ- 


\section{Chapter 2}

ment can be adjusted to increase adherence and compliance, especially for the low social-economic classes or 3) preferentially both.

To conclude, lifestyle intervention programs are feasible and cost-effective for the long-term and will probably be the most important tool to alleviate the burden of diabetes and related complications in the future, and to sustain healthy ageing. Thus, the question is no longer whether lifestyle interventions might be effective, but under which circumstances they will be most effective. 


\section{References}

1. Wild S, Roglic G, Green A, Sicree R, King H. Global prevalence of diabetes: estimates for the year 2000 and projections for 2030. Diabetes Care. 2004;27:1047-1053.

2. de Vegt F, Dekker JM, Jager A, et al. Relation of impaired fasting and postload glucose with incident type 2 diabetes in a Dutch population: The Hoorn Study. Jama. 2001;285:2109-2113.

3. Groop L. Pathogenesis of type 2 diabetes: the relative contribution of insulin resistance and impaired insulin secretion. Int J Clin Pract Suppl. 2000:3-13.

4. Kitabchi AE, Temprosa M, Knowler WC, et al. Role of insulin secretion and sensitivity in the evolution of type 2 diabetes in the diabetes prevention program: effects of lifestyle intervention and metformin. Diabetes. 2005;54:2404-2414.

5. Saad MF, Knowler WC, Pettitt DJ, Nelson RG, Charles MA, Bennett PH. A two-step model for development of non-insulin-dependent diabetes. Am J Med. 1991;90:229-235.

6. Alberti KG, Zimmet P, Shaw J. International Diabetes Federation: a consensus on Type 2 diabetes prevention. Diabet Med. 2007;24:451-463.

7. Bazzano LA, Serdula M, Liu S. Prevention of type 2 diabetes by diet and lifestyle modification. J Am Coll Nutr. 2005;24:310-319.

8. Edelstein SL, Knowler WC, Bain RP, et al. Predictors of progression from impaired glucose tolerance to NIDDM: an analysis of six prospective studies. Diabetes. 1997;46:701-710.

9. Marshall JA, Hoag S, Shetterly S, Hamman RF. Dietary fat predicts conversion from impaired glucose tolerance to NIDDM. The San Luis Valley Diabetes Study. Diabetes Care. 1994;17:50-56.

10. Lindstrom J, Louheranta A, Mannelin M, et al. The Finnish Diabetes Prevention Study (DPS): Lifestyle intervention and 3-year results on diet and physical activity. Diabetes Care. 2003;26:3230-3236.

11. Swinburn BA, Metcalf PA, Ley SJ. Long-term (5-year) effects of a reduced-fat diet intervention in individuals with glucose intolerance. Diabetes Care. 2001;24:619-624.

12. Lindahl B, Nilsson TK, Jansson JH, Asplund K, Hallmans G. Improved fibrinolysis by intense lifestyle intervention. A randomized trial in subjects with impaired glucose tolerance. J Intern Med. 1999;246:105-112.

13. Carr DB, Utzschneider KM, Boyko EJ, et al. A reduced-fat diet and aerobic exercise in Japanese Americans with impaired glucose tolerance decreases intra-abdominal fat and improves insulin sensitivity but not beta-cell function. Diabetes. 2005;54:340-347.

14. Oldroyd JC, Unwin NC, White M, Mathers JC, Alberti KG. Randomised controlled trial evaluating lifestyle interventions in people with impaired glucose tolerance. Diabetes Res Clin Pract. 2006;72:117-127.

15. Roumen C, Corpeleijn E, Feskens EJ, Mensink M, Saris WH, Blaak EE. Impact of 3-year lifestyle intervention on postprandial glucose metabolism: the SLIM study. Diabet Med. 2008;25:597-605.

16. Herder C, Peltonen M, Koenig W, et al. Systemic immune mediators and lifestyle changes in the prevention of type 2 diabetes: results from the Finnish Diabetes Prevention Study. Diabetes. 2006;55:23402346.

17. Eriksson KF, Lindgarde F. Prevention of type 2 (non-insulin-dependent) diabetes mellitus by diet and physical exercise. The 6-year Malmo feasibility study. Diabetologia. 1991;34:891-898.

18. Pan XR, Li GW, Hu YH, et al. Effects of diet and exercise in preventing NIDDM in people with impaired glucose tolerance. The Da Qing IGT and Diabetes Study. Diabetes Care. 1997;20:537-544.

19. Tuomilehto J, Lindstrom J, Eriksson JG, et al. Prevention of type 2 diabetes mellitus by changes in lifestyle among subjects with impaired glucose tolerance. N Engl J Med. 2001;344:1343-1350.

20. Knowler WC, Barrett-Connor E, Fowler SE, et al. Reduction in the incidence of type 2 diabetes with lifestyle intervention or metformin. N Engl J Med. 2002;346:393-403.

21. Lindstrom J, Ilanne-Parikka P, Peltonen M, et al. Sustained reduction in the incidence of type 2 diabetes by lifestyle intervention: follow-up of the Finnish Diabetes Prevention Study. Lancet. 2006;368:16731679.

22. Li G, Zhang P, Wang J, et al. The long-term effect of lifestyle interventions to prevent diabetes in the China Da Qing Diabetes Prevention Study: a 20-year follow-up study. Lancet. 2008;371:1783-1789.

23. Kosaka K, Noda M, Kuzuya T. Prevention of type 2 diabetes by lifestyle intervention: a Japanese trial in IGT males. Diabetes Res Clin Pract. 2005;67:152-162.

24. Ramachandran A, Snehalatha C, Mary S, Mukesh B, Bhaskar AD, Vijay V. The Indian Diabetes Prevention Programme shows that lifestyle modification and metformin prevent type 2 diabetes in Asian Indian subjects with impaired glucose tolerance (IDPP-1). Diabetologia. 2006;49:289-297. 


\section{Chapter 2}

25. Gillies CL, Abrams KR, Lambert PC, et al. Pharmacological and lifestyle interventions to prevent or delay type 2 diabetes in people with impaired glucose tolerance: systematic review and meta-analysis. Bmj. 2007;334:299.

26. Colditz GA, Willett WC, Rotnitzky A, Manson JE. Weight gain as a risk factor for clinical diabetes mellitus in women. Ann Intern Med. 1995;122:481-486.

27. Chan JM, Rimm EB, Colditz GA, Stampfer MJ, Willett WC. Obesity, fat distribution, and weight gain as risk factors for clinical diabetes in men. Diabetes Care. 1994;17:961-969.

28. Han TS, Feskens EJ, Lean ME, Seidell JC. Associations of body composition with type 2 diabetes mellitus. Diabet Med. 1998;15:129-135.

29. Mishra GD, Carrigan G, Brown WJ, Barnett AG, Dobson AJ. Short-term weight change and the incidence of diabetes in midlife: results from the Australian Longitudinal Study on Women's Health. Diabetes Care. 2007;30:1418-1424.

30. Hamman RF, Wing RR, Edelstein SL, et al. Effect of weight loss with lifestyle intervention on risk of diabetes. Diabetes Care. 2006;29:2102-2107.

31. Uusitupa M, Lindi V, Louheranta A, Salopuro T, Lindstrom J, Tuomilehto J. Long-term improvement in insulin sensitivity by changing lifestyles of people with impaired glucose tolerance: 4-year results from the Finnish Diabetes Prevention Study. Diabetes. 2003;52:2532-2538.

32. Thamer C, Machann J, Stefan N, et al. High visceral fat mass and high liver fat are associated with resistance to lifestyle intervention. Obesity (Silver Spring). 2007;15:531-538.

33. Tiikkainen $M$, Bergholm R, Vehkavaara $S$, et al. Effects of identical weight loss on body composition and features of insulin resistance in obese women with high and low liver fat content. Diabetes. 2003;52:701-707.

34. Langendonk JG, Kok P, Frolich M, Pijl H, Meinders AE. Decrease in visceral fat following diet-induced weight loss in upper body compared to lower body obese premenopausal women. Eur J Intern Med. 2006;17:465-469.

35. Langendonk JG, Pijl H, Toornvliet AC, et al. Circadian rhythm of plasma leptin levels in upper and lower body obese women: influence of body fat distribution and weight loss. J Clin Endocrinol Metab. 1998;83:1706-1712.

36. Gray DS, Fujioka K, Colletti PM, et al. Magnetic-resonance imaging used for determining fat distribution in obesity and diabetes. Am J Clin Nutr. 1991;54:623-627.

37. Fujimoto WY, Jablonski KA, Bray GA, et al. Body Size and Shape Changes and the Risk of Diabetes in the Diabetes Prevention Program (DPP). Diabetes. 2007.

38. Borkman M, Storlien LH, Pan DA, Jenkins AB, Chisholm DJ, Campbell LV. The relation between insulin sensitivity and the fatty-acid composition of skeletal-muscle phospholipids. N Engl J Med. 1993;328:238244.

39. Feskens EJ, van Dam RM. Dietary fat and the etiology of type 2 diabetes: an epidemiological perspective. Nutr Metab Cardiovasc Dis. 1999;9:87-95.

40. Vessby B, Aro A, Skarfors E, Berglund L, Salminen I, Lithell H. The risk to develop NIDDM is related to the fatty acid composition of the serum cholesterol esters. Diabetes. 1994;43:1353-1357.

41. Frayn KN BE. Metabolic fuels and obesity; carbohydrate and lipid metabolism in skeletal muscle and adipose tissue: Blackwell Publishing Ltd 2005.

42. Heilbronn L, Smith SR, Ravussin E. Failure of fat cell proliferation, mitochondrial function and fat oxidation results in ectopic fat storage, insulin resistance and type II diabetes mellitus. Int J Obes Relat Metab Disord. 2004;28 Suppl 4:S12-21.

43. Muoio DM, Newgard CB. Obesity-related derangements in metabolic regulation. Annu Rev Biochem. 2006;75:367-401.

44. van Hall G, Steensberg A, Sacchetti $M$, et al. Interleukin-6 stimulates lipolysis and fat oxidation in humans. J Clin Endocrinol Metab. 2003;88:3005-3010.

45. Carey AL, Steinberg GR, Macaulay SL, et al. Interleukin-6 increases insulin-stimulated glucose disposal in humans and glucose uptake and fatty acid oxidation in vitro via AMP-activated protein kinase. Diabetes. 2006;55:2688-2697.

46. Mather KJ, Funahashi T, Matsuzawa $\mathrm{Y}$, et al. Adiponectin, change in adiponectin, and progression to diabetes in the Diabetes Prevention Program. Diabetes. 2008;57:980-986.

47. Kopp HP, Kopp CW, Festa A, et al. Impact of weight loss on inflammatory proteins and their association with the insulin resistance syndrome in morbidly obese patients. Arterioscler Thromb Vasc Biol. 2003;23:1042-1047. 
48. Lazzer S, Vermorel M, Montaurier C, Meyer M, Boirie Y. Changes in adipocyte hormones and lipid oxidation associated with weight loss and regain in severely obese adolescents. Int J Obes (Lond). 2005;29:1184-1191.

49. Aas AM, Seljeflot I, Torjesen PA, Diep LM, Thorsby PM, Birkeland KI. Blood glucose lowering by means of lifestyle intervention has different effects on adipokines as compared with insulin treatment in subjects with type 2 diabetes. Diabetologia. 2006;49:872-880.

50. Corpeleijn E, Feskens EJ, Jansen EH, Mensink M, Saris WH, Blaak EE. Lifestyle intervention and adipokine levels in subjects at high risk for type 2 diabetes: the Study on Lifestyle intervention and Impaired glucose tolerance Maastricht (SLIM). Diabetes Care. 2007;30:3125-3127.

51. Bobbert T, Rochlitz $\mathrm{H}$, Wegewitz $\mathrm{U}$, et al. Changes of adiponectin oligomer composition by moderate weight reduction. Diabetes. 2005;54:2712-2719.

52. Laaksonen DE, Lindstrom J, Lakka TA, et al. Physical activity in the prevention of type 2 diabetes: the Finnish diabetes prevention study. Diabetes. 2005;54:158-165.

53. Carnethon MR, Prineas RJ, Temprosa M, Zhang ZM, Uwaifo G, Molitch ME. The association among autonomic nervous system function, incident diabetes, and intervention arm in the Diabetes Prevention Program. Diabetes Care. 2006;29:914-919.

54. Mensink M, Blaak EE, Corpeleijn E, Saris WH, de Bruin TW, Feskens EJ. Lifestyle intervention according to general recommendations improves glucose tolerance. Obes Res. 2003;11:1588-1596.

55. Torjesen PA, Birkeland KI, Anderssen SA, Hjermann I, Holme I, Urdal P. Lifestyle changes may reverse development of the insulin resistance syndrome. The Oslo Diet and Exercise Study: a randomized trial. Diabetes Care. 1997;20:26-31.

56. Church TS, Earnest CP, Skinner JS, Blair SN. Effects of different doses of physical activity on cardiorespiratory fitness among sedentary, overweight or obese postmenopausal women with elevated blood pressure: a randomized controlled trial. Jama. 2007;297:2081-2091.

57. Donnelly JE, Smith B, Jacobsen DJ, et al. The role of exercise for weight loss and maintenance. Best Pract Res Clin Gastroenterol. 2004;18:1009-1029.

58. Sial S, Coggan AR, Hickner RC, Klein S. Training-induced alterations in fat and carbohydrate metabolism during exercise in elderly subjects. Am J Physiol. 1998;274:E785-790.

59. Schrauwen P, van Aggel-Leijssen DP, Hul G, et al. The effect of a 3-month low-intensity endurance training program on fat oxidation and acetyl-CoA carboxylase-2 expression. Diabetes. 2002;51:22202226.

60. van Aggel-Leijssen DP, Saris WH, Wagenmakers AJ, Senden JM, van Baak MA. Effect of exercise training at different intensities on fat metabolism of obese men. J Appl Physiol. 2002;92:1300-1309.

61. Mensink M, Blaak EE, Wagenmakers AJ, Saris WH. Lifestyle intervention and fatty acid metabolism in glucose-intolerant subjects. Obes Res. 2005;13:1354-1362.

62. Itani SI, Ruderman NB, Schmieder F, Boden G. Lipid-induced insulin resistance in human muscle is associated with changes in diacylglycerol, protein kinase C, and IkappaB-alpha. Diabetes. 2002;51:20052011.

63. Krssak M, Falk Petersen K, Dresner A, et al. Intramyocellular lipid concentrations are correlated with insulin sensitivity in humans: a 1H NMR spectroscopy study. Diabetologia. 1999;42:113-116.

64. Schmitz-Peiffer C. Signalling aspects of insulin resistance in skeletal muscle: mechanisms induced by lipid oversupply. Cell Signal. 2000;12:583-594.

65. Segal KR, Edano A, Abalos A, et al. Effect of exercise training on insulin sensitivity and glucose metabolism in lean, obese, and diabetic men. J Appl Physiol. 1991;71:2402-2411.

66. Shojaee-Moradie F, Baynes KC, Pentecost C, et al. Exercise training reduces fatty acid availability and improves the insulin sensitivity of glucose metabolism. Diabetologia. 2007;50:404-413.

67. Pate RR, Pratt M, Blair SN, et al. Physical activity and public health. A recommendation from the Centers for Disease Control and Prevention and the American College of Sports Medicine. Jama. 1995;273:402407.

68. Saris WH, Blair SN, van Baak MA, et al. How much physical activity is enough to prevent unhealthy weight gain? Outcome of the IASO 1st Stock Conference and consensus statement. Obes Rev. 2003;4:101-114.

69. Hu G, Lakka TA, Kilpelainen TO, Tuomilehto J. Epidemiological studies of exercise in diabetes prevention. Appl Physiol Nutr Metab. 2007;32:583-595.

70. Wareham NJ. Epidemiological studies of physical activity and diabetes risk, and implications for diabetes prevention. Appl Physiol Nutr Metab. 2007;32:778-782.

71. Sigal RJ, Kenny GP, Boule NG, et al. Effects of aerobic training, resistance training, or both on glycemic control in type 2 diabetes: a randomized trial. Ann Intern Med. 2007;147:357-369. 


\section{Chapter 2}

72. Nelson ME, Rejeski WJ, Blair SN, et al. Physical activity and public health in older adults: recommendation from the American College of Sports Medicine and the American Heart Association. Med Sci Sports Exerc. 2007;39:1435-1445.

73. Praet SF, van Loon L. Exercise: the brittle cornerstone of type 2 diabetes treatment. Diabetologia. 2008;51:398-401.

74. Wing RR, Hamman RF, Bray GA, et al. Achieving weight and activity goals among diabetes prevention program lifestyle participants. Obes Res. 2004;12:1426-1434.

75. Morrato EH, Hill JO, Wyatt HR, Ghushchyan V, Sullivan PW. Physical activity in u.s. Adults with diabetes and at risk for developing diabetes, 2003. Diabetes Care. 2007;30:203-209.

76. Hu FB, Sigal RJ, Rich-Edwards JW, et al. Walking compared with vigorous physical activity and risk of type 2 diabetes in women: a prospective study. Jama. 1999;282:1433-1439.

77. Hu FB, Manson JE, Stampfer MJ, et al. Diet, lifestyle, and the risk of type 2 diabetes mellitus in women. N Engl J Med. 2001;345:790-797.

78. van Dam RM, Rimm EB, Willett WC, Stampfer MJ, Hu FB. Dietary patterns and risk for type 2 diabetes mellitus in U.S. men. Ann Intern Med. 2002;136:201-209.

79. Meyer KA, Kushi LH, Jacobs DR, Jr., Slavin J, Sellers TA, Folsom AR. Carbohydrates, dietary fiber, and incident type 2 diabetes in older women. Am J Clin Nutr. 2000;71:921-930.

80. Montonen J, Knekt $\mathrm{P}$, Jarvinen $\mathrm{R}$, Aromaa A, Reunanen A. Whole-grain and fiber intake and the incidence of type 2 diabetes. Am J Clin Nutr. 2003;77:622-629.

81. Salmeron J, Ascherio A, Rimm EB, et al. Dietary fiber, glycemic load, and risk of NIDDM in men. Diabetes Care. 1997;20:545-550.

82. Franz MJ, Bantle JP, Beebe CA, et al. Evidence-based nutrition principles and recommendations for the treatment and prevention of diabetes and related complications. Diabetes Care. 2002;25:148-198.

83. Song $\mathrm{Y}$, Manson JE, Buring JE, Liu S. A prospective study of red meat consumption and type 2 diabetes in middle-aged and elderly women: the women's health study. Diabetes Care. 2004;27:2108-2115.

84. Wolever TM, Mehling C. High-carbohydrate-low-glycaemic index dietary advice improves glucose disposition index in subjects with impaired glucose tolerance. Br J Nutr. 2002;87:477-487.

85. Jenkins DJ, Axelsen M, Kendall CW, Augustin LS, Vuksan V, Smith U. Dietary fibre, lente carbohydrates and the insulin-resistant diseases. Br J Nutr. 2000;83 Suppl 1:S157-163.

86. Astrup A, Astrup A, Buemann B, Flint A, Raben A. Low-fat diets and energy balance: how does the evidence stand in 2002? Proc Nutr Soc. 2002;61:299-309.

87. Hays NP, Starling RD, Liu X, et al. Effects of an ad libitum low-fat, high-carbohydrate diet on body weight, body composition, and fat distribution in older men and women: a randomized controlled trial. Arch Intern Med. 2004;164:210-217.

88. Lindstrom J, Peltonen M, Eriksson JG, et al. High-fibre, low-fat diet predicts long-term weight loss and decreased type 2 diabetes risk: the Finnish Diabetes Prevention Study. Diabetologia. 2006;49:912-920.

89. Vessby B, Unsitupa M, Hermansen $K$, et al. Substituting dietary saturated for monounsaturated fat impairs insulin sensitivity in healthy men and women: The KANWU Study. Diabetologia. 2001;44:312319.

90. Summers LK, Fielding BA, Bradshaw HA, et al. Substituting dietary saturated fat with polyunsaturated fat changes abdominal fat distribution and improves insulin sensitivity. Diabetologia. 2002;45:369-377.

91. Riccardi G, Giacco R, Rivellese AA. Dietary fat, insulin sensitivity and the metabolic syndrome. Clin Nutr. 2004;23:447-456.

92. Jump DB, Clarke SD. Regulation of gene expression by dietary fat. Annu Rev Nutr. 1999;19:63-90.

93. Hartweg J, Perera R, Montori V, Dinneen S, Neil HA, Farmer A. Omega-3 polyunsaturated fatty acids (PUFA) for type 2 diabetes mellitus. Cochrane Database Syst Rev. 2008:CD003205.

94. Hulver MW, Berggren JR, Carper MJ, et al. Elevated stearoyl-CoA desaturase-1 expression in skeletal muscle contributes to abnormal fatty acid partitioning in obese humans. Cell Metab. 2005;2:251-261.

95. Corpeleijn E, Feskens EJ, Jansen EH, et al. Improvements in glucose tolerance and insulin sensitivity after lifestyle intervention are related to changes in serum fatty acid profile and desaturase activities: the SLIM study. Diabetologia. 2006;49:2392-2401.

96. Weyrich P, Stefan N, Haring HU, Laakso M, Fritsche A. Effect of genotype on success of lifestyle intervention in subjects at risk for type 2 diabetes. J Mol Med. 2007;85:107-117.

97. Wang J, Kuusisto J, Vanttinen M, et al. Variants of transcription factor 7-like 2 (TCF7L2) gene predict conversion to type 2 diabetes in the Finnish Diabetes Prevention Study and are associated with impaired glucose regulation and impaired insulin secretion. Diabetologia. 2007;50:1192-1200. 
98. Lindi VI, Uusitupa MI, Lindstrom J, et al. Association of the Pro12Ala polymorphism in the PPAR-gamma2 gene with 3-year incidence of type 2 diabetes and body weight change in the Finnish Diabetes Prevention Study. Diabetes. 2002;51:2581-2586.

99. Bouchard C, Leon AS, Rao DC, Skinner JS, Wilmore JH, Gagnon J. The HERITAGE family study. Aims, design, and measurement protocol. Med Sci Sports Exerc. 1995;27:721-729.

100.An P, Teran-Garcia M, Rice T, et al. Genome-wide linkage scans for prediabetes phenotypes in response to 20 weeks of endurance exercise training in non-diabetic whites and blacks: the HERITAGE Family Study. Diabetologia. 2005;48:1142-1149.

101.Teran-Garcia M, Santoro N, Rankinen T, et al. Hepatic lipase gene variant $-514 C>T$ is associated with lipoprotein and insulin sensitivity response to regular exercise: the HERITAGE Family Study. Diabetes. 2005;54:2251-2255.

102.Teran-Garcia M, Rankinen T, Rice T, et al. Variations in the four and a half LIM domains 1 gene (FHL1) are associated with fasting insulin and insulin sensitivity responses to regular exercise. Diabetologia. 2007.

103. Stefan N, Machann J, Schick F, et al. New imaging techniques of fat, muscle and liver within the context of determining insulin sensitivity. Horm Res. 2005;64 Suppl 3:38-44.

104.Stefan N, Thamer C, Staiger H, et al. Genetic variations in PPARD and PPARGC1A determine mitochondrial function and change in aerobic physical fitness and insulin sensitivity during lifestyle intervention. J Clin Endocrinol Metab. 2007;92:1827-1833.

105.Stefan N, Machicao F, Staiger H, et al. Polymorphisms in the gene encoding adiponectin receptor 1 are associated with insulin resistance and high liver fat. Diabetologia. 2005;48:2282-2291.

106.Siitonen N, Pulkkinen L, Mager U, et al. Association of sequence variations in the gene encoding adiponectin receptor 1 (ADIPOR1) with body size and insulin levels. The Finnish Diabetes Prevention Study. Diabetologia. 2006;49:1795-1805.

107. Brandeau ML. Modeling complex medical decision problems with the Archimedes model. Ann Intern Med. 2005;143:303-304.

108.Palmer AJ, Roze S, Valentine WJ, Spinas GA, Shaw JE, Zimmet PZ. Intensive lifestyle changes or metformin in patients with impaired glucose tolerance: modeling the long-term health economic implications of the diabetes prevention program in Australia, France, Germany, Switzerland, and the United Kingdom. Clin Ther. 2004;26:304-321.

109. Herman WH, Hoerger TJ, Brandle M, et al. The cost-effectiveness of lifestyle modification or metformin in preventing type 2 diabetes in adults with impaired glucose tolerance. Ann Intern Med. 2005;142:323332.

110.Laupacis A, Feeny D, Detsky AS, Tugwell PX. How attractive does a new technology have to be to warrant adoption and utilization? Tentative guidelines for using clinical and economic evaluations. Cmaj. 1992;146:473-481.

111.Eddy DM, Schlessinger L, Kahn R. Clinical outcomes and cost-effectiveness of strategies for managing people at high risk for diabetes. Ann Intern Med. 2005;143:251-264.

112.Lindgren $\mathrm{P}$, Lindstrom J, Tuomilehto J, et al. Lifestyle intervention to prevent diabetes in men and women with impaired glucose tolerance is cost-effective. Int J Technol Assess Health Care. 2007;23:177183.

113.Schuit AJ, Wendel-Vos GC, Verschuren WM, et al. Effect of 5-year community intervention Hartslag Limburg on cardiovascular risk factors. Am J Prev Med. 2006;30:237-242.

114.Jacobs-van der Bruggen MA, Bos G, Bemelmans WJ, Hoogenveen RT, Vijgen SM, Baan CA. Lifestyle interventions are cost-effective in people with different levels of diabetes risk: results from a modeling study. Diabetes Care. 2007;30:128-134.

115. Ratner RE. An update on the Diabetes Prevention Program. Endocr Pract. 2006;12 Suppl 1:20-24.

116.Saaristo T, Peltonen M, Keinanen-Kiukaanniemi S, et al. National type 2 diabetes prevention programme in Finland: FIN-D2D. Int J Circumpolar Health. 2007;66:101-112.

117. Lindstrom J, Tuomilehto J. The diabetes risk score: a practical tool to predict type 2 diabetes risk. Diabetes Care. 2003;26:725-731.

118. Lindstrom J, Peltonen M, Eriksson JG, et al. Determinants for the effectiveness of lifestyle intervention in the Finnish Diabetes Prevention Study. Diabetes Care. 2008.

119.Perry IJ. Healthy diet and lifestyle clustering and glucose intolerance. Proc Nutr Soc. 2002;61:543-551.

120.Steyn NP, Mann J, Bennett PH, et al. Diet, nutrition and the prevention of type 2 diabetes. Public Health Nutr. 2004;7:147-165.

121.Filozof C, Fernandez Pinilla MC, Fernandez-Cruz A. Smoking cessation and weight gain. Obes Rev. 2004;5:95-103. 


\section{Chapter 2}

122.Canoy D, Wareham N, Luben R, et al. Cigarette smoking and fat distribution in 21,828 British men and women: a population-based study. Obes Res. 2005;13:1466-1475.

123. Bartholomew LK, Parcel GS, Kok G. Intervention mapping: a process for developing theory- and evidence-based health education programs. Health Educ Behav. 1998;25:545-563.

124.Baptiste-Roberts K, Gary TL, Beckles GL, et al. Family history of diabetes, awareness of risk factors, and health behaviors among African Americans. Am J Public Health. 2007;97:907-912.

125.Nigg CR. There is more to stages of exercise than just exercise. Exerc Sport Sci Rev. 2005;33:32-35.

126.Vallis M, Ruggiero L, Greene G, et al. Stages of change for healthy eating in diabetes: relation to demographic, eating-related, health care utilization, and psychosocial factors. Diabetes Care. 2003;26:14681474.

127.Glanz K, Patterson RE, Kristal AR, et al. Stages of change in adopting healthy diets: fat, fiber, and correlates of nutrient intake. Health Educ Q. 1994;21:499-519.

128.Jackson ES, Tucker CM, Herman KC. Health value, perceived social support, and health self-efficacy as factors in a health-promoting lifestyle. J Am Coll Health. 2007;56:69-74.

129.Wylie G, Hungin AP, Neely J. Impaired glucose tolerance: qualitative and quantitative study of general practitioners' knowledge and perceptions. Bmj. 2002;324:1190.

130.Burnet DL, Elliott LD, Quinn MT, Plaut AJ, Schwartz MA, Chin MH. Preventing diabetes in the clinical setting. J Gen Intern Med. 2006;21:84-93.

131.Poskiparta M, Kasila K, Kiuru P. Dietary and physical activity counselling on type 2 diabetes and impaired glucose tolerance by physicians and nurses in primary healthcare in Finland. Scand J Prim Health Care. 2006;24:206-210.

132. Bassuk SS, Manson JE. Epidemiological evidence for the role of physical activity in reducing risk of type 2 diabetes and cardiovascular disease. J Appl Physiol. 2005;99:1193-1204.

133. Stone NJ, Saxon D. Approach to treatment of the patient with metabolic syndrome: lifestyle therapy. Am J Cardiol. 2005;96:15E-21E.

134.Ball K, Crawford D. Socioeconomic status and weight change in adults: a review. Soc Sci Med. 2005;60:1987-2010.

135. Kamphuis CB, Giskes K, de Bruijn GJ, Wendel-Vos W, Brug J, van Lenthe FJ. Environmental determinants of fruit and vegetable consumption among adults: a systematic review. Br J Nutr. 2006;96:620-635.

136.Agardh E, Ahlbom A, Andersson T, et al. Socio-economic position at three points in life in association with type 2 diabetes and impaired glucose tolerance in middle-aged Swedish men and women. Int J Epidemiol. 2007;36:84-92.

137. Barrera M, Jr., Toobert DJ, Angell KL, Glasgow RE, Mackinnon DP. Social support and social-ecological resources as mediators of lifestyle intervention effects for type 2 diabetes. J Health Psychol. 2006;11:483-495. 


\section{IMPACT OF 3-YEAR LIFESTYLE INTERVENTION ON POSTPRANDIAL GLUCOSE METABOLISM}

The SLIM study

Cheryl Roumen, Eva Corpeleijn, Edith J.M. Feskens, Marco Mensink, Wim H. M. Saris, Ellen E. Blaak.

Diabetic Medicine. 2008 May;25(5):597-605. 


\section{Chapter 3}

\section{Abstract}

\section{Objective}

To evaluate the effect of a 3-year diet- and exercise lifestyle intervention, based on general public health recommendations, on glucose tolerance, insulin resistance and metabolic cardiovascular risk factors in Dutch subjects with impaired glucose tolerance (IGT).

\section{Method}

Subjects 147 IGT subjects (75 male, 72 female) were randomized to the intervention group (INT) or control group (CON). 106 subjects (52 INT, 54 CON) completed 3 years of intervention. Annually, glucose, insulin and free fatty acid (FFA) concentrations were determined during fasting and after an oral glucose tolerance test and measurements of body weight, serum lipids, blood pressure and maximal aerobic capacity.

\section{Results}

According to our completers analysis, the lifestyle intervention improved body weight (INT: $-1.08 \pm 4.30 \mathrm{~kg}$; CON: $+0.16 \pm 4.91 \mathrm{~kg}, \mathrm{p}=0.01$ ), HOMA index for insulin resistance and 2-hour FFA. 2-Hour glucose concentrations improved in INT, most pronounced after 1 year with a regain to baseline values after 3 years, from $8.59 \pm 1.55 \mathrm{mM}$ to 8.55 $\pm 0.34 \mathrm{mM}$, but deteriorated in CON: from $8.46 \pm 1.84 \mathrm{mM}$ to $9.35 \pm 2.50 \mathrm{mM}(p=0.02)$. For INT, diabetes incidence was reduced by $58 \%(p=0.025)$.

\section{Conclusion}

Our lifestyle intervention showed a sustained beneficial effect on 2-hr glucose concentrations, insulin resistance and 2-hr FFA, even after 3 years. Our lifestyle intervention is efficacious, but for implementation more information is warranted on determinants of adherence. 
Introduction

Impaired glucose tolerance (IGT) is an obligatory transition state between normal glucose tolerance and type 2 diabetes, and from a health perspective IGT subjects are an important high-risk target group for the prevention of type 2 diabetes and related complications.

We demonstrated previously in the SLIM Study (Study on Lifestyle intervention and IGT Maastricht) (1), that a combined diet- and exercise lifestyle intervention can improve the postprandial glucose metabolism and insulin resistance in IGT subjects with a relatively high level of physical activity and low prevalence of obesity. The Diabetes Prevention Study (DPS) showed a tendency towards an improved glucose tolerance during a 3-yr lifestyle intervention program $(0.4 \mathrm{mM}$ difference in 2-hr glucose) (2). Also, the DPS as well as the Diabetes Prevention Program (DPP) showed that changes in lifestyle can prevent the onset of type 2 diabetes in IGT subjects by $58 \%$ over a $3-y r$ period (3-4). Although the SLIM study is relatively small compared to the DPS and DPP, its advantage is that we performed a detailed phenotyping of HOMAIR, 2-hr glucose, 2-hr insulin, 2-hr FFA concentrations and performed a test for maximal aerobic capacity $\left(\mathrm{VO}_{2} \mathrm{max}\right)$ at baseline and follow-up. We have performed mechanistic studies to underscore our intervention results (5-6). Additionally, we have a wellcontrolled exercise program in which subjects participated at an intensity of at least $70 \%$ of their maximal peak oxygen consumption ( $\left.\mathrm{VO}_{2} \mathrm{max}\right)$.

Elevated 2-hr glucose concentrations are an important risk factor for the development of type 2 diabetes, but also for cardiovascular disease (CVD) (7). Prolonged postprandial glucose excursions can be considered a risk marker of insulin resistance and dyslipidemia that collectively impact on CVD risk (8). In IGT subjects, disturbances in fatty acid utilization are already present (5) and increased plasma free fatty acids (FFA) have been associated with type 2 diabetes, insulin resistance and CVD risk (9). Moreover, IGT has been related to the Metabolic Syndrome (MetS), which is a clustering of pathologies associated with insulin resistance, type 2 diabetes and CVD risk (1012).

The SLIM project offers the opportunity to address the impact of lifestyle changes on glucose tolerance and maximal aerobic capacity, as an objective measure for physical fitness. Furthermore, we provide specific data regarding lifestyle efficacy and effectiveness. Our aim was to investigate the impact of a 3-year lifestyle intervention on glucose homeostasis after an oral glucose tolerance test (OGTT) in IGT subjects. In addition, we assessed the changes in metabolic CVD risk factors and evaluated the impact of the lifestyle intervention on the incidence of type 2 diabetes.

\section{Patients and methods}

The SLIM project (Study on Lifestyle Intervention and Impaired Glucose Tolerance Maastricht) is a randomized controlled trial, designed to study whether a 6-yr combined dietary and physical activity intervention program can improve glucose tolerance in IGT subjects (13). In addition, changes in body composition, body fat distribution, fasting and 2-hr insulin and plasma glucose concentrations, FFA levels, serum lipids, 


\section{Chapter 3}

blood pressure and maximal aerobic capacity are determined. This report concerns the results after 3 years of intervention.

\section{Study design and subjects}

The study design has been described in detail previously (13). Briefly, subjects with an increased risk for glucose intolerance were selected from a cohort in the area of Maastricht, and invited to undergo a capillary standard OGTT. Those subjects with a 2hr blood glucose concentration $>7.8 \mathrm{mM}$ were invited for a second venous OGTT. For inclusion, mean 2-hr glucose concentration of both OGTTs had to be between 7.8 and $12.5 \mathrm{mM}$ and fasting glucose concentration $<7.8 \mathrm{mM}$. Data obtained during the second (venous) OGTT were used as baseline values. Exclusion criteria were known diabetes, glucose concentrations outside the inclusion criteria, chronic illness, medication known to interfere with glucose tolerance, participation in a vigorous exercise and/or diet program.

Screening and inclusion of subjects for the SLIM study occurred between March 1999 and May 2000 and in 2002. In total, 147 subjects were included in our study. All analyses in this paper were adjusted for the screening period. Subjects were randomized with stratification for sex and mean 2-hr plasma glucose concentration to the intervention group (INT: 74 subjects; 38 male, 36 female) or the control group (CON: 73 subjects; 37 male, 36 female). It was calculated, according to the preliminary results after 1 year of the Finnish DPS (14), that 50-60 subjects per group would be sufficient to detect a $1.0 \mathrm{mmol} / \mathrm{l}$ difference in $2-\mathrm{hr}$ glucose concentration between groups. Data analyses of the 3-year results include those subjects still participating in the study (completers, $n=106: 52$ INT subjects and 54 CON subjects). 41 Subjects (22 INT, 19 CON) were unable to adhere for 3 years of study of whom 28 subjects, (14 INT and 14 CON) completed the first year. From all dropouts, 32 subjects discontinued the study (16 INT, 16 CON ) due to medical reasons in 10 cases, lack of time in 7 cases, lack of motivation in 7 cases, dissatisfaction in 3 cases, no response in 1 case, no transportation in 1 case, unknown in 2 cases and death in 1 case. 9 Subjects did not attend all annual measurements.

\section{Lifestyle Intervention}

The intervention program consisted of a dietary and physical activity part. Dietary recommendations were based on the Dutch guidelines for a healthy diet (Dutch Nutrition Council). A skilled dietician gave personal dietary advice during a one-hour counseling session every 3 months, after consideration of a 3-day food record. In addition, subjects received individual advice on how to increase their level of physical activity to at least 30 minutes a day for at least 5 days a week. A body weight loss of 5-7\% was the objective. Dietary intake and physical activity were documented in 3-day records and new goals were set and documented for future reference. Furthermore, subjects were encouraged to participate in a combined aerobic- and resistance exercise program in which subjects participated at an intensity of at least $70 \%$ of their maximal peak oxygen consumption $\left(\mathrm{VO}_{2} \mathrm{max}\right)$. Three times a year subjects were asked to participate 
in the exercise program using a heartbeat watch to validate the exercise intensity. Control subjects were only briefly informed about the beneficial effects of a healthy diet and physical activity, whereas no individual advice was provided.

\section{Measurements}

Body weight was measured with an electronical scale to the nearest $0.1 \mathrm{~kg}$. Waist was measured to the nearest $0.5 \mathrm{~cm}$, with the subject in standing position at the level midway between the lowest rib and the iliacal crest. Body fat percentage was determined by using a bio impedance (Hydra S ecf/icf, rev1.0d, Xitron technologies).

A 3-day weighed food record (two weekdays and 1 weekend day) was kept before the annual visit. Nutrient intake was calculated using the Dutch food table (NEVO version 1996). An incremental exhaustive exercise test was performed on an electronically braked bicycle ergometer to determine maximal peak oxygen consumption $\left(\mathrm{VO}_{2} \max \right)$.

Changes in glucose tolerance were studied using an OGTT. Plasma glucose, FFA and serum lipids were measured in the fasting state and after 2 hours, with a standard enzymatic technique, automated on a Cobas Fara centrifugal analyzer. Plasma insulin concentration was measured with a Radio Immuno Assay (Cat. \#HI-14K, Linco Research) that shows no cross-reactivity with pro-insulin. HBA1c was determined in a fasting serum sample with high-performance liquid chromatography. The HOMA-IR index for insulin resistance was calculated as described by Matthews et al., (1985) (15). Low-density lipoprotein (LDL) cholesterol was calculated according to the formula of Friedewald (16). Blood pressure was measured with a Maxi Stabil 3 pressostabil (CE0047, Speidel en Keller) in duplo with the subject in supine position, after 10 minutes of rest.

The MetS was defined according to the NCEP criteria (17) as having 3 or more of the following conditions: waist circumference greater than $102 \mathrm{~cm}$ in men and greater than $88 \mathrm{~cm}$ in women; fasting serum triglyceride levels of at least $1.7 \mathrm{mM}(\geq 150 \mathrm{mg} / \mathrm{dl})$; high-density lipoprotein (HDL) cholesterol level less than $1.03 \mathrm{mM}(<40 \mathrm{mg} / \mathrm{dl})$ in men and less than $1.30 \mathrm{mM}(<50 \mathrm{mg} / \mathrm{dl})$ in women; blood pressure of $130 / 85 \mathrm{~mm} \mathrm{Hg}$ or greater; and fasting glucose levels of at least $6.2 \mathrm{mM}(110 \mathrm{mg} / \mathrm{l})$. Subjects using antihypertensive drugs or lipid lowering medication were classified positive for the respective criterion. The incidence of type 2 diabetes was determined by one OGTT according to WHO criteria of 1999 (18).

\section{Statistical analysis}

Data analysis was conducted using SPSS for Macintosh (version 10.0) on subjects who completed 3 years of lifestyle intervention ( $n=106$, completers analysis). In addition, we analyzed all available data of all 147 subjects, including those who dropped out before the 3-yr examination, to indicate intention-to-treat. Insulin, serum lipids and FFA concentrations were not normally distributed and were In-transformed. Data are presented as mean \pm SD. Differences between groups were tested with a Student's $t$ 


\section{Chapter 3}

test for independent samples or by a $\chi^{2}$ test when applicable. Changes over time between groups were assessed using ANOVA for repeated measures for the completers analysis and with MIXED linear models for the intention-to-treat analysis. A p-value of less than 0.05 was considered statistically significant. All tests were twosided.

\section{Statement of ethics}

We certify that all applicable institutional and governmental regulations concerning the ethical use of human volunteers were followed during this research. The Medical Ethical Review Committee of Maastricht University approved the study protocol and all subjects gave their written informed consent before the start of the study.

\section{Results}

Table 3.1 shows the baseline characteristics of the subjects who completed the 3-yr period. Age was higher in CON compared to INT ( $p=0.001)$, whereas no differences were seen in other baseline characteristics. Within each study group, men had a significantly higher weight, waist-to-hip ratio and maximal aerobic capacity and a lower fat percentage and HDL cholesterol levels, compared to women $\left(p_{\text {all }}<0.05\right)$.

After 1 year, INT subjects had a mean weight change of $-2.77 \pm 3.69 \mathrm{~kg}$ versus $0.62 \pm 3.92 \mathrm{~kg}$ in CON subjects ( $p=0.003$, time $x$ group interaction) (table 3.2 ). After 3 years, the weight change between groups became smaller but remained statistically significant different ( $p=0.01$, time $x$ group interaction). Moreover, after 3 years, the increase over time in body fat percentage and body fat mass was smaller in INT compared to CON, ( $p=0.006$ and $p=0.016$, respectively, time $x$ group interaction). Furthermore, INT subjects improved their maximal aerobic capacity $\left(\mathrm{VO}_{2} \max \right)$, while that of CON aggravated $(p=0.02$ ) (table 3.2 ). Intention-to-treat analysis did not change these results (table 3.2). Exercise intensity was regularly monitored during the exercise program by means of heart rate recording. After 3 years, the mean heart frequency during the exercise program was $76 \%$ of the maximal heart frequency, indicating the moderate to high intensity. Intervention subjects who participated in the exercise program during at least the second and third year $(n=17)$ increased their maximal aerobic capacity and tended to increase more compared to those who did not participate in the exercise program $(n=25),+0.17 \mathrm{l} / \mathrm{min}$ versus $-0.03 \mathrm{l} / \mathrm{min}$, respectively $(p=0.08)$. The intervention group increased in the number of days that they were at least 30 minutes physically active in doing bicycling, gardening or doing sports with $0.89 \pm 2.75$ days while those of the control group decreased with $-0.55 \pm 3.31$ days, $p=0.046$. In the total study population, an increase in the number of days at least 30 minutes physically active in doing bicycling, gardening or doing sports was significantly associated with an increase in aerobic capacity (correlation coefficient $R=0.34, p=0.01$ ). In line with these results, fat intake decreased significantly more in INT vs. CON ( $p$ interaction $<0.001$ ) and carbohydrate intake increased more in INT compared to CON ( $p$ interaction $=0.001$ ). Fiber intake increased more in INT compared to CON ( $p$ interaction=0.05). 
Table 3.1 Baseline characteristics of the subjects participating in the 3-yr SLIM lifestyle intervention study.

\begin{tabular}{|c|c|c|c|}
\hline & & Intervention group & Control group \\
\hline $\mathrm{n}$ (male/female) & & $52(28 / 24)$ & $54(30 / 24)$ \\
\hline Age & (years) & $54.2 \pm 5.8$ & $58.4 \pm 6.8^{*}$ \\
\hline Weight & (kg) & $87.5 \pm 13.7$ & $83.0 \pm 11.7$ \\
\hline BMI & $\left(\mathrm{kg} / \mathrm{m}^{2}\right)$ & $29.6 \pm 3.8$ & $29.2 \pm 3.3$ \\
\hline Waist & $(\mathrm{cm})$ & $103.2 \pm 10.6$ & $102.4 \pm 9.2$ \\
\hline Body fat percentage & (\%) & $38.4 \pm 6.3$ & $37.5 \pm 6.4$ \\
\hline Body fat mass & $(\mathrm{kg})$ & $33.4 \pm 7.2$ & $31.0 \pm 6.6$ \\
\hline Body fat free mass & (kg) & $54.1 \pm 10.4$ & $51.9 \pm 9.4$ \\
\hline $\mathrm{VO}_{2} \max$ & $(1 / \min )$ & $2.22 \pm 0.61$ & $2.13 \pm 0.55$ \\
\hline Fasting glucose & $(\mathrm{mmol} / \mathrm{l})$ & $5.97 \pm 0.87$ & $5.90 \pm 0.70$ \\
\hline 2-hr Glucose & $(\mathrm{mmol} / \mathrm{l})$ & $8.59 \pm 1.55$ & $8.46 \pm 1.84$ \\
\hline HBA1c & (\%) & $5.6 \pm 0.5$ & $5.8 \pm 0.5$ \\
\hline Fasting insulin & $(\mathrm{mU} / \mathrm{l})$ & $18.0 \pm 6.3$ & $17.1 \pm 6.9$ \\
\hline 2-hr Insulin & $(\mathrm{mU} / \mathrm{l})$ & $103.3 \pm 73.0$ & $96.4 \pm 89.9$ \\
\hline HOMA-IR & & $4.82 \pm 2.04$ & $4.55 \pm 2.05$ \\
\hline Triglycerides & $(\mathrm{mmol} / \mathrm{l})$ & $1.56 \pm 1.33$ & $1.49 \pm 0.88$ \\
\hline Total Cholesterol & $(\mathrm{mmol} / \mathrm{l})$ & $5.17 \pm 0.78$ & $5.25 \pm 0.84$ \\
\hline HDL Cholesterol & $(\mathrm{mmol} / \mathrm{l})$ & $1.14 \pm 0.30$ & $1.11 \pm 0.27$ \\
\hline LDL Cholesterol & $(\mathrm{mmol} / \mathrm{l})$ & $3.40 \pm 0.78$ & $3.47 \pm 0.71$ \\
\hline FFA & $(\mu \mathrm{mol} / \mathrm{l})$ & $589 \pm 231$ & $551 \pm 172$ \\
\hline 2-hr FFA & $(\mu \mathrm{mol} / \mathrm{l})$ & $115 \pm 79$ & $102 \pm 42$ \\
\hline Diastolic blood pressure & $(\mathrm{mm} \mathrm{Hg})$ & $90 \pm 9$ & $88 \pm 7$ \\
\hline Systolic blood pressure & $(\mathrm{mm} \mathrm{Hg})$ & $142 \pm 16$ & $145 \pm 14$ \\
\hline
\end{tabular}

Data are Mean $\pm S D, n=106 .{ }^{*} p=0.001$ (Student's t-test).

2-Hour plasma glucose levels decreased in INT from $8.59 \pm 0.24 \mathrm{mM}$ at baseline to 7.96 $\pm 0.29 \mathrm{mM}$ after 1 year and returned to $8.55 \pm 0.34 \mathrm{mM}$ after 3 years (figure 3.1, open circles). In CON an increase was seen from $8.46 \pm 0.23 \mathrm{mM}$ at baseline to $8.83 \pm 0.29$ $\mathrm{mM}$ after 1 year and to $9.35 \pm 0.33 \mathrm{mM}$ after 3 years $(p=0.023$ time $x$ group interaction) (figure 3.1, black squares). In the intention-to-treat analysis, there remained a tendency towards a difference between groups $(p=0.086)$. The difference between groups was $0.87 \mathrm{mM}$ after 1 year and remained relatively constant throughout the study ( $p$ interaction=0.014). 


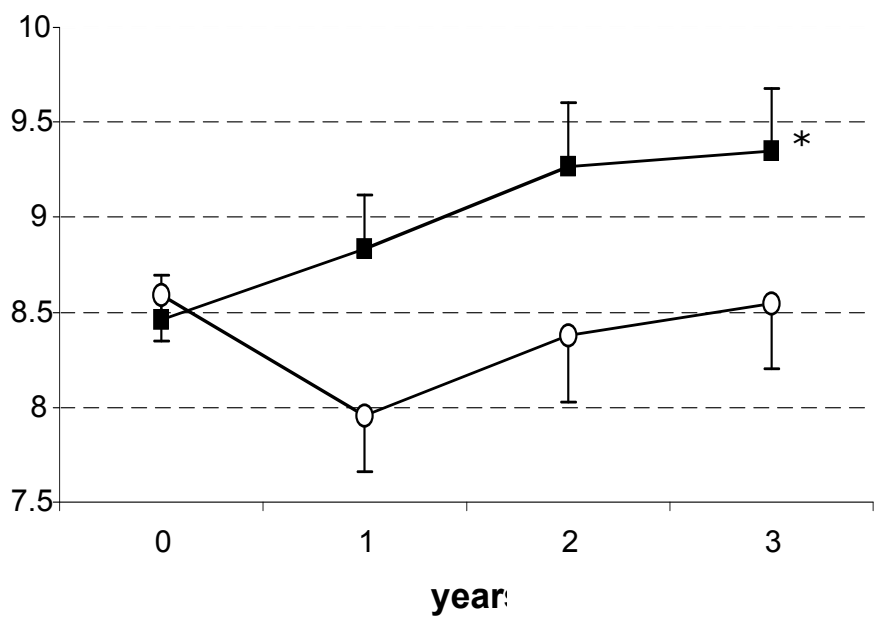

Figure 3.1 2-hr Plasma glucose levels for the intervention group (open circles) and control group (black squares) at baseline and after 1, 2 and 3 years of follow-up. Data are mean \pm SEM, $n=106: 52$ INT, 54 CON. $\mathrm{P}=0.023^{*}$ for the difference between the groups over time (GLM ANOVA for repeated measures).

Multiple linear regression analysis revealed that a decrease in body weight was correlated with a decrease in 2-hr glucose levels $(\beta=0.257 \mathrm{~kg}, \mathrm{p}=0.020)$, and a decrease in 2$\mathrm{hr}$ glucose levels was correlated with an improvement in $\mathrm{VO}_{2} \max (\beta=-0.220 \mathrm{I} / \mathrm{min}$, $p=0.048)$, although not independent of bodyweight loss $(\beta=-0.174 \mathrm{~kg}, p=0.117)$. No differences were observed in fasting plasma glucose and HBA1c in the completers analysis, whereas the change in fasting glucose did become significantly different between groups in the intention-to-treat analysis ( $p=0.04$, table 3.2).

Insulin resistance, as indicated by the HOMA index for insulin resistance (HOMAIR), decreased in the INT after 3 years $(-0.19:-1.11 ; 1.12)$, while there was an increase in $\operatorname{CON}(+0.37$ : $-0.97 ; 1.52)$; $p$ interaction=0.04). Fasting insulin decreased in both groups and 2-hr insulin levels tended to increase more in CON compared to INT ( $p$ interaction=0.07). Using intention-to-treat analysis, differences between groups in insulin levels and HOMA-IR were reduced. Multiple linear regression analysis revealed that the change in body weight was significantly correlated with the change in HOMAIR $(\beta=0.470 \mathrm{~kg}, p<0.001)$, whereas the change in $\mathrm{VO}_{2}$ max was not predictive $(\beta=$ $0.073 \mathrm{l} / \mathrm{min}, \mathrm{p}=0.513$ ). 2-Hr FFA levels decreased more in INT, compared to CON ( $p$ interaction=0.04), whereas the 3 -yr decrease in fasting FFA level was not different between groups (table 3.2).

Triglyceride levels were decreased after 2 years in INT versus an increase in CON, but these differences disappeared after 3 years. Total cholesterol, HDL and LDL concentrations did not change over time, and did not differ between groups ( $\left.p_{\text {all }}>0.05\right)$. Both in INT and CON a decline in time was observed in diastolic blood pressure $(p<0.001)$ and systolic blood pressure $(p=0.001)$, which was not different between groups ( $p=0.14$ and $p=0.92$, respectively). Results on serum lipids and blood pressure were similar for the intention-to-treat analysis and after taking lipid lowering and antihypertensive medication into account respectively. 
Within each study group, men and women did not significantly differ in change over 3 years, except for waist-to-hip ratio and percentage body fat. The waist-to-hip ratio increased in women, but remained relatively stable in men $(p<0.01$ for differences between sex in each study group). In both study groups, the percentage body fat increased slightly in women, whereas a slight decrease was observed for men $(p<0.01$ for differences between sex in each study group).

Prevalence of the MetS rose from $61.4 \%$ at baseline to $66.0 \%$ after 3 years in INT ( $n=44,24$ male $/ 20$ female) and from $58.3 \%$ to $68.8 \%$ in CON ( $n=48,27$ male $/ 21$ female) ( $p=0.630$ for difference between groups). More women (33/41) than men $(29 / 51)$ had the MetS $(p=0.02)$, since more women than men met the criteria for a high waist circumference $(p=0.004)$ and a low HDL cholesterol $(p<0.001)$.

Although the primary outcome of this study was change in 2-hr plasma glucose concentration, we also examined the cumulative diabetes incidence during the study, although the results have to be interpreted with caution, since our study was underpowered for these analyses. In the analysis of the subjects who completed the full 3 years of the study, the cumulative incidence was $18 \%(8 / 44)$ in the intervention group and $38 \%(18 / 47)$ in the control group. The $p$-value of the log-rank test amounted to 0.025 , and the relative risk was $0.42(95 \% \mathrm{Cl} 0.18-0.96)$ (figure 3.2$)$. In the intention-to treat-analysis the cumulative incidence of diabetes in the intervention group was $18 \%$ $(11 / 61)$ compared to $32 \%(19 / 60)$ in the control group. The p-value from the log-rank test comparing the survival curves was 0.07 , the relative risk amounted to $0.52(95 \% \mathrm{Cl}$ $0.25-1.10)$. Adjustment for age and mean weight did not change the outcome of this study.

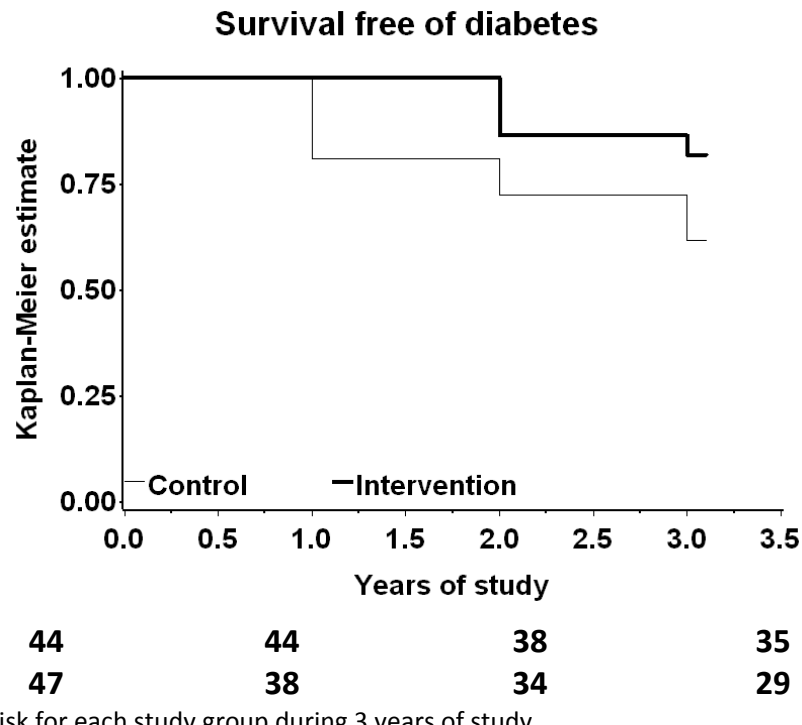

$\begin{array}{lcccc}\text { INT } & 44 & 44 & 38 & 35 \\ \text { CON } & 47 & 38 & 34 & 29 \\ \text { Total subjects at risk for each study } & \text { group during } & 3 \text { years of study }\end{array}$

Figure 3.2 Proportion of subjects without diabetes during the study. The relative risk of diabetes for subjects in the intervention group, as compared with those in the control group, was 0.42 ( $p=0.025$ for the comparison between groups). 


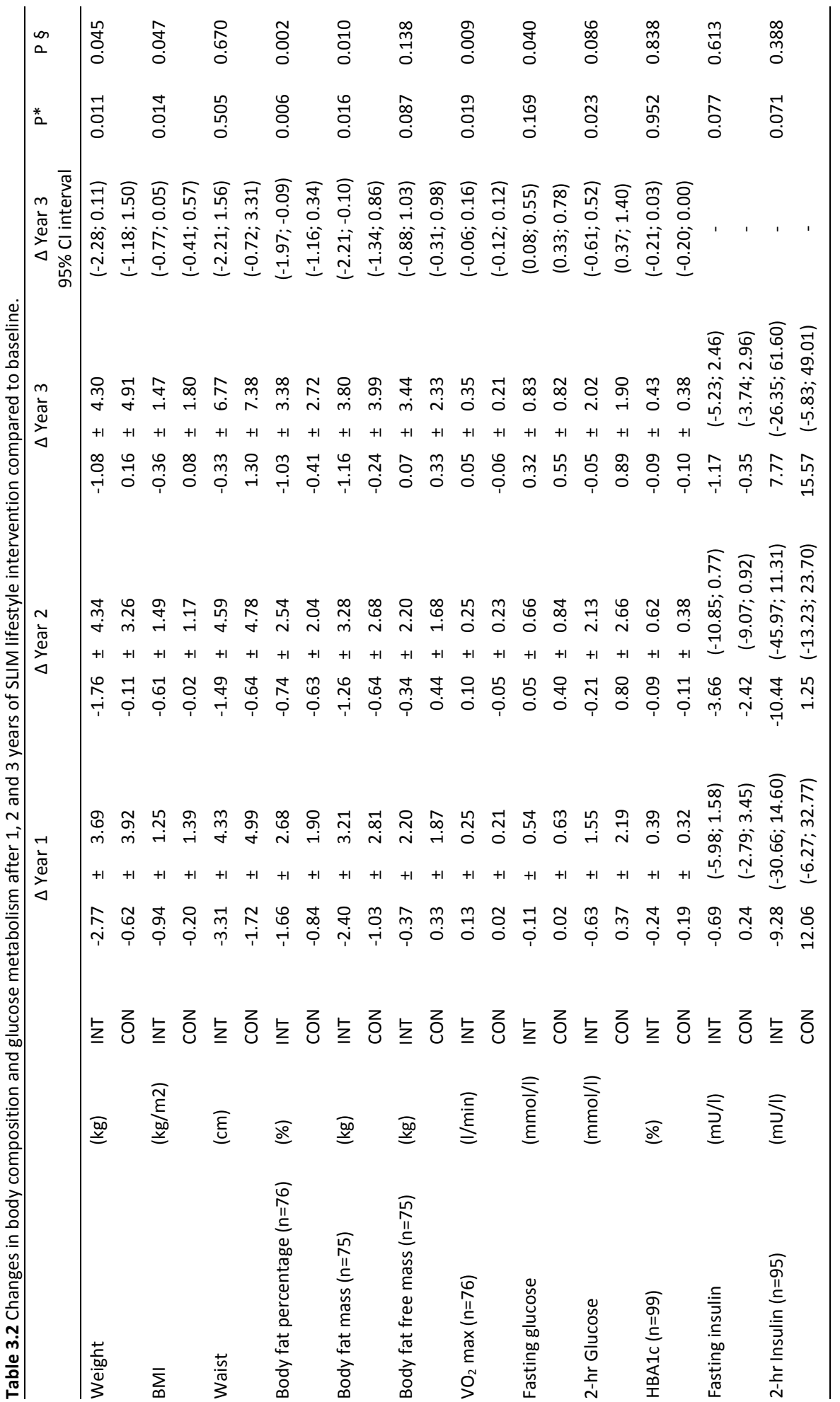




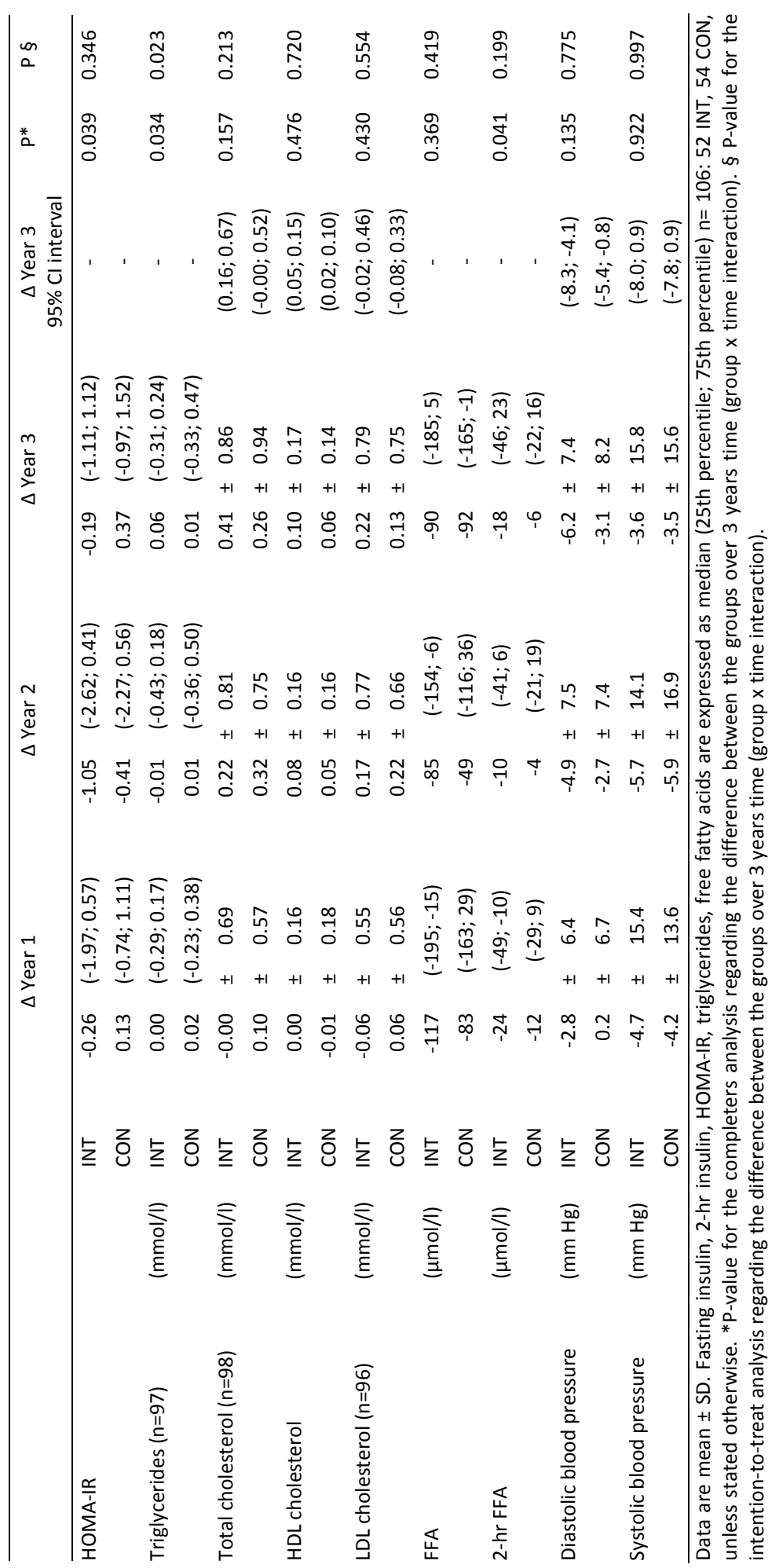




\section{Chapter 3}

At baseline, metabolic characteristics of dropouts $(n=28)$ were similar between INT and CON except for 2-hr insulin levels, which were $81.68 \mathrm{mU} / \mathrm{I}$ in INT and $131.96 \mathrm{mU} / \mathrm{I}$ in CON $(p=0.02)$. The reasons for dropout were similar between INT and CON and no differences in dropout were observed between men and women. Dropouts had a higher baseline BMI, 2-hr plasma glucose levels and a lower maximal aerobic capacity than subjects who completed all 3 years of study ( $p_{\text {all }}<0.05$ for difference between dropouts and completers). As specific dropout can affect the result of our analysis, we performed an intention-to-treat analysis ( $n=147$; table 3.2 ). This analysis affected 2 -hr glucose, insulin and HOMA-IR ( $p>0.05$ for differences between INT and CON), while no significant changes were observed in BMI, waist, body fat mass and distribution, HBA1C $\mathrm{VO}_{2}$ max, serum lipids, blood pressure and dietary intake.

Table 3.3 Changes in energy intake, based on 3-day food records, after 1, 2 and 3 years compared to baseline.

\begin{tabular}{|c|c|c|c|c|c|c|c|c|c|}
\hline & & Baseline & $\Delta \mathrm{Y}$ & ear & & $\Delta$ Year 2 & $\Delta$ Year 3 & $\begin{array}{c}\Delta \text { Year } 3 \\
95 \% \mathrm{Cl} \text { interval }\end{array}$ & $P$ \\
\hline \multicolumn{10}{|l|}{ Energy } \\
\hline \multirow[t]{2}{*}{ (MJ/day) } & INT & $8.8 \pm 2.2$ & -0.7 & \pm & 1.7 & $-0.9 \pm 2.1$ & $-1.1 \pm 1.9$ & $(-1.6 ;-0.5)$ & 0.231 \\
\hline & CON & $8.7 \pm 2.2$ & -0.2 & \pm & 2.0 & $-0.3 \pm 1.8$ & $-0.3 \pm 1.8$ & $(-0.8 ; 0.2)$ & \\
\hline \multicolumn{10}{|l|}{ Total fat } \\
\hline \multirow[t]{2}{*}{ (E\%) } & INT & $36.2 \pm 6.7$ & -4.8 & \pm & 6.3 & $-4.3 \pm 7.6$ & $-4.7 \pm 5.9$ & $(-6.4 ;-3.0)$ & $<0.001$ \\
\hline & CON & $35.0 \pm 6.8$ & -0.2 & \pm & 7.1 & $0.2 \pm 7.0$ & $-0.5 \pm 5.8$ & $(-2.1 ; 1.1)$ & \\
\hline \multicolumn{10}{|c|}{ Saturated fat } \\
\hline \multirow[t]{2}{*}{ (E\%) } & INT & $13.6 \pm 2.9$ & -2.4 & \pm & 2.9 & $-2.3 \pm 3.7$ & $-2.9 \pm 3.2$ & $(-3.8 ;-2.0)$ & $<0.001$ \\
\hline & CON & $13.6 \pm 3.5$ & -0.2 & \pm & 3.2 & $0.1 \pm 3.1$ & $-0.7 \pm 3.1$ & $(-1.6 ; 0.1)$ & \\
\hline \multicolumn{10}{|c|}{ Carbohydrates } \\
\hline \multirow[t]{2}{*}{ (E\%) } & INT & $41.0 \pm 7.4$ & 4.5 & \pm & 5.5 & $5.3 \pm 6.9$ & $4.8 \pm 5.6$ & $(3.3 ; 6.4)$ & 0.001 \\
\hline & CON & $43.4 \pm 7.3$ & 0.3 & \pm & 6.7 & $0.3 \pm 7.0$ & $1.2 \pm 5.4$ & $(-0.3 ; 2.8)$ & \\
\hline \multicolumn{10}{|l|}{ Fiber } \\
\hline \multirow[t]{2}{*}{ (g/MJ) } & INT & $2.7 \pm 0.8$ & 0.5 & \pm & 0.7 & $0.4 \pm 0.8$ & $0.5 \pm 0.6$ & $(0.3 ; 0.7)$ & 0.050 \\
\hline & CON & $2.7 \pm 0.9$ & 0.1 & \pm & 0.8 & $0.2 \pm 0.8$ & $0.2 \pm 0.8$ & $(0.0 ; 0.5)$ & \\
\hline \multicolumn{10}{|l|}{ Alcohol } \\
\hline \multirow[t]{2}{*}{ (E\%) } & INT & $6.2 \pm 7.1$ & -0.6 & \pm & 5.4 & $-1.6 \pm 4.6$ & $-1.5 \pm 3.7$ & $(-2.5 ;-0.4)$ & 0.304 \\
\hline & CON & $5.6 \pm 5.5$ & -0.0 & \pm & 5.6 & $-0.4 \pm 3.7$ & $-0.1 \pm 4.5$ & $(-1.4 ; 1.2)$ & \\
\hline
\end{tabular}

Data are mean \pm SD, $n=96: 47$ INT, 49 CON. 


\section{Discussion}

The SLIM study shows that a lifestyle intervention program according to general guidelines was effective in improving dietary composition (reduction fat intake), and increasing $\mathrm{VO}_{2}$ max, and resulted in a beneficial effect on glucose tolerance and insulin sensitivity in a Dutch population at high risk for type 2 diabetes. After 3 years, the difference between groups in 2-hr plasma glucose levels remained as high as 0.8 $\mathrm{mmol} / \mathrm{I}$ (similar as after 1 year), which was associated with a 58\% reduction in the incidence of diabetes. In addition, HOMA-IR and 2-hr FFA concentrations improved more in the INT group. However, no significant changes were found in components of the metabolic syndrome.

Our lifestyle intervention showed a modest weight reduction after 1 year of -2.8 $\mathrm{kg}$, with a gradual regain in the following years, which is consistent with data from the Finnish DPS: after a weight reduction of $-4.5 \mathrm{~kg}$ during the first year, a regain of approximately $1 \mathrm{~kg}$ after 3 years was observed (2). Furthermore, INT subjects improved their dietary habits by increasing carbohydrate and fiber intake, decreasing fat intake and they improved their $\mathrm{VO}_{2}$ max, indicating that diet and exercise recommendations were (at least partly) followed.

Despite the relatively small weight changes in our study, substantial improvement in 2-hr glucose concentration was observed in the INT, and the difference between groups persisted throughout the 3 years of lifestyle intervention. Although our results seem less impressive than for example the $1.6 \mathrm{mmol} / \mathrm{l}$ reduction in 2-hr glucose by rosiglitazone from the DREAM trial (19), a similar lifestyle intervention from the DPS has recently shown that beneficial lifestyle changes were sustained during a follow-up period for a median of 3 years without individual lifestyle counseling (20), whereas this has not been proven yet for a pharmacological intervention. Furthermore, our lifestyle intervention reduced average weight with $-1.08 \mathrm{~kg}$, whereas the rosiglitazone group in the DREAM trial increased in weight by $2.2 \mathrm{~kg}$, which may be considered disadvantageous for diabetes and CVD risk over the long term.

In contrast to 2-hr glucose, we did not observe a significant difference in fasting glucose concentrations in the completers analysis, which is in agreement with the hypothesis that fasting and postchallenge hyperglycemia may represent phenotypes with distinct natural histories in the evolution of type 2 diabetes (21). Whereas postprandial glucose disposal may be the main defect in IGT, impaired fasting glucose (IFG) may only reflect an abnormal glucose setpoint, but not an abnormal postprandial glucose response (22). Cumulative diabetes incidence was $38 \%$ in CON, but only $18 \%$ in INT, reflecting $58 \%$ less progression towards type 2 diabetes. Intention-to-treat analysis did not appreciably change these results, although the relative risk decreased to $48 \%$ for INT compared to CON $(p=0.07)$. Although our study was not designed to investigate diabetes incidence and thus lacked the statistical power, the results are comparable to results of the Finnish DPS and American DPP, both showing a $58 \%$ diabetes risk reduction after approximately 3 years time (3-4).

The natural progression towards type 2 diabetes, as is observed in the CON, is very high in our IGT group. Our results are in agreement with the Hoorn study (23), which showed a progression of $34 \%$ in isolated IGT subjects during a follow-up of 6.4 years. In the study of Meigs and colleagues (21), 21\% of the subjects with baseline 
IFG/IGT progressed towards type 2 diabetes during a 5-year follow-up. Our study underscores the importance of lifestyle intervention in subjects with IGT, since they are clearly at high risk for developing type 2 diabetes.

In addition, HOMA-IR declined in our completers analysis, indicating improvement in insulin sensitivity. Furthermore, our intervention not only improved glucose homeostasis and insulin sensitivity but also reduced postprandial circulating FFA. Elevation of (postprandial) FFA concentration may induce peripheral (skeletal) muscle and hepatic insulin resistance (24). Thus, reduced FFA concentrations may be one of the mechanisms for an improved insulin sensitivity in these subjects. Furthermore, previous studies showed that in subgroups of these IGT subjects, skeletal muscle fat oxidation capacity and fat oxidation improved after one year of lifestyle intervention, which may also be related to an improved insulin sensitivity (25).

IGT has been associated with an increased CVD risk (26-27) and although our study showed a marked improvement in 2-hr glucose, this was not accompanied by changes between groups in NCEP MetS prevalence. An explanation can be the relatively small number of subjects in each study group, combined with only minor changes in waist circumference and fasting plasma glucose concentrations and no changes in the other MetS criteria. When we applied the MetS criteria of the International Diabetes Federation (IDF) (28) the results were essentially similar.

2-Hr glucose concentrations and HOMA-IR seem more sensitive to minor changes in weight and lifestyle and these criteria may be required for prediction of CVD risk, since type 2 diabetes alone may convey a much greater risk on CVD than the presence of MetS (29). Furthermore, the NCEP MetS does not include CVD risk factors such as age, physical activity or history of CVD events and does not weigh the severity of each criterion, which may be critically important for adequate prediction of CVD risk [29]. Also, endothelial dysfunction, possibly induced by oxidative stress and inflammation, may be associated with IGT and recent discovered CVD risk markers involved in inflammation and coagulation/fibrinolysis like CRP (30), IL-6 and PAI-1 (31) await to be determined.

After 3 years, $28 \%$ of all study subjects (22 out of 74 in INT and 19 out of 73 in CON) discontinued their participation, compared to a dropout rate of $8 \%$ and $7.5 \%$ in the DPS and DPP, respectively. Several explanations for the difference in dropout rate between the DPS, DPP and SLIM can be given. First, our study population was originally recruited from the general population and they may have had less internal motivation to participate in the study, as compared to subjects recruited via advertisements or high-risk screening, as was done in the DPS (14). The DPP recruited subjects from a variety of resources, including informational mailings, advertisements, open screenings and referrals from health care professionals (32). Second, no weight loss program was offered when subjects did not loose weight which may have led to dissatisfaction for participants. Interestingly, our dropout percentage is similar to that observed in the DREAM trial (19), with $29.3 \%$ (772/2635) dropout in the rosiglitazone group and $25.0 \%$ $(658 / 2634)$ in the control group. Our dropouts were in a worse metabolic condition at baseline than completers, but the dropout rate was not different between study groups. Intention-to-treat analysis revealed that the difference in 2-hr glucose tolerance, HOMA-IR and 2-hr FFA was less pronounced, which suggests selective drop-out according to subjects in the intervention group with smaller improvements. To in- 
crease effectiveness of our lifestyle intervention in a clinical setting, we underscore the importance of more insight in the unknown determinants to participate in a lifestyleintervention and to remain adherent.

In conclusion, our lifestyle intervention program, aimed at increasing physical activity and using a healthy diet, resulted in a sustained beneficial effect on 2-hr glucose concentrations, insulin resistance and 2-hr FFA in a population at high risk for type 2 diabetes, even after 3 years, which was associated with a reduced risk for developing type 2 diabetes. Although there was some selective dropout, intention-totreat analysis still showed a similar trend in results with a significant difference in fasting glucose and a tendency towards a difference in 2-hr glucose and diabetes incidence. No effect was observed on components of the metabolic syndrome or on fasting glucose concentrations, suggesting that fasting and postchallenge hyperglycemia may represent phenotypes with distinct natural histories in the evolution of type 2 diabetes. Our lifestyle intervention is efficacious, but due to the relatively high dropout rate of subjects in worse metabolic condition, additional information on determinants of adherence and dropout for increased effectiveness and successful implementation is needed.

\section{Acknowledgements}

We thank Jos Stegen, Tanja Hermans-Limpens and Marja Ockeloen - van der Hulst for their help during the OGTT's and with the dietary intervention. This work was supported by grants from the Dutch Diabetes Research Foundation (DFN 98.901 and 2000.00.020), the Netherlands Organization for Health Research and Development (ZonMW 940-35-034) and the Netherlands Organization for Scientific Research (NWO 2200.0139). 


\section{Chapter 3}

\section{References}

1. Mensink M, Blaak EE, Corpeleijn E, Saris WH, de Bruin TW, Feskens EJ. Lifestyle intervention according to general recommendations improves glucose tolerance. Obes Res. 2003 Dec;11(12):1588-96.

2. Lindstrom J, Louheranta A, Mannelin M, Rastas M, Salminen V, Eriksson J, et al. The Finnish Diabetes Prevention Study (DPS): Lifestyle intervention and 3-year results on diet and physical activity. Diabetes Care. 2003 Dec;26(12):3230-6.

3. Tuomilehto J, Lindstrom J, Eriksson JG, Valle TT, Hamalainen H, Ilanne-Parikka P, et al. Prevention of type 2 diabetes mellitus by changes in lifestyle among subjects with impaired glucose tolerance. $\mathrm{N}$ Engl J Med. 2001 May 3;344(18):1343-50.

4. Knowler WC, Barrett-Connor E, Fowler SE, Hamman RF, Lachin JM, Walker EA, et al. Reduction in the incidence of type 2 diabetes with lifestyle intervention or metformin. N Engl J Med. 2002 Feb 7;346(6):393-403.

5. Mensink M, Blaak EE, van Baak MA, Wagenmakers AJ, Saris WH. Plasma free Fatty Acid uptake and oxidation are already diminished in subjects at high risk for developing type 2 diabetes. Diabetes. 2001 Nov;50(11):2548-54.

6. Corpeleijn E, Feskens EJ, Jansen EH, Mensink M, Saris WH, de Bruin TW, et al. Improvements in glucose tolerance and insulin sensitivity after lifestyle intervention are related to changes in serum fatty acid profile and desaturase activities: the SLIM study. Diabetologia. 2006 Oct;49(10):2392-401.

7. The DECODE study group: Is the current definition for diabetes relevant to mortality risk from all causes and cardiovascular and noncardiovascular diseases? Diabetes Care. 2003 Mar;26(3):688-96.

8. Tushuizen ME, Diamant M, Heine RJ. Postprandial dysmetabolism and cardiovascular disease in type 2 diabetes. Postgrad Med J. 2005 Jan;81(951):1-6.

9. Blaak EE, Wagenmakers AJ, Glatz JF, Wolffenbuttel BH, Kemerink GJ, Langenberg CJ, et al. Plasma FFA utilization and fatty acid-binding protein content are diminished in type 2 diabetic muscle. Am J Physiol Endocrinol Metab. 2000 Jul;279(1):E146-54.

10. Liese AD, Schulz M, Fang F, Wolever TM, D'Agostino RB, Jr., Sparks KC, et al. Dietary glycemic index and glycemic load, carbohydrate and fiber intake, and measures of insulin sensitivity, secretion, and adiposity in the Insulin Resistance Atherosclerosis Study. Diabetes Care. 2005 Dec;28(12):2832-8.

11. Reaven GM. Banting lecture 1988. Role of insulin resistance in human disease. Diabetes. 1988 Dec;37(12):1595-607.

12. Petersen JL, McGuire DK. Impaired glucose tolerance and impaired fasting glucose--a review of diagnosis, clinical implications and management. Diab Vasc Dis Res. 2005 Feb;2(1):9-15.

13. Mensink M, Corpeleijn E, Feskens EJ, Kruijshoop M, Saris WH, de Bruin TW, et al. Study on lifestyleintervention and impaired glucose tolerance Maastricht (SLIM): design and screening results. Diabetes Res Clin Pract. 2003 Jul;61(1):49-58.

14. Eriksson J, Lindstrom J, Valle T, Aunola S, Hamalainen H, Ilanne-Parikka P, et al. Prevention of Type II diabetes in subjects with impaired glucose tolerance: the Diabetes Prevention Study (DPS) in Finland. Study design and 1-year interim report on the feasibility of the lifestyle intervention programme. Diabetologia. $1999 \mathrm{Jul} ; 42(7): 793-801$.

15. Matthews DR, Hosker JP, Rudenski AS, Naylor BA, Treacher DF, Turner RC. Homeostasis model assessment: insulin resistance and beta-cell function from fasting plasma glucose and insulin concentrations in man. Diabetologia. 1985 Jul;28(7):412-9.

16. Friedewald WT, Levy RI, Fredrickson DS. Estimation of the concentration of low-density lipoprotein cholesterol in plasma, without use of the preparative ultracentrifuge. Clin Chem. 1972 Jun;18(6):499502.

17. Executive Summary of The Third Report of The National Cholesterol Education Program (NCEP) Expert Panel on Detection, Evaluation, And Treatment of High Blood Cholesterol In Adults (Adult Treatment Panel III). Jama. 2001 May 16;285(19):2486-97.

18. WHO. Definition, diagnosis and classification of diabetes mellitus. Report of WHO Consultation. Part 1: Diagnosis and Classification of Diabetes Mellitus Geneva, Switzerland; 1999.

19. Gerstein HC, Yusuf S, Bosch J, Pogue J, Sheridan P, Dinccag N, et al. Effect of rosiglitazone on the frequency of diabetes in patients with impaired glucose tolerance or impaired fasting glucose: a randomised controlled trial. Lancet. 2006 Sep 23;368(9541):1096-105.

20. Lindstrom J, Ilanne-Parikka P, Peltonen M, Aunola S, Eriksson JG, Hemio K, et al. Sustained reduction in the incidence of type 2 diabetes by lifestyle intervention: follow-up of the Finnish Diabetes Prevention Study. Lancet. 2006 Nov 11;368(9548):1673-9. 
21. Meigs JB, Muller DC, Nathan DM, Blake DR, Andres R. The natural history of progression from normal glucose tolerance to type 2 diabetes in the Baltimore Longitudinal Study of Aging. Diabetes. 2003 Jun;52(6):1475-84.

22. Bock G, Dalla Man C, Campioni M, Chittilapilly E, Basu R, Toffolo G, et al. Pathogenesis of pre-diabetes: mechanisms of fasting and postprandial hyperglycemia in people with impaired fasting glucose and/or impaired glucose tolerance. Diabetes. 2006 Dec;55(12):3536-49.

23. de Vegt F, Dekker JM, Jager A, Hienkens E, Kostense PJ, Stehouwer CD, et al. Relation of impaired fasting and postload glucose with incident type 2 diabetes in a Dutch population: The Hoorn Study. Jama. 2001 Apr 25;285(16):2109-13.

24. Frayn KN BE. Metabolic fuels and obesity; carbohydrate and lipid metabolism in skeletal muscle and adipose tissue: Blackwell Publishing Ltd 2005.

25. Mensink M, Blaak EE, Wagenmakers AJ, Saris WH. Lifestyle intervention and fatty acid metabolism in glucose-intolerant subjects. Obes Res. 2005 Aug;13(8):1354-62.

26. DECODE Study Group tEDEG. Glucose tolerance and cardiovascular mortality: comparison of fasting and 2-hour diagnostic criteria. Arch Intern Med. 2001 Feb 12;161(3):397-405.

27. Saydah SH, Loria CM, Eberhardt MS, Brancati FL. Subclinical states of glucose intolerance and risk of death in the U.S. Diabetes Care. 2001 Mar;24(3):447-53.

28. Alberti KG, Zimmet $P$, Shaw J. International Diabetes Federation: a consensus on Type 2 diabetes prevention. Diabet Med. 2007 May;24(5):451-63.

29. Malik S, Wong ND, Franklin SS, Kamath TV, L'Italien GJ, Pio JR, et al. Impact of the metabolic syndrome on mortality from coronary heart disease, cardiovascular disease, and all causes in United States adults. Circulation. 2004 Sep 7;110(10):1245-50.

30. Haffner S, Temprosa M, Crandall J, Fowler S, Goldberg R, Horton E, et al. Intensive lifestyle intervention or metformin on inflammation and coagulation in participants with impaired glucose tolerance. Diabetes. 2005 May;54(5):1566-72.

31. Hamalainen H, Ronnemaa T, Virtanen A, Lindstrom J, Eriksson JG, Valle TT, et al. Improved fibrinolysis by an intensive lifestyle intervention in subjects with impaired glucose tolerance. The Finnish Diabetes Prevention Study. Diabetologia. 2005 Nov;48(11):2248-53.

32. The Diabetes Prevention Program: baseline characteristics of the randomized cohort. The Diabetes Prevention Program Research Group. Diabetes Care. 2000 Nov;23(11):1619-29. 



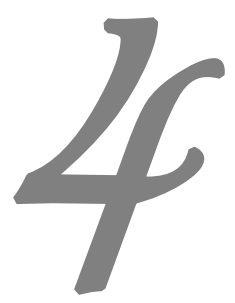

\section{PREDICTORS OF INTERVENTION OUCOME AND DROPOUT}

The SLIM study

Cheryl Roumen, Edith J.M. Feskens, Eva Corpeleijn, Marco Mensink, Wim H. M. Saris, Ellen E. Blaak.

submitted 


\section{Chapter 4}

Abstract

Objective

To evaluate the effect of a 4.1 year (range 3-6 years) lifestyle intervention according to general public health recommendations on glucose tolerance and dropout in a Dutch population with impaired glucose tolerance (IGT).

\section{Method}

In the Study on Lifestyle intervention and Impaired glucose tolerance Maastricht (SLIM), 147 Caucasian IGT subjects were randomized to an intervention group ( $n=74$, 38 male, 36 female (INT)) and control group ( $n=73,37$ male, 36 female (CON)). Annually, subjects underwent measurements of body weight, anthropometry, glucose tolerance (OGTT), insulin resistance (HOMA-IR), maximal aerobic capacity $\left(\mathrm{VO}_{2} \mathrm{max}\right)$, blood lipids and blood pressure. INT received individual advice regarding a healthy diet and physical activity.

\section{Results}

INT decreased their saturated fat intake $(p<0.05)$ and $\mathrm{VO}_{2} \max (p=0.04)$, versus CON. Body weight did not change between groups. After a decrease, 2-hr glucose levels overall increased in INT (+0.11 mmol/l), but significantly less than CON $(+1.18 \mathrm{mmol} / \mathrm{l}$; $p=0.04)$. Diabetes incidence was lower in INT versus CON ( $30 \%$ versus $56 \%, p=0.04)$. Change in body weight was associated with change in 2 -hr glucose levels ( $\beta=0.399$ $\mathrm{mmol} / \mathrm{l}, \mathrm{p}=0.02)$. Dropouts $(\mathrm{n}=32)$ had a lower maximal aerobic capacity and social economic status and a higher BMI and 2-hr glucose, compared to non-dropouts $(n=115)$.

\section{Conclusion}

Prolonged feasible changes in diet and physical activity prevent deterioration of glucose tolerance and reduce diabetes risk. Body weight changes is the strongest predictor of changes in 2-hr glucose levels. Low social economic status, low maximal aerobic capacity and high BMI and 2-hr glucose are indicative of dropout to the program. 
Introduction

Type 2 diabetes needs effective prevention measures for curbing the growing burden worldwide. Diabetes incidence is 10-20 times greater in those with impaired glucose tolerance (IGT) or impaired fasting glucose (IFG) than those with normal glycemia (1). Lifestyle interventions in IGT are an efficacious $(2,3)$ and cost-effective $(4)$ way to prevent type 2 diabetes $(5,6)$, even after active counseling is stopped (7).

Lifestyle changes towards general guidelines for diet and physical activity seems inversely associated with diabetes risk (8), indicating that the more strict compliance to the regime, the better the outcome. The Diabetes Prevention Program (DPP) has shown that a lifestyle-induced reduction in body weight was most associated with a reduced diabetes risk (9). This study, the Study on Lifestyle intervention and Impaired glucose tolerance Maastricht (SLIM), showed that subjects who adhered to both the dietary as well as the physical activity recommendations had the greatest one-year improvement in bodyweight, waist and fasting insulin (10) and prevented deterioration of 2-hr glucose levels after 3 years (3).

The dropout rate in lifestyle interventions is an important factor associated with a decreased efficacy of the program. Overall, dropout rate varies highly between lifestyle interventions with or without medication $(5,6,11-13)$, depending on the patient population, the medical condition, the form of treatment, but also the complexity of the regime and the period of time. The SLIM regime has a complex regime and a longterm follow-up. Therefore, this study offers the opportunity to increase our knowledge on determinants of dropout and intervention outcome (2-hr glucose tolerance) may contribute to a more efficient and targeted intervention to prevent and/or treat type 2 diabetes in the future.

The aim of the present SLIM study was to 1 ) assess the effectiveness of a lifestyle intervention on glucose tolerance and related cardiovascular risk factors during a mean follow-up of 4.1 years, 2) to examine which lifestyle behaviors changed during the course of the intervention, 3) to examine whether change in these lifestyle behaviors was associated with change in glucose tolerance and 4) to determine factors associated with dropout to the program. The present paper extends previously published 3year results by providing novel information on determinants of intervention outcome and dropout, which can help optimize identification, lifestyle effect and adherence in high-risk subjects.

\section{Methods}

The SLIM study (Study on Lifestyle intervention and Impaired glucose tolerance Maastricht) is a randomized controlled trial, evaluating the effect of a combined dietary and physical activity intervention program on glucose tolerance in IGT subjects (10). Changes in body composition, fasting and 2-hr insulin and plasma glucose concentrations, serum lipids, blood pressure and maximal aerobic capacity are determined annually. The Medical Ethical Review Committee of Maastricht University approved the study protocol and all subjects gave their written informed consent before the start of the study. 


\section{Study design and subjects}

The study design has been described in detail previously (10). Briefly, subjects with an increased risk for glucose intolerance, e.g. family history of diabetes, age $>40$ years, $\mathrm{BMI}>25 \mathrm{~kg} / \mathrm{m}^{2}$, were selected from a cohort in the area of Maastricht, and were invited to undergo a capillary standard Oral Glucose Tolerance Test (OGTT) (response rate $46.2 \%$, see reference (14)) at the University of Maastricht. Those subjects with a 2$\mathrm{hr}$ blood glucose concentration $>7.8 \mathrm{mmol} / \mathrm{l}$ were invited for a second venous OGTT. For inclusion, mean 2-hr glucose concentration of both OGTTs had to be between 7.8 and $12.5 \mathrm{mmol} / \mathrm{l}$ and fasting glucose concentration $<7.8 \mathrm{mmol} / \mathrm{I}$. Data obtained during the second (venous) OGTT were used as baseline values. Exclusion criteria were known diabetes, chronic illness, medication known to interfere with glucose tolerance, participation in a vigorous exercise and/or diet program. The incidence of type 2 diabetes was determined according to WHO criteria of 1999 (15).

Screening and inclusion started in 1999. Originally, the study follow-up was 3 years, but this was extended to 6 years in 2002. In 2002, a second screening period was performed, and an additional 33 subjects were included in the study. In total, the study population consists of 147 subjects. It was calculated, according to the preliminary results after 1 year of the Finnish DPS (16), that 50-60 subjects per group would be sufficient to detect a $1.0 \mathrm{mmol} / \mathrm{l}$ difference in 2-hr glucose concentration between groups. The study was completed in June 2006 (see figure 4.1). Subjects were randomized, with stratification for sex and mean 2-hr plasma glucose concentration, to either the intervention group (INT: 74 subjects; 38 male, 36 female) or the control group (CON: 73 subjects; 37 male, 36 female). At the end of the intervention, 58 INT (78\%) and 57 CON (78\%) completed at least 3 years of lifestyle intervention, of whom 6 INT and 3 CON did not attend all measurements. This means that the participants in the INT group attended the quarterly meetings with the dietician in addition to the annual meetings and that the participants in the CON group attended the annual meetings. In total 32 subjects (16 INT, 16 CON) discontinued study participation and were classified as dropout. Reason for discontinuation did not differ between study groups $(p=0.85)$. The SLIM flow-chart is presented in figure 4.1.

\section{Lifestyle Intervention}

The intervention program consisted of a dietary and physical activity part. Dietary recommendations were based on the Dutch guidelines for a healthy diet (Dutch Nutrition Council). A skilled dietician gave personal dietary advice during a one-hour counseling session every 3 months, based on a 3-day food record. A 3-day weighed food record (two weekdays and 1 weekend day) was kept before the annual visit. Nutrient intake was calculated using the Dutch food table (NEVO version 1996). After consideration of a 3-day physical activity record, subjects received personalized advice by the researcher and/or dietician on how to increase their level of physical activity to at least 30 minutes a day for at least 5 days a week. Subjects were encouraged to participate in a free, supervised combined aerobic- and resistance exercise program, especially designed for this study, which was offered at 3 different days and time points every week until the end of the study. Intensity of the program was evaluated three times a 
year, by wearing a heart rate monitor during the training sessions. The intensity of the program was at least $70 \%$ of the maximal peak oxygen consumption $\left(\mathrm{VO}_{2} \mathrm{max}\right)$. Control subjects received no individual advice, only annual general information about the beneficial effects of a healthy diet and physical activity.

\section{Measurements}

In both groups, several measurements were performed annually including an OGTT, insulin levels, $\mathrm{VO}_{2} \max$, body weight, waist circumference, body fat percentage, blood pressure, HBA1c, cholesterol and HDL. Body weight was measured with an electronical scale to the nearest $0.1 \mathrm{~kg}$. Waist was measured to the nearest $0.5 \mathrm{~cm}$, with the subject in standing position at the level midway between the lowest rib and the iliacal crest. Body fat percentage was determined by skinfold measurements (17). Blood pressure was measured in duplo with a Maxi Stabil 3 pressostabil (CE0047; Speidel en Keller, Jungingen, Germany) with the subject in supine position, after 10 minutes of rest. The mean of both measurements was used in the analyses. On a separate occasion, an incremental exhaustive exercise test was performed on an electronically braked bicycle ergo meter to determine maximal peak oxygen consumption ( $\left.\mathrm{VO}_{2} \mathrm{max}\right)$. Changes in glucose tolerance were studied using an OGTT. Blood samples were drawn after an overnight fast and again 2 hours after an oral glucose load ( 75 gram glucose). Plasma glucose was measured, with a standard enzymatic technique, automated on a Cobas Fara centrifugal analyzer. Plasma insulin concentration was measured with a Radio Immuno Assay (catalogue no. HI-14K; Linco Research, St Charles, MO, USA) that shows no cross-reactivity with pro-insulin. The HOMA-IR index for insulin resistance was calculated as described by Matthews et al., (1985)(18). Glycated hemoglobin (HBA1c) was determined in a fasting serum sample with high-performance liquid chromatography (reference values for our laboratory 4.4-6.2\%). Total cholesterol, HDL cholesterol, and triglycerides levels were measured, with a standard enzymatic technique, automated on a Cobas Fara centrifugal analyzer. Low-density lipoprotein (LDL) cholesterol was calculated according to the formula of Friedewald (19). In a questionnaire, subjects were asked to fill in their highest educational background. At baseline and annually until year 3, physical activity was measured with the Short QUestionnaire to ASsess Health-enhancing physical activity (SQUASH) in all participants, which proved to be fairly reliable and reasonably valid (20). This Dutch questionnaire contains 10 questions about the number of days spent per week, the average time spent per day and intensity regarding four activity categories: commuting activities, leisure time activities, household activities and activities at work and school. The questionnaire categorizes all activities into light, moderate and vigorous intensity activities, based on MET (metabolic equivalent) values defined by Ainsworth's compendium of physical activities (21) and the respondents' age.

\section{Statistical analysis}

Data analysis was conducted using SPSS for Windows (version 14.1). Insulin and serum lipid concentrations were not normally distributed and were In-transformed. Data are 
presented as mean \pm SD in the tables and text, and as mean \pm SEM in the figures to improve graphical presentation. Differences between groups at baseline were tested with a Student's t test for independent samples or a chi-square test. Changes over time between groups were assessed using mixed model analysis on intention to treat, which included all available observations, including those from later dropouts. P-values of interaction between group and time were used to indicate differences between the groups as a result of the lifestyle intervention. Survival analysis was used to determine the hazard ratio for diabetes development and to produce a Kaplan-Meier graph. Stepwise backward linear regression analysis was used to determine which parameters were associated with changes in glucose tolerance. A p-value of less than 0.05 was considered statistically significant. All tests were two-sided.

Results

Effectiveness of the lifestyle intervention

At baseline, no differences between the randomized groups were seen apart from age, which was higher in the control subjects ( $58.8 \pm 8.4$ years) compared to the intervention subjects ( $55.0 \pm 6.5$ years, $p=0.001$ for differences between groups; table 4.1 ). The age difference remained similar between groups during the lifestyle intervention period.

The SLIM intervention had a beneficial effect on 2-hr glucose levels and diabetes risk. 2-Hr glucose levels decreased in INT in the first 4 years of the study and increased slightly at the end of the study. In CON, 2-hr glucose increased from $8.80 \pm 2.09 \mathrm{mmol} / \mathrm{l}$ to $9.38 \pm 2.45 \mathrm{mmol} / \mathrm{l}, \mathrm{p}=0.041$ for average difference between groups (figure $4.2 \mathrm{D}$ ). Diabetes incidence was higher in the control group compared to the intervention group with a $\mathrm{p}$-value of the log-rank test that amounted to 0.04 and a relative risk of 0.53 (95\% Cl 0.29-0.97) (figure 4.3).

\section{Lifestyle-induced behavior change}

During the lifestyle intervention, intervention subjects decreased their total fat intake $(p=0.01$ time $x$ group interaction, figure $4.2 A)$ and increased their carbohydrate intake from $40.9 \pm 7.5 \mathrm{E} \%$ at baseline to $46.7 \pm 5.9 \mathrm{E} \%$ at the end of the study $(p=0.002)$, whereas the increase was smaller in CON (+1.2 E\%). INT decreased their saturated fat intake with $2.4 \%$, while a minor decrease of $0.9 \%$ was observed for CON $(p<0.001)$. Fiber intake increased in INT from $2.7 \pm 0.7 \mathrm{mg} / \mathrm{MJ}$ to $3.4 \pm 1.1 \mathrm{mg} / \mathrm{MJ}$ and increased less in CON from $2.7 \pm 0.9 \mathrm{mg} / \mathrm{MJ}$ to $3.3 \pm 1.2 \mathrm{mg} / \mathrm{MJ}$ ( $\mathrm{p}=0.05$ between groups). Changes in energy, cholesterol, protein and alcohol intake were similar between study groups ( $p>0.05$, data not shown). Data on energy intake from baseline to year 3 have been published previously (3).

During the lifestyle intervention, body weight decreased in INT after 1 year (-2.47 $\mathrm{kg}$ ) and during the first 4 years $(-0.32 \mathrm{~kg})$ (table 4.1$)$, but increased to baseline value at the end of the study, whereas body weight did not change in CON ( $p=0.20$, figure 4.2B). 
Maximal aerobic capacity $\left(\mathrm{VO}_{2} \mathrm{max}\right)$ improved more in INT, compared to CON, $\mathrm{p}=0.042$ (figure $4.2 \mathrm{C}$ ). To verify the association between physical activity and aerobic capacity we looked at the number of days that subjects were at least 30 minutes physically active doing walking, bicycling, gardening or doing sports after 3 years. Statistical analyses revealed that the number of active days per week increased significantly in the intervention group from $2.9 \pm 2.4$ days at baseline to $3.8 \pm 2.5$ days after 3 years (change: $0.9 \pm 2.8$ days), while those of the control group decreased from $3.0 \pm 2.6$ days at baseline to $2.5 \pm 2.7$ days (change: $-0.55 \pm 3.31$ days (mean $\pm S D$ )), $p=0.05$ between groups. In the total study population, the increase in number of days was significantly associated with an increase in aerobic capacity (Pearson's correlation coefficient $\mathrm{R}=0.343, \mathrm{p}=0.01$ ). No differences between groups or over time were observed in fasting glucose, fasting insulin and 2-hr insulin, HOMA-IR, triglycerides, total cholesterol, HDL and LDL cholesterol, diastolic and systolic blood pressure or medication use ( $p>0.05$, table 4.1).

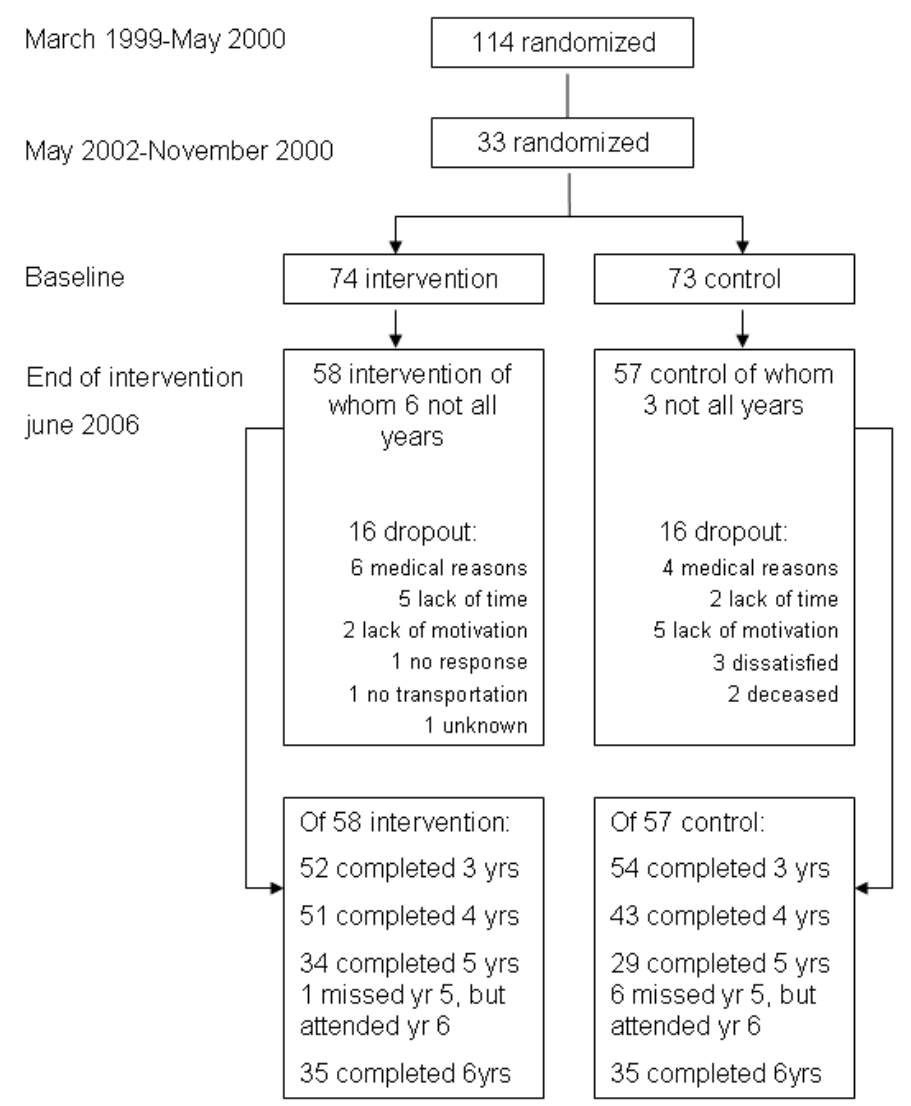

Figure 4.1 Trial profile of the SLIM intervention study in the Netherlands between the year 2000 and 2006. Participants who dropped out of the program were treated as censored observations in the intention-totreat analyses. 


\section{Chapter 4}

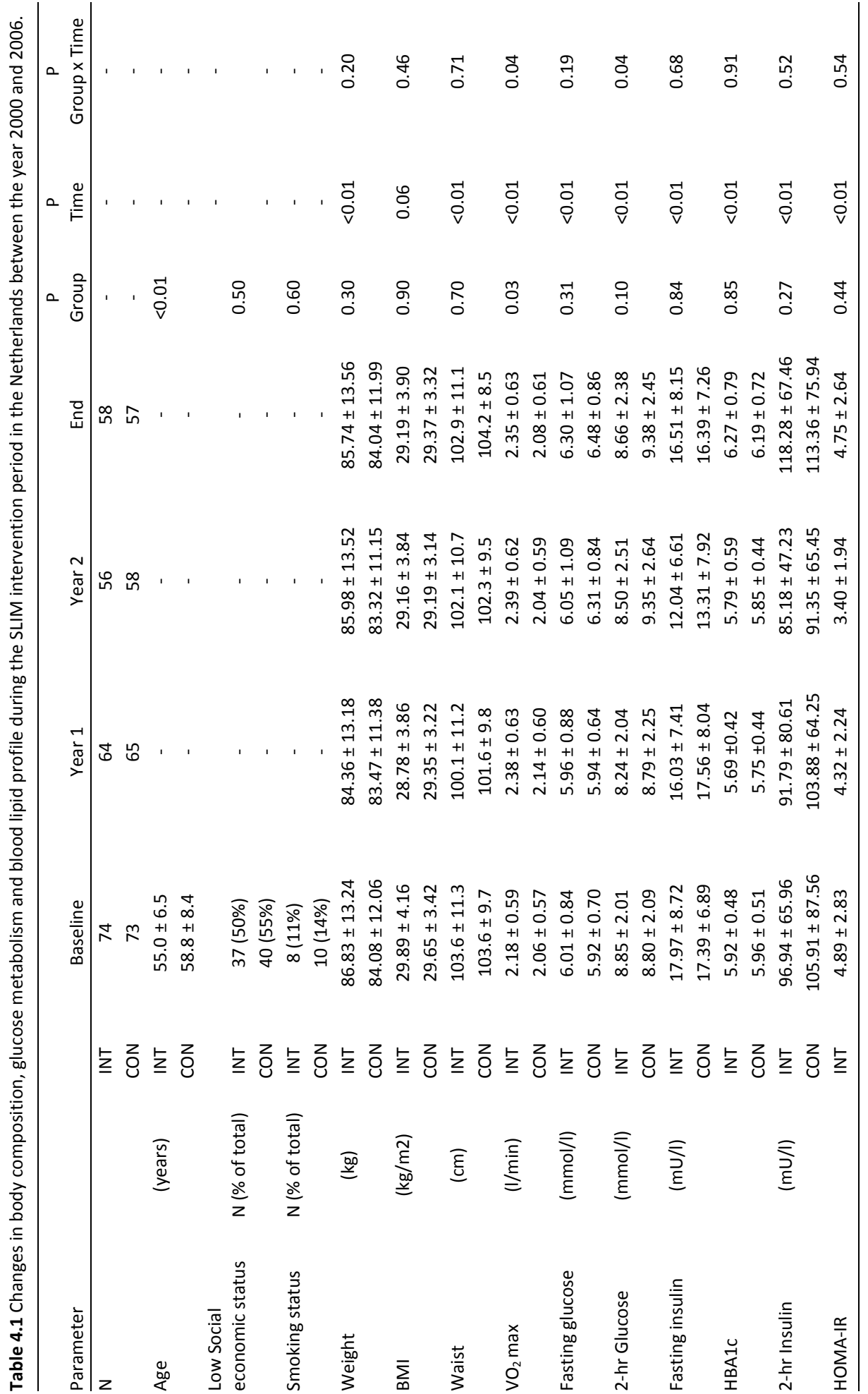


Predictors of intervention outcome

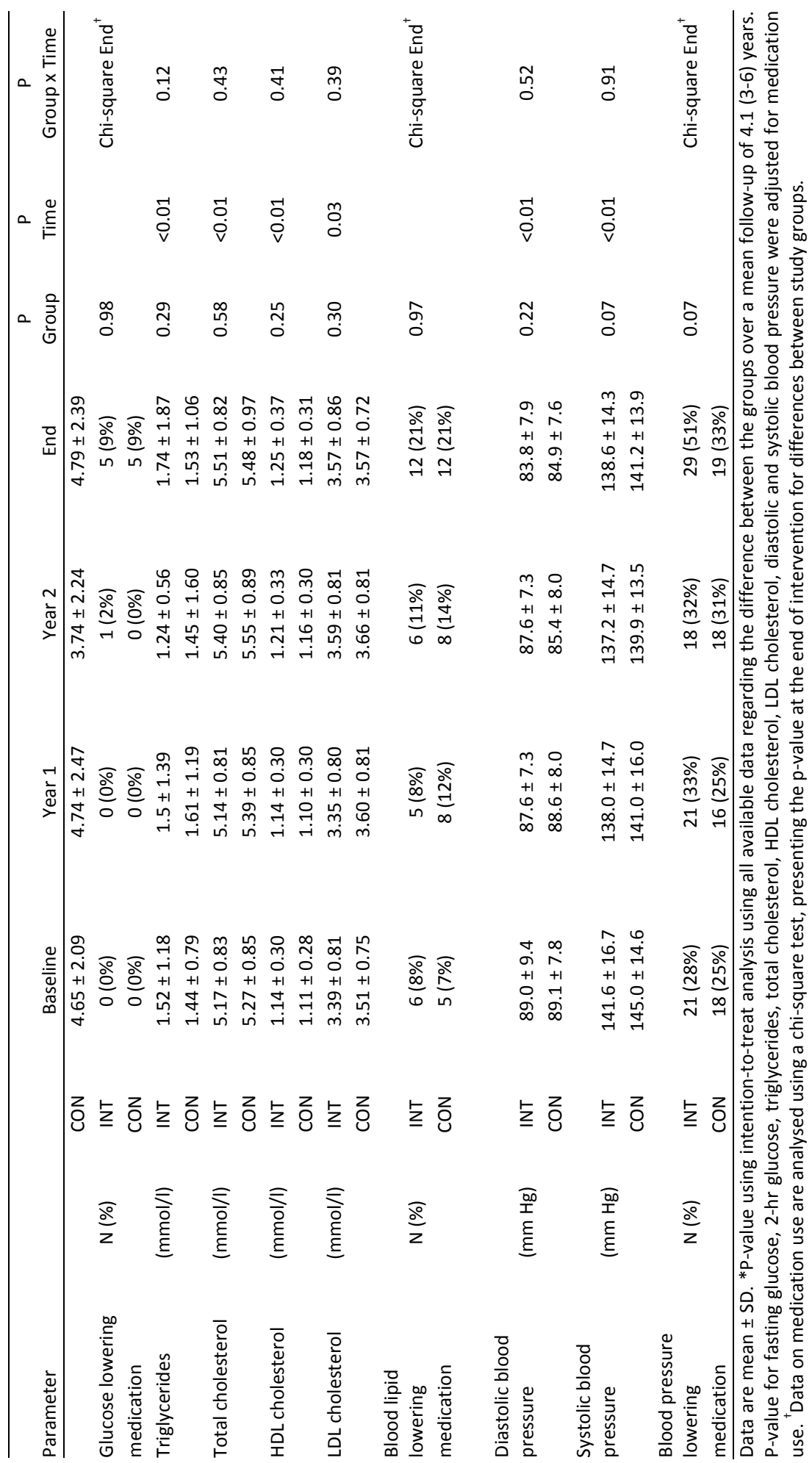


Regression analysis in INT $(n=49)$ revealed that in a model including $\Delta$ body weight, $\Delta$ maximal aerobic capacity, $\Delta$ total fat intake and $\Delta$ fiber intake as covariates, only $\Delta$ body weight was significantly associated with changes in 2 -hr glucose levels $(\beta=0.303$ $\mathrm{mmol} / \mathrm{l}, \mathrm{p}=0.04)$. When replacing $\Delta$ bodyweight with $\Delta$ waist circumference, this parameter was slightly more strongly associated with $\Delta 2$-hr glucose $(\beta=0.316 \mathrm{mmol} / \mathrm{l}$, $p=0.03)$. In the control group, suprailiacal skinfold thickness and age at baseline predicted worsening in 2-hr glucose levels $(\beta=0.19 \mathrm{~cm}, p=0.05 ; \beta=0.23 \mathrm{mmol} / \mathrm{l}, p=0.01)$.

Factors associated with dropout to the program.

At the end of the study, 115 (58 INT/57 CON) subjects were still participating and 32 (16 INT/16 CON) had dropped out. At baseline, adherent subjects had a higher $\mathrm{VO}_{2}$ $\max (p<0.05)$, were higher educated and had a lower BMI and 2-hr glucose levels compared to dropouts $(p<0.01$, table 4.2 ). Results were similar when tested for the intervention group and control group separately.
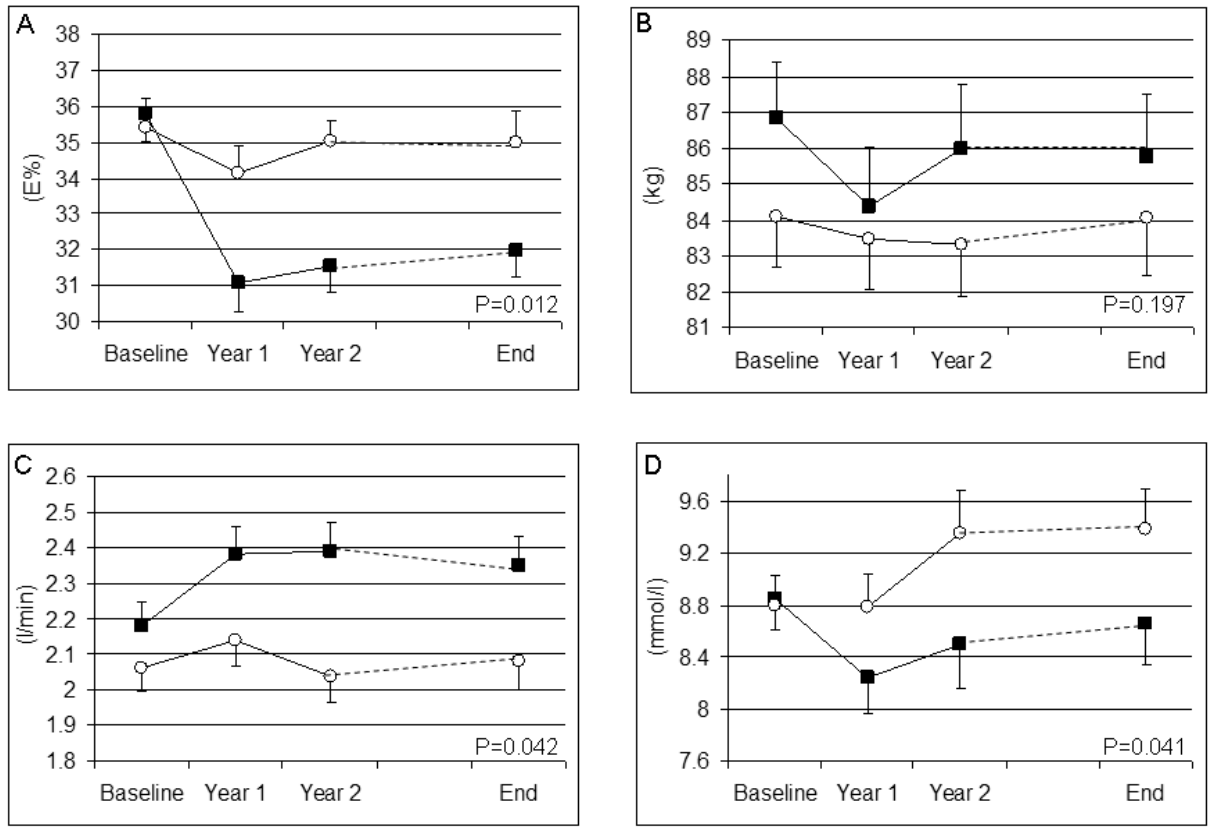

Figure 4.2 A-D. Changes in lifestyle parameters and 2-hr glucose concentrations, during a combined dietand-exercise lifestyle intervention to prevent type 2 diabetes (SLIM study). The study was performed in the Netherlands between the year 2000 and 2006. Data are presented as mean \pm SEM. Total fat intake (A), Body weight (B), VO2 $\max (\mathrm{C})$, and 2-hr plasma glucose levels (D) for the intervention group (black squares) and control group (open triangles) at baseline, after 1 year, 2 years and at the end of the lifestyle intervention (mean 4.1 years). Dashed lines between year 2 and endpoint represents estimate progression in between. 
Table 4.2 Baseline characteristics of participants of the SLIM lifestyle intervention, which was held between the year 2000 and 2006 in the Netherlands. Participants who completed the full study protocol (completers) were compared to those who discontinued participation previous to the end of the study (dropouts).

\begin{tabular}{|c|c|c|c|c|}
\hline & & Completers & Dropouts & $\mathrm{P}$ \\
\hline $\mathrm{N}$ & & 115 & 32 & - \\
\hline INT (male/female) & & $58(30 / 28)$ & $16(7 / 9)$ & 0.49 \\
\hline CON (male/female) & & $57(31 / 26)$ & $16(6 / 10)$ & 0.13 \\
\hline Age & (years) & $56.2 \pm 7.1$ & $58.3 \pm 6.7$ & 0.16 \\
\hline Low Social Economic Status & $\mathrm{N}$ (\% of total) & 47 (41\%) & $23(72 \%)$ & $<0.01$ \\
\hline Smoking status & $\mathrm{N}$ (\% of total) & $15(13 \%)$ & $3(9 \%)$ & 0.62 \\
\hline Weight & (kg) & $85.1 \pm 13.0$ & $87.0 \pm 11.4$ & 0.46 \\
\hline BMI & $(\mathrm{kg} / \mathrm{m} 2)$ & $29.4 \pm 3.5$ & $31.3 \pm 4.4$ & $<0.01$ \\
\hline Waist & $(\mathrm{cm})$ & $102.8 \pm 10.2$ & $106.6 \pm 11.3$ & 0.07 \\
\hline Body fat percentage & (\%) & $38.1 \pm 6.3$ & $40.4 \pm 6.4$ & 0.07 \\
\hline Diastolic blood pressure & $(\mathrm{mm} \mathrm{Hg})$ & $89.3 \pm 8.4$ & $88.2 \pm 9.6$ & 0.52 \\
\hline Systolic blood pressure & $(\mathrm{mm} \mathrm{Hg})$ & $142.8 \pm 15.7$ & $145.1 \pm 16.0$ & 0.47 \\
\hline $\mathrm{VO}_{2} \max$ & $(1 / \min )$ & $2.2 \pm 0.6$ & $1.9 \pm 0.6$ & 0.04 \\
\hline Fasting glucose & $(\mathrm{mmol} / \mathrm{l})$ & $5.9 \pm 0.8$ & $6.1 \pm 0.7$ & 0.23 \\
\hline 2-hr Glucose & $(\mathrm{mmol} / \mathrm{l})$ & $8.6 \pm 1.7$ & $9.8 \pm 2.8$ & $<0.01$ \\
\hline HBA1c & (\%) & $5.9 \pm 0.5$ & $6.1 \pm 0.5$ & 0.15 \\
\hline Fasting insulin & $(\mathrm{mU} / \mathrm{l})$ & $17.4 \pm 6.6$ & $18.8 \pm 11.5$ & 0.94 \\
\hline 2-hr Insulin & $(\mathrm{mU} / \mathrm{I})$ & $99.12 \pm 78.9$ & $110.6 \pm 72.9$ & 0.42 \\
\hline HOMA-IR & & $4.6 \pm 2.0$ & $5.2 \pm 3.8$ & 0.79 \\
\hline Triglycerides & $(\mathrm{mmol} / \mathrm{l})$ & $1.4 \pm 0.7$ & $1.4 \pm 0.6$ & 0.91 \\
\hline Total cholesterol & $(\mathrm{mmol} / \mathrm{l})$ & $5.2 \pm 0.8$ & $5.3 \pm 1.0$ & 0.73 \\
\hline HDL cholesterol & $(\mathrm{mmol} / \mathrm{l})$ & $1.1 \pm 0.3$ & $1.1 \pm 0.3$ & 0.95 \\
\hline LDL cholesterol & $(\mathrm{mmol} / \mathrm{l})$ & $3.4 \pm 0.7$ & $3.5 \pm 0.9$ & 0.56 \\
\hline Total energy intake & (MJ/day) & $8.8 \pm 2.4$ & $8.2 \pm 2.1$ & 0.18 \\
\hline Total fat intake & $(E n \%)$ & $35.6 \pm 6.7$ & $35.5 \pm 6.4$ & 0.94 \\
\hline Saturated fat intake & $(E n \%)$ & $13.6 \pm 3.2$ & $13.4 \pm 3.2$ & 0.74 \\
\hline Total carbohydrate intake & $(E n \%)$ & $42.2 \pm 7.5$ & $43.8 \pm 6.0$ & 0.31 \\
\hline Fiber intake & (mg/MJ) & $2.7 \pm 0.8$ & $2.9 \pm 0.9$ & 0.17 \\
\hline Alcohol consumption & (En\%) & $5.8 \pm 6.3$ & $4.2 \pm 7.6$ & 0.24 \\
\hline
\end{tabular}

Data are Mean \pm SD. 


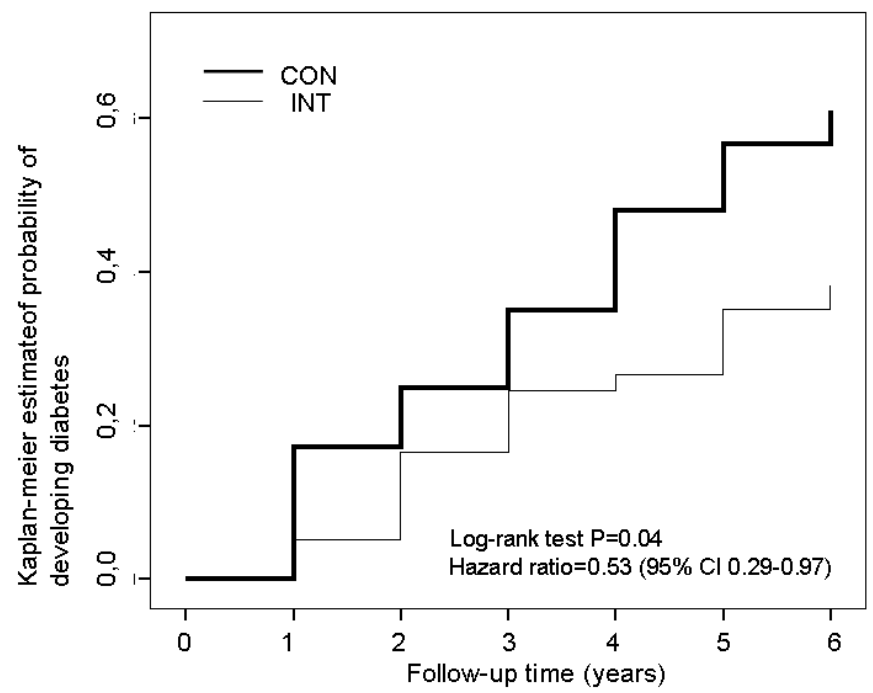

Figure 4.3 Proportion of subjects with diabetes during the SLIM lifestyle intervention in the Netherlands between the year 2000 and 2006. Cumulative diabetes incidence in the intervention group and control group. The relative risk of diabetes for subjects in the intervention group, as compared with those in the control group, was 0.53 ( $\mathrm{P}=0.04$ for the comparison between the groups).

\section{Discussion}

The present study demonstrates long-term effectiveness of lifestyle intervention in the Dutch setting as well as novel information on factors associated with dropout and intervention outcomes. Our findings add to the knowledge about identification, lifestyle effect and adherence in certain high-risk subgroups, and optimize implementation.

\section{Effectiveness of the SLIM lifestyle intervention}

In our lifestyle intervention the difference in 2-hr plasma glucose levels between groups remained as high as $0.72 \mathrm{mmol} / \mathrm{l}$, which was associated with a diabetes risk reduction of $47 \%$, despite no significant differences in body weight between groups. The diabetes risk reduction is similar to that found in the DPS $(6,7)$ and DPP $(5)$. The control group showed a relatively small increase in 2-hr glucose levels and one may argue that the control group would not reflect the actual general population. However, at present, self-monitoring, self-tests, multimedia attention and increasing information availability and presentation of diabetes and diabetes-related complications may well increase awareness of the general population and induce small changes in their dietary and physical activity habits. The control group in our study may therefore be reflective of the informed general population at present. 
Lifestyle-induced behavior change

At the end of the lifestyle intervention, subjects in the intervention group had a sustained higher aerobic capacity compared to the control group, and intervention subjects had increased their total number of physically active days per week. Unfortunately, we were not able to analyze whether attendance to the exercise program predicted the outcome of the intervention due to limited power. However, since approximately $70 \%$ of the intervention subjects also used other exercise facilities or physical activities, the total number of physically active days per week may be more indicative for the whole intervention group. Physical activity may independently reduce diabetes risk (9), also by sustaining weight loss (9). Even small sustained increases in physical activity, as was also observed in this study, seem beneficial in the long term. Surprisingly, changes in aerobic capacity were not correlated with changes in glucose tolerance, possibly due to lack of statistical power for aerobic capacity ( $n=48$ for the intervention group).

Similar to the DPS, our lifestyle intervention did not have an effect on cholesterol, triglyceride levels and blood pressure, or on medication use, which could have masked the lifestyle effects (22). A high consumption of carbohydrates results in a rise in triglyceride concentrations (23). Body weight loss, mediated by both a low-fat or a high-fat diet may reduce triglyceride levels (24). It is possible that in the present lifestyle intervention, the increased carbohydrate intake and an increase in maximal aerobic capacity leveled out potential effects on plasma triglycerides.

\section{Associations between changes in lifestyle behavior and changes in glucose tolerance}

In agreement with previous results from the DPP (9), stepwise regression analyses revealed that variation in body weight loss and waist circumference was the most important determinant of the change glucose tolerance. It can therefore be assumed that adherence to a more rigid regime regarding weight loss, compared to what we have achieved in our study, may result in even greater improvements in glucose tolerance and diabetes risk reduction.

\section{Factors associated with dropouts to the intervention program}

A limitation in the present study is the seemingly high dropout rate, $21 \%$ in total (31 out of the 147 subjects). This percentage is higher compared to previous reports of the DPS (6) and the DPP (5). On the other hand, our dropout percentage is similar to that of other lifestyle interventions after $1-2$ year follow-up $(25,26)$ and to that observed in the DREAM trial after a follow-up for a median of 3 years (27), with $29.3 \%$ (772/2635) dropout in the rosiglitazone group and $25.0 \%$ (658/2634) in the control group. Two explanations for the difference between the DPS, DPP and SLIM can be given. First, our participants were originally extracted from the general population and they may have had less internal motivation to participate in the study, as compared to subjects recruited via advertisements, as was done in the DPS (16). Second, no weight loss program was provided which may have led to dissatisfaction for participants. In our 
study, subjects unable to participate until the end of the study had a lower social economic status, a lower $\mathrm{VO}_{2}$ max and a higher $\mathrm{BMI}$ and 2-hr glucose levels at baseline, than those who completed the study. This clustering of factors is known from previous studies, which have found that a low educational background is associated with increased risk for obesity (28) and that a low occupational position in adulthood is associated with a higher prevalence of type 2 diabetes in men and women (29).

Subjects with a low maximal aerobic capacity were more likely to become a dropout. This is similar to a previous report in the U.S. showing that especially high-risk subjects do not engage in regular physical activity (30). Therefore, these subjects may be especially prone to dropout en stay in their non-active physical behavior. More studies are necessary that investigate why certain groups of people drop out and how this can be changed.

\section{Conclusions}

Our results underscore that prolonged feasible changes in diet and physical activity prevent deterioration of glucose tolerance and reduce diabetes risk by $47 \%$ over a mean of 4.1 years. Variation in body weight loss and waist circumference was most strongly associated with the improved glucose tolerance, exemplifying the importance of body weight and central body fat reduction. A low social economic status and a low maximal aerobic capacity are indicative of dropout to the program, suggesting that these subjects may need special attention to achieve beneficial changes in their lifestyle and metabolic profile.

\section{Acknowledgements}

We thank Jos Stegen, Tanja Hermans-Limpens and Marja Ockeloen - van der Hulst for their help during the OGTT's and with the dietary intervention. This work was supported by grants from the Dutch Diabetes Research Foundation (DFN 98.901 and 2000.00.020), the Netherlands Organization for Scientific Research (940-35-034 and 2200.0139). 


\section{References}

1. Magliano DJ, Barr EL, Zimmet PZ, Cameron AJ, Dunstan DW, Colagiuri S, et al. Glucose indices, health behaviors, and incidence of diabetes in Australia: the Australian Diabetes, Obesity and Lifestyle Study. Diabetes Care. 2008 Feb;31(2):267-72.

2. Gillies CL, Abrams KR, Lambert PC, Cooper NJ, Sutton AJ, Hsu RT, et al. Pharmacological and lifestyle interventions to prevent or delay type 2 diabetes in people with impaired glucose tolerance: systematic review and meta-analysis. Bmj. 2007 Feb 10;334(7588):299.

3. Roumen C, Corpeleijn E, Feskens EJ, Mensink M, Saris WH, Blaak EE. Impact of 3-year lifestyle intervention on postprandial glucose metabolism: the SLIM study. Diabet Med. 2008 May;25(5):597-605.

4. Jacobs-van der Bruggen MA, Bos G, Bemelmans WJ, Hoogenveen RT, Vijgen SM, Baan CA. Lifestyle interventions are cost-effective in people with different levels of diabetes risk: results from a modeling study. Diabetes Care. 2007 Jan;30(1):128-34.

5. Knowler WC, Barrett-Connor E, Fowler SE, Hamman RF, Lachin JM, Walker EA, et al. Reduction in the incidence of type 2 diabetes with lifestyle intervention or metformin. N Engl J Med. 2002 Feb 7;346(6):393-403.

6. Tuomilehto J, Lindstrom J, Eriksson JG, Valle TT, Hamalainen H, Ilanne-Parikka P, et al. Prevention of type 2 diabetes mellitus by changes in lifestyle among subjects with impaired glucose tolerance. N Engl J Med. 2001 May 3;344(18):1343-50.

7. Lindstrom J, Ilanne-Parikka P, Peltonen M, Aunola S, Eriksson JG, Hemio K, et al. Sustained reduction in the incidence of type 2 diabetes by lifestyle intervention: follow-up of the Finnish Diabetes Prevention Study. Lancet. 2006 Nov 11;368(9548):1673-9.

8. Simmons RK, Harding AH, Jakes RW, Welch A, Wareham NJ, Griffin SJ. How much might achievement of diabetes prevention behaviour goals reduce the incidence of diabetes if implemented at the population level? Diabetologia. 2006 May;49(5):905-11.

9. Hamman RF, Wing RR, Edelstein SL, Lachin JM, Bray GA, Delahanty L, et al. Effect of weight loss with lifestyle intervention on risk of diabetes. Diabetes Care. 2006 Sep;29(9):2102-7.

10. Mensink M, Blaak EE, Corpeleijn E, Saris WH, de Bruin TW, Feskens EJ. Lifestyle intervention according to general recommendations improves glucose tolerance. Obes Res. 2003 Dec;11(12):1588-96.

11. Digenio AG, Mancuso JP, Gerber RA, Dvorak RV. Comparison of methods for delivering a lifestyle modification program for obese patients: a randomized trial. Ann Intern Med. 2009 Feb 17;150(4):25562.

12. Poston WS, Haddock CK, Pinkston MM, Pace P, Reeves RS, Karakoc N, et al. Evaluation of a primary careoriented brief counseling intervention for obesity with and without orlistat. J Intern Med. 2006 Oct;260(4):388-98.

13. Hoeger KM, Kochman L, Wixom N, Craig K, Miller RK, Guzick DS. A randomized, 48-week, placebocontrolled trial of intensive lifestyle modification and/or metformin therapy in overweight women with polycystic ovary syndrome: a pilot study. Fertil Steril. 2004 Aug;82(2):421-9.

14. Mensink M, Corpeleijn E, Feskens EJ, Kruijshoop M, Saris WH, de Bruin TW, et al. Study on lifestyleintervention and impaired glucose tolerance Maastricht (SLIM): design and screening results. Diabetes Res Clin Pract. 2003 Jul;61(1):49-58.

15. WHO. Definition, diagnosis and classification of diabetes mellitus. Report of WHO Consultation. Part 1: Diagnosis and Classification of Diabetes Mellitus Geneva, Switzerland; 1999.

16. Eriksson J, Lindstrom J, Valle T, Aunola S, Hamalainen H, llanne-Parikka P, et al. Prevention of Type II diabetes in subjects with impaired glucose tolerance: the Diabetes Prevention Study (DPS) in Finland. Study design and 1-year interim report on the feasibility of the lifestyle intervention programme. Diabetologia. 1999 Jul;42(7):793-801.

17. Durnin JV, Womersley J. Body fat assessed from total body density and its estimation from skinfold thickness: measurements on 481 men and women aged from 16 to 72 years. $\mathrm{Br} J$ Nutr. 1974 Jul;32(1):77-97.

18. Matthews DR, Hosker JP, Rudenski AS, Naylor BA, Treacher DF, Turner RC. Homeostasis model assessment: insulin resistance and beta-cell function from fasting plasma glucose and insulin concentrations in man. Diabetologia. 1985 Jul;28(7):412-9.

19. Friedewald WT, Levy RI, Fredrickson DS. Estimation of the concentration of low-density lipoprotein cholesterol in plasma, without use of the preparative ultracentrifuge. Clin Chem. 1972 Jun;18(6):499-502.

20. Wendel-Vos GC, Schuit AJ, Saris WH, Kromhout D. Reproducibility and relative validity of the short questionnaire to assess health-enhancing physical activity. J Clin Epidemiol. 2003 Dec;56(12):1163-9. 


\section{Chapter 4}

21. Ainsworth BE, Haskell WL, Leon AS, Jacobs DR, Jr., Montoye HJ, Sallis JF, et al. Compendium of physical activities: classification of energy costs of human physical activities. Med Sci Sports Exerc. 1993 Jan;25(1):71-80.

22. Ilanne-Parikka P, Eriksson JG, Lindstrom J, Peltonen M, Aunola S, Hamalainen $\mathrm{H}$, et al. Effect of Lifestyle Intervention on the Occurrence of Metabolic Syndrome and its Components in the Finnish Diabetes Prevention Study. Diabetes Care. 2008 Jan 9.

23. Parks EJ, Hellerstein MK. Carbohydrate-induced hypertriacylglycerolemia: historical perspective and review of biological mechanisms. Am J Clin Nutr. 2000 Feb;71(2):412-33.

24. Tay J, Brinkworth GD, Noakes M, Keogh J, Clifton PM. Metabolic effects of weight loss on a very-lowcarbohydrate diet compared with an isocaloric high-carbohydrate diet in abdominally obese subjects. J Am Coll Cardiol. 2008 Jan 1;51(1):59-67.

25. Oldroyd JC, Unwin NC, White M, Mathers JC, Alberti KG. Randomised controlled trial evaluating lifestyle interventions in people with impaired glucose tolerance. Diabetes Res Clin Pract. 2006 May;72(2):117-27.

26. Swinburn BA, Metcalf PA, Ley SJ. Long-term (5-year) effects of a reduced-fat diet intervention in individuals with glucose intolerance. Diabetes Care. 2001 Apr;24(4):619-24.

27. Gerstein HC, Yusuf S, Bosch J, Pogue J, Sheridan P, Dinccag N, et al. Effect of rosiglitazone on the frequency of diabetes in patients with impaired glucose tolerance or impaired fasting glucose: a randomised controlled trial. Lancet. 2006 Sep 23;368(9541):1096-105.

28. Ball K, Crawford D. Socioeconomic status and weight change in adults: a review. Soc Sci Med. 2005 May;60(9):1987-2010.

29. Agardh E, Ahlbom A, Andersson T, Efendic S, Grill V, Hallqvist J, et al. Socio-economic position at three points in life in association with type 2 diabetes and impaired glucose tolerance in middle-aged Swedish men and women. Int J Epidemiol. 2007 Feb;36(1):84-92.

30. Morrato EH, Hill JO, Wyatt HR, Ghushchyan V, Sullivan PW. Physical activity in u.s. Adults with diabetes and at risk for developing diabetes, 2003. Diabetes Care. 2007 Feb;30(2):203-9. 


\section{PERSONAL AND ENVIRONMENTAL FACTORS ASSOCIATED WITH ADHERENCE TO A LIFESTYLE INTERVENTION AMONG PERSONS WITH IMPAIRED GLUCOSE TOLERANCE}

The SLIM study

Patricia van Assema, Cheryl Roumen, Jascha de Nooijer, Ilse Mesters, Edith Feskens, Ellen Blaak

submitted 


\section{Chapter 5}

\section{Abstract}

Objective

To assess adherence to physical activity and nutrition advices in adults with impaired glucose tolerance (IGT) participating in a lifestyle intervention study, and to determine personal and environmental factors that may have affected adherence.

\section{Method}

59 participants in the intervention group completed a self-administered questionnaire measuring potential personal and environmental determinants, derived from a number of influential theoretical models, after a follow-up of 2 or 4 years. Measures of adherence were derived from food records and the SQUASH (Short QUestionnaire to ASsess Health enhancing physical activity) completed during one of the annual measurements of the trial.

\section{Results}

Adherence to the lifestyle advices of the SLIM intervention ranged from 22 to $70 \%$. Participants self-rated their adherence to the physical activity and nutrition advices much more positive. Multiple regression analysis revealed that adherence to the physical activity advice was only positively associated with level of physical activity at baseline. Adherence to the nutrition advices was lower among participants who usually do the shopping for their household, participants who feel less susceptible for getting diabetes and younger participants. Improvement of dietary and physical activity behaviors compared to baseline was smallest among those with better baseline behaviors.

\section{Conclusion}

This study once more shows that inadequate adherence is a problem for intervention efficacy. Two possible ways to improve adherence in the present diabetes prevention intervention are to increase perceived susceptibility to getting diabetes and to decrease misconception about own adherence. 
Introduction

The pandemic of type 2 diabetes is an enormous public health problem due to the high prevalence (1), the diabetes-associated morbidity $(2)$ and premature mortality $(3,4)$ and the financial burden $(5,6)$. Lifestyle interventions in subjects at high risk for developing type 2 diabetes, i.e. those with impaired glucose tolerance (IGT), have proven to be cost-effective (7) and effective in reducing diabetes risk by affecting the risk factors for the development of type 2 diabetes (8-10). Important risk factors for the development of type 2 diabetes include a diet low in fiber, high in fat and especially saturated fat $(11,12)$, reduced physical activity, a high body mass index (BMI) (13) and an abdominal fat distribution $(14,15)$.

The Study on Lifestyle intervention and Impaired glucose tolerance Maastricht (SLIM) is a 6 y randomized controlled trial to study the effect of a lifestyle intervention (healthy nutrition, increased physical activity) in adults with IGT in the age 40-65 years. This study has shown to be effective $(10,16,17)$ and the results are comparable to other intervention trials (18). However, non-adherence to lifestyle interventions is a widespread problem (19) in need of clarification so that the success of lifestyle interventions involve the majority of the target group instead of a selected few. Adherence has been defined by WHO as "the extent to which a person's behavior - taking medication, following a diet, and/or executing lifestyle changes, corresponds with agreed recommendations from a health care provider" (19). Estimates of non-adherence range from $0 \%$ to $100 \%$, with $50 \%$ being an average, depending on the patient population, medical condition, form of treatment, and the definition of adherence $(20,21)$. Adherence tends to be low when the regimen is complex, must be followed for a long period of time, requires changes in the person's lifestyle and is designed to prevent rather than cure illness (21). The current SLIM regimen has all these characteristics.

The aims of the present study were to assess adherence to the physical activity and nutrition advices of the SLIM- intervention and to determine personal and environmental factors that may have affected adherence. Factors associated with adherence to nutrition and physical activity advices among IGT subjects have not been studied yet. For the present study potential influencing factors were derived from reviews of earlier studies in related populations and fields, and from a number of influential theoretical models that explain behavior and behavioral change (22-24), because no single model seems to be universally valid $(23,24)$ (see table 5.1 ). Attitudes, social influences, perceived behavioral control, barriers, perceived disease susceptibility and severity, past behavior, family foods rules and responsibilities, intervention characteristics, and participant characteristics were included as potential influencing factors. More insight in the association between these factors and adherence may help to develop targeted lifestyle implementation strategies for the prevention and treatment of diabetes and its related complications (table 5.1). 


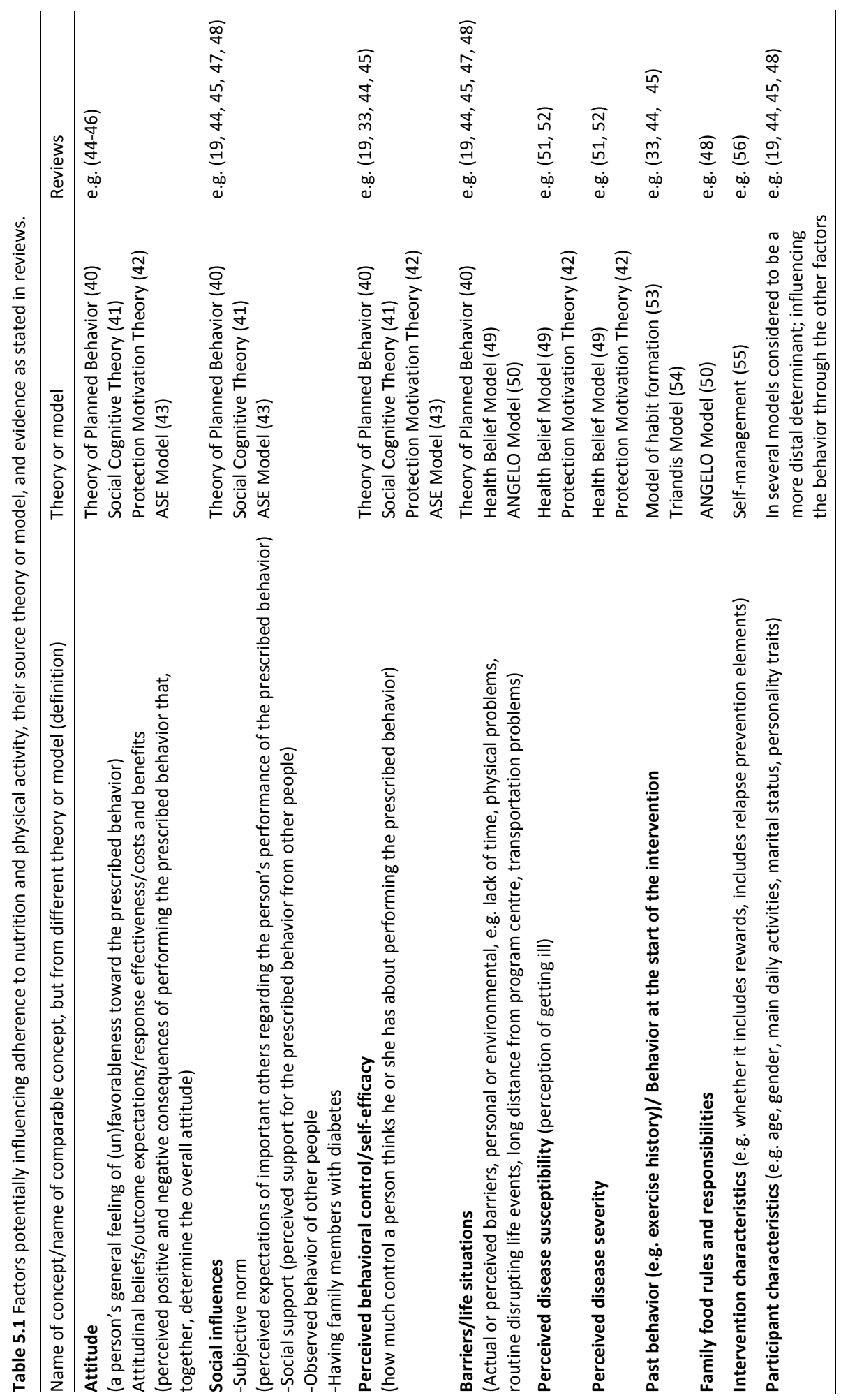


Methods

\section{SLIM Intervention}

The design of the study has been described before (25). Briefly, skilled dieticians conducted every three months one-hour individual counseling sessions with the participants regarding their dietary habits and physical activity at the research institute. Dietary advice was based on the Dutch guidelines for a healthy diet $(26,27)$. The participants were stimulated to consume less than $30-35 \%$ of energy intake as fat, less than $10 \%$ of energy intake as saturated fat, and at least $3 \mathrm{~g} / \mathrm{MJ}$ of fiber a day. In addition, a body weight loss of 5-10 kg was aimed at, depending on degree of obesity. Dietary advice was based on 3-day food records ( 2 weekdays, 1 weekend day) that participants kept before they visited the dietician.

With respect to physical activity, participants were stimulated to be moderateintense physically active for at least 30 minutes on at least five days of the week (28, 29). Individual advice was given (e.g., walking, cycling, swimming) and individual goals were set and evaluated during every visit. Furthermore, participants were encouraged to participate in a Physical Activity Program (PAP) given 3 times a week, especially designed for the study. These free 1-hour PAP sessions consisted of aerobic exercise training and resistance training and were given 3 times a week. A skilled trainer supervised the exercise sessions.

\section{Research population and measures}

Participants were included in the SLIM study in either $1999 / 2000$ or 2002 . The study design has been described in detail previously $(10,30)$. Subjects with an increased risk for glucose intolerance were selected from a cohort in the area of Maastricht, and invited to undergo a capillary standard oral glucose tolerance test (OGTT). Those subjects with a 2-hr blood glucose concentration $>7.8 \mathrm{mmol} / \mathrm{l}$ were invited for a second venous OGTT. For inclusion, mean 2 -hr glucose concentration of both OGTTs had to be between 7.8 and $12.5 \mathrm{mmol} / \mathrm{l}$ and fasting glucose concentration $<7.8 \mathrm{mM}$. Exclusion criteria were known diabetes, glucose concentrations outside the inclusion criteria, chronic illness, medication known to interfere with glucose tolerance, participation in a vigorous exercise and/or diet program.

Subjects were randomized with stratification for sex and mean 2-hr plasma glucose concentration to the intervention group or the control group. All 72 persons from the intervention group with a follow-up of four years (inclusion period 19992000) or two years (inclusion period 2002) were asked to participate in the present study, including the 23 persons that dropped out of the study meanwhile. For the present study, data were derived from the baseline SLIM measurements (time 1: baseline) and the annual measurement that took place between September 2003 and April 2004 (time 2 in the present study) during which the participants completed an adherence questionnaire. 


\section{Measures derived from the annual measurement}

As a measure of adherence to the nutrition advices the daily energy percentage (E\%) of total and saturated fat intake, and fiber intake (g) was derived from weighted 3-day food records. Nutrient intake was calculated using the Dutch food table (NEVO version 1996) (31). For each of the three nutrients an adherence score of one point was given if intake was in accordance with the dietary advice, i.e. below $35 \mathrm{E} \%$ for total fat, below $10 \mathrm{E} \%$ for saturated fat and more than 3 grams per day for fiber intake. An overall adherence score for the nutrition norms was made by summing the scores for the three nutrients (range from 0 to 3 ). Adherence to the physical activity advices was assessed with one item from the Short QUestionnaire to ASsess Health enhancing physical activity (SQUASH), i.e., on how many days a week are you physically active for at least 30 minutes (32). Finally, gender, baseline age, and time since inclusion (4 versus 2 years) were derived from the baseline measurement.

\section{Adherence questionnaire}

The adherence questionnaire was handed out during the time 2 annual measurements or mailed to the persons who dropped out. The participants were asked to complete the questionnaire at home. Participants that returned the questionnaire received a small present.

The adherence questionnaire included measures of potential influencing factors as well as self-rated adherence to the advices. Unless indicated, items were measured with bipolar five-point scales, e.g. completely agree to completely disagree, very easy to very difficult (scored from -2 to 2 ). Participants were asked to keep the last six months in mind in answering the questions. All measures were used in earlier studies and operationalized in accordance with theoretical guidelines (33), but most needed some adaptation to the intervention at hand.

To assess attitude, seven beliefs towards adherence to the physical activity advices were measured (e.g. is important, pleasant, helps to prevent diabetes). Similarly, eleven attitudinal beliefs towards the PAP, six beliefs towards adherence to the nutrition advices, and five beliefs towards the counseling sessions with the dietician were measured. The items were summed and divided by the number of items to obtain four overall attitude scores (Cronbach's $\alpha$ 's ranged from 0.80 to 0.90 ).

Subjective norms were measured by questioning the perceived opinions of household members as well as other family members/friends about whether the study participant should adhere to the physical activity/nutrition advices. Furthermore, observed physical activity and nutrition behavior of household members and other family members/friends as well as their support in adhering to the advices was questioned.

Perceived behavioral control was assessed by asking how easy or difficult it is to adhere to the physical activity and nutrition advices, and to participate in the PAP. Perceived counseling characteristics was assessed with five items, i.e., the dieticians talks with me about the results of adherence, whether my expectations are met, reasons for non-adherence, solutions for better adherence, and gives compliments about the things I do well (Cronbach's $\alpha=0.85$ ). 
For eleven potential barriers it was asked how often the barrier had been a reason for not adhering to the physical activity or nutrition advices, e.g., illness of themselves or others, new job, holidays (Cronbach's $\alpha$ respectively 0.75 and 0.83 ).

As potential environmental barriers to participating in the PAP the participants were questioned about the distance from their home to the sport facilities, transportation issues, and convenience of the times.

Physical activity history was measured by asking how physically active participants were as a child, and as an adult before the start of the project.

Three items questioned prevalence (yes or no) of food rules at home, i.e. rules about eating times, rules that certain products (such as snacks or candy) should not be eaten too often, and rules that certain food products (such as fruit and vegetables) should be eaten regularly. To assess responsibilities in the household it was questioned who usually does the shopping and the cooking.

Diabetes related questions included whether they have family members or friends with diabetes, perceived seriousness of diabetes, and perceived susceptibility for developing diabetes.

As participant characteristics, educational level, household size, and main daily activities were measured.

Finally, participants were asked how often a week/month they participated in the PAP, and two items assessed self-rated adherence, i.e. whether they themselves thought they adhered to respectively the physical activity and nutrition advices well.

\section{Analyses}

The data were analyzed using the SPSS 13.0 (SPSS inc., Chicago, IL, USA). A positive score is believed to correspond with good adherence. To identify causes of dropout, multiple logistic regression of dropout (yes/no) on gender, time of inclusion and age was done.

To assess associations between adherence and potential influential factors, first univariate regression coefficients between the adherence measures and the potential influencing factors were calculated. Only factors with a regression coefficient of a significance level of less than 0.1 were included as independent variables in two backward multivariate linear regression analyses with respectively adherence to the physical activity advices and adherence to the nutrition advices as dependent variable. Similar analyses were conducted with relative measures of adherence as independent variables, i.e. change in number of days physically active for at least 30 minutes compared to baseline and a change in adherence score for the nutrition advices.

Results

Response rates, attrition and participant characteristics

Fifty-nine participants completed the questionnaire ( $82 \%$ response). The mean age of participants at baseline was 44.4 years (range 31-56; SD 5.7) and $54.2 \%$ were male. 


\section{Chapter 5}

Time since inclusion was two years for $27.1 \%$ and four years for $72.9 \%$ of the participants. Almost half $(49.0 \%)$ had a low educational level (primary or basic vocational school), $32.1 \%$ a medium (secondary vocational or high school), and $18.9 \%$ a high educational level (college or university level). Most participants (84.9\%) shared a household with one or more others. About half (47.5\%) had a paid job.

The thirteen persons who did not complete the adherence questionnaire were all SLIM dropouts. Reasons for the 13 persons to dropout were medical problems, time restraints or lack of motivation. Gender, time of inclusion and age were not identified as causes of dropout. Dietary intake and physical activity data from the annual measurement at baseline and present were available for respectively 49 and 48 of the participants. Item non-response was low (0-6 missing values) for most items. For a few items (social influence items towards physical activity, the items about barriers and attitudinal beliefs towards participating in the PAP) non-response was higher (maximum 13 missing values). Scales were calculated accepting missing data for a minority of the items in that scale. Missing data were not substituted.

\section{Adherence}

Table 5.2 shows that two or four years after study inclusion about one third of the participants adhered to the norm on physical activity. Compared to baseline, the percentage participants that adhered to the norm increased by $6.2 \%$. More than $60 \%$ self-rated to adhere to the physical activity advices at least most of the time.

With regard to the dietary advices, almost $70 \%$ of the participants adhered to the norm on total fat intake. The norm on fiber intake and saturated fat intake was reached by more than half and about one third of the participants, respectively. Compared to baseline, percentage adherence to the norm of all three dietary advices increased with more than $20 \%$. Twenty-two percent of the participants adhered to all three advices, representing an increase of $18 \%$. More than $60 \%$ self-rated to adhere to all the nutrition advices at least most of the time. Self-reported participation in the PAP was $60.3 \%$ never, $18.9 \%$ once a week, $13.8 \%$ twice a week and $6.9 \%$ three times a week (table 5.2).

\section{Personal and environmental factors}

Table 5.3 shows that overall participants had positive attitudes, meaning that participants had a general favorable feeling towards the prescribed advices (indicated as a positive value). Participants also had positive scores on perceived subjective norms towards the physical activity advices as well as the nutrition advices, and perceived characteristics of the counseling sessions. Participants had less positive scores on the observed physical activity as well as nutrition behavior of others, perceived support of others in adhering to the physical activity and nutrition advices, their exercise history, self-efficacy towards adhering to the physical activity and nutrition advices, and barriers to come to PAP. Participants indicated that barriers for adhering to the physical activity as well as nutrition advices did not occur very often. 
Food rules were prevalent in most households. Most participants did not usually do the shopping, but about half usually did the cooking.

Regarding diabetes-related variables, getting diabetes was perceived to be very serious, but own susceptibility was rated lower. Most participants had a friend or family member with diabetes (table 5.3).

With regard to specific attitudinal beliefs towards adhering to the physical activity advices (not in table), participants were most positive about 'the importance' and 'pleasantness' and that 'it helps to feel more fit', and least positive about adherence to the physical activity advices as 'being a way to reduce medication'. 'Importance' and that 'it helps to prevent diabetes' were perceived to be the most positive aspects of adherence to the nutrition advices, while 'pleasantness' and 'results of adhering to the nutrition advices in comparison with initial expectations' were evaluated least positive.

With regard to participating in the PAP, the study participants were most positive about 'importance', 'PAP being a separate program' and 'the supervisors'. The least positive scores were given on items questioning whether the PAP is 'pleasant', 'boring', 'childish', 'though', and 'too long'.

With regard to the counseling sessions, the 'expertise of the dietician' and the 'pleasantness' were evaluated most positive. Participants were least positive about whether the sessions 'help to adhere to the advices' and 'are adapted to their daily life'.

Table 5.2 Dietary intake and adherence to the nutrition advices $(n=49)$, and adherence to the physical activity advices $(n=48)$ : mean score $(S D)$ or percentage.

\begin{tabular}{|c|c|c|c|}
\hline & Baseline & $\begin{array}{l}\text { Two/four years } \\
\text { after inclusion }\end{array}$ & Change \\
\hline \multicolumn{4}{|l|}{ Fat } \\
\hline $\begin{array}{l}\text { E\% from fat } \\
\% \text { less than } 35 \text { en\% from fat }\end{array}$ & $\begin{array}{c}35.89(6.79) \\
46.9\end{array}$ & $\begin{array}{c}31.88(5.93) \\
69.4\end{array}$ & $\begin{array}{c}-4.00(7.28) \\
22.5\end{array}$ \\
\hline \multicolumn{4}{|l|}{ Saturated fat } \\
\hline $\begin{array}{l}\text { E\% from saturated fat } \\
\% \text { less than } 10 \text { en\% from saturated fat }\end{array}$ & $\begin{array}{c}13.59(2.98) \\
6.1\end{array}$ & $\begin{array}{l}11.00(2.88) \\
30.6\end{array}$ & $\begin{array}{c}-2.60(3.73) \\
24.5\end{array}$ \\
\hline \multicolumn{4}{|l|}{ Fiber } \\
\hline $\begin{array}{l}\text { fiber (grams) } \\
\% \text { at least } 3 \text { gram }\end{array}$ & $\begin{array}{c}2.68(0.77) \\
28.6\end{array}$ & $\begin{array}{l}3.12(0.82) \\
57.1\end{array}$ & $\begin{array}{l}0.45(0.87) \\
28.5\end{array}$ \\
\hline \multicolumn{4}{|l|}{ Adherence to nutrition advices } \\
\hline score (range 0-3) & $\begin{array}{c}0.82(0.88) \\
4.1\end{array}$ & $\begin{array}{c}1.57(1.02) \\
22.4\end{array}$ & $\begin{array}{c}0.76(1.18) \\
18.3\end{array}$ \\
\hline $\begin{array}{l}\% \text { all nutrition advices } \\
\% \text { self-rated adherence }\end{array}$ & & 62.7 & \\
\hline \multicolumn{4}{|l|}{ Adherence to physical activity advices } \\
\hline number of days physically active & $\begin{array}{c}2.95(2.35) \\
29.2\end{array}$ & $\begin{array}{l}3.11(2.68) \\
35.4\end{array}$ & $\begin{array}{c}0.17(2.81) \\
6.2\end{array}$ \\
\hline $\begin{array}{l}\% \text { at least } 5 \text { days } \\
\% \text { self-rated adherence }\end{array}$ & 29.2 & $\begin{array}{l}35.4 \\
61.4\end{array}$ & 0.2 \\
\hline
\end{tabular}




\section{Chapter 5}

Table 5.3 Factors associated with adherence to SLIM advices: mean score (SD) or percentage ( $n=59)$.

\begin{tabular}{|c|c|}
\hline Variables & Score \\
\hline \multicolumn{2}{|l|}{ Attitude (scales -2 to 2 ) } \\
\hline -physical activity advices & $1.02(0.56)$ \\
\hline -nutrition advices & $0.96(0.53)$ \\
\hline -PAP & $0.97(0.57)$ \\
\hline -counseling sessions & $1.09(0.51)$ \\
\hline \multicolumn{2}{|l|}{ Subjective norm household members (-2 to 2 ) } \\
\hline -physical activity advices & $1.49(0.73)$ \\
\hline -nutrition advices & $1.45(0.80)$ \\
\hline \multicolumn{2}{|c|}{ Subjective norm other family members and friends ( -2 to 2 ) } \\
\hline -physical activity advices & $1.19(0.84)$ \\
\hline -nutrition advices & $1.12(0.83)$ \\
\hline \multicolumn{2}{|l|}{ Behavior household members (-2 to 2$)$} \\
\hline -Physical activity & $0.04(0.85)$ \\
\hline -Nutrition & $0.89(0.60)$ \\
\hline \multicolumn{2}{|c|}{ Behavior other family members and friends (-2 to 2$)$} \\
\hline -physical activity & $0.04(0.77)$ \\
\hline -nutrition & $0.21(0.65)$ \\
\hline \multicolumn{2}{|l|}{ Support household members (-2 to 2 ) } \\
\hline -physical activity advices & $0.63(0.91)$ \\
\hline -nutrition advices & $0.61(0.92)$ \\
\hline \multicolumn{2}{|l|}{ Support other family and friends (-2 to 2 ) } \\
\hline -physical activity advices & $0.09(0.89)$ \\
\hline -nutrition advices & $-0.07(0.74)$ \\
\hline \multicolumn{2}{|l|}{ Perceived behavioral control (-2 to 2$)$} \\
\hline -physical activity advices & $0.31(1.03)$ \\
\hline -PAP & $0.29(1.06)$ \\
\hline -nutrition advices & $0.04(0.89)$ \\
\hline Counseling characteristics (scale $-\mathbf{2}$ to 2 ) & $1.21(0.62)$ \\
\hline \multicolumn{2}{|l|}{ Past exercise (-2 to 2 ) } \\
\hline -as a child & $-0.28(1.08)$ \\
\hline -as an adult & $-0.30(0.94)$ \\
\hline \multicolumn{2}{|c|}{ Occurrence of barriers for adhering to advices (scales 1-5) } \\
\hline -physical activity advices & $4.08(0.53)$ \\
\hline -nutrition advices & $4.19(0.61)$ \\
\hline \multicolumn{2}{|l|}{ Barriers for participating in PAP } \\
\hline -Distance (mean km) & $10.85(20.20)$ \\
\hline$-A$ lot of time for transportation (-2 to 2$)$ & $0.38(1.12)$ \\
\hline -Problems with transportation (-2 to 2 ) & $0.78(1.12)$ \\
\hline -Convenience of times (-2 to 2 ) & $0.18(1.25)$ \\
\hline \multicolumn{2}{|l|}{ Food rules (\% yes) } \\
\hline -when to eat & 63.8 \\
\hline -products that should be eaten met mate & 50.0 \\
\hline -product that should be eaten regularly & 67.2 \\
\hline \multicolumn{2}{|l|}{ Household responsibilities (\% yes) } \\
\hline -Usually do the shopping & 28.0 \\
\hline -Usually do the cooking & 52.8 \\
\hline \multicolumn{2}{|l|}{ Diabetes related variables } \\
\hline -Family or friends with diabetes (\% yes) & 72.9 \\
\hline -Seriousness of getting diabetes $(0-3)$ & $2.41(0.62)$ \\
\hline -Susceptibility for getting diabetes (-2 to 2 ) & $0.38(0.78)$ \\
\hline
\end{tabular}

A positive score indicates a score positive to adherence. 
Table 5.4 shows that only adherence to the physical activity advices at baseline was positively associated with present adherence to the physical activity advices. Number of active days at baseline was negatively associated with change in the number of days that participants were physically active for at least $30 \mathrm{~min}$ compared to baseline. This means that participants who were most active at baseline showed the least increase in number of days physically active.

Usually do the shopping and susceptibility for getting diabetes were negatively associated with adherence to the nutrition advices. Age was positively associated with adherence to the nutrition advices. Usually do the shopping and baseline adherence were negatively associated with change in the adherence score for the nutrition advices compared to baseline (table 5.4).

Table 5.4 Multivariate associations between adherence and personal and environmental factors.

\begin{tabular}{|c|c|c|}
\hline & Standardized $\beta$ & $P$ \\
\hline \multicolumn{3}{|l|}{ Adherence to physical activity advices } \\
\hline Adherence at baseline & 0.40 & 0.01 \\
\hline \multicolumn{3}{|l|}{ Number of active days at baseline } \\
\hline \multicolumn{3}{|l|}{ Adherence to nutrition advices } \\
\hline Usually do the shopping & -0.31 & 0.03 \\
\hline Susceptibility for getting diabetes & -0.49 & 0.00 \\
\hline Age & 0.38 & 0.01 \\
\hline Change in adherence & -0.33 & 0.01 \\
\hline Usually do the shopping & -0.47 & 0.00 \\
\hline Adherence at baseline & & \\
\hline
\end{tabular}

\section{Discussion}

Adherence to the lifestyle advices of the SLIM intervention ranged from 22 to $70 \%$, which is in line with the international literature where estimates of non-adherence have often been found to be quite suboptimal, especially for lifestyle interventions (20, 21).

Adherence to the physical activity advice (being moderately active at least 30 minutes on at least five days a week) was only positively associated with the number of active days at baseline. This is in line with the results of some earlier studies (34). However, increase in number of active days was negatively associated with number of active days at baseline. This might be due to the statistical analyses in which the change of a variable is strongly inversely associated with the baseline value (regression to the mean). Another explanation is a ceiling effect or because of social comparison, i.e. those who are already quite active see that they are more active than other participants, and therefore already quite satisfied with their present behavior. This finding means that treatment efficacy of the physical activity part of the intervention is less in participants with a relatively high initial level of physical activity. 
Adherence to the nutrition advices was lower among participants who usually do the shopping for their household, participants who feel less susceptible for getting diabetes and younger participants. Participants who usually do the shopping also improved less compared to baseline than other participants. There were no differences between men and women with regard the people who usually do the shopping. Similar to the physical activity advices, improvement of dietary habits compared to baseline was smallest among those with better baseline dietary habits. These results indicate that it is important that the dieticians discuss susceptibility with participants and aim to achieve realistic perceptions of the risk of getting diabetes among all participants. This potential fear arousing information should however be balanced with information and strategies to help coping and increase perceived effectiveness of the behavioral changes (35).

Age is not a behavioral determinant that can be changed, but it needs to be realized that adherence to the dietary advices seems to be especially difficult for younger participants. This also applies to those who are responsible for the household shopping. Further research should give insight into why these subgroups have lower adherence rates. Those who do the shopping might for instance face more treats.

An interesting finding is that participants self-rated their adherence to the physical activity advice as well as the nutrition advices much more positive than the more objective measure. Misconceptions of own dietary intake and exercise behavior have been found before in earlier studies, and are a barrier towards desirable behavioral changes (36-38). Aside from reasons of giving socially desirable answers, a possible cause for misconceptions about own dietary intake is that the dietary advice was quite complicated, and people might have needed more personal feedback on whether they achieved the recommendations. It is, however, considered less obvious that people grossly misinterpret the advice to be active at least 30 minutes a day for at least five days a week. Another explanation for misconception might be that people do not compare their behavior with an objective norm, but with other people who are doing worse (39). People need to be made aware of this tendency.

Several factors that were found to be associated with adherence to nutrition and physical activity advices in earlier studies (see table 5.1) were not found to be significant in this study. This might be due to some methodological problems of our study. Due to the small sample size, only a few independent variables could be included in the multivariate tests. We dealt with this by conducting univariate analyses first. Subsequently only a few variables with the highest univariate associations were included in the multivariate test. Nonetheless, the analyses did not have much power.

Another issue is that the sample consisted of two subsamples, i.e., participants who were included two years ago and participants who were included four years ago. The small sample size did not allow subgroup analyses. However, we included time of inclusion as potential determinant in the univariate analyses, but no significant associations were found (data not shown).

We consider the broad conceptual framework including both personal and environmental factors to be a strong point of the study. Many earlier adherence studies tended to be patient blaming by a strong focus on patient-related factors. There has been a relative neglect of environmental factors (19). However, we also had to select out of the many factors that have been suggested in the literature as possible predic- 
tors of adherence. We selected concepts from the most influential theories and models. Reviews of studies into factors associated with adherence to nutrition and physical activity advices in related field and populations were studied for empirical evidence. Our approach is in line with recommendations in the field of health promotion to combine insights from different theories $(24,40)$. However, using concepts from different theories also has a drawback, because the relations between the concepts are no longer taken into account, and no distinction is made between more distal or more proximal determinants. It is because of this that our study cannot provide an explanation why younger participants and participants who are responsible for the household shopping are less adherent.

The descriptive data of the potential influential factors revealed several opportunities for improvement of the intervention, for instance with regard to support from family and friends, perceived behavioral control, and certain beliefs about consequences of adherence. However, aside from the susceptibility and misconception issue, we did not find evidence in the present study that improvements in the SLIM intervention, such as achievement of more social support or more positive attitudinal beliefs would also improve adherence.

\section{Implications}

This study once more shows that inadequate adherence is a problem for intervention efficacy. Two possible ways to improve adherence in the present diabetes prevention intervention are to increase perceived susceptibility to getting diabetes and to decrease misconception about own adherence.

\section{Acknowledgements}

We thank all subjects for their participation in this study and we thank Jos Stegen, Tanja Hermans-Limpens and Marja Ockeloen - van der Hulst for their help during the oral glucose tolerance tests and with the dietary intervention. This work was supported by grants from the Dutch Diabetes Research Foundation (DFN 98.901 and 2000.00.020), the Netherlands Organization for Scientific Research (940-35-034 and 2200.0139). 


\section{Chapter 5}

\section{References}

1. Wild S, Roglic G, Green A, Sicree R, King H. Global prevalence of diabetes: estimates for the year 2000 and projections for 2030. Diabetes Care. 2004 May;27:1047-53.

2. Chaturvedi $\mathrm{N}$. The burden of diabetes and its complications: trends and implications for intervention. Diabetes Research and Clinical Practice. 2007;76:S3-S12.

3. Cusick M, Meleth AD, Agron E, Fisher MR, Reed GF, Knatterud GL, et al. Associations of mortality and diabetes complications in patients with type 1 and type 2 diabetes: early treatment diabetic retinopathy study report no.27. Diabetes Care. 2005;28:617-25.

4. Mulnier HE, Seaman HE, Raleigh VS, Soedamah-Muthu SS, Colhoun HM, Lawrenson RA. Mortality in people with type 2 diabetes in the UK. Diabetes Medicine. 2006;23:516-21.

5. Currie CJ, Poople CD, Woehl A, Morgan CL, Cawley S, Rousculp MD, et al. The financial costs of healthcare treatment for people with Type 1 or Type 2 diabetes in the UK with particular reference to differing severity of peripheral neuropathy. Diabetes Medicine. 2007;24:187-94.

6. Johnson JA, Pohar SL, Majumdar SR. Health care use and costs in the decade after identification of type 1 and type 2 diabetes: a population-based study. Diabetes Care. 2006;29:2403-8.

7. Jacobs-van der Bruggen MA, Bos G, Bemelmans WJ, Hoogenveen RT, Vijgen SM, Baan CA. Lifestyle interventions are cost-effective in people with different levels of diabetes risk: results from a modeling study. Diabetes Care. 2007;30:128-34.

8. Tuomilehto J, Lindstrom J, Eriksson JG, Valle TT, Hamalainen H, Ilanne-Parikka P, et al. Prevention of type 2 diabetes mellitus by changes in lifestyle among subjects with impaired glucose tolerance. $\mathrm{N}$ Engl J Med. 2001 May 3;344:1343-50.

9. Knowler WC, Barrett-Connor E, Fowler SE, Hamman RF, Lachin JM, Walker EA, et al. Reduction in the incidence of type 2 diabetes with lifestyle intervention or metformin. N Engl J Med. 2002 Feb 7;346:393-403.

10. Roumen C, Corpeleijn E, Feskens EJ, Mensink M, Saris WH, Blaak EE. Impact of 3-year lifestyle intervention on postprandial glucose metabolism: the SLIM study. Diabet Med. 2008 May;25(5):597-605.

11. van Dam RM, Rimm EB, Willett WC, Stampfer MJ, Hu FB. Dietary patterns and risk for type 2 diabetes mellitus in U.S. men. Annals of Internal Medicine. 2002;136:201-9.

12. Hu FB, Manson JE, Stampfer MJ, Colditz GA, Liu S, Solomon CG, et al. Diet, lifestyle, and the risk of type 2 diabetes mellitus in women. New England Journal of Medicine. 2001;345:790-7.

13. Colditz GA, Willett WC, Rotnitzky A, Manson JE. Weight gain as a risk factor for clinical diabetes mellitus in women. Annals of Internal Medicine. 1995;122:481-6.

14. Chan JM, Rimm EB, Colditz GA, Stampfer MJ, Willett WC. Obesity, fat distribution, and weight gain as risk factors for clinical diabetes in men. Diabetes Care. 1994;17:961-9.

15. Han TS, Feskens EJM, Lean ME, Seidell JC. Associations of body composition with type 2 diabetes mellitus. Diabetic Medicine. 1998;15:129-35.

16. Mensink M, Blaak EE, Corpeleijn E, Saris WH, T.W. dB, Feskens EJM. Lifestyle intervention according to general recommendations improves glucose tolerance. Obesity Research. 2003;11:1588-96.

17. Mensink M, Feskens EJM, Saris WH, de Bruin TW, Blaak EE. Study on Lifestyle Intervention and Impaired Glucose Tolerance Maastricht (SLIM): preliminary results after one year. International Journal of Obesity and Related Metabolic Disorders. 2003;27:377-84.

18. Gillies CL, Abrams KR, Lambert PC, Cooper NJ, Sutton AJ, Hsu RT, et al. Pharmacological and lifestyle interventions to prevent or delay type 2 diabetes in people with impaired glucose tolerance: systematic review and meta-analysis. British Medical Journal. 2007;334:299.

19. WHO. Adherence to long-term therapies: Evidence for action. Geneva: WHO; 2003.

20. Myers LB, Midence K. Concepts and issues in adherence. In: Myers LB, Midence K, editors. Adherence to treatment in medical conditions. Amsterdam: Harwood Academic Publishers; 1998. p. 1-24.

21. Bosworth HB, Weinberger M, Oddone EZ. Introduction. In: Bosworth HB, Oddone EZ, Weinberger M, editors. Patient treatment adherence: Concepts, interventions, and measurement. Mahwah: Lawrence Erlbaum Associates; 2006. p. 3-11.

22. Clark NM, Becker MH. Theoretical models and strategies for improving adherence and disease management. In: Shumaker SA, Schron EB, Ockene JK, McBee WL, editors. The handbook of health behavior change: Springer Publishing Company; 2004. p. 5-32.

23. Horne R, Weinman J. Predicting treatment adherence: An overview of theoretical models. In: Myers LB, Midence K, editors. Adherence to treatment in medical conditions. Amsterdam: Harwood Academic Publishers; 1998. p. 25-50. 
24. Bosworth $\mathrm{HB}$, Voils $\mathrm{Cl}$. Theoretical models to understand treatment adherence. In: Bosworth HB, Oddone EZ, Weinberger M, editors. Patient treatment adherence: Concepts, interventions, and measurement. Mahwah: Lawrence Erlbaum Associates; 2006. p. 13-46.

25. Mensink M, Corpeleijn E, Feskens EJ, Kruijshoop M, Saris WH, de Bruin TW, et al. Study on lifestyleintervention and impaired glucose tolerance Maastricht (SLIM): design and screening results. Diabetes Res Clin Pract. 2003 Jul;61(1):49-58.

26. Dutch Nutrition Council. Adviesrichtlijnen goede voeding (Advice guidelines healthy nutrition). Den Haag: Dutch Nutrition Council; 1986.

27. Health Council of the Netherlands. Guidelines for a healthy diet 2006. Den Haag: Health Council of the Netherlands; 2006.

28. Pate RR, Pratt M, Blair SN. Physical activity and public health: a recommendation from the Centers for Disease Control and Prevention and the American College of Sports Medicine. Journal of the American Medical Association. 1995;273:402-7.

29. Kemper HCG, Ooijendijk WTM, Stiggelbout M. Consensus about the Dutch recommendation for physical activity to promote health (Consensus over de Nederlandse norm gezond bewegen). Tijdschrift voor Gezondheidswetenschappen. 2000;78:180-3.

30. Mensink M, Blaak EE, Corpeleijn E, Saris WH, de Bruin TW, Feskens EJ. Lifestyle intervention according to general recommendations improves glucose tolerance. Obes Res. 2003 Dec;11(12):1588-96.

31. Voedingsstoffenbestand. SN. Nederlands voedingsstoffenbestand NEVO tabel 1996. Den Haag, The Netherlands: Voorlichtingsbureau voor de voeding.; 1998.

32. Wendel-Vos GC, Schuit AJ, Saris WH, Kromhout D. Reproducibility and relative validity of the short questionnaire to assess health-enhancing physical activity. Journal of Clinical Epidemiology. 2003;56:1163-9.

33. Conner M, Norman P, editors. Predicting health behaviour. Berkshire: Open University Press; 2005.

34. Martin KA, Sinden AR. Who will stay and who will go? A review of older adults' adherence to randomized controlled trials of exercise. Journal of Aging and Physical Activity. 2001;9:91-114.

35. Ruiter RA, Kok G, Verplanken B, Brug J. Evoked fear and effects of appeals on attitudes to performing breast self-examination: an information-processing perspective. Health Education Research. 2001;16:307-19.

36. Brug J, van Assema P, Kok G, Lenderink T, Glanz K. Self-rated dietary fat intake: Associations with objective assessment of fat, psychosocial factors, and intention to change. Journal of Nutrition Education. 1994;26:218-23.

37. Lechner L, Brug J, de Vries H. Misconceptions of fruit and vegetable consumption: Differences between objective and subjective estimation of intake. Journal of Nutrition Education. 1997;29:313-20.

38. Lechner L, Bolman C, van Dijke M. Factors related to misperception of physical activity in The Netherlands and implications for health promotion programmes. Health Promotion International. 2006;21:104-12.

39. Oenema A, Brug J. Exploring the occurence and nature of comparison of one's own perceived dietary fat intake to that of self-selected others. Appetite. 2003;41:259-64.

40. Glanz K, Rimer BK. Theory at a glance: A guide for health promotion practice. NIH publ. no. 92-3316. Bethesda: National Cancer Institute; 1995.

41. Ajzen I. Attitude, personality, and behavior: Milton Keynes: Open University Press; 2005.

42. Bandura A. Social Foundations of thought and action. A social cognitive theory. Englewood Cliffs, N.J.: Prentice Hall; 1986.

43. Rogers RW. Cognitive and physiological processes in fear appeals and attitude change: A revised theory of protection motivation. In: Cacioppo JT, Petty RE, editors. Social psychophysiology: A source book. New York: Guilford Press; 1983. p. 153-76.

44. de Vries H, Dijkstra M, Kuhlman P. Self-efficacy: the third factor besides attitude and subjective norm as a predictor of behavioural intentions. Health Education Research. 1988;3:273-82.

45. Dominick KL, Morey M. Adherence to physical activity. In: Bosworth HB, Oddone EZ, Weinberger M, editors. Patient treatment adherence: Concepts, interventions, and measurement. Mahwah: Lawrence Erlbaum Associates; 2006. p. 49-94.

46. Jones F, Harris P, McGee L. Adherence to prescribed exercise. In: Myers LB, Midence K, editors. Adherence to treatment in medical conditions. Amsterdam: Harwood Academic 1998. p. 343-62.

47. Nicholson Perry K, Rapoport L, Wardle J. Adherence to lipid-lowering dietary advice. Adherence to treatment in medical conditions. Amsterdam: Harwood Academic Publishers; 1998. p. 311-42. 


\section{Chapter 5}

48. Landel-Graham J, Yount SE, Rudnicki SR. Diabetes Mellitus. In: Nezu AM, Maguth Nezu C, Geller PA, editors. Handbook of psychology, volume 9: Health psychology. Hoboken: John Wiley \& Sons; 2002. p. 191-217.

49. Yancy WS, Boan J. Adherence to diet recommendations. In: Bosworth HB, Oddone EZ, Weinberger M, editors. Patient treatment adherence: Concepts, interventions, and measurement. Mahwah: Lawrence Erlbaum Associates; 2006. p. 95-124.

50. Rosenstock IM. The health belief model and preventive health behavior. Health Education Monographs. 1974;2:354-86.

51. Swinburn B, Egger G, Raza F. Dissecting obesogenic environments: the development and application of a framework for identifying and prioritizing environmental interventions for obesity. Prev Med. 1999 Dec;29(6 Pt 1):563-70.

52. Janz NK, Becker MH. The health belief model : a decade later. Health Education Quarterly. 1984;11:147.

53. Floyd DL, Prentice-Dunn S, Rogers RW. A meta-analysis of research on protection motivation theory. Journal of Applied Social Psychology. 2000 Feb;30(2):407-29.

54. Aarts H, Paulussen T, Schaalma H. Physical exercise habit: on the conceptualization and formation of habitual behaviors. Health Education Reserach. 1997;12:363-74.

55. Triandis HC. Values, attitude, and interpersonal behavior. In: Howe HE, editor. Nebraska Symposium on Motivation. Lincoln: University of Nebraska Press; 1980.

56. Mesters I, Creer T, Gerards F. Self-management and respiratory disorders, guiding patients from health counseling and self-management perspectives. In: Kaptein A, Creer T, editors. Respiratory disorders and behavioral medicine. London: Matin Dunitz; 2002.

57. Norris SL, Engelgau MM, Narayan KM. Effectiveness of self-management training in type 2 diabetes: a systematic review of randomized controlled trials. Diabetes Care. 2001 Mar;24(3):561-87. 


\section{LIFESTYLE INTERVENTION, 1-YEAR CHANGES IN GLUCOSE TOLERANCE AND INFLAMMATORY AND IMMUNE MARKERS}

The SLIM study

Cheryl Roumen, Eva Corpeleijn, Edith J.M. Feskens, Eugène H.J.M. Jansen, Wim H. M. Saris, Ellen E. Blaak.

submitted 


\section{Chapter 6}

Abstract

Objective

To evaluate whether changes in glucose tolerance and insulin resistance are related to changes in inflammation and immune markers in Dutch subjects with impaired glucose tolerance (IGT).

\section{Method}

In the Study of Lifestyle intervention and Impaired glucose tolerance Maastricht (SLIM), 147 IGT subjects were randomized to a lifestyle intervention, directed towards diet and physical activity, or a control group. From 104 subjects at baseline and after 1y, glucose tolerance, body weight, anthropometric measurements, maximal aerobic capacity, C-reactive protein (CRP), interleukin-6 (IL-6), complement factor 3 (C3) and 4 (C4), and plasminogen activator inhibitor-1 (PAI-1) concentrations were determined. Insulin resistance was estimated using the homeostasis model assessment for insulin resistance (HOMA-IR).

\section{Results}

$\Delta 2$-hr Glucose was positively related with $\Delta \mathrm{CRP}, \Delta \mathrm{IL}-6, \Delta \mathrm{C} 3, \Delta \mathrm{C} 4$, independent of $\Delta$ body weight, $\Delta$ saturated fat intake, $\Delta$ maximal aerobic capacity, age, medication use, smoking status. The relation between $\Delta \mathrm{IL}-6$ and 2-hr glucose was independent of the other markers. $\triangle \mathrm{HOMA}-\mathrm{IR}$ was related to $\triangle \mathrm{PAI}-1$ and $\triangle \mathrm{C} 3$, but this relation disappeared after correction for $\Delta$ body weight.

\section{Conclusion}

The 1-year lifestyle intervention effectively reduced body weight and 2-hr glucose levels, but did not change CRP, IL-6, C3 and C4 levels. These latter inflammation factors were related to reductions in 2-hr glucose levels, not affected by lifestyle changes. Change in IL-6 was the only marker related with the change in 2-hr glucose, independent of the other markers, supporting the concept that IL-6 may be considered as a 'nontraditional' risk marker in the etiology of glucose intolerance. 
Introduction

With global rates of type 2 diabetes mellitus rising, it has become essential to understand its etiology in order to obtain clues for a more effective prevention or treatment. Lifestyle interventions have already proven to be effective in the prevention of type 2 diabetes in subjects with impaired glucose tolerance (IGT) (1). The Study on Lifestyle intervention and Impaired glucose tolerance Maastricht (SLIM) has shown that changes in nutritional intake and physical activity according to general guidelines results in a sustained improvement in 2-hr glucose values in subjects at high risk for type 2 diabetes $(2,3)$. Furthermore, sustained lifestyle changes and a reduction in diabetes incidence are observed after a lifestyle intervention, even after discontinuation of active counseling (4). Information on the underlying mechanisms, responsible for the positive lifestyle effect and on determinants of intervention success may provide information for a more personalized intervention and a more targeted implementation into the health care system.

There is increasing evidence that markers of low-grade inflammation and fibrinolysis, i.e. interleukin-6 (IL-6), C-reactive protein (CRP) and plasminogen activator inhibitor 1 (PAI-1), are related to the insulin resistant state (5) and predict the development of type 2 diabetes (6-9). Increased IL-6 levels seem to predict future risk of type 2 diabetes, although CRP may be a stronger predictor than IL-6 $(7,10,11)$. Also, high PAl-1 levels are associated with diabetes incidence, which is mediated by body weight and insulin resistance (12). In addition, the complement system may be involved in the development of type 2 diabetes, since complement factor 3 (C3) was associated with diabetes development in middle-aged men (13). Additionally, C3 and complement factor 4 (C4) are expressed in adipose tissue with a high expression in intra-abdominal adipose tissue of obese men, suggesting that (visceral) adipose tissue may mediate the relationship between $\mathrm{C} 3$ and diabetes risk (14).

Until now, several studies have shown that lifestyle interventions can reduce CRP $(15,16)$, IL-6 $(15,17)$ and PAI-1 levels $(18,19)$. To the best of our knowledge, only mechanistic and population-based cohort studies have provided evidence for a relationship between elevated levels of C3 and diabetes development, whereas the effect of lifestyle interventions on C3 are still unknown. The aim of this study was to evaluate the 1-yr effect of a lifestyle intervention based on general public health recommendation towards a healthy diet and physical activity level and to evaluate if the individual outcome of the intervention may be partly reflected in the plasma profile of immunological and inflammatory markers. Therefore, the present study investigated the effect of the lifestyle intervention on CRP, IL-6, C3, C4 and PAI-1 and investigated to what extent these markers are related to observed changes in glucose tolerance and insulin resistance.

\section{Methods}

The SLIM study (Study on Lifestyle Intervention and Impaired Glucose Tolerance Maastricht) is a randomized controlled trial, designed to study whether a 6-yr combined dietary and physical activity intervention program can improve glucose tolerance 
in IGT subjects. This paper will present data from the 104 subjects who completed the 1-year intervention and on whom complete data of inflammation markers was available. In addition, changes in body composition, fasting and 2-hr insulin and plasma glucose concentrations, free fatty acid levels and maximal aerobic capacity were determined. The Medical Ethical Review Committee of Maastricht University approved the study protocol and all subjects gave their written informed consent before the start of the study.

\section{Study design and subjects}

The study design has been described in detail previously (20). Briefly, subjects with an increased risk for glucose intolerance, e.g. family history of diabetes, age $>40$ years, $\mathrm{BMI}>25 \mathrm{~kg} / \mathrm{m} 2$, were selected from a cohort in the area of Maastricht, and invited to undergo a capillary standard Oral Glucose Tolerance Test (OGTT) (response rate $46.2 \%$, see reference (20)). Those subjects with a 2-hr blood glucose concentration $>7.8 \mathrm{mM}$ were told their status and invited for a second venous OGTT after and overnight fast. For inclusion, mean 2-hr glucose concentration of both OGTTs had to be between 7.8 and $12.5 \mathrm{mM}$ and fasting glucose concentration $<7.8 \mathrm{mM}$. Data obtained during the second (venous) OGTT were used as baseline values. Exclusion criteria were known diabetes, glucose concentrations outside the inclusion criteria, chronic illness known to interfere with glucose tolerance or that makes participation of a lifestyle intervention and/or 5-year survival improbable, medication known to interfere with glucose tolerance, and participation in a vigorous exercise and/or diet program. The study population consisted of 147 subjects. Subjects were randomized with stratification for sex and mean 2-hr plasma glucose concentration to the intervention group (INT: 74 subjects; 38 male, 36 female) or the control group (CON: 73 subjects; 37 male, 36 female). It was calculated, according to the preliminary results after 1 year of the Finnish DPS (21), that 50-60 subjects per group would be sufficient to detect a $1.0 \mathrm{mmol} / \mathrm{l}$ difference in 2-hr glucose concentration between groups. Data analyses of these 1-year results include 104 subjects: 51 INT subjects and 53 CON subjects on whom complete data were available. Data of 43 subjects were not included in the analyses due to incomplete data for regression analysis $(n=27)$ and dropout $(n=16,10$ INT: 3M/7F, 6 CON: $5 \mathrm{M} / 1 \mathrm{~F}$ ). The latter subjects did not complete the first year due to lack of time in 6 cases, medical reasons in 5 cases, lack of motivation in 2 cases, dissatisfaction in 2 cases and lack of mobility in 1 case. Between excluded and included subjects, i.e. between dropouts and completers, there were no differences in age, BMI, 2-hr glucose levels, homeostasis model assessment for insulin resistance (HOMA-IR, calculation based on fasting glucose and insulin levels), saturated fat intake, CRP, IL-6, C3, C4 and PAI-1. Dropouts had a lower maximal aerobic capacity at baseline compared to completers $(p=0.01)$.

\section{Lifestyle Intervention}

The intervention program consisted of a dietary and physical activity part. Dietary recommendations were based on the Dutch guidelines for a healthy diet (Dutch Nutri- 
tion Council) and consisted of a carbohydrate intake of at least 55 energy\% (E\%), a total fat intake of 30-35 E\%, with a saturated fat intake below $10 \mathrm{E} \%$. A skilled dietician gave personal dietary advice during a one-hour counseling session every 3 months, after consideration of a 3-day food record (two weekdays, one weekend day). In addition, subjects received individual advice on how to increase their level of physical activity to at least 30 minutes a day for at least 5 days a week (22). Furthermore, subjects were encouraged to participate in a free, supervised combined aerobic- and resistance exercise program, especially designed for this study. Three times a year subjects were asked to participate in the exercise program using heart rate monitoring and continuous registration to validate the exercise intensity, which was approximately $70 \%$ of their maximal peak oxygen consumption $\left(\mathrm{VO}_{2} \mathrm{max}\right)$. Control subjects were only briefly informed about the beneficial effects of a healthy diet and physical activity, whereas no individual advice was provided.

\section{Measurements and Biochemical analyses}

Body weight was measured with an electronical scale to the nearest $0.1 \mathrm{~kg}$. Waist was measured to the nearest $0.5 \mathrm{~cm}$, with the subject in standing position at the level midway between the lowest rib and the iliacal crest. Blood pressure was measured with a Maxi Stabil 3 pressostabil (CE0047, Speidel en Keller, Jungingen, Germany) in duplo with the subject in supine position, after 10 minutes of rest. The 3-day food records were analyzed for nutrient intake using the Dutch food table (NEVO version 1996). An incremental exhaustive exercise test was performed on an electronically braked bicycle ergometer to determine maximal peak oxygen consumption ( $\left.\mathrm{VO}_{2} \mathrm{max}\right)$. Changes in glucose tolerance were studied using an OGTT, as explained above. Plasma glucose and free fatty acids (FFA) were measured in the fasting state and after 2 hours, using a standard enzymatic technique, automated on a Cobas Fara centrifugal analyzer (intra assay coefficient variation for glucose was $1.50 \%$, the inter-assay coefficient variation was 3.66\%). Plasma insulin concentration was measured with a Radio Immuno Assay (Cat. \#HI-14K, Linco Research, St. Charles, MO, USA) that shows no crossreactivity with pro-insulin. The HOMA-IR index for insulin resistance was calculated as described by Matthews et al.(23). Glycated haemoglobin (HBA1c) was determined in a fasting serum sample with high-performance liquid chromatography (reference values for our laboratory 4.4-6.2\%). hsCRP, C3 and C4 were measured in duplicate in fasting serum using an autoanalyser (Hitachi 912, Roche Diagnostics, Almere, The Netherlands). IL-6 was measured in duplicate in fasting EDTA plasma with a high-sensitive ELISA assay (R\&D systems, Abingdon, United Kingdom). PAI-1 was measured in duplicate in fasting EDTA plasma with an ELISA assay (Zymutest, Hyphen Biomed, NEUVILLESUR-OISE, France).

\section{Statistical analysis}

SPSS for Windows (version 14.1) was used for statistical analysis. Insulin, FFA concentrations and CRP, IL-6, C3, C4 were not normally distributed and were therefore Intransformed. Data are presented as mean \pm SD; non-linear variables are expressed as 


\section{Chapter 6}

median $\left(25^{\text {th }}-75^{\text {th }}\right.$ percentile). Differences between groups were tested with a Student's $t$ test for independent samples or by a $\chi^{2}$ test when applicable. ANOVA was used to assess the effect of group, time and group $x$ time interaction. Adjustment for dichotomous variables in the linear regression analyses was done using dummy variables. Adjustment for lifestyle changes in the multiple linear regression analyses was done by inclusion of three different variables representing changes in body weight, dietary pattern and physical fitness. A p-value of less than 0.05 was considered statistically significant. All tests were two-sided.

\section{Results}

\section{General lifestyle effects}

At baseline, no differences were seen in subject' characteristics apart from age, which was higher in the control group compared to the intervention group $(p=0.02)$ (table 6.1). After 1 year, body weight decreased in intervention subjects from $87.7 \mathrm{~kg}$ to 84.1 $\mathrm{kg}$, whereas a smaller decrease was observed in the control subjects $(p=0.004$, time $x$ group interaction, table 6.1). 2-Hour plasma glucose levels decreased in the intervention group from $8.9 \pm 2.2 \mathrm{mM}$ at baseline to $8.4 \pm 1.7 \mathrm{mM}$ after 1 year. In the control group an increase was seen from $8.1 \pm 2.1 \mathrm{mM}$ at baseline to $8.8 \pm 2.3 \mathrm{mM}$ after 1 year ( $p=0.006$ time $x$ group interaction). 2 -hr Insulin levels showed a significant reduction in the intervention group compared to the control group $(p=0.004)$. No differences between groups were observed in fasting plasma glucose, HBA1c, fasting insulin and HOMA-IR (table 6.1). No subjects developed type 2 diabetes (fasting glucose $>7.0$ $\mathrm{mmol} / \mathrm{l}$ and/or 2 -hr glucose $>11.1 \mathrm{mmol} / \mathrm{l}$ ) during the first year of study.

In line with the reduction in body weight, total fat intake and saturated fat intake decreased significantly more in the intervention subjects and carbohydrate intake and fiber intake increased more in the intervention subjects, compared to the control subjects $\left(p_{\text {all }}<0.01\right.$, table 6.2$)$.

Changes in CRP, IL-6, C3, C4 and PAI-1 did not differ between study groups ( $p_{\text {all }}>0.05$, table 6.1).

\section{Inflammation and immune markers and glucose tolerance}

We evaluated if the individual outcome of the intervention, i.e. changes in 2-hr glucose levels and changes in HOMA-IR, are reflected in the plasma profile of immunological and inflammatory markers. Since the randomization, i.e. lifestyle intervention or control, did not affect the levels of CRP, IL-6, C3 and C4 and PAI-1, study groups were combined (total group, $n=104$ ). In the total group, 1-year changes in CRP, IL-6, C3 $\left(p_{\text {all }}<0.01\right)$ and to a lesser extend $C 4(p<0.05)$ were significantly positively related with changes in 2-hr glucose levels (table 6.3, crude analysis). The associations between $\Delta \mathrm{IL}-$ 6 and $\Delta C 3$ and $\Delta 2-\mathrm{hr}$ glucose were similar when tested in the intervention group separately (data not shown). When these analyses were adjusted for three major aspects of the lifestyle intervention, i.e. changes in body weight, saturated fat intake 
Inflammatory factors and lifestyle intervention

Table 6.1 Participant characteristics at baseline and after 1 year of the Dutch SLIM lifestyle intervention.

\begin{tabular}{|c|c|c|c|c|c|c|c|c|}
\hline & & \multicolumn{2}{|c|}{ Intervention group } & \multicolumn{2}{|c|}{ Control group } & \multicolumn{3}{|c|}{$\mathrm{P}$} \\
\hline & & Baseline & After 1 year & Baseline & After 1 year & Group & Time & $\begin{array}{l}\text { Group } \\
\text { x Time }\end{array}$ \\
\hline Men/women (n) & & $31 / 20(51)$ & $31 / 20(51)$ & $31 / 22(53)$ & $31 / 22(53)$ & 0.81 & - & - \\
\hline Smokers & $(\%)$ & 14 & 12 & 13 & 23 & 0.49 & 0.51 & 0.02 \\
\hline $\begin{array}{l}\text { Medication use } \\
\text { for blood pressure }\end{array}$ & (\%) & 27 & 33 & 23 & 25 & 0.55 & 0.06 & 0.35 \\
\hline $\begin{array}{l}\text { Medication use } \\
\text { for blood lipids }\end{array}$ & (\%) & 6 & 10 & 8 & 11 & 0.78 & 0.10 & 0.99 \\
\hline Age & (years) & $55.6 \pm 6.0$ & - & $58.7 \pm 1.0^{*}$ & - & 0.02 & - & - \\
\hline Body weight & (kg) & $87.7 \pm 13.1$ & $85.1 \pm 12.7$ & $84.1 \pm 13.1$ & $83.5 \pm 12.1$ & 0.30 & 0.00 & $<0.01$ \\
\hline BMI & $\left(\mathrm{kg} / \mathrm{m}^{2}\right)$ & $29.7 \pm 3.5$ & $28.8 \pm 3.4$ & $29.5 \pm 3.6$ & $29.3 \pm 3.2$ & 0.82 & $<0.01$ & 0.01 \\
\hline Waist & $(\mathrm{cm})$ & $103.8 \pm 9.9$ & $100.3 \pm 10.2$ & $103.3 \pm 10.0$ & $101.8 \pm 10.2$ & 0.78 & $<0.02$ & 0.05 \\
\hline VO2 max & $(1 / \min )$ & $2.3 \pm 0.6$ & $2.4 \pm 0.6$ & $2.1 \pm 0.5$ & $2.1 \pm 0.6$ & 0.06 & 0.00 & 0.02 \\
\hline Fasting glucose & $(\mathrm{mmol} / \mathrm{l})$ & $6.1 \pm 0.9$ & $6.0 \pm 0.9$ & $5.8 \pm 0.6$ & $5.9 \pm 0.6$ & 0.21 & 0.77 & 0.06 \\
\hline 2-hr Glucose & $(\mathrm{mmol} / \mathrm{l})$ & $8.9 \pm 2.2$ & $8.1 \pm 2.1$ & $8.4 \pm 1.7$ & $8.8 \pm 2.3$ & 0.75 & 0.34 & $<0.01$ \\
\hline HBA1c & (\%) & $6.0 \pm 0.5$ & $5.8 \pm 0.4$ & $5.9 \pm 0.5$ & $5.7 \pm 0.5$ & 0.35 & $<0.01$ & 0.24 \\
\hline Fasting insulin & $(\mathrm{mU} / \mathrm{l})$ & $\begin{array}{c}17.8 \\
(11.4 ; 21.8)\end{array}$ & $\begin{array}{c}15.3 \\
(9.9 ; 20.8)\end{array}$ & $\begin{array}{c}16.7 \\
(11.4 ; 22.7)\end{array}$ & $\begin{array}{c}16.0 \\
(10.3 ; 22.6)\end{array}$ & 0.55 & 0.13 & 0.12 \\
\hline 2-hr Insulin & $(\mathrm{mU} / \mathrm{l})$ & $\begin{array}{c}88.5 \\
(60.0 ; 120.6)\end{array}$ & $\begin{array}{c}66.9 \\
(47.2 ; 101.4)\end{array}$ & $\begin{array}{c}82.0 \\
(61.3 ; 122.7)\end{array}$ & $\begin{array}{c}95.1 \\
(59.5 ; 139.7)\end{array}$ & 0.09 & 0.96 & $<0.01$ \\
\hline HOMA-IR & & $\begin{array}{c}4.8 \\
(3.1 ; 6.0)\end{array}$ & $\begin{array}{c}4.0 \\
(2.6 ; 5.9)\end{array}$ & $\begin{array}{c}4.3 \\
(2.8 ; 5.9)\end{array}$ & $\begin{array}{c}4.2 \\
(2.5 ; 5.8)\end{array}$ & 0.80 & 0.27 & 0.08 \\
\hline FFA & $(\mu \mathrm{mol} / \mathrm{l})$ & $\begin{array}{c}562 \\
(459 ; 682)\end{array}$ & $\begin{array}{c}435 \\
(366 ; 572)\end{array}$ & $\begin{array}{c}549 \\
(421 ; 663)\end{array}$ & $\begin{array}{c}483 \\
(386 ; 585)\end{array}$ & 0.99 & $<0.01$ & 0.13 \\
\hline 2-hr FFA & $(\mu \mathrm{mol} / \mathrm{l})$ & $\begin{array}{c}100 \\
(79 ; 126)\end{array}$ & $\begin{array}{c}72 \\
(60 ; 89)\end{array}$ & $\begin{array}{c}100 \\
(74 ; 121)\end{array}$ & $\begin{array}{c}78 \\
(60 ; 108)\end{array}$ & 0.65 & $<0.01$ & $<0.01$ \\
\hline CRP & $(\mathrm{mg} / \mathrm{l})$ & $\begin{array}{c}2.6 \\
(1.3 ; 4.9)\end{array}$ & $\begin{array}{c}2.5 \\
(0.8 ; 4.9)\end{array}$ & $\begin{array}{c}3.1 \\
(1.3 ; 4.8)\end{array}$ & $\begin{array}{c}2.5 \\
(1.7 ; 4.8)\end{array}$ & 0.13 & 0.39 & 0.11 \\
\hline IL-6 & $(\mathrm{pg} / \mathrm{ml})$ & $\begin{array}{c}1.5 \\
(1.1 ; 2.0)\end{array}$ & $\begin{array}{c}1.4 \\
(1.0 ; 1.9)\end{array}$ & $\begin{array}{c}1.6 \\
(1.2 ; 2.6)\end{array}$ & $\begin{array}{c}1.8 \\
(1.2 ; 2.3)\end{array}$ & 0.06 & 0.27 & 0.34 \\
\hline C3 & $(\mathrm{g} / \mathrm{l})$ & $\begin{array}{c}1.3 \\
(1.1 ; 1.4)\end{array}$ & $\begin{array}{c}1.3 \\
(1.1 ; 1.4)\end{array}$ & $\begin{array}{c}1.3 \\
(1.1 ; 1.4)\end{array}$ & $\begin{array}{c}1.3 \\
(1.1 ; 1.4)\end{array}$ & 0.93 & 0.69 & 0.21 \\
\hline C4 & $(\mathrm{g} / \mathrm{l})$ & $\begin{array}{c}0.3 \\
(0.2 ; 0.3)\end{array}$ & $\begin{array}{c}0.3 \\
(0.2 ; 0.3)\end{array}$ & $\begin{array}{c}0.3 \\
(0.3 ; 0.3)\end{array}$ & $\begin{array}{c}0.3 \\
(0.3 ; 0.3)\end{array}$ & 0.95 & 0.47 & 0.21 \\
\hline PAI-1 & (ng/ml) & $\begin{array}{c}46.0 \\
(38.5 ; 60.3)\end{array}$ & $\begin{array}{c}48.4 \\
(39.3 ; 57.3)\end{array}$ & $\begin{array}{c}46.7 \\
(33.1 ; 53.0)\end{array}$ & $\begin{array}{c}48.8 \\
(40.5 ; 55.0)\end{array}$ & 0.55 & 0.33 & 0.12 \\
\hline
\end{tabular}

Data are Mean \pm SD, $n=104$. Fasting insulin, 2-hr insulin, HOMA-IR, FFAs, CRP, IL-6, C3, C4 and PAI-1 are expressed as median (25th percentile; 75 th percentile. 


\section{Chapter 6}

and maximal aerobic capacity, as well as age, medication use and smoking status, all aforementioned associations remained significant (table 6.3, adjusted). Replacement of body weight by BMI and inclusion of gender in these models did not affect the outcomes significantly. To estimate which of these markers had an independent contribution on the change in 2-hr glucose levels, we carried out stepwise linear regression analysis in a model that included $\Delta \mathrm{CRP}, \Delta \mathrm{IL}-6, \Delta \mathrm{C} 3, \Delta \mathrm{C} 4$, age, smoking status, mean value 2 -hr glucose of concentrations, $\Delta$ bodyweight, $\Delta$ saturated fat intake and $\Delta \mathrm{VO}_{2}$ max. Of all the inflammation markers, only $\Delta \mathrm{IL}-6$ was independently associated with $\Delta 2$-hr glucose. Delta IL-6 explained $6.7 \%$ of the variation in glucose tolerance. Also in the intervention group separately, IL- 6 was the only marker significantly associated with $\Delta 2$-hr glucose when adjusting for the aforementioned lifestyle changes $(p=0.04$, data not shown).

CRP levels above $10 \mathrm{mg} / \mathrm{ml}$ may be indicative of infection. To investigate whether the association between CRP and 2-hr glucose was not mediated by the acute-phase response, 10 subjects ( 7 INT: 5F/2M, 3 CON: $1 F / 2 M$ ) were excluded with CRP levels above $10 \mathrm{mg} / \mathrm{ml}$ at baseline or at year 1 . Exclusion of these subjects abolished the significant correlation between $\Delta C R P$ and $\Delta 2-h r$ glucose $(\beta=0.131 \mathrm{mmol} / \mathrm{l}, \mathrm{p}=0.19)$.

Table 6.2 Energy intake, based on 3-day food records, of participants of the SLIM lifestyle intervention at baseline and after 1 year.

\begin{tabular}{|c|c|c|c|c|c|c|c|c|c|c|c|}
\hline \multirow[b]{2}{*}{ Energy } & \multirow[b]{2}{*}{ (MJ/day) } & \multirow[b]{2}{*}{ INT } & \multicolumn{3}{|c|}{ Baseline } & \multicolumn{3}{|c|}{ Year 1} & \multirow{2}{*}{$\frac{\text { P Group }}{0.68}$} & \multirow{2}{*}{$\frac{\text { P Time }}{0.01}$} & \multirow{2}{*}{$\frac{\text { P Group X Time }}{0.06}$} \\
\hline & & & 9.1 & \pm & 2.3 & 8.1 & \pm & 2.1 & & & \\
\hline & & CON & 8.5 & \pm & 2.3 & 8.4 & \pm & 2.3 & & & \\
\hline \multirow[t]{2}{*}{ Total fat } & (E\%) & INT & 35.8 & \pm & 5.4 & 30.8 & \pm & 6.7 & 0.10 & $<0.01$ & $<0.01$ \\
\hline & & CON & 35.5 & \pm & 7.2 & 34.5 & \pm & 6.3 & & & \\
\hline \multirow[t]{2}{*}{ Saturated fat } & (E\%) & INT & 13.6 & \pm & 2.4 & 11.3 & \pm & 2.9 & 0.04 & $<0.01$ & $<0.01$ \\
\hline & & CON & 13.8 & \pm & 3.4 & 13.3 & \pm & 3.5 & & & \\
\hline \multirow[t]{2}{*}{ Carbohydrates } & (E\%) & INT & 41.9 & \pm & 7.5 & 46.9 & \pm & 7.7 & 0.52 & $<0.01$ & $<0.01$ \\
\hline & & CON & 43.0 & \pm & 7.4 & 44.1 & \pm & 7.6 & & & \\
\hline \multirow[t]{2}{*}{ Fiber } & (g/MJ) & INT & 2.7 & \pm & 0.8 & 3.2 & \pm & 1.0 & 0.08 & $<0.01$ & $<0.01$ \\
\hline & & CON & 2.7 & \pm & 1.0 & 2.7 & \pm & 0.8 & & & \\
\hline \multirow[t]{2}{*}{ Alcohol } & (E\%) & INT & 6.1 & \pm & 7 & 4.9 & \pm & 6.2 & 0.87 & 0.26 & 0.36 \\
\hline & & CON & 5.4 & \pm & 5.9 & 5.3 & \pm & 5.6 & & & \\
\hline
\end{tabular}

Data are mean $\pm S D$

Inflammation and immune markers in relation to insulin resistance

The 1-year changes in PAI-1 and C3 were positively associated with changes in estimated insulin resistance (table 6.3, crude). However, these associations were to a large extent explained by $\Delta$ body weight (after adjustment $p>0.5$ ). 
Table 6.3 Linear regression analysis of the 1y changes during the SLIM lifestyle intervention in 2-hr glucose levels on changes in markers of inflammation, fibrinolysis and the immune system crude and after adjustment.

\begin{tabular}{|c|c|c|c|c|c|c|c|c|}
\hline \multirow[b]{2}{*}{ Dependent } & \multirow[b]{2}{*}{ Independent } & & \multicolumn{3}{|c|}{ Crude } & \multicolumn{3}{|c|}{ Adjusted } \\
\hline & & & Standardized $\beta$ & $\mathrm{P}$ & Adjusted $\mathrm{R}^{2}$ & Standardized $\beta$ & $\mathrm{P}$ & Adjusted $\mathrm{R}^{2}$ \\
\hline \multicolumn{9}{|c|}{$\Delta$ 2-hr Glucose } \\
\hline & $\Delta \mathrm{IL}-6$ & $(\mathrm{pg} / \mathrm{ml})$ & 0.26 & $<0.001$ & 0.11 & 0.32 & 0.001 & 0.25 \\
\hline & $\Delta \mathrm{C} 3$ & $(\mathrm{~g} / \mathrm{l})$ & 0.37 & $<0.001$ & 0.17 & 0.27 & 0.01 & 0.22 \\
\hline & $\Delta \mathrm{C} 4$ & $(\mathrm{~g} / \mathrm{l})$ & 0.23 & 0.02 & 0.10 & 0.22 & 0.03 & 0.20 \\
\hline & $\triangle \mathrm{PAI}-1$ & (ng/ml) & 0.06 & 0.53 & 0.05 & -0.08 & 0.45 & 0.17 \\
\hline \multirow[t]{5}{*}{$\triangle \mathrm{HOMA}-\mathrm{IR}$} & $\triangle \mathrm{CRP}$ & $(\mathrm{mg} / \mathrm{l})$ & 0.04 & 0.73 & -0.01 & -0.09 & 0.25 & 0.47 \\
\hline & $\Delta \mathrm{IL}-6$ & (pg/ml) & -0.03 & 0.78 & -0.01 & -0.07 & 0.37 & 0.46 \\
\hline & $\Delta \mathrm{C} 3$ & $(\mathrm{~g} / \mathrm{l})$ & 0.35 & 0.001 & 0.11 & 0.07 & 0.44 & 0.47 \\
\hline & $\Delta \mathrm{C} 4$ & (g/l) & 0.08 & 0.43 & 0.01 & -0.02 & 0.81 & 0.47 \\
\hline & $\Delta \mathrm{PAl}-1$ & (ng/ml) & 0.23 & 0.02 & 0.05 & 0.04 & 0.61 & 0.48 \\
\hline
\end{tabular}

Regression model adjusted for age, study group, mean value of the dependent and independent (crude) and in addition medication use, smoking status, and the change in body weight, saturated fat intake and maximal aerobic capacity (adjusted).

\section{Discussion}

The lifestyle intervention used in the SLIM study is effective in preventing deterioration in glucose tolerance (3), but does not affect CRP, IL-6, C3, C4 or PAI-1 levels. However, the first four of these markers are significantly associated with 1-year changes in 2-hr glucose levels and these associations are not affected by lifestyle changes, i.e. changes in body weight, saturated fat intake and maximal aerobic capacity. IL- 6 was the strongest marker associated with 2-hr glucose, independent of the other markers studied, suggesting that these markers and especially IL-6 may be linked to the etiology of glucose intolerance.

\section{Inflammation and immune markers and glucose tolerance}

The change in IL-6 levels was the only marker related with $\Delta 2-\mathrm{hr}$ glucose, independent of the other markers and lifestyle changes, suggesting that IL-6 has an essential role in the changes of glucose tolerance, compared to the other markers investigated. The relationship between 2-hr glucose and IL- 6 has been established before in crosssectional studies $(24,25)$ and is in agreement with previous findings showing a plasma 
IL-6 increase in response to acute hyperglycemic spikes (26) and increased IL-6 production from muscle in the postprandial phase of IGT men (27). In agreement with our results, IGT was recently found to be associated with IL-6 levels in a well-functioning older population, independent of obesity, fat distribution and inflammation-related conditions (28).

The association between IL-6 and 2-hr glucose, independent of the other markers investigated, suggests an effect of IL- 6 independent of the acute-phase response. IL- 6 may negatively affect insulin sensitivity via a stimulatory action on adipose tissue lipolysis (29) or by direct effects on skeletal muscle affecting insulin-stimulated glucose disposal (30). However, in the present study we could not demonstrate a relationship between IL-6 and markers of insulin metabolism (fasting insulin, HOMA-IR or 2-hr insulin). The strong relationship between IL-6 and 2-hr glucose may be explained by an inhibitory effect of IL-6 on insulin signaling in the liver (31), i.e. by decreasing insulinmediated suppression of endogenous glucose production (EGP) (32), observed in animal studies. Human studies to verify this hypothesis are scarce. One study showed no effect of IL-6 on EGP (30), but this study was done in healthy individuals and not in subjects with a disturbed glucose metabolism. IL-6 may also increase insulin secretion promoting hyperinsulinemia, possibly via a $\mathrm{Ca}^{2+}$-dependent mechanism (33), although limited in vivo studies are available at present.

High CRP levels are indicative of infection. Exclusion of 10 subjects with high CRP levels attenuated the relation between 2-hr glucose and CRP. Therefore, we cannot exclude involvement of the acute-phase response mediating the association between CRP and 2-hr glucose. The 10 subjects were more often current smokers, suggesting that they may be especially vulnerable for progression towards type 2 diabetes.

The mechanism behind the positive association between IL- 6 and C3 and C4 may be due to hepatic synthesis of C3 and C4, which is regulated by proinflammatory cytokines, such as IL-6 (34). Up to now, there is limited information regarding the relationship between inflammation factors and the complement system in the development of type 2 diabetes. Recently, CRP, C3 and C4 were all associated with body fat in healthy adolescents, while no statement was made concerning the mutual relationships (35).

Body weight did not explain the relationship between $\Delta \mathrm{C} 3$ and $\Delta 2$-hr glucose, suggesting that C3 may have effects on the glucose metabolism, not mediated by body weight (36). C3 has been shown previously to be related to diabetes development (13), independently of the main indexes of abdominal and general obesity and has shown to be strongly related to 2 -hr glucose in non-diabetic Pima Indians (37). These data suggest a detrimental effect of C3 on the development of type 2 diabetes, while the mechanism is still unclear.

\section{Inflammation and immune markers and insulin resistance}

Changes in PAI-1 were associated with HOMA-IR, which was largely explained by changes in body weight. In the Diabetes Prevention Program a similar association was found with tissue plasminogen activator (tPA), which is used to estimate the level of antifibrinolytic activity, and HOMA-IR, independent of measures of demographics, adiposity, insulin and glucose (38). Also, Festa et al. (2006) found the relation of PAI-1 
to incident diabetes to be independent of insulin resistance and/or bodyweight (12). Lifestyle interventions have shown to be able to reduce PAI-1 levels $(18,19)$, but more mechanistic studies are necessary to clarify the role of adipose tissue in the relationship between PAI-1 and insulin resistance.

Body weight also explained the positive relation between changes in C3 and $\triangle$ HOMA-IR, suggesting that adipose tissue may mediate this relationship. These data suggest that besides the liver, adipose tissue may be a proinflammatory source of C3 production which seems consistent with findings of a high C3 expression in (omental) adipose tissue (14).

Our study has several limitations that need to be addressed. First, the sample size was relatively small. However, the original power calculation suggest that these numbers are sufficient to detect a $1.0 \mathrm{mmol} / \mathrm{l}$ difference in glucose tolerance. Also, our study shows strong associations $(p<0.001)$, despite the relatively low sample size. In addition, characterization of immunological and inflammatory markers was more comprehensive than in previous studies. Second, associations were performed combining the two study groups together, whereas the control group was not given personalized lifestyle advice. However, as can be observed in the one-year decrease in body weight, subjects in the control group had their own 'mini intervention'. Several reasons may have attributed to the change in body weight e.g. increasing awareness of the advantages of a healthy lifestyle. In addition, regression analyses were adjusted for study group and the main results regarding IL-6 and C3 were similar in the intervention group separately as well.

In summary, the changes in 2-hr glucose observed in our lifestyle intervention study were associated with changes in IL-6, C3 and C4, independent of study group, age, medication use, smoking status and lifestyle changes. Change in IL- 6 was the only marker related with the change in 2-hr glucose independently of the other markers, suggesting that IL- 6 is an independent mediator of glucose tolerance and may be considered as a 'nontraditional' risk marker in the etiology of type 2 diabetes mellitus.

\section{Acknowledgements}

We thank Jos Stegen, Tanja Hermans-Limpens and Marja Ockeloen - van der Hulst for their help during the OGTT's and with the dietary intervention and Hans Cremers and Piet Beekhof for the measurements of CRP, C3, C4, IL-6 and PAI-1. This work was supported by grants from the Dutch Diabetes Research Foundation (DFN 98.901 and 2000.00.020), the Netherlands Organization for Health Research and Development (ZonMW 940-35-034 and 2200.0139). 


\section{Chapter 6}

\section{References}

1. Knowler WC, Barrett-Connor E, Fowler SE, Hamman RF, Lachin JM, Walker EA, et al. Reduction in the incidence of type 2 diabetes with lifestyle intervention or metformin. N Engl J Med. 2002;346:393-403.

2. Mensink M, Blaak EE, Corpeleijn E, Saris WH, de Bruin TW, Feskens EJ. Lifestyle intervention according to general recommendations improves glucose tolerance. Obes Res. 2003;11:1588-96.

3. Roumen C, Corpeleijn E, Feskens EJ, Mensink M, Saris WH, Blaak EE. Impact of 3-year lifestyle intervention on postprandial glucose metabolism: the SLIM study. Diabet Med. 2008;25:597-605.

4. Lindstrom J, Ilanne-Parikka P, Peltonen M, Aunola S, Eriksson JG, Hemio K, et al. Sustained reduction in the incidence of type 2 diabetes by lifestyle intervention: follow-up of the Finnish Diabetes Prevention Study. Lancet. 2006;368:1673-9.

5. Festa A, Hanley AJ, Tracy RP, D’Agostino R, Jr., Haffner SM. Inflammation in the prediabetic state is related to increased insulin resistance rather than decreased insulin secretion. Circulation. 2003;108:1822-30.

6. Herder C, Peltonen M, Koenig W, Kraft I, Muller-Scholze S, Martin S, et al. Systemic immune mediators and lifestyle changes in the prevention of type 2 diabetes: results from the Finnish Diabetes Prevention Study. Diabetes. 2006;55:2340-6.

7. Pradhan AD, Manson JE, Rifai N, Buring JE, Ridker PM. C-reactive protein, interleukin 6, and risk of developing type 2 diabetes mellitus. Jama. 2001;286:327-34.

8. Schmidt MI, Duncan BB, Sharrett AR, Lindberg G, Savage PJ, Offenbacher S, et al. Markers of inflammation and prediction of diabetes mellitus in adults (Atherosclerosis Risk in Communities study): a cohort study. Lancet. 1999;353:1649-52.

9. Festa A, D'Agostino R, Jr., Tracy RP, Haffner SM. Elevated levels of acute-phase proteins and plasminogen activator inhibitor-1 predict the development of type 2 diabetes: the insulin resistance atherosclerosis study. Diabetes. 2002;51:1131-7.

10. Hu FB, Meigs JB, Li TY, Rifai N, Manson JE. Inflammatory markers and risk of developing type 2 diabetes in women. Diabetes. 2004;53:693-700.

11. Spranger J, Kroke A, Mohlig M, Hoffmann K, Bergmann MM, Ristow M, et al. Inflammatory cytokines and the risk to develop type 2 diabetes: results of the prospective population-based European Prospective Investigation into Cancer and Nutrition (EPIC)-Potsdam Study. Diabetes. 2003;52:812-7.

12. Festa A, Williams K, Tracy RP, Wagenknecht LE, Haffner SM. Progression of plasminogen activator inhibitor-1 and fibrinogen levels in relation to incident type 2 diabetes. Circulation. 2006;113:1753-9.

13. Engstrom G, Hedblad B, Eriksson KF, Janzon L, Lindgarde F. Complement C3 is a risk factor for the development of diabetes: a population-based cohort study. Diabetes. 2005;54:570-5.

14. Gabrielsson BG, Johansson JM, Lonn M, Jernas $M$, Olbers $T$, Peltonen $M$, et al. High expression of complement components in omental adipose tissue in obese men. Obes Res. 2003;11:699-708.

15. Esposito K, Pontillo A, Di Palo C, Giugliano G, Masella M, Marfella R, et al. Effect of weight loss and lifestyle changes on vascular inflammatory markers in obese women: a randomized trial. Jama. 2003;289:1799-804.

16. Haffner S, Temprosa M, Crandall J, Fowler S, Goldberg R, Horton E, et al. Intensive lifestyle intervention or metformin on inflammation and coagulation in participants with impaired glucose tolerance. Diabetes. 2005;54:1566-72.

17. Monzillo LU, Hamdy O, Horton ES, Ledbury S, Mullooly C, Jarema C, et al. Effect of lifestyle modification on adipokine levels in obese subjects with insulin resistance. Obes Res. 2003;11:1048-54.

18. Hamdy O, Ledbury S, Mullooly C, Jarema C, Porter S, Ovalle K, et al. Lifestyle modification improves endothelial function in obese subjects with the insulin resistance syndrome. Diabetes Care. 2003;26:2119-25.

19. Hamalainen H, Ronnemaa T, Virtanen A, Lindstrom J, Eriksson JG, Valle TT, et al. Improved fibrinolysis by an intensive lifestyle intervention in subjects with impaired glucose tolerance. The Finnish Diabetes Prevention Study. Diabetologia. 2005;48:2248-53.

20. Mensink M, Corpeleijn E, Feskens EJ, Kruijshoop M, Saris WH, de Bruin TW, et al. Study on lifestyleintervention and impaired glucose tolerance Maastricht (SLIM): design and screening results. Diabetes Res Clin Pract. 2003;61:49-58.

21. Eriksson J, Lindstrom J, Valle T, Aunola S, Hamalainen H, llanne-Parikka P, et al. Prevention of Type II diabetes in subjects with impaired glucose tolerance: the Diabetes Prevention Study (DPS) in Finland. Study design and 1-year interim report on the feasibility of the lifestyle intervention programme. Diabetologia. 1999;42:793-801. 
22. American College of Sports Medicine Position Stand. The recommended quantity and quality of exercise for developing and maintaining cardiorespiratory and muscular fitness, and flexibility in healthy adults. Med Sci Sports Exerc. 1998;30:975-91.

23. Matthews DR, Hosker JP, Rudenski AS, Naylor BA, Treacher DF, Turner RC. Homeostasis model assessment: insulin resistance and beta-cell function from fasting plasma glucose and insulin concentrations in man. Diabetologia. 1985;28:412-9.

24. Cardellini M, Andreozzi F, Laratta E, Marini MA, Lauro R, Hribal ML, et al. Plasma interleukin-6 levels are increased in subjects with impaired glucose tolerance but not in those with impaired fasting glucose in a cohort of Italian Caucasians. Diabetes Metab Res Rev. 2007;23:141-5.

25. Muller S, Martin S, Koenig W, Hanifi-Moghaddam P, Rathmann W, Haastert B, et al. Impaired glucose tolerance is associated with increased serum concentrations of interleukin 6 and co-regulated acutephase proteins but not TNF-alpha or its receptors. Diabetologia. 2002;45:805-12.

26. Esposito K, Nappo F, Marfella R, Giugliano G, Giugliano F, Ciotola M, et al. Inflammatory cytokine concentrations are acutely increased by hyperglycemia in humans: role of oxidative stress. Circulation. 2002;106:2067-72.

27. Corpeleijn E, Saris WHM, Jansen EHJM, Roekaerts PMHJ, Feskens EJM, Blaak EE. Postprandial Interleukin-6 Release from Skeletal Muscle in Men with Impaired Glucose Tolerance Can Be Reduced by Weight Loss. J Clin Endocrinol Metab. 2005;90:5819-24.

28. de Rekeneire N, Peila R, Ding J, Colbert LH, Visser M, Shorr RI, et al. Diabetes, hyperglycemia, and inflammation in older individuals: the health, aging and body composition study. Diabetes Care. 2006;29:1902-8.

29. van Hall G, Steensberg A, Sacchetti M, Fischer C, Keller C, Schjerling $P$, et al. Interleukin-6 stimulates lipolysis and fat oxidation in humans. J Clin Endocrinol Metab. 2003;88:3005-10.

30. Carey AL, Steinberg GR, Macaulay SL, Thomas WG, Holmes AG, Ramm G, et al. Interleukin-6 increases insulin-stimulated glucose disposal in humans and glucose uptake and fatty acid oxidation in vitro via AMP-activated protein kinase. Diabetes. 2006;55:2688-97.

31. Klover PJ, Zimmers TA, Koniaris LG, Mooney RA. Chronic exposure to interleukin- 6 causes hepatic insulin resistance in mice. Diabetes. 2003;52:2784-9.

32. Klover PJ, Clementi AH, Mooney RA. Interleukin-6 depletion selectively improves hepatic insulin action in obesity. Endocrinology. 2005;146:3417-27.

33. Shimizu H, Ohtani K, Kato $Y$, Mori M. Interleukin-6 increases insulin secretion and preproinsulin mRNA expression via Ca2+-dependent mechanism. J Endocrinol. 2000;166:121-6.

34. Ramadori G, Christ B. Cytokines and the hepatic acute-phase response. Semin Liver Dis. 1999;19:141-55.

35. Warnberg J, Nova E, Moreno LA, Romeo J, Mesana MI, Ruiz JR, et al. Inflammatory proteins are related to total and abdominal adiposity in a healthy adolescent population: the AVENA Study. Am J Clin Nutr. 2006;84:505-12.

36. Yang $\mathrm{Y}$, Lu HL, Zhang J, Yu HY, Wang HW, Zhang MX, et al. Relationships among acylation stimulating protein, adiponectin and complement $\mathrm{C} 3$ in lean vs obese type 2 diabetes. Int J Obes (Lond). 2006;30:439-46.

37. Weyer C, Tataranni PA, Pratley RE. Insulin action and insulinemia are closely related to the fasting complement C3, but not acylation stimulating protein concentration. Diabetes Care. 2000;23:779-85.

38. Lipid, lipoproteins, C-reactive protein, and hemostatic factors at baseline in the diabetes prevention program. Diabetes Care. 2005;28:2472-9. 



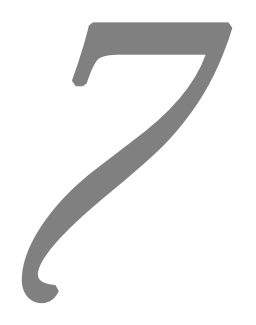

\section{INFLAMMATORY FACTORS AND ADIPOKINES AND LIFESTYLE INTERVENTION OUTCOME AFTER 3 YEARS IN HIGH-RISK SUBJECTS FOR TYPE 2 DIABETES}

The SLIM study

Cheryl Roumen, Edith J.M. Feskens, Eva Corpeleijn, Eugène H.J.M Jansen, Wim H. M. Saris, MD, Ellen E. Blaak. 


\section{Abstract}

\section{Objective}

To investigate the effect of lifestyle intervention according to general recommendations on circulating adiponectin, resistin, leptin, plasminogen-activator inhibitor-1 (PAI1), C-reactive protein (CRP), Complement factor 3 (C3) and Interleukin-6 (IL-6) in subjects at risk for diabetes as well as the potential of these inflammation factors as biomarkers of changes in glucose metabolism and insulin resistance.

\section{Method}

In the Study on Lifestyle intervention and Impaired glucose tolerance Maastricht (SLIM), 147 subjects with impaired glucose tolerance were randomized to either a combined diet-and-exercise intervention or a control program. At baseline and after 1 , 2 and 3 years, an oral glucose tolerance test, an exercise test, and anthropometric measurements were performed. After 3 years, complete data of 102 subjects (50 intervention and 52 control) were obtained.

\section{Results}

Over the 3 years, leptin levels increased less in the intervention group, compared to the control group $\left(p_{\mathrm{all}}<0.05\right)$. High baseline leptin levels were predictive of improvements in glucose tolerance, partly independent of body fat mass, suggesting a role of leptin mediating glucose tolerance. Independent of changes in body weight, saturated fat intake and maximal aerobic capacity, 3-yr changes in PAI-1 levels were significantly positively associated with changes in HOMA-IR.

\section{Conclusion}

The 3-yr SLIM lifestyle intervention blunts the increase in leptin levels in the intervention group compared to the control group. Baseline leptin levels are reflective of baseline body weight and are indicative of beneficial lifestyle-induced changes in 2-hr glucose levels. 
Introduction

There is increasing evidence for a relationship between inflammatory factors and the progression towards type 2 diabetes (1-3). C-reactive protein (CRP) and IL-6 concentrations are increased in obesity and have been reported to be significantly elevated in impaired glucose tolerance subjects (IGT) compared with normoglycemic subjects, as shown in the KORA Survey 2000 (4). In the DPS lifestyle intervention study, CRP was the best predictor for progression towards type 2 diabetes in the control group after a mean of 3.9 years (1). Plasminogen activator inhibitor 1 (PAI-1), a factor known to be involved in blood clotting, has also been able to predict the development of type 2 diabetes, an effect independent of body weight (5). Also, baseline complement factor 3 (C3), mainly produced by the liver, has recently been shown to be predictive of diabetes development after 6.1 years in non-diabetic healthy men (6).

Adipo(cyto)kines, endocrine factors that are produced by adipose tissue, may also be associated with the development of type 2 diabetes. Among others, adipose tissue secretes adiponectin, leptin and resistin. Based on animal and in vitro data, resistin was originally thought to be a hormone linking obesity with insulin resistance, possibly by having antagonistic effects compared to those of insulin (7). However, recent human studies provide conflicting data showing no association between resistin and insulin resistance $(8 ; 9)$. Adiponectin is solely produced by adipose tissue and hypoadiponectinemia is associated with Impaired Glucose Tolerance (IGT) in non-diabetic men (10) and has shown to be predictive of diabetes development in Pima Indians (2) as well as in a Caucasian IGT population (3). In these studies, the relationship between low adiponectin levels and progression towards type 2 diabetes was not completely explained by fat mass, suggesting adiponectin as a marker for metabolic status, e.g. adipocyte dysfunction. Both adiponectin and leptin are suggested to be associated with diabetes development and cardiovascular disease via pathways involving fat metabolism, inflammation and vascular function $(10 ; 11)$.

Lifestyle interventions have been shown to reduce CRP, IL-6 (12), PAI-1 (13) after 1 year as well as leptin after periods of 1-2 years (14), together with improvements in glucose tolerance and insulin sensitivity. Currently, limited lifestyle intervention studies have reported a potential effect on adipokines and inflammation factors that extends periods of 1-2 years. Furthermore, besides the effect of lifestyle intervention on adipokines and inflammation factors, more information is also warranted on the relationship between inflammation factors and lifestyle intervention outcome. The objective of this study was to investigate the effect of a 3-yr lifestyle intervention on adipokines and inflammation markers in subjects with impaired glucose tolerance. In addition, we established the potential of inflammatory factors as biomarkers for lifestyle induced improvements in glucose metabolism and insulin resistance. 


\section{Chapter 7}

\section{Methods}

\section{Screening}

The Study on Lifestyle intervention and Impaired glucose tolerance Maastricht (SLIM) is a randomized controlled trial, designed to study whether a 6-yr combined dietary and physical activity intervention program can improve glucose tolerance in subjects with impaired glucose tolerance (IGT). Study design, inclusion and exclusion criteria, and the diet and exercise program of SLIM have previously been described in detail $(15 ; 16)$. Briefly, subjects with an increased risk for glucose intolerance, e.g. family history of diabetes, age $>40$ years, $\mathrm{BMI}>25 \mathrm{~kg} / \mathrm{m} 2$, were selected from a cohort in the area of Maastricht, the Netherlands and invited to undergo a capillary standard oral glucose tolerance test (OGTT), response rate $46.2 \%$, see reference (15). Those subjects with a 2-h blood glucose concentration $>7.8 \mathrm{mmol} / \mathrm{l}$ were invited for a second venous OGTT. For inclusion, mean 2-h glucose concentration of both OGTTs had to be between 7.8 and $12.5 \mathrm{mmol} / \mathrm{l}$ and fasting glucose concentration $<7.0 \mathrm{mmol} / \mathrm{l}$. Data obtained during the second (venous) OGTT were used as baseline values. Exclusion criteria were known diabetes, chronic illness, medication known to interfere with glucose tolerance and participation in a vigorous exercise and/or diet program.

\section{Inclusion}

Screening and inclusion of subjects for the SLIM study occurred between March 1999 and May 2000 and in 2002. A total of 147 subjects were included in our study. Subjects were randomized with stratification for sex and mean 2-hr plasma glucose concentration to the intervention group (INT: 74 subjects; 38 male, 36 female) or the control group (CON: 73 subjects; 37 male, 36 female). From the preliminary 1-yr results of the Finnish DPS (17), we calculated that 50-60 subjects per group would be sufficient to detect a $1.0 \mathrm{mmol} / \mathrm{l}$ difference in 2 -h glucose concentration between groups. Of the 147 subjects enrolled, 106 completed the first 3 years. For regression analysis, four subjects were excluded because of missing values for adipokine or inflammation factors (data analyses in $n=102$ : 50 INT subjects and 52 CON subjects). Reasons for dropout have been reported previously (18). The study protocol was approved by the local medical ethical committee of the Maastricht University. All subjects gave written informed consent.

\section{Intervention}

The intervention program consisted of a dietary and physical activity part. Dietary recommendations were based on the Dutch guidelines for a healthy diet (Dutch Nutrition Council) and consisted of a carbohydrate intake of at least 55 energy\% (E\%), a total fat intake of 30-35 E\%, with a saturated fat intake below $10 \mathrm{E} \%$. A skilled dietician gave personal dietary advice during a one-hour counseling session every 3 months, after consideration of a 3-day food record (two weekdays, one weekend day). In addition, subjects received individual advice on how to increase their level of physical 
activity to at least 30 minutes a day for at least 5 days a week (19). Furthermore, subjects were encouraged to participate in a free, supervised combined aerobic- and resistance exercise program, especially designed for this study, which was offered to them 4 times a week Participation in the exercise program was monitored and 17 subjects participated at least once a week during the second and third year. Intensity of the exercise program was determined using heart rate monitoring which was approximately $70 \%$ of their maximal peak oxygen consumption $\left(\mathrm{VO}_{2} \mathrm{max}\right)$. Control subjects were only briefly informed about the beneficial effects of a healthy diet and physical activity, whereas no individual advice was given.

\section{Measurements}

In both groups, several measurements were performed annually including an OGTT as a measurement of glucose tolerance, insulin levels, $\mathrm{VO}_{2} \mathrm{max}$, body weight, waist circumference, body fat percentage, blood pressure, HBA1c, cholesterol and HDL. Body weight was measured with an electronical scale to the nearest $0.1 \mathrm{~kg}$. Waist was measured to the nearest $0.5 \mathrm{~cm}$, with the subject in standing position at the level midway between the lowest rib and the iliacal crest. Blood pressure was measured with a Maxi Stabil 3 sphygmomanometer (CE0047, Speidel en Keller, Jungingen, Germany) in duplo with the subject in supine position, after 10 minutes of rest. The 3-day food records were analyzed for nutrient intake using the Dutch food table (NEVO version 1996). An incremental exhaustive exercise test was performed on an electronically braked bicycle ergometer to determine maximal peak oxygen consumption $\left(\mathrm{VO}_{2}\right.$ max). The HOMA-IR index for insulin resistance was calculated as described by Matthews et al.(20). The incidence of DM2 was determined according to WHO criteria of 1999 (21). Low-density lipoprotein (LDL) cholesterol was calculated according to the Friedewald formula (22).

During the OGTT, plasma glucose, free fatty acids (FFA) and insulin were measured in the fasting state and after 2 hours, using a standard enzymatic technique, automated on a Cobas Fara centrifugal analyzer (intra assay coefficient variation for glucose was $1.50 \%$, the inter-assay coefficient variation was $3.66 \%$ ). Plasma insulin concentration was measured with a Radio Immuno Assay (Cat. \#HI-14K, Linco Research, St. Charles, MO, USA) that shows no cross-reactivity with pro-insulin. Glycated haemoglobin (HBA1C) was determined in a fasting serum sample with high-performance liquid chromatography (reference values for our laboratory 4.4-6.2\%). In addition, adipokines and inflammation markers are determined. Stored plasma samples were analyzed for levels of fasting plasma adiponectin (total adiponectin: full length and globular, coefficient of variation (CV) 5.8\%), resistin (homodimeric, CV 3.7\%), leptin (CV 3.7\%), PAI-1 (CV 2.3\%) with enzyme-linked immunosorbent assays (Biovendor, Heidelberg, Germany). Samples were analyzed with paired samples from each subject run in the same batch. hsCRP, C3 and C4 were measured in duplicate in fasting serum using an autoanalyser (Hitachi 912, Roche Diagnostics, Almere, The Netherlands). IL-6 was measured in duplicate in fasting EDTA plasma with a high-sensitive ELISA assay (R\&D systems, Abingdon, United Kingdom). 


\section{Chapter 7}

\section{Statistics}

Data analysis was conducted using SPSS for Windows (version 14.1). Data are presented as mean $\pm S D$ or, if not normally distributed (insulin, leptin, adiponectin, resistin, CRP, IL-6), as median ( $25^{\text {th }}-75^{\text {th }}$ percentile). Repeated-measures ANOVA were used for differences between groups over time. A two-tailed $P$ value of 0.05 was considered statistically significant. Multiple linear regression models in the total group (intervention + control) were used to assess whether baseline or 3-yr change of inflammatory markers were predictive of the change in 2-hr glucose levels and HOMA-IR index. The models used for multiple linear regression analyses are based on the standard model (model 1) which is adjusted for inclusion time, study group, age, medication use and smoking status and in addition for mean of the dependent and independent variables when investigating the changes in inflammatory markers. Lifestyle variables, like body weight, maximal aerobic fitness and saturated fat intake were added sequentially to each model to assess to what extent the associations were an indirect effect of lifestyle factors.

Results

\section{Baseline characteristics}

At baseline, inflammation markers were not different between study groups. During the 3-yr lifestyle intervention, the intervention group decreased in body weight (-1.1 $\mathrm{kg}$ ) and in HOMA-IR $(-0.2)$, whilst the control group increased in these parameters $(p<0.05$, table 7.1$) . \mathrm{VO}_{2 \max }$ improved in the intervention group $(+0.2 \mathrm{l} / \mathrm{min})$ compared to a stable $\mathrm{VO}_{2 \max }$ in the control group $(\mathrm{p}=0.02)$. In the intervention group, 2 -hr glucose levels returned to baseline values whereas $2-\mathrm{hr}$ glucose levels in the control group deteriorated $(p=0.02)$. In the intervention group, saturated fat intake decreased more compared to the control group $(p<0.01)$.

\section{Leptin}

Table 7.1 shows that during the 3-yr lifestyle intervention leptin levels increased more in the control group $(+4.4 \mathrm{ng} / \mathrm{ml}, 95 \% \mathrm{Cl}: 2.3$ to 6.6$)$ compared to the intervention group $(+1.0 \mathrm{ng} / \mathrm{ml}, 95 \% \mathrm{Cl}-0.8$ to $2.8 ; \mathrm{p}<0.01)$. In the total group (intervention and control group together), baseline leptin levels were related to changes in 2-hr glucose levels, even after adjustment for baseline body weight (table 7.2, model 2). Baseline leptin levels were not related to changes in HOMA-IR, when adjusted for baseline body weight, $\mathrm{VO}_{2}$ max and saturated fat intake (table 7.2, model 3). In the standard model, $\triangle$ leptin was related to $\triangle \mathrm{HOMA}-\mathrm{IR}$, but this relationship was abolished when adjusted for $\Delta$ body weight ( $p=0.10$, table 7.3 , model 2 ). 
Table 7.1 Levels of inflammation factors at baseline and after 3 years of follow-up in the SLIM study, according to study group. Data are mean \pm SD or median (25th-75th percentile)

\begin{tabular}{|c|c|c|c|c|c|c|c|c|}
\hline & & \multicolumn{2}{|c|}{ Baseline } & \multicolumn{2}{|c|}{ Year 3} & \multirow[b]{2}{*}{ Group } & \multirow[b]{2}{*}{ Time } & \multirow[b]{2}{*}{$\begin{array}{c}\text { Group } X \\
\text { Time }\end{array}$} \\
\hline & & Intervention & Control & Intervention & Control & & & \\
\hline $\mathrm{n}$ (male/female) & 102 & $50(26 / 24)$ & $52(27 / 25)$ & $50(26 / 24)$ & $52(27 / 25)$ & - & - & - \\
\hline Body weight & (kg) & $87.5 \pm 13.7$ & $82.9 \pm 11.7$ & $86.4 \pm 13.7$ & $83.1 \pm 11.1$ & 0.23 & $<0.01$ & 0.01 \\
\hline $\mathrm{VO}_{2} \max$ & $(\mathrm{l} / \mathrm{min})$ & $2.2 \pm 0.6$ & $2.1 \pm 0.5$ & $2.4 \pm 0.6$ & $2.1 \pm 0.7$ & 0.02 & $<0.01$ & 0.02 \\
\hline Saturated fat intake & $(\mathrm{E} \%)$ & $13.6 \pm 2.9$ & $13.6 \pm 3.5$ & $10.7 \pm 3.0$ & $12.9 \pm 3.2$ & $<0.01$ & $<0.01$ & $<0.01$ \\
\hline 2-hr glucose & $(\mathrm{mmol} / \mathrm{l})$ & $8.6 \pm 1.6$ & $8.5 \pm 1.8$ & $8.5 \pm 2.3$ & $9.3 \pm 2.5$ & 0.09 & 0.09 & 0.02 \\
\hline HOMA-IR & & $4.8 \pm 2.0$ & $4.6 \pm 2.1$ & $4.6 \pm 2.1$ & $5.0 \pm 2.1$ & 0.81 & $<0.01$ & 0.04 \\
\hline Leptin & (ng/ml) & $\begin{array}{c}19.2 \\
(15.7-22.7)\end{array}$ & $\begin{array}{c}16.2 \\
(13.1-19.4)\end{array}$ & $\begin{array}{c}20.2 \\
(16.3-24.2)\end{array}$ & $\begin{array}{c}20.7 \\
(17.0-24.5)\end{array}$ & 0.57 & $<0.01$ & $<0.01$ \\
\hline C3 & $(\mathrm{g} / \mathrm{l})$ & $1.3 \pm 0.2$ & $1.3 \pm 0.2$ & $1.5 \pm 0.3$ & $1.5 \pm 0.3$ & 0.78 & $<0.01$ & 0.92 \\
\hline PAI-1 & (ng/ml) & $49.2 \pm 16.9$ & $44.0 \pm 13.3$ & $29.4 \pm 9.7$ & $30.4 \pm 9.6$ & 0.94 & $<0.01$ & 0.43 \\
\hline Resistin & (ng/ml) & $\begin{array}{c}3.6 \\
(3.1-4.0)\end{array}$ & $\begin{array}{c}3.6 \\
(3.2-4.0)\end{array}$ & $\begin{array}{c}2.8 \\
(2.5-3.1)\end{array}$ & $\begin{array}{c}2.7 \\
(2.5-2.9)\end{array}$ & 0.76 & $<0.01$ & 0.58 \\
\hline CRP & $(\mathrm{mg} / \mathrm{l})$ & $\begin{array}{c}3.9 \\
(2.9-4.9)\end{array}$ & $\begin{array}{c}4.1 \\
(2.2-6.1)\end{array}$ & $\begin{array}{c}3.5 \\
(2.6-4.5)\end{array}$ & $\begin{array}{c}3.9 \\
(1.9-6.0)\end{array}$ & 0.71 & 0.27 & 0.77 \\
\hline IL-6 & $(\mathrm{pg} / \mathrm{ml})$ & $\begin{array}{c}2.2 \\
(1.0-3.4)\end{array}$ & $\begin{array}{c}2.3 \\
(1.6-3.0)\end{array}$ & $\begin{array}{c}2.2 \\
(1.0-3.4)\end{array}$ & $\begin{array}{c}2.8 \\
(1.6-4.1)\end{array}$ & 0.18 & 0.11 & 0.95 \\
\hline Adiponectin & (ug/ml) & $\begin{array}{c}13.4 \\
(11.5-15.2)\end{array}$ & $\begin{array}{c}14.2 \\
(12.4-15.9)\end{array}$ & $\begin{array}{c}9.1 \\
(8.0-10.2)\end{array}$ & $\begin{array}{c}8.9 \\
(8.0-9.8)\end{array}$ & 0.27 & $<0.01$ & 0.66 \\
\hline
\end{tabular}

C3

The lifestyle intervention did not affect C3 levels (table 7.1). In the total group, baseline C3 levels were not associated with changes in 2-hr glucose levels or HOMA-IR (table 7.2). $\triangle \mathrm{C} 3$ and $\triangle \mathrm{HOMA}-\mathrm{IR}$ were positively related in the standard model but this relationship disappeared after adjustment for body weight (table 7.3, model 2). The positive relation between $\Delta \mathrm{C} 3$ and 2 -hr glucose concentration in the standard model became non-significant after additional adjustment for changes in body weight, saturated fat intake and $\mathrm{VO}_{2} \max (\mathrm{p}=0.07$, table 7.3 , model 3 ).

PAI-1

The lifestyle intervention did not affect PAI-1 levels. Baseline PAI-1 was not associated with change in HOMA-IR or 2-h glucose (table 7.2). In the total group, $\triangle \mathrm{PAI}-1$ was positively associated with $\triangle \mathrm{HOMA}-\mathrm{IR}$, even after adjustment for change in body weight, $\mathrm{VO}_{2}$ max and saturated fat intake $(\mathrm{p}=0.02$, table 7.3 , model 3$)$. 


\section{Chapter 7}

Table 7.2 Multivariable associations between baseline levels and changes in HOMA-IR and 2-hr glucose levels during the 3-yr SLIM lifestyle intervention. Models are built with increasing complexity.

\begin{tabular}{|c|c|c|c|c|c|c|c|}
\hline & & \multicolumn{2}{|l|}{ Model 1} & \multicolumn{2}{|l|}{ Model 2} & \multicolumn{2}{|c|}{ Model 3} \\
\hline & & $\begin{array}{c}\text { Standardized } \\
\beta\end{array}$ & $P$ & $\begin{array}{c}\text { Standardized } \\
\beta\end{array}$ & $P$ & $\begin{array}{c}\text { Standardized } \\
\beta\end{array}$ & $\mathrm{P}$ \\
\hline$\triangle \mathrm{HOMA}-\mathrm{IR}$ & Baseline Leptin & -0.20 & 0.13 & -0.34 & 0.03 & -0.22 & 0.25 \\
\hline \multirow[t]{6}{*}{$\mathrm{N}=93$} & Baseline C3 & 0.05 & 0.61 & 0.04 & 0.74 & -0.07 & 0.55 \\
\hline & Baseline PAI-1 & -0.04 & 0.68 & -0.06 & 0.54 & -0.17 & 0.16 \\
\hline & Baseline Resistin & 0.02 & 0.84 & 0.02 & 0.87 & 0.05 & 0.68 \\
\hline & Baseline CRP & 0.10 & 0.33 & 0.09 & 0.39 & 0.09 & 0.46 \\
\hline & Baseline IL-6 & 0.11 & 0.29 & 0.11 & 0.31 & 0.04 & 0.75 \\
\hline & Baseline Adiponectin & -0.14 & 0.26 & -0.14 & 0.25 & -0.16 & 0.20 \\
\hline$\Delta$ 2-hr Glucose & Baseline Leptin & -0.28 & 0.03 & -0.37 & 0.02 & -0.17 & 0.38 \\
\hline \multirow[t]{6}{*}{$\mathrm{N}=102$} & Baseline C3 & -0.15 & 0.13 & -0.16 & 0.15 & -0.22 & 0.06 \\
\hline & Baseline PAI-1 & -0.04 & 0.67 & -0.02 & 0.83 & -0.11 & 0.32 \\
\hline & Baseline Resistin & 0.15 & 0.26 & 0.16 & 0.25 & 0.08 & 0.59 \\
\hline & Baseline CRP & 0.04 & 0.68 & 0.05 & 0.62 & 0.03 & 0.79 \\
\hline & Baseline IL-6 & -0.06 & 0.53 & -0.05 & 0.61 & -0.14 & 0.22 \\
\hline & Baseline Adiponectin & -0.05 & 0.64 & -0.05 & 0.66 & -0.48 & 0.70 \\
\hline
\end{tabular}

Model 1: Adjusted for, inclusion time, study group, age, medication use and smoking status. Model 2: Model $1+$ adjustment for baseline body weight.

Model 3: Model $1+$ adjustment for baseline body weight, maximal aerobic fitness and saturated fat intake

\section{Resistin}

The lifestyle intervention did not affect resistin levels and baseline resistin levels showed no association with $\triangle$ HOMA-IR or $\Delta 2$-hr glucose (table 7.2). However, $\Delta$ resistin was inversely associated with $\triangle \mathrm{HOMA}-\mathrm{IR}$ (table 7.3, model 1 ). Adjustment for changes in body weight did not change this association (table 7.3, model2). The relationship became borderline significant $(p=0.07)$ after additional adjustment for changes in saturated fat intake and $\mathrm{VO}_{2}$ max.

CRP

The lifestyle intervention did not affect CRP levels. Also, (the change in) CRP levels did not show any relationship with changes in HOMA-IR or 2-hr glucose (table 7.2 and table 7.3). 


\section{IL-6 and Adiponectin}

The lifestyle intervention did not alter the levels of IL-6 and adiponectin. Nor baseline, neither change in these adipokines was related to (change in) HOMA-IR or 2-hr glucose (table 7.2 and table 7.3).

Table 7.3 Multivariable associations between changes inflammation factors and changes in HOMA-IR and 2hr glucose during the 3-yr SLIM lifestyle intervention. Models are built with increasing complexity.

\begin{tabular}{|c|c|c|c|c|c|c|c|}
\hline & & \multicolumn{2}{|c|}{ Model 1} & \multicolumn{2}{|c|}{ Model 2} & \multicolumn{2}{|c|}{ Model 3} \\
\hline & & $\begin{array}{c}\text { Standardized } \\
\beta\end{array}$ & $\mathrm{P}$ & $\begin{array}{c}\text { Standardized } \\
\beta\end{array}$ & $\mathrm{P}$ & $\begin{array}{c}\text { Standardized } \\
\beta\end{array}$ & $\mathrm{P}$ \\
\hline$\triangle \mathrm{HOMA}-\mathrm{IR}$ & $\Delta$ Leptin & 0.49 & $<0.01$ & 0.20 & 0.10 & 0.07 & 0.65 \\
\hline \multirow[t]{6}{*}{$\mathrm{N}=93$} & $\Delta \mathrm{C} 3$ & 0.29 & 0.01 & -0.05 & 0.65 & -0.09 & 0.49 \\
\hline & $\triangle \mathrm{PAl}-1$ & 0.32 & 0.01 & 0.24 & 0.02 & 0.28 & 0.02 \\
\hline & $\Delta$ Resistin & -0.37 & 0.04 & -0.38 & 0.01 & -0.36 & 0.07 \\
\hline & $\triangle \mathrm{CRP}$ & 0.11 & 0.31 & -0.03 & 0.77 & -0.04 & 0.70 \\
\hline & $\Delta \mathrm{IL}-6$ & 0.01 & 0.97 & -0.03 & 0.79 & -0.01 & 0.95 \\
\hline & $\Delta$ Adiponectin & -0.01 & 0.95 & 0.01 & 0.95 & -0.02 & 0.90 \\
\hline$\Delta$ 2-hr Glucose & $\Delta$ Leptin & 0.12 & 0.23 & -0.04 & 0.77 & -0.16 & 0.35 \\
\hline \multirow[t]{6}{*}{$\mathrm{N}=102$} & $\Delta \mathrm{C} 3$ & 0.26 & $<0.01$ & 0.18 & 0.11 & 0.24 & 0.07 \\
\hline & $\Delta \mathrm{PAl}-1$ & 0.18 & 0.08 & 0.14 & 0.17 & 0.05 & 0.71 \\
\hline & $\Delta$ Resistin & -0.27 & 0.09 & -0.26 & 0.09 & -0.10 & 0.63 \\
\hline & $\triangle \mathrm{CRP}$ & 0.07 & 0.48 & 0.20 & 0.03 & 0.17 & 0.14 \\
\hline & $\Delta \mathrm{IL}-6$ & 0.11 & 0.26 & 0.10 & 0.30 & 0.14 & 0.26 \\
\hline & $\Delta$ Adiponectin & 0.01 & 0.96 & 0.00 & 1.00 & -0.19 & 0.27 \\
\hline
\end{tabular}

Model 1: Adjusted for mean of the dependent and independent, inclusion time, study group, age, medication use and smoking status.

Model 2: Model $1+$ adjustment for change in body weight

Model 3: Model 1 + adjustment for change in body weight, maximal aerobic fitness and saturated fat intake

\section{Discussion}

After adjustment for baseline body weight, maximal aerobic capacity and saturated fat intake, none of the baseline parameters measured were related to changes in estimated insulin resistance. At baseline, high leptin levels were predictive of an improvement of glucose tolerance and this association was independent of baseline body weight. The association was also independent of baseline 2-hr glucose levels. It would go beyond the scope of this study to discuss the mechanism behind this association. Although speculative, high baseline leptin levels in our subjects may reflect leptin resistance, similar to insulin resistance, with increasing leptin concentrations target cells become resistant to its actions (23). It is also possible that a high secretion of leptin per unit fat mass may stimulate fatty acid oxidation and improve the metabolic profile (24). 
During this study, leptin levels increased more in the control compared to the intervention group and there was a significant relationship between change in leptin levels and change in HOMA-IR, an effect that disappeared after correction for change in body weight. Exercise is also know to reduce circulating leptin levels (25), and the 1-yr results of this study (14) have suggested an association between changes in leptin levels and HOMA-IR partly independent of changes in body composition, possibly reflecting a change in leptin sensitivity. However, it can be speculated that after 3 years, the impact of body weight changes seem to predominate the possible exerciseinduced effect on leptin sensitivity.

The 3-yr changes in PAI-1 levels were related to changes in HOMA-IR, independent of changes in body weight, maximal aerobic capacity and saturated fat intake. This is in agreement with previous results in non-diabetic healthy subjects who found an association between the changes in PAI-1 and the changes in HOMA-IR after a followup of 5.2 years (26). The finding that the relationship between PAI-1 and HOMA-IR persisted after correction for changes in body weight indicates that changes in adipocyte function rather than fat mass per se may contribute to the improved metabolic profile. Multiple factors seem to influence PAl-1 expression (27) and diabetes incidence, e.g. triglycerides, free fatty acids, glucose and subclinical inflammation, suggesting that changes in PAI-1 may be a marker of the complex mechanism underlying obesity and diabetes development.

The 3-yr changes in C3 levels were positively associated with changes in 2-hr glucose levels, which was for a large part explained by change in body weight. Previous studies have shown a relationship between C3 and 2-hr glucose in non-diabetic Pima Indians (28) and with diabetes development in men aged 38-50 years (6), independently of abdominal and general obesity. The attenuation of the relationship between changes in C3 and 2-hr glucose may be due to the relatively small sample size. Although C3 is mainly produced in the liver, the finding that body weight attenuated the relationship indicates that $\mathrm{C} 3$ may also be produced by other tissues like adipose tissue. However, an indirect effect of adipose tissue mass (29) (i.e. FFA inducing inflammation (30)) on liver C3 production also offers a plausible explanation. Another possible explanation may be that C3 levels reflect ASP, the proteolytic fragment of $C 3$, which stimulates glucose uptake and lipid storage in adipose tissue $(31 ; 32)$. A reduced uptake of glucose and fatty acids in adipose tissue of IGT subjects could be related to a blunted response to activation of the C3-ASP system.

Based on animal and in vitro data, resistin was originally thought to be a hormone linking obesity with insulin resistance (7). In contrast with other human studies (8; 9) we did find a relationship between changes in resistin and changes in insulin resistance, which was independent of changes in body weight. Further studies have to elucidate the exact role of resistin in insulin resistance

In conclusion, the 3-yr SLIM lifestyle intervention blunts the increase in leptin levels, compared to the control group. At baseline, high leptin levels are predictive of improvements of glucose tolerance, independent of baseline body weight, suggesting a role of leptin mediating glucose tolerance, partly independent of body fat mass. A trend was observed for a relationship between 3-year changes in resistin levels and changes in HOMA-IR and between changes in C3 levels and changes in 2-hr glucose levels. Lifestyle intervention did not affect PAI-1 levels, despite a positive association 
between the changes in PAI-1 levels and changes in estimated insulin resistance. Baseline leptin levels are reflective of baseline body weight and are indicative of beneficial lifestyle-induced changes in 2-hr glucose levels.

\section{Acknowledgements}

We thank Jos Stegen, Tanja Hermans-Limpens and Marja Ockeloen - van der Hulst for their help during the OGTT's and with the dietary intervention and Hans Cremers and Piet Beekhof for the measurements of the adipokines. This work was supported by grants from the Dutch Diabetes Research Foundation (DFN 98.901 and 2000.00.020), the Netherlands Organization for Health Research and Development (ZonMW 940-35034 and 2200.0139). 


\section{Chapter 7}

\section{References}

1. Herder C, Peltonen M, Koenig W, Kraft I, Muller-Scholze S, Martin S, et al. Systemic immune mediators and lifestyle changes in the prevention of type 2 diabetes: results from the Finnish Diabetes Prevention Study. Diabetes. 2006 Aug;55(8):2340-6.

2. Lindsay RS, Funahashi T, Hanson RL, Matsuzawa Y, Tanaka S, Tataranni PA, et al. Adiponectin and development of type 2 diabetes in the Pima Indian population. Lancet. 2002 Jul 6;360(9326):57-8.

3. Mather KJ, Funahashi T, Matsuzawa Y, Edelstein S, Bray GA, Kahn SE, et al. Adiponectin, change in adiponectin, and progression to diabetes in the Diabetes Prevention Program. Diabetes. 2008 Apr;57(4):980-6.

4. Muller S, Martin S, Koenig W, Hanifi-Moghaddam P, Rathmann W, Haastert B, et al. Impaired glucose tolerance is associated with increased serum concentrations of interleukin 6 and co-regulated acutephase proteins but not TNF-alpha or its receptors. Diabetologia. 2002 Jun;45(6):805-12.

5. Festa A, D'Agostino R, Jr., Tracy RP, Haffner SM. Elevated levels of acute-phase proteins and plasminogen activator inhibitor-1 predict the development of type 2 diabetes: the insulin resistance atherosclerosis study. Diabetes. $2002 \mathrm{Apr} ; 51(4): 1131-7$.

6. Engstrom G, Hedblad B, Eriksson KF, Janzon L, Lindgarde F. Complement C3 is a risk factor for the development of diabetes: a population-based cohort study. Diabetes. 2005 Feb;54(2):570-5.

7. Steppan CM, Bailey ST, Bhat S, Brown EJ, Banerjee RR, Wright CM, et al. The hormone resistin links obesity to diabetes. Nature. 2001 Jan 18;409(6818):307-12.

8. Lee JH, Chan JL, Yiannakouris N, Kontogianni M, Estrada E, Seip R, et al. Circulating resistin levels are not associated with obesity or insulin resistance in humans and are not regulated by fasting or leptin administration: cross-sectional and interventional studies in normal, insulin-resistant, and diabetic subjects. J Clin Endocrinol Metab. 2003 Oct;88(10):4848-56.

9. Hasegawa $G$, Ohta $M$, Ichida $Y$, Obayashi $H$, Shigeta $M$, Yamasaki $M$, et al. Increased serum resistin levels in patients with type 2 diabetes are not linked with markers of insulin resistance and adiposity. Acta Diabetol. 2005 Jun;42(2):104-9.

10. Otsuka F, Sugiyama S, Kojima S, Maruyoshi H, Funahashi T, Sakamoto T, et al. Hypoadiponectinemia is associated with impaired glucose tolerance and coronary artery disease in non-diabetic men. Circ J. 2007 Nov;71(11):1703-9.

11. Wannamethee SG, Tchernova J, Whincup P, Lowe GD, Kelly A, Rumley A, et al. Plasma leptin: associations with metabolic, inflammatory and haemostatic risk factors for cardiovascular disease. Atherosclerosis. 2007 Apr;191(2):418-26.

12. Esposito K, Pontillo A, Di Palo C, Giugliano G, Masella M, Marfella R, et al. Effect of weight loss and lifestyle changes on vascular inflammatory markers in obese women: a randomized trial. Jama. 2003 Apr 9;289(14):1799-804.

13. Hamalainen H, Ronnemaa T, Virtanen A, Lindstrom J, Eriksson JG, Valle TT, et al. Improved fibrinolysis by an intensive lifestyle intervention in subjects with impaired glucose tolerance. The Finnish Diabetes Prevention Study. Diabetologia. 2005 Nov;48(11):2248-53.

14. Corpeleijn E, Feskens EJ, Jansen EH, Mensink M, Saris WH, Blaak EE. Lifestyle intervention and adipokine levels in subjects at high risk for type 2 diabetes: the Study on Lifestyle intervention and Impaired glucose tolerance Maastricht (SLIM). Diabetes Care. 2007 Dec;30(12):3125-7.

15. Mensink M, Corpeleijn E, Feskens EJ, Kruijshoop M, Saris WH, de Bruin TW, et al. Study on lifestyleintervention and impaired glucose tolerance Maastricht (SLIM): design and screening results. Diabetes Res Clin Pract. 2003 Jul;61(1):49-58.

16. Mensink M, Blaak EE, Corpeleijn E, Saris WH, de Bruin TW, Feskens EJ. Lifestyle intervention according to general recommendations improves glucose tolerance. Obes Res. 2003 Dec;11(12):1588-96.

17. Eriksson J, Lindstrom J, Valle T, Aunola S, Hamalainen H, Ilanne-Parikka P, et al. Prevention of Type II diabetes in subjects with impaired glucose tolerance: the Diabetes Prevention Study (DPS) in Finland. Study design and 1-year interim report on the feasibility of the lifestyle intervention programme. Diabetologia. $1999 \mathrm{Jul} ; 42(7): 793-801$.

18. Roumen C, Corpeleijn E, Feskens EJ, Mensink M, Saris WH, Blaak EE. Impact of 3-year lifestyle intervention on postprandial glucose metabolism: the SLIM study. Diabet Med. 2008 May;25(5):597-605.

19. American College of Sports Medicine Position Stand. The recommended quantity and quality of exercise for developing and maintaining cardiorespiratory and muscular fitness, and flexibility in healthy adults. Med Sci Sports Exerc. 1998 Jun;30(6):975-91. 
20. Matthews DR, Hosker JP, Rudenski AS, Naylor BA, Treacher DF, Turner RC. Homeostasis model assessment: insulin resistance and beta-cell function from fasting plasma glucose and insulin concentrations in man. Diabetologia. 1985 Jul;28(7):412-9.

21. de Vegt F, Dekker JM, Jager A, Hienkens E, Kostense PJ, Stehouwer CD, et al. Relation of impaired fasting and postload glucose with incident type 2 diabetes in a Dutch population: The Hoorn Study. Jama. 2001 Apr 25;285(16):2109-13.

22. Friedewald WT, Levy RI, Fredrickson DS. Estimation of the concentration of low-density lipoprotein cholesterol in plasma, without use of the preparative ultracentrifuge. Clin Chem. 1972 Jun;18(6):499502.

23. Greenberg AS, Obin MS. Obesity and the role of adipose tissue in inflammation and metabolism. Am J Clin Nutr. 2006 Feb;83(2):461S-5S.

24. Begriche K, Letteron P, Abbey-Toby A, Vadrot N, Robin MA, Bado A, et al. Partial leptin deficiency favors diet-induced obesity and related metabolic disorders in mice. Am J Physiol Endocrinol Metab. 2008 May;294(5):E939-51.

25. Pasman WJ, Westerterp-Plantenga MS, Saris $\mathrm{WH}$. The effect of exercise training on leptin levels in obese males. Am J Physiol. 1998 Feb;274(2 Pt 1):E280-6.

26. Festa A, Williams K, Tracy RP, Wagenknecht LE, Haffner SM. Progression of plasminogen activator inhibitor-1 and fibrinogen levels in relation to incident type 2 diabetes. Circulation. 2006 Apr 11;113(14):1753-9.

27. Lyon $\mathrm{CJ}$, Hsueh WA. Effect of plasminogen activator inhibitor-1 in diabetes mellitus and cardiovascular disease. Am J Med. 2003 Dec 8;115 Suppl 8A:62S-8S.

28. Weyer C, Tataranni PA, Pratley RE. Insulin action and insulinemia are closely related to the fasting complement C3, but not acylation stimulating protein concentration. Diabetes Care. 2000 Jun;23(6):779-85.

29. Choy LN, Rosen BS, Spiegelman BM. Adipsin and an endogenous pathway of complement from adipose cells. J Biol Chem. 1992 Jun 25;267(18):12736-41.

30. Zimmer B, Hartung HP, Scharfenberger G, Bitter-Suermann D, Hadding U. Quantitative studies of the secretion of complement component $\mathrm{C} 3$ by resident, elicited and activated macrophages. Comparison with C2, C4 and lysosomal enzyme release. Eur J Immunol. 1982 May;12(5):426-30.

31. Cianflone K, Xia Z, Chen LY. Critical review of acylation-stimulating protein physiology in humans and rodents. Biochim Biophys Acta. 2003 Jan 31;1609(2):127-43.

32. Maslowska M, Sniderman AD, Germinario R, Cianflone K. ASP stimulates glucose transport in cultured human adipocytes. Int J Obes Relat Metab Disord. 1997 Apr;21(4):261-6. 



\section{CHANGES IN TRANSFERRIN ARE RELATED TO CHANGES IN INSULIN RESISTANCE}

The SLIM study

Cheryl Roumen, Edith J.M. Feskens, Eugène H.J.M. Jansen, Wim H. M. Saris, Ellen E. Blaak

Diabetic Medicine. 2008 Dec;25(12):1478-82. 
Abstract

\section{Objective}

To evaluate the effect of a lifestyle intervention on serum transferrin and ferritin levels and the relationship between changes in transferrin and ferritin and changes in glucose tolerance and insulin resistance.

\section{Method}

Randomized controlled lifestyle intervention directed at a healthy diet and increased physical activity in subjects with IGT.

\section{Results}

After 1 year, ferritin levels tended to decrease in the intervention group as compared to the control group $(p=0.06)$. Transferrin change was independently related to the change in HOMA-IR and ferritin change was related to the change in 2-hr FFA.

\section{Conclusions}

Changes in insulin sensitivity and postprandial lipid metabolism are related to changes in iron metabolism. 


\section{Introduction}

High serum transferrin and ferritin levels have been associated with the onset of hyperglycemia, insulin resistance and type 2 diabetes in several studies $(1,2)$, indicating that the iron status may play a role in the etiology of type 2 diabetes. The novelty of the present study is that it aims to evaluate the effect of lifestyle changes on transferrin and ferritin levels and the relationship between changes in transferrin and ferritin concentration and glucose tolerance and insulin resistance.

\section{Methods}

The SLIM study (Study on Lifestyle Intervention and Impaired Glucose Tolerance Maastricht) is a randomized controlled trial investigating a 6-yr dietary and physical activity intervention on glucose tolerance in subjects with impaired glucose tolerance (IGT). The local Medical Ethical Review Committee approved the study protocol. The study design has been described before (3). Participants gave their informed consent before the start of the study.

\section{Study design and subjects}

The study is described previously (3). For inclusion, mean 2-hr glucose concentration of 2 oral glucose tolerance tests had to be between 7.8 and $12.5 \mathrm{mmol} / \mathrm{l}$ and fasting glucose concentration $<7.8 \mathrm{mmol} / \mathrm{l}$. Originally, 147 subjects were randomized to a intervention (INT) or control group (CON), with stratification for 2-hr glucose levels and sex. The one-year examination included 129 subjects (see table 8.1).

\section{Lifestyle intervention}

Intervention subjects were individually guided (every 3 months visits) to achieve a healthy diet of 55 Energy\% carbohydrates, 35 Energy\% fat, <10 Energy\% saturated fat and more than $3 \mathrm{~g} / \mathrm{MJ}$ fiber each day, and to increase physical activity to at least 30 minutes a day for at least 5 days a week. Subjects were encouraged to participate in a free aerobic- and resistance exercise program. Control subjects received annually general information about the beneficial effects of a healthy diet and increased physical activity.

\section{Laboratory and clinical measurements}

Body weight was measured with an electronical scale to the nearest $0.1 \mathrm{~kg}$. Waist was measured to the nearest $0.5 \mathrm{~cm}$, with the subject in standing position at the level midway between the lowest rib and the iliacal crest. Plasma glucose, free fatty acids (FFA) were measured after an overnight fast and 2 hours after the use of a 75 gram glucose drink (OGTT), with standard enzymatic techniques, automated on a Cobas Fara centrifugal analyzer. Plasma insulin concentration was measured before and during the 


\section{Chapter 8}

OGTT with a Radio Immuno Assay (Cat. \#HI-14K, Linco Research) that shows no crossreactivity with pro-insulin. Transferrin, ferritin and high-sensitive C-reactive protein (CRP) were measured after an overnight fast in serum using an autoanalyser (Hitachi 912, Roche Diagnostics, Almere, The Netherlands). The HOMA-IR index for insulin resistance was calculated as described by Matthews et al. (1985) (4).

\section{Statistical analysis}

Insulin, FFA, ferritin, CRP were not normally distributed and were In-transformed. Subjects with CRP $(n=12)$ levels above $10 \mathrm{mg} / \mathrm{l}$ were excluded from analysis. Changes over time between groups were assessed using ANOVA (SPSS for Windows 14.0). Multiple linear regressions were used to evaluate the relationship between the individual changes in transferrin and ferritin and the individual changes in glucose levels and insulin resistance.

\section{Results}

Table 8.1 Subjects characteristics at baseline and after 1 year.

\begin{tabular}{|c|c|c|c|c|c|c|c|c|}
\hline & & \multicolumn{2}{|c|}{ Baseline } & \multicolumn{2}{|c|}{ Year 1} & \multirow{2}{*}{$\begin{array}{r}\text { Time } \\
\mathrm{P}\end{array}$} & \multirow{2}{*}{$\begin{array}{c}\text { Group } \\
\mathrm{P}\end{array}$} & \multirow{2}{*}{$\begin{array}{l}\begin{array}{r}\text { Group } \\
\mathrm{x} \text { Time }\end{array} \\
\mathrm{P}\end{array}$} \\
\hline & & INT & CON & INT & CON & & & \\
\hline & $\mathrm{N}$ & $64(35 \mathrm{~m} / 29 f)$ & 65 (34m/31f) & 64 (35m/29f) & $65(34 \mathrm{~m} / 31 \mathrm{f})$ & & & \\
\hline Body weight & (kg) & $86.7 \pm 1.60$ & $84.1 \pm 1.59$ & $84.4 \pm 1.53$ & $83.5 \pm 1.53$ & $<0.001$ & 0.46 & 0.01 \\
\hline $\mathrm{BMI}$ & $\left(\mathrm{kg} / \mathrm{m}^{2}\right)$ & $29.62 \pm 0.45$ & $29.60 \pm 0.45$ & $28.83 \pm 0.44$ & $29.41 \pm 0.44$ & $<0.001$ & 0.66 & 0.01 \\
\hline Waist & $(\mathrm{cm})$ & $102.95 \pm 1.25$ & $103.22 \pm 1.24$ & $100.11 \pm 1.31$ & $101.60 \pm 1.30$ & $<0.001$ & 0.62 & 0.15 \\
\hline Vo2 max & (I/min) & $2.28 \pm 0.08$ & $2.10 \pm 0.08$ & $2.38 \pm 0.08$ & $2.11 \pm 0.08$ & 0.01 & 0.06 & 0.03 \\
\hline Fasting glucose & $(\mathrm{mmol} / \mathrm{l})$ & $6.05 \pm 0.10$ & $5.89 \pm 0.10$ & $5.95 \pm 0.10$ & $5.94 \pm 0.10$ & 0.61 & 0.52 & 0.12 \\
\hline 2-hr glucose & $(\mathrm{mmol} / \mathrm{l})$ & $8.82 \pm 0.25$ & $8.55 \pm 0.24$ & $8.2 \pm 0.27$ & $8.79 \pm 0.27$ & 0.28 & 0.62 & 0.01 \\
\hline Fasting insulin & $(\mathrm{mU} / \mathrm{l})$ & $17.78 \pm 1.01$ & $17.45 \pm 1.00$ & $16.03 \pm 0.99$ & $17.68 \pm 0.97$ & 0.26 & 0.64 & 0.32 \\
\hline 2-hr insulin & $(\mathrm{mU} / \mathrm{l})$ & $97.79 \pm 10.38$ & $100.19 \pm 10.47$ & $90.31 \pm 9.71$ & $104.45 \pm 9.80$ & 0.96 & 0.48 & 0.05 \\
\hline HOMA-IR & & $4.88 \pm 0.32$ & $4.64 \pm 0.32$ & $4.32 \pm 0.30$ & $4.74 \pm 0.30$ & 0.25 & 0.81 & 0.22 \\
\hline Transferrin & $(\mathrm{g} / \mathrm{l})$ & $2.56 \pm 0.05$ & $2.44 \pm 0.05$ & $2.55 \pm 0.05$ & $2.44 \pm 0.05$ & 0.82 & 0.08 & 0.72 \\
\hline Ferritin & $(\mu \mathrm{g} / \mathrm{l})$ & $164.10 \pm 21.54$ & $188.64 \pm 21.20$ & $143.80 \pm 18.77$ & $165.22 \pm 18.48$ & $<0.001$ & 0.41 & 0.06 \\
\hline Fasting FFA & $(\mu \mathrm{mol} / \mathrm{l})$ & $602.61 \pm 25.58$ & $567.00 \pm 25.38$ & $476.04 \pm 18.08$ & $480.44 \pm 17.94$ & $<0.001$ & 0.69 & 0.12 \\
\hline 2-hr FFA & $(\mu \mathrm{mol} / \mathrm{l})$ & $114.30 \pm 7.68$ & $100.75 \pm 7.61$ & $80.57 \pm 4.67$ & $86.51 \pm 4.63$ & $<0.001$ & 0.90 & 0.02 \\
\hline CRP & $(\mathrm{mg} / \mathrm{l})$ & $2.94 \pm 0.30$ & $3.02 \pm 0.28$ & $2.49 \pm 0.31$ & $3.07 \pm 0.29$ & 0.04 & 0.25 & 0.16 \\
\hline
\end{tabular}

Data are mean \pm SEM. $(n=129)$. $P$ was measured by ANOVA repeated measures. For all skewed variables (fasting insulin, 2-hr insulin, HOMA-IR, transferrin, ferritin) statistics were performed on In-transformed values.

\section{Baseline characteristics}

At baseline, INT subjects were younger than CON subjects $(54.9 \pm 0.83 \mathrm{yr}$ versus $58.4 \pm 0.87 \mathrm{yr}, \mathrm{p}=0.004$ ). 18 Subjects ( 6 male, 12 female; 10 INT, 8 CON) discontinued 
the study and were excluded. They had a lower $\mathrm{VO}_{2}$ max, higher 2-hr glucose levels $\left(p_{\text {all }}<0.05\right)$ and a higher BMI $(p=0.06)$ at baseline than those who continued participation.

\section{Results of 1-yr intervention}

INT subjects decreased more in body weight and BMI versus CON $(p<0.05)$. Mean 2 -hr glucose, 2-hr insulin, 2-hr FFA decreased more in INT $\left(\mathrm{p}_{\text {all }}<0.05\right)$ and ferritin tended to decrease compared to the $\mathrm{CON}$ group (table 8.1). $\mathrm{VO}_{2}$ max increased in INT with no changes in CON. Change in transferrin level was similar across groups.

Table 8.2 Standardized regression coefficients of 1-yr changes in transferrin and ferritin regressed 1-yr changes in metabolic parameters.

\begin{tabular}{lcccccccccc}
\hline Change in & & Transferrin & P & Transferrin & P & Ferritin & $P$ & Ferritin & $P$ \\
& & & Unadjusted & & Adjusted & & Unadjusted & & Adjusted \\
\hline Change in BMI & $(\mathrm{kg} / \mathrm{m} 2)$ & 0.217 & 0.018 & 0.221 & 0.019 & 0.042 & 0.638 & 0.010 & 0.912 \\
Change in Waist & $(\mathrm{cm})$ & 0.118 & 0.193 & 0.172 & 0.064 & -0.007 & 0.937 & -0.035 & 0.705 \\
Change in Fasting Glucose & $(\mathrm{mmol} / \mathrm{l})$ & 0.146 & 0.139 & 0.185 & 0.064 & -0.006 & 0.954 & -0.032 & 0.744 \\
Change in 2-hr Glucose & $(\mathrm{mmol} / \mathrm{l})$ & 0.133 & 0.174 & 0.132 & 0.184 & 0.119 & 0.210 & 0.080 & 0.405 \\
Change in Fasting Insulin & $(\mathrm{mU} / \mathrm{l})$ & 0.299 & 0.001 & 0.292 & 0.002 & 0.001 & 0.987 & -0.024 & 0.799 \\
Change in 2-hr Insulin & $(\mathrm{mU} / \mathrm{l})$ & 0.188 & 0.063 & 0.153 & 0.148 & 0.050 & 0.613 & 0.016 & 0.875 \\
Change in HOMA & & 0.295 & 0.002 & 0.305 & 0.001 & -0.002 & 0.982 & -0.032 & 0.736 \\
Change in Fasting FFA & $(\mu \mathrm{mol} / \mathrm{l})$ & 0.214 & 0.038 & 0.199 & 0.066 & 0.090 & 0.366 & 0.074 & 0.482 \\
Change in 2-hr FFA & $(\mu \mathrm{mol} / \mathrm{l})$ & -0.037 & 0.725 & $<0.001$ & 0.998 & 0.224 & 0.020 & 0.225 & 0.030 \\
Change in CRP & $(\mathrm{mg} / \mathrm{l})$ & -0.002 & 0.983 & -0.003 & 0.974 & 0.174 & 0.067 & 0.157 & 0.105
\end{tabular}

Unadjusted: regression analysis adjusted for the baseline value of the dependent and independent variables. Adjusted: regression analysis adjusted for age, gender, random assignment and the baseline value of the dependent and independent variables. Data are expressed as standardized betas. For all skewed variables (fasting insulin, 2-hr insulin, HOMA-IR, fasting FFA, 2-hr FFA, CRP, transferrin, ferritin) statistics were performed on In-transformed values.

\section{Regression analyses}

Changes in transferrin and ferritin were inversely associated $(r=-0.49 ; p<0.01)$. Change in transferrin was higher in men than in women, was positively associated with change in BMI, fasting insulin, HOMA-IR and fasting FFA ( $\left.p_{\text {allI }}<0.05\right)$, and tended to be associated with change in 2-hr insulin (table 8.2). $\triangle$ Transferrin explained $7.5 \%$ of the change in $\triangle$ HOMA-IR ( $p=0.02$ ). Results were comparable when analysis was performed on INT and CON separately (data not shown). After adjustment for age, gender and study group, change in transferrin remained independently associated with change in BMI, fasting insulin and HOMA-IR. In addition, the association between change in transferrin 


\section{Chapter 8}

and change in HOMA-IR was also independent of changes in BMI and fasting FFA $(\beta=0.285 \mathrm{~g} / \mathrm{l}, \mathrm{p}=0.02)$. When replacing HOMA-IR with fasting insulin, results were essentially similar $(\beta=0.252 \mathrm{mU} / \mathrm{l}, \mathrm{p}=0.04)$.

For serum ferritin, no association with changes in glucose tolerance or insulin sensitivity were observed. Change in serum ferritin was significantly positively associated with change in $\Delta 2$-hr FFA, independent of age, gender, study group and change in $\operatorname{CRP}(\beta=0.247 \mu \mathrm{g} / \mathrm{l}, \mathrm{p}=0.02)$.

\section{Discussion}

Epidemiological studies have demonstrated that the iron metabolism may be involved in the etiology of type 2 diabetes $(1,2,5)$. In our observational study, changes in transferrin levels were positively associated with changes in estimated insulin resistance in subjects at high risk for developing type 2 diabetes, i.e. those with impaired glucose tolerance. Although these data do not imply causality, they are compatible with the results of the DESIR study (1), which showed that transferrin predicted changes in fasting insulin. The mechanism behind the relationship between transferrin and insulin resistance is still unclear. This study and the DESIR findings merit further investigation to clarify causality between transferrin, insulin resistance and the development of type 2 diabetes.

Our intervention program did not affect transferrin, possibly due to the variation in response to the lifestyle intervention within study groups. Our intervention program tended to reduce ferritin, which has been associated with type 2 diabetes onset (2), fasting insulin and fasting glucose (1). In other studies, ferritin and other inflammation markers such as $\mathrm{C}$-reactive protein have also been associated with the metabolic syndrome $(6,7)$. In our study, ferritin and 2-hr FFA levels were positively associated, independent of CRP as an indicator of the acute phase response, suggesting involvement of the iron status itself in the regulation of 2-hr FFA levels. The mechanism by which iron may stimulate lipolysis is unclear, but ferritin may catalyze hydroxyl radicals (8) and contribute to insulin resistance.

In conclusion, lifestyle-induced changes in transferrin levels were related to changes in fasting insulin, whilst change in ferritin was related to change in postprandial fatty acids. These data have shown an association between changes in insulin sensitivity and postprandial lipid metabolism with changes in iron metabolism.

\section{Acknowledgements}

This work was supported by grants from the Dutch Diabetes Research Foundation (DFN 98.901 and 2000.00.020), the Netherlands Organization for Scientific Research (94035-034 and 2200.0139). 


\section{References}

1. Fumeron F, Pean F, Driss F, Balkau B, Tichet J, Marre M, et al. Ferritin and transferrin are both predictive of the onset of hyperglycemia in men and women over 3 years: the data from an epidemiological study on the Insulin Resistance Syndrome (DESIR) study. Diabetes Care. 2006 Sep;29(9):2090-4.

2. Forouhi NG, Harding AH, Allison M, Sandhu MS, Welch A, Luben R, et al. Elevated serum ferritin levels predict new-onset type 2 diabetes: results from the EPIC-Norfolk prospective study. Diabetologia. 2007 May;50(5):949-56.

3. Mensink M, Corpeleijn E, Feskens EJ, Kruijshoop M, Saris WH, de Bruin TW, et al. Study on lifestyleintervention and impaired glucose tolerance Maastricht (SLIM): design and screening results. Diabetes Res Clin Pract. 2003 Jul;61(1):49-58.

4. Matthews DR, Hosker JP, Rudenski AS, Naylor BA, Treacher DF, Turner RC. Homeostasis model assessment: insulin resistance and beta-cell function from fasting plasma glucose and insulin concentrations in man. Diabetologia. $1985 \mathrm{Jul} ; 28(7): 412-9$.

5. Fernandez-Real JM, Moreno JM, Lopez-Bermejo A, Chico B, Vendrell J, Ricart W. Circulating soluble transferrin receptor according to glucose tolerance status and insulin sensitivity. Diabetes Care. 2007 Mar;30(3):604-8.

6. Ford ES. The metabolic syndrome and C-reactive protein, fibrinogen, and leukocyte count: findings from the Third National Health and Nutrition Examination Survey. Atherosclerosis. 2003 Jun;168(2):351-8.

7. Jehn M, Clark JM, Guallar E. Serum ferritin and risk of the metabolic syndrome in U.S. adults. Diabetes Care. 2004 Oct;27(10):2422-8.

8. Rumberger JM, Peters T, Jr., Burrington C, Green A. Transferrin and iron contribute to the lipolytic effect of serum in isolated adipocytes. Diabetes. 2004 Oct;53(10):2535-41. 



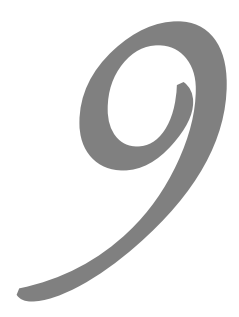

GENERAL DISCUSSION 

Over decades type 2 diabetes has changed from a chronic metabolic disease in elderly into a major health problem affecting an increasing number of people worldwide (1). Diabetes-related complications are considerable and prevention and treatment of diabetes are of utmost importance to increase quality of life and reduce the increasing health care costs. Pharmacological treatment has shown to be effective in reducing diabetes risk, but lifestyle interventions have shown to be even more effective than pharmacological treatment $(2 ; 3)$. Even more, the effect of lifestyle interventions is sustained over more than a decade after active counseling is discontinued $(4 ; 5)$. However, non-adherence to lifestyle interventions is a widespread problem (6) and tends to be high with increasing time and complexity and when designed to prevent rather than cure illness (7). In this thesis, we focused on the potential benefits of a combined nutritional and exercise intervention strategy to stimulate a healthy lifestyle and, as such, improve glucose tolerance, insulin sensitivity and prevent/postpone the development of type 2 diabetes in a group of subjects at risk. In addition, this thesis describes potential behavioral as well as metabolic factors related to lifestyle outcome and adherence, in light of future implementation strategies.

\subsection{Can lifestyle intervention prevent or postpone the development of type 2 diabetes?}

It has been known for several years that lifestyle interventions targeting changes in dietary intake and composition and changes in physical activity frequency and intensity reduce diabetes risk in IGT subjects $(2 ; 8 ; 9)$ (as reviewed in chapter 2). Based on estimates from the Diabetes Prevention Program (DPP), lifestyle interventions seem to postpone diabetes onset with approximately 11 years, and prevent diabetes onset with $20 \%$ (10). In recent years, more has become known about long-term effectiveness (3-5) and cost-effectiveness (10-12).

In chapter 3, we showed that the SLIM lifestyle intervention, following general public health guidelines, is effective in reducing body weight $(-1.1 \mathrm{~kg})$ and improving maximal aerobic capacity $\left(\mathrm{VO}_{2 \max }\right)(+0.05 \mathrm{l} / \mathrm{min})(13)$. After 3 years, the $0.8 \mathrm{mmol} / \mathrm{l}$ difference in 2-hr glucose levels between study groups was associated with a $58 \%$ reduction in diabetes incidence. This is consistent with the diabetes risk reductions found in the major lifestyle intervention studies in the USA and Finland, i.e. the DPP (2) and DPS (8).The course of body weight and 2-hr glucose levels is similar to that found in the Diabetes Prevention Study (DPS). They showed a weight reduction of $-4.5 \mathrm{~kg}$ and a 2-hr glucose reduction of $-0.9 \mathrm{mmol} / \mathrm{l}$ during the first year and a regain of approximately $1 \mathrm{~kg}$ and $0.4 \mathrm{mmol} / \mathrm{l}$ after 3 years, respectively (14).

At the end of the SLIM study, after minimal 3 years and maximal 6 years of intervention (mean 4.1 years), a significant beneficial effect remained on $\mathrm{VO}_{2} \max (0.3 \mathrm{l} / \mathrm{min}$ difference between intervention and control group). 2-hr Glucose $(0.7 \mathrm{mmol} / \mathrm{l}$ difference between intervention and control group) improved and dietary composition improved (reduced total and saturated fat, increased fiber and carbohydrate intake), despite loss of effect on body weight (chapter 4). Including all available observations, diabetes risk reduction was $47 \%$ for the intervention group relative to the control group. Most lifestyle interventions show a beneficial lifestyle effect on diabetes risk, 
while the effect on 2-hr glucose levels have been far less consistent (chapter 2). Interestingly, in the DPS a borderline effect on $2-\mathrm{hr}$ glucose $(-0.1 \mathrm{mmol} / \mathrm{l}, \mathrm{p}=0.07)$ is still associated with a diabetes risk reduction of $58 \%$ (14). Part of the risk reduction may be mediated via other pathways than $2 \mathrm{hr}$-glucose, e.g. on fasting glucose levels, via subclinical inflammatory factors (15) or restoration of $\beta$-cell function (16).

Lifestyle interventions, i.e. SLIM, have shown to be more cost-effective than metformin treatment $(10 ; 11)$ and have shown to be effective resulting in sustained beneficial effects on 2-hr glucose levels and diabetes risk.

\subsection{Lifestyle intervention and the metabolic syndrome}

As mentioned above, current evidence clearly indicates the effect of lifestyle interventions in reducing diabetes incidence as clinical endpoint. However, do lifestyle interventions also reduce metabolic syndrome features?

In recent years, the metabolic syndrome has evolved as a term for a clustering of metabolic disorders associated with diabetes and cardiovascular risk, including most often criteria for hypertension, (abdominal) obesity, a disturbed blood lipid spectrum and an impaired glucose metabolism. Several definitions of the metabolic syndrome exist (17), and besides the debate regarding whether obesity or insulin resistance plays a central role in the in the underlying pathophysiology, the clinical relevance of the syndrome has not been established yet. In chapter 3, we did not observe a lifestyle intervention-induced effect on the prevalence the metabolic syndrome or the individual components waist circumference, fasting trigyceride levels, HDL cholesterol levels, blood pressure or fasting glucose levels, despite a marked improvement in 2-hr glucose. The minor changes in body weight and waist circumference may be responsible for the lack of effect on the metabolic syndrome. In the DPP (18) and DPS (19), a lifestyle intervention reduced the incidence of metabolic syndrome by $38-41 \%$. In both studies, the reduction in metabolic syndrome appeared strongly related to a reduction in waist circumference, while in SLIM no significant changes in waist were observed after 3 years. It seems that sustained body weight loss, and primarily reduced abdominal fat, is necessary to reduce the metabolic syndrome. A recent 15 -week low-calorie diet showed that body weight loss of nearly $10 \%$ reduces the metabolic syndrome by $61 \%$, in obese, primarily female subjects (20).

\subsection{Dropout and adherence}

Lifestyle interventions face the challenge of keeping participants in the program and sustaining adherence to the program, especially when implemented in the health care system. Dropout to the SLIM intervention was $28 \%$ after 3 years (chapter 3 ), compared to a dropout rate of $8 \%$ and $7.5 \%$ in the DPS and DPP, respectively. It is not entirely clear why the dropout rate in SLIM is higher compared to the DPS and DPP. However, subjects in SLIM had less overweight compared to the subjects in the DPS and DPP. Therefore, our SLIM subjects may have had more difficulties to loose weight and be satisfied about it. In addition, we observed that half of the SLIM participants had a low 
socio-economic status, which was a strong determinant of dropout (chapter 4). In Europe, mortality rates and poorer self-assessments of health, are higher in groups of lower socioeconomic status compared to the higher-status counterparts (21). Recent Dutch research has also shown that higher educated people not only live longer, but also spend a longer period of their lives in good health (22). In the SLIM study, approximately $50 \%$ of the subjects had a low socio-economic status, which is higher than the general proportion in Limburg in 2006, ranging from 33-38\% (23). Although the SLIM population may not be a representative sample of the general population, it may well represent the vulnerable group at high risk for diabetes and other metabolic disturbances. The high dropout rate in the SLIM study is worrisome and exemplifies the difficulty to reach and sustain lifestyle changes in this vulnerable group and, as such, increase the quality of life. The dropout rate of SLIM is not specific for lifestyle interventions. Also non-lifestyle studies have reported high drop-out rates, i.e. the DREAM trial (24), with $29.3 \%$ dropout in the rosiglitazone group.

In chapter 5, we showed that a low perceived susceptibility to getting diabetes and misconception about own adherence are associated with non-adherence in participants. Increasing awareness could be a way to improve adherence in participants as well as clinicians, since awareness and perception of advantages $(25 ; 26)$ have been shown to play a critical role in adherence of a certain behavior. Perceived susceptibility, as well as awareness and motivation have also been found important mediators of participation (26). Also, restricting the travel time towards the exercise facility could have improved adherence, although our study did not confirm this (27). Both sufficient participation and adherence to the lifestyle changes are necessary for cost-effective implementation in the general population (28). Increasing awareness and changing perceived susceptibility to one that is more likely to be true may reduce refusal and dropout to the lifestyle program, although scientific studies are warranted that study these approaches. Other factors that were associated with decreased adherence like doing the shopping and cooking or being male are more difficult to explain and need further investigation.

\subsection{Lifestyle approach versus pharmacological approach}

Not all subjects that initially participate in lifestyle interventions comply with the regime, respond metabolically and are able to continue adherence. For subjects that are unable to adhere or do not show a beneficial metabolic response, a pharmacological approach, with or without lifestyle changes, may be considered. In the prevention and treatment of diabetes, pharmacological approaches have also been used and with success $(3 ; 24)$. Unfortunately, the effect by medication is only present when adhering to the prescription and is not sustained over several years after discontinuation, as is the case for lifestyle interventions $(4 ; 5)$.

In the Diabetes Reduction Assessment with Ramipril and Rosiglitazone Medication (DREAM) trial, subjects with IGT, IFG, or both were randomly assigned to receive rosiglitazone or placebo for a median of 3 years (24). Rosiglitazone substantially reduced incident type 2 diabetes (hazard ratio 0.36 for isolated IGT) and a larger number of subjects receiving rosiglitazone progressed towards normoglycemia (hazard ratio 
1.7) than did individuals receiving placebo. However, the occurrence of heart failure was higher in the rosiglitazone group (hazard ratio 7.0), as tended the overall cardiovascular events $(p=0.08)$. In light of prevention of major cardiovascular events, a recent study from the USA and Canada showed that compared to standard drug therapy, intensive drug therapy to target normal glycated hemoglobin levels for 3.5 years, using several medications, increased mortality and did not significantly reduce cardiovascular events (29). New pharmacological approaches on diabetes incidence and cardiovascular outcome are currently investigated in subjects with IGT, like the effect of valsartan, a selective angiotensin II antagonist acting on the $A T_{1}$ receptor subtype (30). Lifestyle interventions can have multiple beneficial metabolic effects beyond glycemic control and should therefore remain the cornerstone in the prevention and treatment of type 2 diabetes. Pharmacological treatment targeting glycemic control is a plausible treatment for subjects with incident type 2 diabetes when lifestyle interventions have not reached a beneficial effect.

\subsection{Factors associated with the lifestyle-induced effect on glucose} tolerance, insulin resistance and diabetes risk

The total effect of lifestyle interventions depends on its components namely the effects on body weight, body composition, dietary intake and composition and physical activity. Genetic susceptibility and gender can mediate the lifestyle-induced effect.

\subsubsection{Body weight}

In the Netherlands, approximately $46 \%$ of the Dutch adults were overweight in 2007 (31), which seems to be the most important risk factor for type 2 diabetes (32-36). In the SLIM study, body weight loss and reduced waist circumference were the strongest predictors of changes in 2-hr glucose levels, as discussed in chapter 4. Although body weight is the strongest predictor of 2-hr glucose in SLIM, at the end of the study a beneficial effect on 2-hr glucose levels was sustained, most likely due to sustained changes in dietary composition and $\mathrm{VO}_{2} \mathrm{max}$. In the SLIM study, 1-year changes in insulin sensitivity were partly related to changes in fatty acid profile of serum cholesteryl esters (which partly reflect dietary fatty acid intake), and in particular to changes in desaturase activities (37). This suggests that the shift in fatty acid composition of the diet (reduced saturated fat) may have explained part of the positive lifestyle effects.

Not all adipose tissue depots seem to have an equal contribution to diabetes risk. A study has shown that a minor loss of body weight, accompanied by a major reduction in visceral and liver fat, was associated with improved insulin sensitivity $(38 ; 39)$. Reductions in visceral fat depot may depend on the initial fat size (40-42). It is still unclear if there is an inverse dose-response relationship between a reduction in visceral fat and insulin sensitivity, or if the visceral fat depot has to decrease below a specific threshold to have a metabolic benefit (38). To date, the results of SLIM once more reinforce that reductions in body weight and especially waist circumference are most strongly associated with a reduced diabetes risk. Future studies have yet to determine to what extent body fat distribution and changes in adipose tissue depots 
add to the metabolic benefits of traditional lifestyle factors, i.e. body weight reduction, improved dietary composition and increased physical activity.

\subsubsection{Dietary composition}

Dietary intake and dietary composition have attributed to the obesity and diabetes epidemic. Therefore, it is rational to realign our eating habits with our physiological needs (43). The term 'dietary pattern' comprises multiple components and this section will highlight several of them, including fat, fiber, carbohydrate intake, and glycemic index.

Total fat, and especially saturated fat intake is an important diabetes risk factor (44; 45). Reduced-fat diets without energy restriction have been shown to reduce weight with 3-5 kilograms $(46 ; 47)$, sustain weight loss and reduce diabetes incidence (45). In chapter 3 and chapter 4, we confirmed that changes in dietary composition towards a reduction in total and saturated fat, and an increase in carbohydrate and fiber intake, was associated with a beneficial effect on 2-hr glucose levels and a reduction in diabetes incidence. A reduction in total fat intake may affect diabetes development by a decrease in lipid overflow and triglyceride storage in other tissues than adipose tissue. Although the type of fatty acids may also play a role in the development of type 2 diabetes $(37 ; 48 ; 49)$, we did not investigate this in this thesis.

Dietary fibers can reduce the rate of glucose absorption in the intestine, thereby lowering postprandial glycemic, insulinemic responses (50) and improving insulin sensitivity (51). In SLIM, fiber intake increased more in the intervention group, as compared to the control group (chapter 3 ) and a recent meta-analysis once more established the importance of dietary fibers in reducing diabetes risk (52). In the DPS (45), high fiber was a independent contributor to a reduced diabetes risk. High glycemic-index, low-fiber diets, independently increase the risk of type 2 diabetes and cardiovascular disease $(53 ; 54)$. A reduced glycemic response diet seems to improve $\beta$ cell function in IGT subjects (55). In addition, a recent meta-analysis and review has shown that a reduced glycemic response diet in combination with unavailable carbohydrate intake is followed by favorable changes in, among others, insulin sensitivity (56).

Proteins of high biological value, i.e. whey protein, seem to have a high potential of reducing postprandial glucose levels as well as to increase satiety (57). Another potential dietary factor is alcohol use. Light to moderate alcohol use (defined as 0.5 to 1 drink daily for women, and 1 to 2 drinks daily for men) is associated with increased insulin sensitivity, lower postprandial glucose levels and better health $(58 ; 59)$. With regard to the relationship between alcohol abuse and diabetes development, little information has been published. In SLIM, we did not observe a significant change in alcohol use and total protein intake (chapter 3).

The SLIM study shows that an intervention consisting of four meetings a year with a trained dietician with advice for a healthy diet is effective in changing the dietary composition towards reduced fat and increased carbohydrates and fiber intake after 36 years. Although these changes may help to reduce diabetes risk, body weight reduction seems the most important factor. 


\subsubsection{Physical activity}

In the Netherlands and across most European countries less than half of the population is sufficiently active. The Eurobarometer study in 2006 showed that the prevalence of sufficient physical activity for health (5 times a week 30 minutes moderately active or 3 times a week vigorously active) across the Netherlands was $44 \%$, ranging from $40 \%$ in women to $48 \%$ in men (60). Among European countries, the Netherlands had the highest prevalence of people with sufficient physical activity, while in contrast, it also inhabited the second-highest prevalence of people who sit at least 6 hours per day (60). More studies regarding sedentary time should be performed, but there seems to be a positive correlation with waist circumference, independent of moderate-to-vigorous physical activity (61).

In SLIM, we showed that the lifestyle intervention was effective in increasing $\mathrm{VO}_{2}$ max after 3-6 years (chapter 3 and chapter 4 ) and in the intervention group this was accompanied by an increased number of days that subjects were at least $30 \mathrm{~min}$ physically active (bicycling, gardening or doing sports). In addition, we showed that $\mathrm{VO}_{2}$ max is higher in subjects that continue participation of the lifestyle intervention until the end of the study.

Current physical activity recommendations to maintain health and prevent disease are at least 30 minutes of moderate-intensity physical activity on most, preferably all days of the week $(62 ; 63)$, which seem an effective and safe way to improve insulin sensitivity and insulin secretion (64) and prevent type 2 diabetes in all populations (65). However, recent studies investigating interval training (with brief high intensities $~ 95 \%$ $\mathrm{VO}_{2} \max$ ) suggests that this type of interval training may be more powerful than training at $70 \% \mathrm{VO}_{2} \mathrm{max}$ in eliciting changes in the metabolic disturbances associated with IGT and heart failure patients (66-71). If interval training is at least as effective as moderate intensity training, than more exercise options can be provided, i.e. those that limit time use (71). The SLIM study lacks the statistical power to draw conclusions about the efficacy of exercise or leisure time physical activity in increasing aerobic capacity. In conclusion, it seems that high intensity exercise may be more effective for beneficial metabolic changes, while leisure-time physical activity may be easier to put into practice. In addition, low-intensity physical activity and physical activity during leisure time and work should also be encouraged since even moderate levels of usual physical activity are associated with significantly reduced 2 -hr glucose levels (72) and a reduced risk of mortality and cardiovascular disease in men and women $(73 ; 74)$.

\subsubsection{Genetics}

In the SLIM study, genetic variation has not yet been analyzed while the interaction of genes with the environment may play a role in the metabolic response to a lifestyle intervention. Several gene-environment interactions have been found, e.g. the X/Ala genotype of the PPARY-2 Pro12Ala SNP seems associated with bad lifestyle habits, but subjects with this genotype may also profit more from the lifestyle intervention (75). Also, in the Tübinger Lifestyle Intervention Program (TULIP) (76), which followed the DPS lifestyle protocol, showed that the minor G allele of SNP rs2267668 in PPARD and the minor serine-encoding allele of the common Gly482Ser SNP in PPARGC1A were 
independently associated with less increase in individual anaerobic threshold (77), indicating that these alleles impair the effectiveness of aerobic training.

To conclude, genetic variation can play a role in the response to a lifestyle intervention. Studies involving interactions between genes and lifestyle intervention response are still limited and need confirmation in large cohorts. When more conclusive evidence is provided, the effectiveness of tailored lifestyle programs should be tested in subgroups with genotypes that are associated with adequate and impaired metabolic response to a lifestyle intervention (78).

\subsubsection{Gender}

Across the general population, lifestyle changes may differ between men and women. In the SLIM lifestyle intervention group, men had higher fasting glucose, blood pressure, caloric intake, and lower HDL cholesterol levels at baseline, similar to recent results from the DPP (79), presumably making their diabetes risk higher. After 1 year in SLIM, lifestyle-induced changes in 2-hr glucose were similar across both sexes and after 3 years similar changes were observed, except for waist-hip ratio and percentage of body fat which increased in women but remained relatively stable in men (chapter 3 ). After 1 year in the DPP, men showed a greater decrease in 2-hr glucose levels when losing $>3 \%$ body weight (79), while diabetes incidence was not lower in men, compared to women. The greater decrease in 2-hr glucose levels may not have leveled out the contribution of the high fasting glucose levels at baseline in men. Although it is plausible that sex differences mediate metabolic and cardiovascular risk, sex per se does not seem to be a predictor of coronary heart disease mortality in subjects with type 2 diabetes (80). Studies powered to examine sex-specific consequences of different prevention strategies would be useful.

\subsection{Adipokines and Inflammation factors}

Work over the past decades has revealed that adipose tissue is metabolically active in controlling glucose homeostasis and insulin sensitivity. With increasing adipose tissue mass and reduced adipose tissue function, the lipid buffering capacity of adipose tissue decreases, resulting in an increased flux of lipids to non-adipose tissues like muscle and liver (lipid overflow). Secondly, the function of adipose tissue to secrete multiple biologically active proteins may be impaired (81). Adipocyte dysfunction is characterized by hypertrophied adipocytes with an altered secretion of adipokines and high secretion of monocyte chemoattractant protein-1 (MCP-1) perhaps enhancing macrophage infiltration and the pro-inflammatory state $(82 ; 83)$. Results from chapter 6 and 7 will be discussed in light of these hypotheses.

In the SLIM study, we observed a relation between change in complement factor 3 (C3) and change in 2-hr glucose, after 1 and borderline after 3 years of intervention, independent of changes in body weight (chapter 6 and chapter 7). Our results were similar to those found in non-diabetic Pima Indians (84), suggesting a relation between C3 and diabetes development at least partly independent of obesity (85; 86). The mechanisms underlying these associations are unclear. Acylation stimulating protein 
(ASP), a peptide hormone which is formed by the protolytic cleavage of C3, may stimulate the uptake of glucose and fatty acids in adipose tissue (87). Hypothetically, a blunted response to the C3-ASP system could be related to increased levels of C3, glucose and lipids (88). C3 is mainly produced in the liver (89) and cytokines may stimulate C3 production as well as the production of lipids, thereby reducing insulin resistance. In contrast to the relationship with 2-hr glucose, in SLIM, changes in C3 and changes in HOMA-IR were explained by changes in body weight (chapter 6 and chapter 7). Besides the liver, adipose tissue may be a proinflammatory source of $\mathrm{C} 3$ production (90), by activated macrophages (91) and adipocytes (92). In agreement with another study (93), C3 was a stronger inflammatory marker than CRP, both of which may reflect the hepatic inflammatory contribution to diabetes development.

In the SLIM 1-year results (chapter 6), we observed an independent relationship between changes in 2-hr glucose and changes in IL-6. In a prospective study with 3075 men and women aged 70-79 years, IGT has shown to be associated with IL-6 (94). Also in cross-sectional studies IGT has been associated with increased IL-6 levels (95; 96). These findings are in agreement with previous results showing an increased IL-6 production from muscle in the postprandial phase of IGT men (97). The strong relationship between IL- 6 and 2-hr glucose may possibly be explained by an inhibitory effect of IL-6 on insulin signaling in the liver (98), i.e. by decreasing insulin-mediated suppression of endogenous glucose production (EGP) (99), as observed in animal studies. Human studies to verify this hypothesis are scarce. One study showed no effect of IL-6 on EGP (100), but this study was done in healthy individuals and not in subjects with a disturbed glucose metabolism. Surprisingly, after 3 years, IL-6 was no longer associated with 2-hr glucose levels (chapter 7). The mechanism explaining this result is not clear, IL-6 may only have a short-term effect on 2-hr glucose levels. On the long term, IL-6 does not seem to play an important role. IL-6 seems to play a physiological role when increased during relatively short periods, while it seems to have a pathological role when elevated chronically. The rapid rate at which IL- 6 is cleared after infusion $(101 ; 102)$ or exercise $(103)$ suggests that chronic elevation of IL-6 is not desirable (104).

Lifestyle interventions may have beneficial effects on inflammation factors (105; 106), although we were unable to confirm this directly in the SLIM study. We did observe that beneficial changes in glucose tolerance in the intervention and control group together were associated with changes in CRP, IL- 6 and C3 after 1 year and borderline with C3 after 3 years. This suggests that beneficial changes in glucose tolerance may be partly explained through changes in these inflammatory markers. However, the magnitude of these factors in contributing to the etiology of type 2 diabetes and vascular abnormalities remains to be determined.

In the SLIM study, leptin levels increased significantly less in the intervention group compared to the control group (chapter 7). Changes in leptin were associated with changes in HOMA-IR after 1 year (107) and after 3 years (chapter 7). Changes in body weight appeared the primary factor explaining this relationship. Similarly, in previous studies in men but in not women, baseline leptin levels were related to incident diabetes $(108 ; 109)$, independent of markers of body fat. The higher levels of leptin observed in women, compared to men, may be an explanation, suggesting a 
non-linear relationship in women between leptin levels and insulin resistance/ diabetes development.

After 3 years of lifestyle intervention, changes in PAI-1 were associated with changes in HOMA-IR, independent of changes in body weight, saturated fat intake and $\mathrm{VO}_{2} \max$ (chapter 7). After 1 year however, body weight loss abolished the relationship between changes in PAI-1 and changes in HOMA-IR, similar with previous findings $(106 ; 110 ; 111)$ (chapter 6$)$. The results after 3 years are similar to those found in the DPP (112). Multiple factors seem to influence PAI-1 expression (113) and diabetes incidence, e.g. triglycerides, free fatty acids, glucose and subclinical inflammation, suggesting that in accordance with our findings, changes in adipocyte function rather than fat mass per se may contribute to the improved metabolic profile. The beneficial changes in adipocyte function may become apparent when they are not overshadowed anymore by beneficial changes in adipocyte mass. Also, genetic variation in PAI-1 may influence diabetes incidence, since genetically obese and diabetic (ob/ob) mice lacking the PAl-1 gene have reduced adiposity and amelioration of the diabetic phenotype (114). Changes in PAI-1 may be a marker of the complex mechanism underlying obesity and diabetes development.

In this lifestyle intervention study, the 1-year results (107) and the 3-yr results (chapter 7) have shown not to affect adiponectin levels. Some other lifestyle interventions did find an increase adiponectin levels, which seemed mediated by reductions in fat mass $(115 ; 116)$ while others did not in diabetic or obese subjects $(117 ; 118)$. Adiponectin, seems to be modestly affected by lifestyle changes while baseline adiponectin seems a strong predictor of incident diabetes in the DPP (119). Physical activity does not seem to influence adiponectin levels, while considerable weight loss restores high adiponectin levels $(120 ; 121)$.

Lifestyle interventions according to general recommendations for a healthy dietary intake and composition as well as a healthy physical activity level seem to have little effect on adipokine levels. However, adipokines seem to play a role in the deterioration of glucose tolerance and insulin sensitivity, as shown in the SLIM study for leptin. Although more research is necessary to verify the role of adipokines in the development of type 2 diabetes, adipokines seem to reflect processes that influence metabolic status, e.g. adipocyte dysfunction, and do not seem to play an important role in lifestyle-induced improvements in glucose tolerance and insulin resistance during a long-term follow-up.

\subsection{Iron metabolism}

Already in the ancient world, Erasistratus of Chios (304 BC- 250 BC), a Greek anatomist and physician, theorized that many diseases were caused by plethoras, or overabundances, in the blood, and advised that these plethoras be treated, by initially, exercise, sweating, reduced food intake, and vomiting. Herophilus advocated bloodletting. Nowadays, increasing exercise and reducing food intake remain the initial advice in the prevention and treatment of type 2 diabetes, while bloodletting has almost vanished as a therapeutic remedy. A possible therapeutic treatment of blood letting can be found in type 2 diabetic patients with high ferritin concentrations, in which blood 
letting still seems effective in improving insulin sensitivity (122) and vascular dysfunction (123). Also in carriers of the hemochromatosis gene, blood letting, and subsequent iron depletion, ameliorates insulin secretion and sensitivity (124). Improvement of peripheral insulin sensitivity after blood letting may be due to decreased liver iron storage and decreased liver insulin resistance although more studies are warranted.

Markers of the iron metabolism, i.e. ferritin and transferrin, have been associated with the development of hyperglycemia and type 2 diabetes $(122 ; 125 ; 126)$, while the mechanism behind these relationships are still unclear. Iron seems to have lipolytic properties (127) and is a catalyst in the formation of hydroxyl radicals, which are powerful prooxidants that attack cellular membrane lipids, proteins, and nucleic acids (128). Both processes may be related to insulin resistance. In SLIM, we observed a relationship between the 1-yr change in ferritin, the main intracellular iron storage protein, and the change in 2-hr FFA levels (chapter 8). This association suggests that ferritin may be involved in the stimulation of lipolysis, subsequent lipid overflow towards liver and skeletal muscle, and the development of insulin resistance (129). Transferrin, the blood plasma protein for iron ion delivery, was independently positively associated with changes in insulin resistance (chapter 8 ). Besides that transferrin may also have lipolytic properties giving lead to increased circulating free fatty acids concentrations and thereby promoting insulin resistance, we cannot exclude a bidirectional relationship. Therefore, insulin may upregulate transferrin production, as has been shown in human hepatocytes (130) and may stimulate iron uptake by fat cells (131). Overall, these findings merit further investigation to clarify causality and the mechanism behind the iron metabolism, insulin resistance and the development of type 2 diabetes.

\subsection{Implementation strategies}

Currently, subjects at risk for developing type 2 diabetes are detected by measuring fasting glucose levels or HbA1c levels in the general practitioners office. The measurement of 2-hr glucose levels in general practice is time consuming and therefore may not be an even match for fasting glucose, which is easily performed. However, by not measuring 2-hr glucose levels, a considerable group at risk will be missed for prevention purposes. A keen solution may be to incorporate a 2-hr glucose measurement in the increasingly popular health checks, allowing the subject at risk to take the glucose load at home, before coming to the general practitioners office. In any case, general practitioners should be aware and convinced of the clinical significance of IFG and IGT as risk factor for developing type 2 diabetes and the beneficial effects that lifestyle interventions can have on that process. Besides 2-hr glucose levels, risk scores have become an appealing tool to predict diabetes risk and several questionnaires have been proposed as a simple, practical, non-invasive and inexpensive way of identification $(62 ; 132 ; 133)$. These questionnaires include criteria of obesity, family history, age cardiovascular history, gestational history, drug history (62) and criteria of physical activity, fruit and vegetable intake $(132 ; 133)$. The Finnish Diabetes risk score (FINDRISC) seems to better predict diabetes incidence than metabolic syndrome (17) and the German Diabetes Risk Score (134). In the Netherlands, the Finnish questionnaire has been shown to be a reasonably good predictor of diabetes incidence (135). Smok- 
ing status, alcohol use, and physical activity do not seem to add to the predictive value of the variables age, BMI, waist circumference, family history of diabetes, history of hypertension, history of high blood glucose, all of which were used in the FINDRISC score (134). Until easy and time-limiting methods have been developed and proven to screen high-risk subjects more accurately than fasting glucose, fasting glucose levels remains the primary factor for screening, identification and treating at risk subjects for type 2 diabetes.

For successful implementation of lifestyle interventions, efforts are necessary from the individual and the health care sector as a whole. The private sector and the government can help by stimulating initiatives that stimulate a healthy behavior, i.e. by stimulating stair use and providing healthy food in the canteen. The combined efforts can help to create a stimulating environment for achieving a healthy lifestyle among most individuals (62). In popular words, diabetes prevention will prove effective when we are supportive of the saying: 'All for one and one for all'.

\subsection{Recommendations for future research}

1. Subjects with a low socio-economic status are at risk for dropout to a lifestyle intervention, impaired quality of life and premature death, compared to subjects with a moderate-to-high socio-economic status. Therefore, future studies should investigate how subjects with low socio-economic status can be reached and motivated to change their lifestyle. In addition, future studies should evaluate the relevance and effect of changes in the direct environment to encourage a healthy lifestyle, such as cheap and easy transportation to sports locations.

2. Inadequate adherence is a problem for lifestyle intervention efficacy. The SLIM study shows that perceived susceptibility to getting diabetes and misconception about own adherence are associated with adherence to nutrition and physical activity advices, although other factors like environment and social support may also play a role. Future studies should investigate how susceptibility of disease, conception of adherence and possible other behavioral factors can be influenced so that the person at risk has a truthful perception of their individual situation in which considerations are made. It may be helpful to stimulate high-risk individuals to discuss their (difficulties in) adherence to get a more truthful image of their susceptibility of disease and adherence.

3. Questionnaires and prediction algorithms based on biomarkers have been developed as a tool to predict diabetes incidence and may be used to predict lifestyle success. In recent years, molecular profiling has gained interest since biomarkers for the development of type 2 diabetes can be discovered, as a large number of genes and proteins can be analyzed by high throughput technologies (136). Biomarkers may help to classify high-risk subjects, personalize the preventive actions and increase the success of lifestyle interventions. Although biomarkers may help to facilitate high-risk screening, prediction and prevention, much work remains before these biomarkers can be used in clinical practice. In general practice, fasting glucose levels remains the method for screening and treatment of high blood glucose levels. Future studies are necessary to evaluate how short questionnaires and 
possibly biomarkers can be effectively implemented in the general public health system for the benefit of both the subject at risk as well as the general practitioner.

4. Current physical activity guidelines recommend at least 30 minutes of moderateintensity physical activity on most, preferably all days of the week. However, recent data suggest that high-intensity interval training may be more effective in improving metabolic disturbances associated with IGT. The effectiveness, efficacy and safety of this exercise method should be tested in large randomized trials with populations differing in age and co-morbidities.

5. Inflammation factors, immune markers and adipokines may help to predict intervention success or diabetes development more accurately. These factors may also be used to identify subgroups at risk and subgroups more or less responsive to lifestyle interventions. However, future research should reveal the additional value of identification of subgroups. Like in breast cancer screening, identification may not lead to a better outcome, i.e. less mortality.

\subsection{What does it mean: the way of progress?}

The acknowledgement starts with a statement of Marie Curie: 'The way of progress is neither swift nor easy'. Along with this statement, it should be emphasized that progress as a whole is not a direct consequence of developments in time. As time passes, old problems are solved whereas new ones become known. Therefore, 'progress' should only be used as a term referring to a specific topic in a certain time frame, acknowledging the relative contribution of man to 'progress' and acknowledging problems as exciting part of our passing lives.

Type 2 diabetes mellitus is one of those exciting problems, due to the metabolic complications, the worldwide scale and the multiple components involved in the pathophysiology. In this thesis, we show that lifestyle interventions according to general public health recommendations are effective after 3-6 years and that body weight and waist circumference seem the most important predictors for a reduction in diabetes risk. Lifestyle-induced beneficial changes in dietary composition and maximal aerobic capacity can be sustained with 3-6 years intervention. These factors have independent effects on the reduction of diabetes risk and are of utmost importance in sustaining weight reduction. However, this thesis also brings about new problems, or reinforces old ones. It is still unknown which manner is best to identify subjects at risk and measure their risk, although questionnaires may be promising. In addition, dropout to lifestyle intervention is a serious threat for effectiveness and implementation in the community. Low aerobic capacity, a low social economic status, time constraints and behavioral factors like lack of awareness, motivation and susceptibility may all be important for dropout, making adherence a complex problem. Even more complex is implementation of lifestyle programs. Health care at present is still primarily focused on the treatment of disease, rather than preventing them, exemplifying that a switch will be necessary towards prevention of disease. For this switch to take place, efforts will be necessary from all layers in the population, which amplify, not counteract each other's efforts and thát may be the greatest challenge of all, given the diverse ideas about the challenge: type 2 diabetes mellitus. 


\section{References}

1. Wild S, Roglic G, Green A, Sicree R, King H. Global prevalence of diabetes: estimates for the year 2000 and projections for 2030. Diabetes Care. 2004 May;27(5):1047-53.

2. Knowler WC, Barrett-Connor E, Fowler SE, Hamman RF, Lachin JM, Walker EA, et al. Reduction in the incidence of type 2 diabetes with lifestyle intervention or metformin. N Engl J Med. 2002 Feb 7;346(6):393-403.

3. Gillies CL, Abrams KR, Lambert PC, Cooper NJ, Sutton AJ, Hsu RT, et al. Pharmacological and lifestyle interventions to prevent or delay type 2 diabetes in people with impaired glucose tolerance: systematic review and meta-analysis. Bmj. 2007 Feb 10;334(7588):299.

4. Li G, Zhang P, Wang J, Gregg EW, Yang W, Gong Q, et al. The long-term effect of lifestyle interventions to prevent diabetes in the China Da Qing Diabetes Prevention Study: a 20-year follow-up study. Lancet. 2008 May 24;371(9626):1783-9.

5. Lindstrom J, llanne-Parikka P, Peltonen M, Aunola S, Eriksson JG, Hemio K, et al. Sustained reduction in the incidence of type 2 diabetes by lifestyle intervention: follow-up of the Finnish Diabetes Prevention Study. Lancet. 2006 Nov 11;368(9548):1673-9.

6. WHO. Adherence to long-term therapies: Evidence for action. Geneva: WHO; 2003.

7. Bosworth HB, Weinberger M, Oddone EZ. Introduction. In: Bosworth HB, Oddone EZ, Weinberger M, editors. Patient treatment adherence: Concepts, interventions, and measurement. Mahwah: Lawrence Erlbaum Associates; 2006. p. 3-11.

8. Tuomilehto J, Lindstrom J, Eriksson JG, Valle TT, Hamalainen H, Ilanne-Parikka P, et al. Prevention of type 2 diabetes mellitus by changes in lifestyle among subjects with impaired glucose tolerance. $\mathrm{N}$ Engl J Med. 2001 May 3;344(18):1343-50.

9. Mensink M, Blaak EE, Corpeleijn E, Saris WH, de Bruin TW, Feskens EJ. Lifestyle intervention according to general recommendations improves glucose tolerance. Obes Res. 2003 Dec;11(12):1588-96.

10. Herman WH, Hoerger TJ, Brandle M, Hicks K, Sorensen S, Zhang P, et al. The cost-effectiveness of lifestyle modification or metformin in preventing type 2 diabetes in adults with impaired glucose tolerance. Ann Intern Med. 2005 Mar 1;142(5):323-32.

11. Jacobs-van der Bruggen MA, Bos G, Bemelmans WJ, Hoogenveen RT, Vijgen SM, Baan CA. Lifestyle interventions are cost-effective in people with different levels of diabetes risk: results from a modeling study. Diabetes Care. 2007 Jan;30(1):128-34.

12. Lindgren $\mathrm{P}$, Lindstrom J, Tuomilehto J, Uusitupa $\mathrm{M}$, Peltonen $\mathrm{M}$, Jonsson $\mathrm{B}$, et al. Lifestyle intervention to prevent diabetes in men and women with impaired glucose tolerance is cost-effective. Int J Technol Assess Health Care. 2007 Spring;23(2):177-83.

13. Roumen C, Corpeleijn E, Feskens EJ, Mensink M, Saris WH, Blaak EE. Impact of 3-year lifestyle intervention on postprandial glucose metabolism: the SLIM study. Diabet Med. 2008 May;25(5):597-605.

14. Lindstrom J, Louheranta A, Mannelin M, Rastas M, Salminen V, Eriksson J, et al. The Finnish Diabetes Prevention Study (DPS): Lifestyle intervention and 3-year results on diet and physical activity. Diabetes Care. 2003 Dec;26(12):3230-6.

15. Herder C, Peltonen M, Koenig W, Kraft I, Muller-Scholze S, Martin S, et al. Systemic immune mediators and lifestyle changes in the prevention of type 2 diabetes: results from the Finnish Diabetes Prevention Study. Diabetes. 2006 Aug;55(8):2340-6.

16. Kitabchi AE, Temprosa M, Knowler WC, Kahn SE, Fowler SE, Haffner SM, et al. Role of insulin secretion and sensitivity in the evolution of type 2 diabetes in the diabetes prevention program: effects of lifestyle intervention and metformin. Diabetes. 2005 Aug;54(8):2404-14.

17. Ford ES, Li C, Sattar N. Metabolic syndrome and incident diabetes: current state of the evidence. Diabetes Care. 2008 Sep;31(9):1898-904.

18. Orchard TJ, Temprosa M, Goldberg R, Haffner S, Ratner R, Marcovina S, et al. The effect of metformin and intensive lifestyle intervention on the metabolic syndrome: the Diabetes Prevention Program randomized trial. Ann Intern Med. 2005 Apr 19;142(8):611-9.

19. Ilanne-Parikka P, Eriksson JG, Lindstrom J, Peltonen M, Aunola S, Hamalainen H, et al. Effect of Lifestyle Intervention on the Occurrence of Metabolic Syndrome and its Components in the Finnish Diabetes Prevention Study. Diabetes Care. 2008 Jan 9.

20. Lundgren JD, Malcolm R, Binks M, O'Neil PM. Remission of metabolic syndrome following a 15-week low-calorie lifestyle change program for weight loss. Int J Obes (Lond). 2008 Nov 18.

21. Mackenbach JP, Stirbu I, Roskam AJ, Schaap MM, Menvielle G, Leinsalu M, et al. Socioeconomic inequalities in health in 22 European countries. N Engl J Med. 2008 Jun 5;358(23):2468-81. 


\section{Chapter 9}

22. CBS. Gezondheid en zorg in ciifers 2008. 2008 [cited 200817 November 2008]; Available from:

23. Roedig A. Laagopgeleide beroepsbevolking 2006. Volksgezondheid Toekomst Verkenning, Nationale Atlas Volksgezondheid 2006 [cited 2008 December 17.]; Available from: http://www.rivm.nl/vtv/object_map/o2633n21851.html

24. Gerstein HC, Yusuf S, Bosch J, Pogue J, Sheridan P, Dinccag N, et al. Effect of rosiglitazone on the frequency of diabetes in patients with impaired glucose tolerance or impaired fasting glucose: a randomised controlled trial. Lancet. 2006 Sep 23;368(9541):1096-105.

25. Rutten G, Kremers S, Rutten S, Harting J. A Dutch theory-based cross-sectional survey demonstrated the important role of awareness in guideline implementation. J Clin Epidemiol. 2008 Sep 9.

26. Toft UN, Kristoffersen LH, Aadahl M, von Huth Smith L, Pisinger C, Jorgensen T. Diet and exercise intervention in a general population--mediators of participation and adherence: the Inter99 study. Eur J Public Health. 2007 Oct;17(5):455-63.

27. Thomas N, Alder E, Leese GP. Barriers to physical activity in patients with diabetes. Postgrad Med J. 2004 May;80(943):287-91.

28. Ruge T, Nystrom L, Lindahl B, Hallmans G, Norberg M, Weinehall L, et al. Recruiting high-risk individuals to a diabetes prevention program: how hard can it be? Diabetes Care. 2007 Jul;30(7):e61.

29. Gerstein HC, Miller ME, Byington RP, Goff DC, Jr., Bigger JT, Buse JB, et al. Effects of intensive glucose lowering in type 2 diabetes. N Engl J Med. 2008 Jun 12;358(24):2545-59.

30. Califf RM, Boolell M, Haffner SM, Bethel MA, McMurray J, Duggal A, et al. Prevention of diabetes and cardiovascular disease in patients with impaired glucose tolerance: rationale and design of the Nateglinide And Valsartan in Impaired Glucose Tolerance Outcomes Research (NAVIGATOR) Trial. Am Heart J. 2008 Oct;156(4):623-32.

31. Giesbers H. Overgewicht 1981-2007. Volksgezondheid Toekomst Verkenning, Nationale Atlas Volksgezondheid 2008 [cited 200829 November 2008]; Available from:

32. Colditz GA, Willett WC, Rotnitzky A, Manson JE. Weight gain as a risk factor for clinical diabetes mellitus in women. Ann Intern Med. 1995 Apr 1;122(7):481-6.

33. Chan JM, Rimm EB, Colditz GA, Stampfer MJ, Willett WC. Obesity, fat distribution, and weight gain as risk factors for clinical diabetes in men. Diabetes Care. 1994 Sep;17(9):961-9.

34. Han TS, Feskens EJ, Lean ME, Seidell JC. Associations of body composition with type 2 diabetes mellitus. Diabet Med. 1998 Feb;15(2):129-35.

35. Hamman RF, Wing RR, Edelstein SL, Lachin JM, Bray GA, Delahanty L, et al. Effect of weight loss with lifestyle intervention on risk of diabetes. Diabetes Care. 2006 Sep;29(9):2102-7.

36. Fujimoto WY, Jablonski KA, Bray GA, Kriska A, Barrett-Connor E, Haffner S, et al. Body Size and Shape Changes and the Risk of Diabetes in the Diabetes Prevention Program (DPP). Diabetes. 2007 Mar 30.

37. Corpeleijn E, Feskens EJ, Jansen EH, Mensink M, Saris WH, de Bruin TW, et al. Improvements in glucose tolerance and insulin sensitivity after lifestyle intervention are related to changes in serum fatty acid profile and desaturase activities: the SLIM study. Diabetologia. 2006 Oct;49(10):2392-401.

38. Thamer C, Machann J, Stefan N, Haap M, Schafer S, Brenner S, et al. High visceral fat mass and high liver fat are associated with resistance to lifestyle intervention. Obesity (Silver Spring). 2007 Feb;15(2):531-8.

39. Tiikkainen M, Bergholm R, Vehkavaara S, Rissanen A, Hakkinen AM, Tamminen M, et al. Effects of identical weight loss on body composition and features of insulin resistance in obese women with high and low liver fat content. Diabetes. 2003 Mar;52(3):701-7.

40. Langendonk JG, Kok P, Frolich M, Pijl H, Meinders AE. Decrease in visceral fat following diet-induced weight loss in upper body compared to lower body obese premenopausal women. Eur J Intern Med. 2006 Nov;17(7):465-9.

41. Langendonk JG, Pijl H, Toornvliet AC, Burggraaf J, Frolich M, Schoemaker RC, et al. Circadian rhythm of plasma leptin levels in upper and lower body obese women: influence of body fat distribution and weight loss. J Clin Endocrinol Metab. 1998 May;83(5):1706-12.

42. Gray DS, Fujioka K, Colletti PM, Kim H, Devine W, Cuyegkeng T, et al. Magnetic-resonance imaging used for determining fat distribution in obesity and diabetes. Am J Clin Nutr. 1991 Oct;54(4):623-7.

43. Mitrou PN, Kipnis V, Thiebaut AC, Reedy J, Subar AF, Wirfalt E, et al. Mediterranean dietary pattern and prediction of all-cause mortality in a US population: results from the NIH-AARP Diet and Health Study. Arch Intern Med. 2007 Dec 10;167(22):2461-8.

44. Marshall JA, Hoag S, Shetterly S, Hamman RF. Dietary fat predicts conversion from impaired glucose tolerance to NIDDM. The San Luis Valley Diabetes Study. Diabetes Care. 1994 Jan;17(1):50-6. 
45. Lindstrom J, Peltonen M, Eriksson JG, Louheranta A, Fogelholm M, Uusitupa M, et al. High-fibre, low-fat diet predicts long-term weight loss and decreased type 2 diabetes risk: the Finnish Diabetes Prevention Study. Diabetologia. 2006 May;49(5):912-20.

46. Hays NP, Starling RD, Liu X, Sullivan DH, Trappe TA, Fluckey JD, et al. Effects of an ad libitum low-fat, high-carbohydrate diet on body weight, body composition, and fat distribution in older men and women: a randomized controlled trial. Arch Intern Med. 2004 Jan 26;164(2):210-7.

47. Astrup A. The role of dietary fat in the prevention and treatment of obesity. Efficacy and safety of lowfat diets. Int J Obes Relat Metab Disord. 2001 May;25 Suppl 1:S46-50.

48. Vessby B, Unsitupa M, Hermansen K, Riccardi G, Rivellese AA, Tapsell LC, et al. Substituting dietary saturated for monounsaturated fat impairs insulin sensitivity in healthy men and women: The KANWU Study. Diabetologia. 2001 Mar;44(3):312-9.

49. Summers LK, Fielding BA, Bradshaw HA, llic V, Beysen C, Clark ML, et al. Substituting dietary saturated fat with polyunsaturated fat changes abdominal fat distribution and improves insulin sensitivity. Diabetologia. 2002 Mar;45(3):369-77.

50. Jenkins DJ, Axelsen M, Kendall CW, Augustin LS, Vuksan V, Smith U. Dietary fibre, lente carbohydrates and the insulin-resistant diseases. Br J Nutr. 2000 Mar;83 Suppl 1:S157-63.

51. Pi-Sunyer X. Do glycemic index, glycemic load, and fiber play a role in insulin sensitivity, disposition index, and type 2 diabetes? Diabetes Care. 2005 Dec;28(12):2978-9.

52. Schulze MB, Schulz M, Heidemann C, Schienkiewitz A, Hoffmann K, Boeing H. Fiber and magnesium intake and incidence of type 2 diabetes: a prospective study and meta-analysis. Arch Intern Med. 2007 May 14;167(9):956-65.

53. Beulens JW, de Bruijne LM, Stolk RP, Peeters PH, Bots ML, Grobbee DE, et al. High dietary glycemic load and glycemic index increase risk of cardiovascular disease among middle-aged women: a populationbased follow-up study. J Am Coll Cardiol. 2007 Jul 3;50(1):14-21.

54. Lichtenstein AH, Appel L, Brands M, Carnethon M, Daniels S, Franch HA, et al. Diet and lifestyle recommendations revision 2006: a scientific statement from the American Heart Association Nutrition Committee. Circulation. 2006 Jul 4;114(1):82-96.

55. Wolever TM, Mehling C. High-carbohydrate-low-glycaemic index dietary advice improves glucose disposition index in subjects with impaired glucose tolerance. Br J Nutr. 2002 May;87(5):477-87.

56. Livesey G, Taylor R, Hulshof T, Howlett J. Glycemic response and health--a systematic review and metaanalysis: relations between dietary glycemic properties and health outcomes. Am J Clin Nutr. 2008 Jan;87(1):258S-68S.

57. Nilsson M, Holst JJ, Bjorck IM. Metabolic effects of amino acid mixtures and whey protein in healthy subjects: studies using glucose-equivalent drinks. Am J Clin Nutr. 2007 Apr;85(4):996-1004.

58. O'Keefe JH, Bybee KA, Lavie CJ. Alcohol and cardiovascular health: the razor-sharp double-edged sword. J Am Coll Cardiol. 2007 Sep 11;50(11):1009-14.

59. Brand-Miller JC, Fatema K, Middlemiss C, Bare M, Liu V, Atkinson F, et al. Effect of alcoholic beverages on postprandial glycemia and insulinemia in lean, young, healthy adults. Am J Clin Nutr. 2007 Jun;85(6):1545-51.

60. Sjöström M, Oja P, Hagströmer M, Smith BJ, Bauman A. Health-enhancing physical activity across European Union countries: the Eurobarometer study. Journal of Public Health. 2006;14:291-300.

61. Healy GN, Wijndaele K, Dunstan DW, Shaw JE, Salmon J, Zimmet PZ, et al. Objectively measured sedentary time, physical activity, and metabolic risk: the Australian Diabetes, Obesity and Lifestyle Study (AusDiab). Diabetes Care. 2008 Feb;31(2):369-71.

62. Alberti KG, Zimmet P, Shaw J. International Diabetes Federation: a consensus on Type 2 diabetes prevention. Diabet Med. 2007 May;24(5):451-63.

63. Pate RR, Pratt M, Blair SN, Haskell WL, Macera CA, Bouchard C, et al. Physical activity and public health. A recommendation from the Centers for Disease Control and Prevention and the American College of Sports Medicine. Jama. 1995 Feb 1;273(5):402-7.

64. Bloem CJ, Chang AM. Short-term exercise improves beta-cell function and insulin resistance in older people with impaired glucose tolerance. J Clin Endocrinol Metab. 2008 Feb;93(2):387-92.

65. Hu G, Lakka TA, Kilpelainen TO, Tuomilehto J. Epidemiological studies of exercise in diabetes prevention. Appl Physiol Nutr Metab. 2007 Jun;32(3):583-95.

66. Haskell WL, Lee IM, Pate RR, Powell KE, Blair SN, Franklin BA, et al. Physical activity and public health: updated recommendation for adults from the American College of Sports Medicine and the American Heart Association. Med Sci Sports Exerc. 2007 Aug;39(8):1423-34. 


\section{Chapter 9}

67. Burgomaster KA, Hughes SC, Heigenhauser GJ, Bradwell SN, Gibala MJ. Six sessions of sprint interval training increases muscle oxidative potential and cycle endurance capacity in humans. J Appl Physiol. 2005 Jun;98(6):1985-90.

68. Helgerud J, Hoydal K, Wang E, Karlsen T, Berg P, Bjerkaas M, et al. Aerobic high-intensity intervals improve VO2max more than moderate training. Med Sci Sports Exerc. 2007 Apr;39(4):665-71.

69. Wisloff U, Stoylen A, Loennechen JP, Bruvold M, Rognmo O, Haram PM, et al. Superior cardiovascular effect of aerobic interval training versus moderate continuous training in heart failure patients: a randomized study. Circulation. 2007 Jun 19;115(24):3086-94.

70. Talanian JL, Galloway SD, Heigenhauser GJ, Bonen A, Spriet LL. Two weeks of high-intensity aerobic interval training increases the capacity for fat oxidation during exercise in women. J Appl Physiol. 2007 Apr;102(4):1439-47.

71. Earnest CP. Exercise interval training: An improved stimulus for improving the physiology of prediabetes. Med Hypotheses. 2008 Aug 14.

72. Healy GN, Dunstan DW, Salmon J, Cerin E, Shaw JE, Zimmet PZ, et al. Objectively measured lightintensity physical activity is independently associated with 2-h plasma glucose. Diabetes Care. 2007 Jun;30(6):1384-9.

73. Khaw KT, Jakes R, Bingham S, Welch A, Luben R, Day N, et al. Work and leisure time physical activity assessed using a simple, pragmatic, validated questionnaire and incident cardiovascular disease and allcause mortality in men and women: The European Prospective Investigation into Cancer in Norfolk prospective population study. Int J Epidemiol. 2006 Aug;35(4):1034-43.

74. Schnohr $\mathrm{P}$, Lange $\mathrm{P}$, Scharling $\mathrm{H}$, Jensen JS. Long-term physical activity in leisure time and mortality from coronary heart disease, stroke, respiratory diseases, and cancer. The Copenhagen City Heart Study. Eur J Cardiovasc Prev Rehabil. 2006 Apr;13(2):173-9.

75. Lindi VI, Uusitupa MI, Lindstrom J, Louheranta A, Eriksson JG, Valle TT, et al. Association of the Pro12Ala polymorphism in the PPAR-gamma2 gene with 3-year incidence of type 2 diabetes and body weight change in the Finnish Diabetes Prevention Study. Diabetes. 2002 Aug;51(8):2581-6.

76. Stefan N, Machann J, Schick F, Claussen CD, Thamer C, Fritsche A, et al. New imaging techniques of fat, muscle and liver within the context of determining insulin sensitivity. Horm Res. 2005;64 Suppl 3:38-44.

77. Stefan N, Thamer C, Staiger H, Machicao F, Machann J, Schick F, et al. Genetic variations in PPARD and PPARGC1A determine mitochondrial function and change in aerobic physical fitness and insulin sensitivity during lifestyle intervention. J Clin Endocrinol Metab. 2007 May;92(5):1827-33.

78. Weyrich P, Stefan N, Haring HU, Laakso M, Fritsche A. Effect of genotype on success of lifestyle intervention in subjects at risk for type 2 diabetes. J Mol Med. 2007 Feb;85(2):107-17.

79. Perreault L, Ma Y, Dagogo-Jack S, Horton E, Marrero D, Crandall J, et al. Sex differences in diabetes risk and the effect of intensive lifestyle modification in the Diabetes Prevention Program. Diabetes Care. 2008 Jul;31(7):1416-21.

80. Kanaya AM, Grady D, Barrett-Connor E. Explaining the sex difference in coronary heart disease mortality among patients with type 2 diabetes mellitus: a meta-analysis. Arch Intern Med. 2002 Aug 1226;162(15):1737-45.

81. Guilherme A, Virbasius JV, Puri V, Czech MP. Adipocyte dysfunctions linking obesity to insulin resistance and type 2 diabetes. Nat Rev Mol Cell Biol. 2008 May;9(5):367-77.

82. Sartipy $P$, Loskutoff DJ. Monocyte chemoattractant protein 1 in obesity and insulin resistance. Proc Natl Acad Sci U S A. 2003 Jun 10;100(12):7265-70.

83. Curat CA, Miranville A, Sengenes C, Diehl M, Tonus C, Busse R, et al. From blood monocytes to adipose tissue-resident macrophages: induction of diapedesis by human mature adipocytes. Diabetes. 2004 May;53(5):1285-92.

84. Weyer C, Tataranni PA, Pratley RE. Insulin action and insulinemia are closely related to the fasting complement C3, but not acylation stimulating protein concentration. Diabetes Care. 2000 Jun;23(6):779-85.

85. Engstrom G, Hedblad B, Eriksson KF, Janzon L, Lindgarde F. Complement C3 is a risk factor for the development of diabetes: a population-based cohort study. Diabetes. 2005 Feb;54(2):570-5.

86. Yang Y, Lu HL, Zhang J, Yu HY, Wang HW, Zhang MX, et al. Relationships among acylation stimulating protein, adiponectin and complement C3 in lean vs obese type 2 diabetes. Int J Obes (Lond). 2006 Mar;30(3):439-46.

87. Cianflone K, Xia Z, Chen LY. Critical review of acylation-stimulating protein physiology in humans and rodents. Biochim Biophys Acta. 2003 Jan 31;1609(2):127-43. 
88. Van Harmelen V, Reynisdottir S, Cianflone K, Degerman E, Hoffstedt J, Nilsell K, et al. Mechanisms involved in the regulation of free fatty acid release from isolated human fat cells by acylationstimulating protein and insulin. J Biol Chem. 1999 Jun 25;274(26):18243-51.

89. Alper CA, Johnson AM, Birtch AG, Moore FD. Human $C^{\prime} 3$ : evidence for the liver as the primary site of synthesis. Science. 1969 Jan 17;163(864):286-8.

90. Gabrielsson BG, Johansson JM, Lonn M, Jernas $M$, Olbers $T$, Peltonen $M$, et al. High expression of complement components in omental adipose tissue in obese men. Obes Res. 2003 Jun;11(6):699-708.

91. Zimmer B, Hartung HP, Scharfenberger G, Bitter-Suermann D, Hadding U. Quantitative studies of the secretion of complement component $\mathrm{C} 3$ by resident, elicited and activated macrophages. Comparison with C2, C4 and lysosomal enzyme release. Eur J Immunol. 1982 May;12(5):426-30.

92. Choy LN, Rosen BS, Spiegelman BM. Adipsin and an endogenous pathway of complement from adipose cells. J Biol Chem. 1992 Jun 25;267(18):12736-41.

93. Muscari A, Antonelli S, Bianchi G, Cavrini G, Dapporto S, Ligabue A, et al. Serum C3 is a stronger inflammatory marker of insulin resistance than C-reactive protein, leukocyte count, and erythrocyte sedimentation rate: comparison study in an elderly population. Diabetes Care. 2007 Sep;30(9):2362-8.

94. de Rekeneire N, Peila R, Ding J, Colbert LH, Visser M, Shorr RI, et al. Diabetes, hyperglycemia, and inflammation in older individuals: the health, aging and body composition study. Diabetes Care. 2006 Aug;29(8):1902-8.

95. Cardellini M, Andreozzi F, Laratta E, Marini MA, Lauro R, Hribal ML, et al. Plasma interleukin-6 levels are increased in subjects with impaired glucose tolerance but not in those with impaired fasting glucose in a cohort of Italian Caucasians. Diabetes Metab Res Rev. 2007 Feb;23(2):141-5.

96. Muller S, Martin S, Koenig W, Hanifi-Moghaddam P, Rathmann W, Haastert B, et al. Impaired glucose tolerance is associated with increased serum concentrations of interleukin 6 and co-regulated acutephase proteins but not TNF-alpha or its receptors. Diabetologia. 2002 Jun;45(6):805-12.

97. Corpeleijn E, Saris WHM, Jansen EHJM, Roekaerts PMHJ, Feskens EJM, Blaak EE. Postprandial Interleukin-6 Release from Skeletal Muscle in Men with Impaired Glucose Tolerance Can Be Reduced by Weight Loss. J Clin Endocrinol Metab. 2005 October 1, 2005;90(10):5819-24.

98. Klover PJ, Zimmers TA, Koniaris LG, Mooney RA. Chronic exposure to interleukin-6 causes hepatic insulin resistance in mice. Diabetes. 2003 Nov;52(11):2784-9.

99. Klover PJ, Clementi AH, Mooney RA. Interleukin-6 depletion selectively improves hepatic insulin action in obesity. Endocrinology. 2005 Aug;146(8):3417-27.

100. Carey AL, Steinberg GR, Macaulay SL, Thomas WG, Holmes AG, Ramm G, et al. Interleukin-6 increases insulin-stimulated glucose disposal in humans and glucose uptake and fatty acid oxidation in vitro via AMP-activated protein kinase. Diabetes. 2006 Oct;55(10):2688-97.

101. Steensberg A, van Hall G, Osada T, Sacchetti M, Saltin B, Klarlund Pedersen B. Production of interleukin6 in contracting human skeletal muscles can account for the exercise-induced increase in plasma interleukin-6. J Physiol. 2000 Nov 15;529 Pt 1:237-42.

102. van Hall G, Steensberg A, Sacchetti M, Fischer C, Keller C, Schjerling P, et al. Interleukin- 6 stimulates lipolysis and fat oxidation in humans. J Clin Endocrinol Metab. 2003 Jul;88(7):3005-10.

103. Steensberg A, Febbraio MA, Osada T, Schjerling P, van Hall G, Saltin B, et al. Interleukin-6 production in contracting human skeletal muscle is influenced by pre-exercise muscle glycogen content. J Physiol. 2001 Dec 1;537(Pt 2):633-9.

104. Carey AL, Febbraio MA. Interleukin-6 and insulin sensitivity: friend or foe? Diabetologia. 2004 Jul;47(7):1135-42.

105. Esposito K, Pontillo A, Di Palo C, Giugliano G, Masella M, Marfella R, et al. Effect of weight loss and lifestyle changes on vascular inflammatory markers in obese women: a randomized trial. Jama. 2003 Apr 9;289(14):1799-804.

106. Hamalainen $\mathrm{H}$, Ronnemaa T, Virtanen A, Lindstrom J, Eriksson JG, Valle TT, et al. Improved fibrinolysis by an intensive lifestyle intervention in subjects with impaired glucose tolerance. The Finnish Diabetes Prevention Study. Diabetologia. 2005 Nov;48(11):2248-53.

107. Corpeleijn E, Feskens EJ, Jansen EH, Mensink M, Saris WH, Blaak EE. Lifestyle intervention and adipokine levels in subjects at high risk for type 2 diabetes: the Study on Lifestyle intervention and Impaired glucose tolerance Maastricht (SLIM). Diabetes Care. 2007 Dec;30(12):3125-7.

108. McNeely MJ, Boyko EJ, Weigle DS, Shofer JB, Chessler SD, Leonnetti DL, et al. Association between baseline plasma leptin levels and subsequent development of diabetes in Japanese Americans. Diabetes Care. 1999 Jan;22(1):65-70. 


\section{Chapter 9}

109. Soderberg S, Zimmet P, Tuomilehto J, Chitson P, Gareeboo H, Alberti KG, et al. Leptin predicts the development of diabetes in Mauritian men, but not women: a population-based study. Int J Obes (Lond). $2007 \mathrm{Jul} ; 31(7): 1126-33$.

110. Festa A, Williams K, Tracy RP, Wagenknecht LE, Haffner SM. Progression of plasminogen activator inhibitor-1 and fibrinogen levels in relation to incident type 2 diabetes. Circulation. 2006 Apr 11;113(14):1753-9.

111. Hamdy O, Ledbury S, Mullooly C, Jarema C, Porter S, Ovalle K, et al. Lifestyle modification improves endothelial function in obese subjects with the insulin resistance syndrome. Diabetes Care. 2003 Jul;26(7):2119-25.

112. Lipid, lipoproteins, C-reactive protein, and hemostatic factors at baseline in the diabetes prevention program. Diabetes Care. 2005 Oct;28(10):2472-9.

113. Lyon CJ, Hsueh WA. Effect of plasminogen activator inhibitor-1 in diabetes mellitus and cardiovascular disease. Am J Med. 2003 Dec 8;115 Suppl 8A:62S-8S.

114. Schafer K, Fujisawa K, Konstantinides S, Loskutoff DJ. Disruption of the plasminogen activator inhibitor 1 gene reduces the adiposity and improves the metabolic profile of genetically obese and diabetic ob/ob mice. Faseb J. 2001 Aug;15(10):1840-2.

115. Balagopal P, George D, Yarandi H, Funanage V, Bayne E. Reversal of obesity-related hypoadiponectinemia by lifestyle intervention: a controlled, randomized study in obese adolescents. J Clin Endocrinol Metab. 2005 Nov;90(11):6192-7.

116. Rokling-Andersen MH, Reseland JE, Veierod MB, Anderssen SA, Jacobs DR, Jr., Urdal P, et al. Effects of long-term exercise and diet intervention on plasma adipokine concentrations. Am J Clin Nutr. 2007 Nov;86(5):1293-301.

117. Aas AM, Seljeflot I, Torjesen PA, Diep LM, Thorsby PM, Birkeland KI. Blood glucose lowering by means of lifestyle intervention has different effects on adipokines as compared with insulin treatment in subjects with type 2 diabetes. Diabetologia. 2006 May;49(5):872-80.

118. Bobbert T, Rochlitz H, Wegewitz U, Akpulat S, Mai K, Weickert MO, et al. Changes of adiponectin oligomer composition by moderate weight reduction. Diabetes. 2005 Sep;54(9):2712-9.

119. Mather KJ, Funahashi T, Matsuzawa Y, Edelstein S, Bray GA, Kahn SE, et al. Adiponectin, change in adiponectin, and progression to diabetes in the Diabetes Prevention Program. Diabetes. 2008 Apr;57(4):980-6.

120. Kopp HP, Kopp CW, Festa A, Krzyzanowska K, Kriwanek S, Minar E, et al. Impact of weight loss on inflammatory proteins and their association with the insulin resistance syndrome in morbidly obese patients. Arterioscler Thromb Vasc Biol. 2003 Jun 1;23(6):1042-7.

121. Lazzer S, Vermorel M, Montaurier C, Meyer M, Boirie Y. Changes in adipocyte hormones and lipid oxidation associated with weight loss and regain in severely obese adolescents. Int J Obes (Lond). 2005 Oct;29(10):1184-91.

122. Fernandez-Real JM, Moreno JM, Lopez-Bermejo A, Chico B, Vendrell J, Ricart W. Circulating soluble transferrin receptor according to glucose tolerance status and insulin sensitivity. Diabetes Care. 2007 Mar;30(3):604-8.

123. Fernandez-Real JM, Penarroja G, Castro A, Garcia-Bragado F, Lopez-Bermejo A, Ricart W. Blood letting in high-ferritin type 2 diabetes: effects on vascular reactivity. Diabetes Care. 2002 Dec;25(12):2249-55.

124. Equitani F, Fernandez-Real JM, Menichella G, Koch M, Calvani M, Nobili V, et al. Bloodletting ameliorates insulin sensitivity and secretion in parallel to reducing liver iron in carriers of HFE gene mutations. Diabetes Care. 2008 Jan;31(1):3-8.

125. Fumeron F, Pean F, Driss F, Balkau B, Tichet J, Marre M, et al. Ferritin and transferrin are both predictive of the onset of hyperglycemia in men and women over 3 years: the data from an epidemiological study on the Insulin Resistance Syndrome (DESIR) study. Diabetes Care. 2006 Sep;29(9):2090-4.

126. Forouhi NG, Harding AH, Allison M, Sandhu MS, Welch A, Luben R, et al. Elevated serum ferritin levels predict new-onset type 2 diabetes: results from the EPIC-Norfolk prospective study. Diabetologia. 2007 May;50(5):949-56.

127. Rumberger JM, Peters T, Jr., Burrington C, Green A. Transferrin and iron contribute to the lipolytic effect of serum in isolated adipocytes. Diabetes. 2004 Oct;53(10):2535-41.

128. Meneghini R. Iron homeostasis, oxidative stress, and DNA damage. Free Radic Biol Med. 1997;23(5):783-92.

129. Haap M, Fritsche A, Mensing HJ, Haring HU, Stumvoll M. Association of high serum ferritin concentration with glucose intolerance and insulin resistance in healthy people. Ann Intern Med. 2003 Nov 18;139(10):869-71. 
130. O'Riordain MG, Ross JA, Fearon KC, Maingay J, Farouk M, Garden OJ, et al. Insulin and counterregulatory hormones influence acute-phase protein production in human hepatocytes. Am J Physiol. 1995 Aug;269(2 Pt 1):E323-30.

131. Davis RJ, Corvera S, Czech MP. Insulin stimulates cellular iron uptake and causes the redistribution of intracellular transferrin receptors to the plasma membrane. J Biol Chem. 1986 Jul 5;261(19):8708-11.

132. Lindstrom J, Tuomilehto J. The diabetes risk score: a practical tool to predict type 2 diabetes risk. Diabetes Care. 2003 Mar;26(3):725-31.

133. Schulze MB, Hoffmann K, Boeing H, Linseisen J, Rohrmann S, Mohlig M, et al. An accurate risk score based on anthropometric, dietary, and lifestyle factors to predict the development of type 2 diabetes. Diabetes Care. 2007 Mar;30(3):510-5.

134. Schwarz PE, Li J, Wegner H, Bornstein SR, Lindstrom J, Tuomilehto J. An accurate risk score based on anthropometric, dietary, and lifestyle factors to predict the development of type 2 diabetes: response to Schulze et al. Diabetes Care. 2007 Aug;30(8):e87; author reply e8.

135. Alssema M, Feskens EJ, Bakker SJ, Gansevoort RT, Boer JM, Heine RJ, et al. [Finnish questionnaire reasonably good predictor of the incidence of diabetes in The Netherlands]. Ned Tijdschr Geneeskd. 2008 Nov 1;152(44):2418-24.

136. Collins CD, Purohit S, Podolsky RH, Zhao HS, Schatz D, Eckenrode SE, et al. The application of genomic and proteomic technologies in predictive, preventive and personalized medicine. Vascul Pharmacol. 2006 Nov;45(5):258-67. 